\title{
BLOOD, SWEAT AND TEARS: \\ WOMEN AS NURSES NURSING WOMEN IN THE GYNAECOLOGY WARD - A FEMINIST INTERPRETIVE STUDY
}

\author{
by \\ Annette Diana Huntington
}

\author{
A thesis \\ submitted to the Victoria University of Wellington \\ in fulfilment of the \\ requirements for the degree of \\ Doctor of Philosophy \\ in Nursing.
}

Victoria University of Wellington

1999 


\section{ABSTRACT}

This feminist study is an exploration of the subjectivity of women working as nurses within the gynaecological ward.

Gynaecology has a long history as a unique area of concern to the health practitioners of any given period. However, recently with the development of modern gynaecology, this specialty has become based on male knowledge and male texts, women either as patients or nurses appear voiceless within this canon. Major texts within nursing mirror a medical construction of gynaecology, with the women involved in the discourse again absent from the literature.

To explore the nurses' reality within the gynaecological ward I have undertaken a feminist interpretive study. Feminist research is gaining recognition within nursing and the contribution that such research can make to the development of nursing knowledge is acknowledged within the profession. However, it is within the work of nurse-scholars from Australia that feminist and postmodern ideas are most commonly debated. Their work provides an innovative approach to the exploration of nurses' work. To contribute to this debate I drew on certain specific notions from feminist and postmodern epistemologies to inform my work. These notions of the Other, difference, the body and discourse provided a unique way of viewing the practice of the nurses in this gynaecological setting. These epistemological concepts were then interwoven with feminist strategies to undertake my research.

Through the process of feminist praxis, which included my working alongside the nurses and conducting in-depth interviews, three areas of general concern to the nurses emerged. Firstly the relationships, that is their relationships with each other as nurses and with their women patients. Secondly, the difficulties inherent in nurses' practice in this setting due to the nature of the experiences of the women they were nursing. These difficulties arose in relation to two particular situations, nursing women experiencing a 
mid-trimester termination and nursing women with cancer. Thirdly, the relationship with/in the medical discourse and individual doctors which, according to the nurses, had a major impact on their work.

This study contributes to nursing knowledge by providing a forum for the voices of women as nurses, who nurse women in the gynaecological ward, to be heard. Using concepts from both feminist and postmodern theorising enabled the surfacing of the voices of nurses and interpretation of their experiences from a position of embodied reality. The diversity of the practice of nurses and the importance of recognising and working with this diversity became evident. Writing the text has been an important part of this research. Seeing writing as a political act in the way that many feminists do requires careful attention to the written word. Considering our fundamental nursing texts from a feminist perspective shows that many reflect a medical construction of gynaecological conditions and their treatment. Making explicit the voices of women as nurses is an important step in making women visible within the discourse of gynaecology.

Nursing and feminism have much to offer each other and share an emancipatory goal of positive action to support and assist people in their lives. 


\section{ACKNOWLEDGMENTS}

This research would not have been possible without the support and interest of many people. However, some have contributed in a way that affected my ability to complete this thesis.

First I must thank the nurses who are at the centre of my research and who made the whole project possible. Without their willingness to be involved in the study, I could not have undertaken this research. They accepted me into their world and tolerated and indulged my presence in their very busy days, being always willing to share their experiences, knowledge and expertise.

My research supervisors have provided me with the encouragement and wisdom I needed to complete this project. In the early stages, Professor Jill White's assistance was essential in getting me started on this project. Dr Patricia Laing has been with me throughout this process and her interest and experience as a supervisor were evident in her allowing me to follow my inclinations and ideas throughout this lengthy project. Dr Pamela Wood became involved further on in the journey. Her wisdom, and ability to understand immediately the nature of my work, provided me with great confidence, she has worked with me in a close and supportive way that has been pivotal to the completion of my research.

The institution that was Wellington Polytechnic and is now Massey University in Wellington, has provided me with greatly appreciated support in the form of resources such as time, assistance with fees, study texts and excellent computer facilities. The library staff, in particular Paul Orsman, have provided invaluable assistance throughout the project. I have also appreciated the interest and support of my colleagues within the Department of Nursing, Health and Environmental Sciences. 
I want to thank all my family and friends who have indulged me at various times throughout the process. Particularly, I want to thank Jean Gilmour who has shared the experience of $\mathrm{PhD}$ study, our mutually supportive friendship has been of great value. Also, Dr Robin Watt who, even in the dark moments, never wavered in his belief that I would complete this study. Thank you also to my daughter Emily for her interest from afar, and to my son Nyk who has lived with this research on a daily basis from its beginning, and who has gone through the many ups and downs remaining always positive, supportive and interested. Finally, I want to acknowledge my late father Neville Bramwell who, although rather mystified by the topic and my feminist position, in this as always, provided me with unquestioning love and support. 


\section{TABLE OF CONTENTS}

\section{Chapter $1 \quad$ Positioning my research}

The writing

Reflections on my nursing

A reality check, my return to clinical work

Reading the texts

Feminist ontology

And so ... on

Chapter 2 Re-searching gynaecology

Looking back

Recent times

Gynaecology in New Zealand

Nursing in gynaecology

And the texts

Chapter 3 Feminist representations within nursing

Writing feminism into nursing

Nursing epistemology and feminism $\quad 65$

Feminism and feminism(s) $\quad 70$

Who is writing feminism in nursing $\quad 74$

Feminism's visibility in nursing research $\quad 77$

Feminist theory and nursing women $\quad 84$

Chapter 4 An exploration of knowing $\quad 89$

The Other 98

Difference and Différance $\quad 100$

$\begin{array}{ll}\text { The body } & 107\end{array}$

Discourse $\quad 112$

$\begin{array}{ll}\text { Postmodernism } & 113\end{array}$ 
Chapter 5 Feminist methodology: one woman's way 118

The locale

Meeting Rose, Sarah, Rachel, Alice, Henrietta, Isabelle, Audrey and Bridget

Being with the nurses

Nurse-researcher as participant-observer

The interview experience

Exploring the texts

Managing authenticity

Closure?

The nurses' voices

Chapter 7 Who Cares?

Coping when women are having mid-trimester terminations 192

Coping when women have cancer

Chapter $8 \quad$ Power and resistance: nurses working with/in the medical discourse

The nature of power

The culture of resistance

Chapter 9 Interweaving the texts

The reflexive thread

The written word

Integrating diversity

On being a woman

Working with power

Knowing gynaecology

And the future

A personal reflection 


\section{Chapter 1}

\section{Positioning my research}

Woman must write her self: must write about women and bring women to writing, from which they have been driven away as violently as from their bodies - for the same reasons, by the same law, with the same fatal goal. Woman must put herself into the text - as into the world and into history - by her own movement. (Hélène Cixous 1981, 245)

If we continue to speak this sameness, if we speak to each other as men have spoken for centuries, as they taught us to speak, we will fail each other. Again ... words will pass through our bodies, above our heads, disappear, make us disappear (Luce Irigaray 1980, 69).

$\Omega^{n}$ hese quotations by Hélène Cixous and Luce Irigarary, two of the most influential French feminists, reflect my personal beliefs that underpin this research project, woman must write herself into the text. We are responsible as women and in the case of this project as nurses, for ourselves, for speaking and writing what is important for us, for making our world as women and as nurses. Therefore, writing our world requires us to position ourselves as subjects within our own texts.

What shapes reality for the nurses who are working with women in the gynaecological ward? This question has fascinated and absorbed me, and shaped my life, for the last four years. Exploration of this question has had a profound effect on my feelings about the discipline of nursing and about the development of knowledge, and has resulted in a thesis in which I have endeavoured to capture the fascination I feel for the topic, as well as meet the scholarly requirements of doctoral research. This research is about women in their role as nurses, it is an exploration of their subjectivity, integrated with mine as the researcher. In this study the voices of women as nurses in the gynaecological area 
are heard and positioned within contextual discourses. My feminist positioning has guided this project and supported my commitment to making explicit the voices of the nurses.

Within this research I am positioned as a woman and a nurse which makes connection with the subjectivity of the women in the study unavoidable. Athough our experiences as women and nurses are diverse, due to the shared nature of our reality within these socially constructed positions there are points of connection. Therefore, as the researcher I am positioned close to the nurses who are part of this project. Neutrality of observation is not possible from this point, nor desirable within my feminist philosophical position. Until recently objectivity has been considered an essential element in establishing 'truth', a major focus of the male research enterprise (Stanley and Wise 1993) which has influenced the social sciences generally (Rosaldo 1995). However, this move to recognise and work with subjectivity has led to vigorous debate as feminists sought to gain validity for women's experience. Criticism of the subjective position relates to the apparent impossiblity of making a valid interpretation of the world from this point. Renato Rosaldo $(1995,171)$ argues against the notion of objectivity and discusses some of the criticism of a subjective approach thus, "prejudice and distortion ... putatively derive from the vices of subjectivity: passionate concern, prior knowledge, and ethical engagement." Within the context of my study these socalled 'vices' were undeniably part of the enterprise. I have a passionate concern for the area of gynaecology and for the women who are part of that world. Due to my experiences as a nurse generally, and specifically in the gynaecological ward, there was no doubt that prior knowledge would influence my research in the discipline and in this unique area of practice. Ethical engagement, rather than being a concern due to the 
possibility of distortion was in fact a guiding prinicple of the whole research project. I actively engaged with the nurses and became involved in their world in a manner that reflected an on-going concern for feminist research ethics, including the consideration of power relations inherent within the research relationship. However, this is not to say that closeness to those in the research should merely be accepted uncritically, rather the situation needs to be acknowledged particularly when it impacts on the process of the research. Feminist authors such as Kathleen Lennon and Margaret Whitford $(1994,3)$ support this recognition of the researcher's subjectivity and the need to consider it part of the research process when they say,

Gone is the Enlightenment idea of an Archimedian point where a universal knower can stand and see the world without perspective. All knowers are situated .... and these dimensions of situation all become part of the epistemological context.

These assumptions related to subjectivity underpin this feminist study.

This study contributes to nursing knowledge in three major areas. Firstly, the gynaecological setting is a unique and hybrid area of nursing practice that draws on a complex range of expertise. The reality for nurses working in this area has rarely been explored, and particularly not in a New Zealand context. Exploration of our reality allows us to make explicit our lives as nurses, it contributes to a greater understanding of ourselves and the nature of nursing, and the effects our role as nurses can have on our being. Secondly, gynaecology as a specialty area and a discourse within which nurses work has not previously been explored by nurses. As nurses, knowing the development of the discourses which shape our practice allows us to enter critical debate from an informed position which can lead to us being active participants in change that is focused on improving a woman's experience in an illness focused setting. Thirdly, although feminist research is gaining in popularity in nursing literature, exploring 
nursing using a specific feminist philosophical lens is a recent development in feminist nursing scholarship. Undertaking research into the reality of nurses working in the gynaecological specialty area via feminist epistemology and incorporating notions from the French philosopher Michel Foucault, appears to be a unique linking of philosophy with this specific area of nursing practice. This contributes to the expanding variety of research methodologies that can be used by nurse scholars to develop the knowledge base of our discipline.

Originally, when shaping this research, I thought of undertaking a project that would explore the experiences of women as nurses and patients in the gynaecology ward. However, it soon became clear that for me this was not appropriate. As a nurse, I wanted to explore nursing, what intrigued me was the nurses' reality. It seemed that to know the other, that is the patient, first we must know something of ourselves as nurses. The world of the nurses in the gynaecological specialty area was what fascinated me first and foremost. Yet this did not preclude me from being very aware that the nurse and the woman she is nursing are densely intertwined in the hospital-managed illness situation, and that women patients have their own subjectivity. I could have attempted to add in some aspects of the patients' experience but increasingly I felt this would not do justice to the women who were patients in the area. Being admitted to the gynaecology ward, for whatever reason, is a major event in a woman's life. To give this experience less than total attention, to use their experiences to add a dimension to the nurses' lives did not sit comfortably with either my feelings about nursing or feminist research. When patients, particularly women, are involved in research, they are a vulnerable group and their concerns must be central to the project, each group of women has the right to have their voices heard and be positioned as central. Therefore, I 
chose to undertake this research focused solely on the nurses, but I acknowledge that making explicit the voices of the women as patients in the gynaecological service setting will be an essential part of my future research programme.

This study then has three specific aims. Firstly, to describe the reality for women as nurses who have chosen to work with women in the gynaecological ward. Specific areas of practice are discussed in the three analysis chapters. Secondly, to explore gynaecology as a discourse which shapes our practice in this area. This exploration is undertaken through a discussion of the development of gynaecology as a specialist area of medical care in Chapter Two, and related to nursing particularly in the section on Nursing and gynaecology beginning on page 50. This issue is also returned to in Chapter Eight where I discuss the nurses' relationships within the medical discourse. And thirdly, to use specific feminist epistemological notions, and concepts from the work of Michel Foucault, to explore the reality for nurses working in this area. The theoretical ideas informing this study are discussed in Chapter Three and returned to in Chapter Nine in the section Integrating diversity.

\section{The writing}

Throughout this thesis I have been attentive to characteristics of feminist writing. In accordance with accepted principles the thesis is written in the first person to ensure that as the researcher, I am visible throughout the research process (Webb, 1992a). Luce Irigaray (1985a) believes that women must avoid abstract personhood and points out that "in the language of science there is neither I nor you nor us" (ibid, 74). Rosemarie Tong (1992, 228) when commenting on Irigaray's work, points out that she urges women to: 
... join together in order to find the courage to speak in the active voice, avoiding at all costs, the false security, and ultimate inauthenticity, of the passive voice.

Although this makes explicit within the study the subjectivity of all participants including the researcher, at times I found making myself 'known' in the text challenging. I realised that owning my work by the use of ' $I$ ' was much less comfortable than hiding myself in the text by constructing a traditional research report devoid of researcher subjectivity.

Wherever possible when naming an author in-text for the first time in each chapter, I have included the first name. I have chosen to do this as a deliberate strategy to foreground women's scholarship. I acknowledge the debt I owe to women scholars and nurses whose work has influenced and shaped my work, and who have contributed to the development of knowledge in this field.

This research is focused on the experience of women as nurses and their work with women who are patients in the gynaecological service setting. Therefore, I have used the common terms of 'nurse' and 'patient' throughout the thesis to avoid confusion and make explicit the roles of the women in my study. I have also deliberately used the term 'medical system' in some instances where many writers would use the term 'health system', to describe the social institution which promotes health or provides care when we are ill. I believe this system is still focused on the practices of doctors, that their management of health and illness still structures the type of care provided and that naming the institution as medical more appropriately reflects this emphasis.

This chapter is about positioning, my positioning. It traces my path in relation to this topic, explores the factors that led to my fascination with the subject and which shaped 
the research and, through the chapter outline, gives my reasons for structuring my work in the way I have. My positioning in relation to this research is influenced by my past. Unravelling the threads, that woven together, make up the fabric of experience which led me to my present position, is an element of the reflexivity which characterises feminist research (Fonow and Cook 1991), and which is a theme throughout this study. I have addressed these threads as though they are discrete but in reality they are totally interwoven, each shaping my thoughts and feelings about the other. In the section that follows I discuss the major factors which influenced my decision to embark on this journey. However, I recognise that all my previous experiences will have an influence to a greater or lesser extent, on a project of such a consuming nature. The influences which I have chosen to highlight are some particularly relevant nursing experiences, my practice experience in the gynaecology ward prior to enrolling in the doctoral programme, and my early exploration of the literature about gynaecology, feminism(s) and feminist theory. I will address each of these areas separately before discussing the overall effect they had on the nature of my research.

\section{Reflections on my nursing}

On completing my nursing training in 1970 I immediately removed myself from the general run of the hospital by taking a staff nurse position in the operating theatre where relationships between doctors, senior nursing staff and nurses were much more relaxed. In retrospect I think this was due to my subconscious feeling of dislike at the way the hospital system treated nurses and the messages conveyed in relation to our value and status. At the time I would not have been able to articulate these thoughts but I do remember vividly being infuriated at having to clean up after doctors, stand when either doctors or senior nurses entered the room, and at the obsequious manner of many 
nurses, especially those in senior positions. I was aware even then, that doctors were considered far above nurses in importance and status. I stayed in the theatre environment until having my children and travelling overseas.

On returning to nursing full-time, I deliberately chose to work in the community where I felt the constraining structures of the medically dominated system could be avoided and at times, even subverted. In the community I was responsible for my own practice and, as I saw it, had a much greater degree of control over my own work. I also chose to work with women involved in child bearing and rearing due to my beliefs about this period of women's lives potentially being one of the most difficult. I deliberately avoided the institutional setting because of the realisation that the philosophies inherent in this structure in relation to nurses and women's health, were not compatible with mine.

In 1986 I began my university study, working towards a Bachelor of Nursing degree. Until this time, many of my ideas were based on intuition and feelings. However, time away from practice gave me the opportunity to reflect on nursing generally and, as I was immersed in the academic exploration of nursing, I also gained the theoretical concepts to critique the knowledge and practice of nursing. I thought of the medical system as one of the most conservative institutions in society and I often felt a sense of unease at the way we worked within this major social institution yet appeared to have so little influence on its shape and practices. The dominance of medicine and the effects of this on women, particularly as nurses, seemed so blatant, as Peggy Chinn and Charlene Wheeler $(1985,76)$ say:

Nursing practice typically occurs in the oppressive, reductionalist, milieu of the patriarchal order - the hospital - which does not foster, 
tolerate, endorse, nor approve nursing practice based on nursing's own theories and values.

I took this even further and wondered if nurses could identify their own knowledge and, if not, perhaps their practice would continue to focus on the management and treatment of people in a way which reflected the medical construction of health and illness. Yet this situation never seemed to be questioned by the women in the system. I also felt that perhaps the medical system required the unequal power relations between nurses and doctors to be maintained, nurses had to be kept in their place as this supported the place and power of the doctor. I know many nurses who felt the oppression of the system and either removed themselves completely from it or moved into areas where the medical influence seemed less obvious. Other nurses stayed in areas where the medical model ruled and seemed to use a variety of methods, both overt and covert, to soften the system, to give it a human face. I felt that the work of nurses needed to be carefully explored as, although espousing a holistic approach, at times it seemed that we were not focusing on what was best for the patient but more often on maintaining the institution. I began to think that perhaps the values that dominate our medical system are so pervasive, mirror so perfectly the values of society at large, and are so powerful, that nurses may find it difficult to be aligned to the person rather than the institution.

The relationships between nurses and women also began to intrigue me. The medical system, by nature and practice patriarchal, reflects the values and beliefs about women in society. I came to believe that the medical system could be considered as actually working to make women unwell by inducing dependence (on specialists and drugs), by stripping women of their innate knowledge about their bodies, by professionalising every aspect of women's health for profit and coercing women as nurses to support the status quo by ensuring they identified with the system rather than the women patients. 
With hindsight I realise my ideas at this time reflected a passionate ideological stance which, although important in terms of consciousness raising, I would now critique as essentialising and positioning women in the medical system, both patients and nurses, as passive victims.

After completing my undergraduate degree in 1988 I changed my role from clinical nurse to that of nurse educator in a tertiary institution. When I began working as a nurse educator I chose to work with registered nurses who were returning to study for the purposes of gaining further qualifications. I was interested in nurses who were already working in the system and wanted to be part of developing their awareness of the political nature of the system and hopefully encourage critical debate amongst the nurses. I felt that nurses were kept blind to the issues of power and dominance and were not actively encouraged to critique the structures and philosophy underlying medical dominance generally, and its effects on women specifically. Instead, at that time, nurses seemed to be taught to accept, to explore their practice but not in relation to the philosophical and political reality in which that practice was embedded. Even nursing knowledge seemed to be accepted with little debate and the lack of feminist critique and scholarship in educational settings meant that gender issues were rarely considered.

Enrolling in a Masters paper in Anthropology, "Systems of Healing",' in 1993 was pivotal in developing many of the ideas I had been forming about the nature of western orthodox medicine. Through the exploration of other systems of healing in the world, I was able to put our system into a more global perspective and critique our taken for granted ways of treating illness and disease. I came to the conclusion that western

\footnotetext{
${ }^{\prime}$ Systems of Healing is a Masters paper in Anthropology offered by Massey University, New Zealand.
} 
orthodox medicine is very aggressive, that it relies on a hierarchical model that guarantees the status of the doctor and has modes of intervention such as surgery, drugs and electric shock that seem to be extremely harsh when compared to ways of healing in other cultures. It was during my study for this paper that I was first introduced to the ideas of Michel Foucault and French feminists such as Julie Kristeva. ${ }^{2}$ This was critical for me in terms of how I framed many of my thoughts to do with the medical system, medicine, nursing and the interplay of these discourses in our society.

\section{$A$ reality check, my return to clinical work}

In what was a pivotal decision, in 1994 I decided that I needed to update my clinical skills in an acute area of nursing practice as I had not worked in such an environment for many years. I had an increasing sense of being distanced from the real world of clinical nursing, the education and academic world of nursing was becoming more real than the practice. I was also becoming more interested in the work of nurses in hospitals, in situations where people are labelled as sick and require the assistance of specially trained people, that is nurses. Although I had spent many years working as a nurse in the community I had always had a fascination with the drama and immediacy of acute nursing which stemmed from my time spent working in operating theatres. It seemed that this interest had not disappeared.

For a number of years through my experience working with mothers in the community, my area of interest had been women's health. Therefore, when thinking of possible acute nursing areas in which I might undertake some clinical experience, gynaecology naturally came to mind as the intersection of women-specific illness and acute nursing

\footnotetext{
${ }^{2}$ The work of the French feminists and Michel Foucault is discussed in the epistemology chapter.
} 
practice. Late in 1994 I approached the Unit Manager of a gynaecology ward to gain her permission to work alongside the staff nurses in the ward for this experience. As I thought about going into this area I realised that very rarely in nursing research publications had I come across work that focused on gynaecology per se. Women's health was addressed in terms of conditions such as pregnancy and the issues surrounding women's reproductive role, for example screening for cervical cancer, menopause and breast cancer. Gynaecology as a subject was discussed mainly in comprehensive nursing texts and covered the functional aspects of surgery and subsequent nursing management (as in Smeltzer and Bare 1996). There appeared to be little nursing research in this area and as I was relatively uninformed at the time, my feelings about gynaecological services were inevitably coloured by my readings about women's health generally.

Because I believe in the usefulness of journal writing as a way of reflecting on experience, and my natural inclination is to record new experiences, I decided to keep a brief journal during this time. As a way of increasing my clinical knowledge I found it useful to record detailed examples of how women with certain conditions were cared for, including body care, intravenous therapy, catheter care, drugs, and the technology used and its effects. My journal shows my interest in relearning some of the specific skills nurses undertake in a surgical area, such as removing catheters, drains, clips and sutures, managing intravenous and oxygen therapy, and the administration of specific intravenous drugs.

What appeared when I re-visited these journal entries was a sense of an overwhelming experience in terms of the immediacy of acute conditions, the skill of the nurses, the 
emotional nature of the work, the highly context-specific use of language, and the use of medical technology. I also recorded my feelings about the difficulties inherent in what I came to feel were educational 'sacred cows' such as holistic nursing, an idea that is laboured in nursing education and which has an almost sacred place in nursing knowledge. ${ }^{3}$ Holistic nursing seemed almost impossible in a very acute area where many patients stayed for only one or two days. Because of this I began to question the wisdom of teaching a concept in a way that made it a basic element of practice but which would be unattainable at times for many nurses. Was this the creation of mythology, was holistic nursing more myth than reality? I also became very aware of the reality of the powerful socialising forces at play in the ward. Many nurses seemed to practise on the basis of 'received wisdom' from other nurses which I thought led to a certain homogeneity in approach to patients. At this point, I clearly still felt that you could talk generally of the nursing as a homogenous activity that was practised by all the nurses in the ward.

My initial impression recorded in my journal is of a "very busy, heavily medicalised ward" where "I think the condition is nursed rather than the person" (Journal 1994/95) . However, I was unsure about my impressions and recognised the fact that they would be strongly influenced by my own state of mind, a lot of my ideas reflected my own feelings, as I stated in my journal at the time:

From only one days observation it seemed that the nurses were not focused on nursing practice but were definitely driven by tasks. Or perhaps it was me, I was so focused on tasks that I missed the "nursing" taking place ... perhaps for me it was such a strange place that I couldn't see what was what (Journal 1994).

\footnotetext{
${ }^{3}$ For a discussion and critique of holistic care in nursing see Helen Wilson, 1998, Examining Holistic Health Care, Kai Tiaki Nursing New Zealand.
} 
I thought the ward was inevitably going to be a medicalised, conservative, oppressive setting. I was concerned about where the nurses would fit as the literature seemed to point to nurses largely supporting the dominance of the medical discourse. I tended to think of nurses collectively, a form of essentialism, and I tended to think of the women as victims on the receiving end of an oppressive and almost brutal medical system. On reflection, I think I was seeing what I wanted to see.

However, I also found being immersed in the drama, the 'theatre', of an acute area after so many years absence very stimulating. It seemed to me that healing in modern hospitals is still imbued with drama, as it is in many cultures where healing is intertwined with drama, spirituality and faith. I also admitted quite openly to an enthusiastic interest in the technology of modern hospital care:

I also saw and went over the resus [resuscitation] trolley, the defib [defibrillating] gear and some of the new drugs that are being used, enjoyed it all - fascinating stuff. (Journal 1994).

I recognised that relationships between nursing and medical staff were difficult at times and this was quite apparent from the amount of time the nurses spent talking about the doctors and how they had handled certain situations. I felt this was almost a given in that it supported my own beliefs at the time about the difficult nature of this relationship. It was easy to see this in terms of nurses feeling inferior to the doctors and relate it back to the power of the medical discourse over the health system.

While in the area I got to know the unit manager of the ward, a nurse, who was having a difficult time due to management structures in place at the time. This relationship was extremely important to me as she was very forthcoming, interested and friendly. I felt connected to the ward due to her being so welcoming and willing to share her thoughts 
and feelings. I now think that one of the significant factors in my choosing this topic for my doctoral study was my relationship with this nurse. We had many general discussions about nursing, women's health and gynaecology. Her obvious commitment to the women in the ward validated my increasing interest in both the specialty and the ways of nurses in this setting. She had such a clear view of how the area should function and connected this strongly to her own feminist principles. I was intrigued by this underpinning of practice with a clearly articulated philosophy, as it seemed rare in nurses.

My clinical experiences in the ward at this time connected me to the reality of nursing practice, not as a spectator but as a nurse. I became immersed in nursing practice in an acute gynaecological ward and absorbed by the way nurses worked in this highly emotionally charged and complex setting. I was intrigued as to how gynaecology came to be constructed into the specialty area it is today and the reality for nurses of working in this area.

\section{Reading the texts}

Because of my growing fascination with gynaecology, I began to read the history of women and healing, an exploration that was the beginning of an amazing journey back in time. Back to a point where history and archaeology become blurred, where ideas about how humans lived seem based on conjecture, supposition and on remnants of material culture left by our forebears. It seemed that throughout history there have been people engaged in healing, caring for the sick, and helping people maintain their health (Achterberg 1991). These people have, more often than not, been women. For thousands of years, often in the face of great odds, and in diametric opposition to the prevailing 
hegemony related to women and healing, women seemed to have helped, healed and cared for people, using the resources available to them at any given point in time. Women working with human health and illness drew on the knowledge of the day: herbal lore, surgery, magic and spirituality. As women involved in healing today, nurses draw on a range of healing therapies from the latest technologies to spiritual and intensely individual strategies. It seemed that in this way the practices of women involved in healing have always reflected the beliefs of the day. This led to a great sense of pleasure at the thought of being part of a group whose role is as ancient as human society. I developed a strong feeling of a line of women healers stretching behind me in history and the courage of these women during times when persecution reached its peak, strengthened my commitment to the exploration of the practice of nurses in the present. In conjunction with my exploration of women and healing I began reading in the areas of feminism, science and medicine which led me to 'the body' as subject. The control of women via their bodies was a theme that was woven throughout the feminist critique related to these areas. Control of women's bodies then became a central concern in my reading, particularly the way that medicine, as an off shoot of male science, was considered one of the most powerful discourses controlling women's bodies (Bunkle 1992). The argument that this need to control women came about through fear of the possibilities and power signified by the embodied female seemed powerful and could, I thought, be seen in the practices in the gynaecological ward. Perhaps nurses are unthinkingly involved in practices that enact this control. The dominant ideology will influence the nurse and therefore her practice, which in turn will directly affect the illness experience of the woman being nursed. 
Through my reading related to women and medicine, and its influence in the oppression of women, I began to think that the gynaecology ward must reflect this negative and oppressive attitude to women. This led me to the conclusion that there was little that was positive in the gynaecological services offered by orthodox western medicine. Also, what seemed to be consistently missing in the literature were the voices of women, including women working in the area where gynaecology is enacted and becomes real.

My early exploration of the nursing literature showed little attention to gynaecology, apart from the descriptions of disorders, with outlines of conventional management, in textbooks and journals such as the Journal of Obstetric, Gynecologic and Neo-natal Nursing. My interpretation of this, based on my reading, was that the area was somehow marginalised, not considered that interesting. I thought perhaps gynaecology was largely ignored due to what I would now term its Otherness, the focus of the service being women's problems, things that one doesn't talk about openly and that make people feel uncomfortable. Women were secretive about gynaecological disorders and convention meant men did not ask about such things. This attitude seemed reflected in nursing literature. The lack of interest in gynaecology apart from purely functional considerations, resulted in a complete lack of critique of gynaecology and the role of nurses in this field. In the nursing literature, critique of the way women's health is managed focused more on general areas such as screening, access to resources in the health field, overuse of medical and pharmaceutical resources, and psychosocial issues such as dependency. I thought that the gynaecology ward represented women's oppression in microcosm, that the nurses were not conscious of their role in this and that the women just accepted it. 


\section{Feminist ontology}

Although I feel uneasy about labels I have always considered myself a feminist. I think my discomfort with such labels results from a feeling that grouping all those who believe in working for the rights of women (in whatever form), under the label 'feminist', is as reductionist as those who believe the roles of women are determined by their biology, and that there is something essentially woman. However, in the taxonomy of political and academic persuasions, because the term feminist identifies oneself as a person that believes women have been systematically denied credibility in all aspects of life in a conscious effort to maintain the power and privilege of male hegemony, then I willingly identify myself as a feminist. My positioning as a feminist nurse educator/researcher is an integral part of my life and has therefore shaped my approach to my research. It was impossible to think of undertaking my research from any position other than one that reflected this personal philosophy.

Prior to entering the gynaecology ward I was exposed to the literature in the area of feminist theory, which provided me with a theoretical lens to consider the place of women in the world and the way this may affect gynaecology. The dialogue between feminism and other philosophers, for example Nancy Hartsock's (1990) discussion of Foucault, also provided me with valuable ways of considering the whole area of women's illnesses. Inherent within all these approaches was an interest in power and I realised, prior to settling on my thesis topic, that I was intensely interested in the structure and manifestations of power in our medical system.

Although a feminist, I found it difficult to determine my positioning in relation to the variety of feminist theoretical stances. Although I explored the different types of 
feminism (Tong, 1992) I found that they did not immediately provide me with a framework that was congruent with my instinctive approach to feminist ontology. My personal approach was one of commitment to exploring the place of women in the world, how this positioning came to be, and the effects for women. I felt strongly that exploration of this positioning was the domain of women. This personal feeling gradually led me towards what is often called European or French feminism and some authors such as Tong (1992) see this as synonymous with post-modern feminism. From this perspective feminist activism includes theory development based on the premise that otherwise male theory will continue to be used to define and describe the lives of women, ideas that I develop in Chapter Four which is focused on feminist epistemology. This form of feminism supported my interest in the way male knowledge constructs our world and specifically the modern medical specialty of gynaecology. From this perspective I saw nurses as enmeshed in discourses, including their own, which functioned to ensure the dependency of women on male medical practices. Because of this enmeshing I saw the possibility of nurses in this setting being at once victims and perpetrators, a state of being that seemed congruent with the notions of subjectivity I had developed through exposure to the ideas of post-modernism.

I also realised that nurses in the gynaecological area confront, work and interact with the female body as a biological entity and that when they do this the nurses are in fact confronting a reflection of themselves as an object at the intersecting discourses of science and medicine. However, the nurse in this situation could be seen as an instrument of these discourses, thus making her practice highly complex, personal and suffused with a tension due to her positioning at that nexus. 
In relation to my interest in women in the medical system, Luce Irigaray's (1985b, 1987) work made me question whether a 'male' medical system could ever see women as nurses, from any perspective other than as a 'problem'. Due to women being defined by male structures can they only be visualised in the health system as Other and object? The concept of Other gave me a framework for seeing women as essential, but marginalised, in the health system. Nurses seemed to be working in a marginalised space, a good space in many feminists eyes, for it enables creativity and difference to flourish.

However, I recognised that due to the way the medical system is structured and the status and power accorded the medical discourse it would be almost impossible for nurses working in the institutional setting to ignore the influence of the medical construction of the body and practise on the basis of a differently constructed body. I recognised that at times nurses did endeavour to integrate a person's individual embodied needs with those of the institution. However, the tension created by trying to meet both institutional and patients' needs may well be intolerable and lead to the nurse making pragmatic decisions about what she can or cannot achieve.

\section{And so... on}

My previous clinical experiences and my exposure via the literature to new and seductive interpretations of practices that are taken for granted in nursing, led me to view modern nursing practices sceptically. I considered the knowledges which guided our work as conservative and reactionary. I felt a sense of impatience at our non-critique of our work, at our support of the status quo and our acceptance of the world of health and illness as it is. 
The integration of my personal ideas formed by my life experience, my practice as a nurse, and my exploration of gynaecology and feminism, led to the development of a powerful ideological stance that needed to be critiqued in itself. To be honest, at the end of this exploration of the literature, coupled with my period working in the ward, I think I had the sense of doing some sort of exposé. My study was going to show how gynaecology was still based on the values inherent in Victorian writings on the subject, how it was still used to oppress women, a way of making women docile and obedient through the management of their bodies. I was aware that the influence of this stance on the way I approached the data collection phase of my project could result in a study that showed nothing but support for my ideas. In fact the seductiveness of the ideas I had explored in a way alerted me to the danger of allowing those ideas to go unchallenged. I knew that the strength of my opinions about nursing, feminism and theory would frame my research but that I must continually challenge my interpretations throughout the study.

As these influences became more integrated, the topic for my research became quite clearly focused. Gynaecology, which had been a part of women's lives in some shape or form for thousands of years was, I thought, a fascinating topic. The interwoven threads that had led to this point crystallised in the subject of exploring nurses' reality in the gynaecological ward, an exploration that would have meaning for nurses working in the area. Having outlined major influences on my decision to undertake this journey I outline below the subsequent chapters that explore this topic in depth.

Chapter Two explores the development of the modern specialty area of gynaecology. My aim in this chapter is to provide an understanding of the context within which 
nurses practise in the gynaecology ward today and to show that this context is mutable, not something we should believe is fixed and unchanging. The discussion positions current practice within an historical context and explores the influence of this historical development on nurses' practice. My exploration briefly covers the beginnings of knowledge in the area and some of the major written works on the illnesses of women. The development of modern gynaecology as a specific hospital based area of medical practice, and the transference of the English model of management to New Zealand are discussed. The way in which nursing has followed this development is also explored.

Chapter Three focuses on the place of feminist scholarship within nursing and draws mainly on the work of nurses from Australia and North America. The purpose of this discussion is to position my research within that body of work. I discuss and critique the development and use of feminist perspectives within nursing. The representation of feminist theory in New Zealand nursing literature is also considered. I draw conclusions as to the most common form(s) of feminist scholarship appearing in the nursing literature. This exploration leads into the development of my own epistemological stance discussed in the next chapter.

Chapter Four details my epistemological position and explores the theoretical lens I have used for my research. The writings of feminists who work with ideas from both standpoint and postmodern positions have been central to this research. Initially the ideas expressed in their writings resonated with my personal philosophical stance and, as my work progressed, provided me with strategies for shaping my reading of the multiple texts informing this study. In the chapter I describe the specific notions taken from my reading of the body of feminist scholarship and outline the way these inform 
my research. Also discussed are some ideas from the work of Michel Foucault which are relevant to this study. Although this is a feminist project, in line with a number of feminist authors I felt that the work of this philosopher added to my work. Because of the critical stance shared by feminist writers and Foucault they could be positioned as complementary to each other and to my particular research.

Chapter Five describes in detail the methodology I used for this research. In line with current feminist thought I chose the data collection methods that seemed most appropriate for the exploration of nurses working with women in the gynaecological ward. Methods of data collection and analysis are discussed and justified. The process of reflexivity and its interweaving throughout this research is also discussed. In this chapter I describe the setting in which the research took place, gaining the participants and detail of the ethical issues relevant to the study.

Chapter Six, 'Women working with women', is the first of three chapters based on the data in which the voices of the nurses are apparent. The topic of this chapter is the interpretation of the nurses' experiences when working with their women gynaecological patients, and with each other. In this chapter, as in the subsequent analysis chapters, quotations are used to make explicit the nurses' voices and are interwoven with my own reflections on the issues being raised. In this chapter, as in the others, the notions I have outlined in my discussion of epistemology are used to give a certain reading of the nurses' practices.

Chapter Seven, entitled 'Who cares?', addresses the nature of the nurse's work in the gynaecological ward and the way it can impact on the nurse as a woman. Two 
particular situations, nursing women having mid-trimester termination and women with cancer, are explored and used to highlight the danger that exists for nurses in their everyday practice. The nature of these two challenging clinical situations leads to my reflection on the invisible nature of many of the difficult aspects of nurses' work and my positioning as a feminist in relation to this invisibility.

Chapter Eight, 'Power and resistance: nurses working with/in the medical discourse', is an exploration from the nurses' perspective of the way they work with doctors and the effect this can have on their feelings about themselves and their practice. The resistance of the nurses and the way that they work to manage this relationship is discussed and gives rise to the diversity and individuality of nurses' responses to both the medical discourse and the individual doctors.

Chapter Nine is the discussion, based on reflection and interpretation, in which I interweave the various texts that form this research. Methodological issues that arose during the research are explored and related to nursing research. The aspects of practice that have been raised by the nurses as important when working in gynaecology are discussed and addressed through my particular theoretical lens. Included in this chapter are recommendations for nursing research and practice based on my exploration of the topic. As a basic tenet of feminist research is an emancipatory intent that focuses on change to support or enhance the lives of women, I have included in the recommendations a set of guidelines which will provide the basis of a discussion with nurses to support them in their work. This chapter concludes with a final statement about my experience of undertaking this research. 


\section{Chapter 2}

\section{Re-searching gynaecology}

ynaecology has a long history as a special area of practice for those interested in the care of women in health and illness. Exploration of some aspects of this history is relevant to my research for two main reasons. First, the practice of nurses today is enmeshed in the practices of our past. Exploring the development of gynaecology as a separate specialty area allows us to understand the ideological basis of a discourse which structures and shapes our practice as nurses when working with women in this service. Second, the consequence of consciously 'knowing' that the context within which we practice has shifted and changed over time can assist us to view the discourses that enmesh our practice as mutable and, therefore, able to be influenced and shaped by us as nurses. Having this knowledge can give us power and support us to be active in change processes. The gynaecological services we experience today have largely been shaped by the changes in medical practice that occurred in the nineteenth century. However, this was by no means the beginning of the specialty of gynaecology and to illustrate this I have taken a much longer view and discuss gynaecological practices prior to this period.

It is important to emphasise that this chapter is not a history of gynaecology, rather, as a feminist nurse, I have looked back at specific times and events, through the eyes of those who have written about the history of gynaecology. The conclusions I draw are based on my reflexive feminist reading of the major shifts in gynaecology and the 
implications of these shifts for women. By reflexive I mean that I have engaged with the literature and provided my own interpretation of the readings. Other readers may interpret the literature differently as I believe all 'readings' are open to multiple interpretations. In this chapter I also highlight some of the significant changes or disjunctions that affected the practice of gynaecology, and include the feminist critique of these changes. How the modern development of gynaecology as a medically controlled specialty has influenced the specific services provided for women in New Zealand is discussed. Finally, I turn to nurses and the way that our close and, at times, subordinate relationship with medicine has meant that our representation of gynaecology has been strongly influenced by medical discourse.

The term gynaecology comes from the combining of the Greek gynaikos: of women, with logos: science (Anderson et al 1994) meaning, therefore, the science or study of women. However, in reality, in modern nursing and medical discourse it is the study of little more than women's reproductive organs. An example of a typical definition of gynaecology in current nursing and medical dictionaries is:

a branch of medicine concerned with the health care of women, including their sexual and reproductive function and the diseases of their reproductive organs, except diseases of the breast that require surgery. Unlike most specialities in medicine, gynecology encompasses surgical and nonsurgical expertise. It is almost always studied and practiced in conjunction with obstetrics (Anderson, Anderson and Glanze 1994, 700).

Throughout the gynaecological texts I have explored, the emphasis is clearly on physical problems, and the voices of women are obviously absent, a point noted by Ann Dally (1991, xvi) when she says: 
Women and their experiences were scarcely mentioned, even in books about midwifery and gynaecology. Women's history was largely ignored. Women's experience of gynaecology was never regarded as important. Women were essentially and exclusively patients.

And, as a nurse reading the texts of gynaecology, not only is it the voices of women as patients that are ignored but those of the women working as nurses. Women in either position, nurse or patient, are invisible.

Gynaecology is an unusual specialty in that it crosses the accepted boundaries of orthodox medical practice. This hybrid nature of gynaecology is summed up by Ornella Moscucci $(1993,6)$ :

At different times in its history, gynaecology and its sister specialism obstetrics have been regarded as a branch of physic, a branch of surgery, a specialism of general practice and a subject in its own right on a par with medicine and surgery.

However, the conditions that could be labelled as gynaecological have remained the same from the beginning of recorded history, and presumably for millennia prior to literate history. Historical writings on gynaecology detail specific conditions which are still recognisable today. A typical list of the conditions discussed in the early writings on gynaecology and which would still today result in a woman being referred to a gynaecologist and admitted to a gynaecological ward, are: irregularities in menstruation (menorrhagia, dysmenorrhoea, amenorrhoea), and disease or malfunction of any part of the reproductive organs (ovaries, uterus, cervix, vagina or vulva). ${ }^{1}$ There are several

\footnotetext{
"See Elizabeth Mason-Hohl's 1940 translation of Trotula of Salerno's The Diseases of Women and Beryl Rowland's 1981 translation of the Medieval Women's Guide to Health for examples of women's illnesses.
} 
conditions related to pregnancy that can result in a woman being treated surgically by a gynaecologist who may, or may not, also be the woman's obstetrician, for example ectopic pregnancy and miscarriage, or being treated medically, for example hyperemesis (severe vomiting). This chapter is focused on women's illnesses, that is conditions currently subsumed under the title of gynaecology and managed within the hospital setting. I have not included obstetrics nor, to any great extent, preventative health care, except where reference to these areas is unavoidable due to their close links with treatment for women's illnesses.

Women, it appears, have consistently been the subject of special texts due to the particular and peculiar problems which relate to our role of child-bearing. As Ornella Moscucci $(1993,2)$ says "Because of her role in reproduction, woman is regarded as a special case, a deviation from the norm represented by the male." The ability of women to give birth made them peculiar but essential to male society, this made it necessary to incorporate the study of women into medical studies in any given period. Women's bodies have been the object of the male scholastic and scientific gaze, as evidenced through the authorship of texts yet, according to Beryl Rowland (1981), historically gynaecology has largely been the preserve of women in terms of practice. It seems then that in gynaecology, although the object of the discourse is women and the practitioner a woman, the text was and is, overwhelmingly (though not exclusively) male.

Historically the authoritative word is notoriously difficult to attribute to one specific author. This is because, prior to the development of printing, manuscripts were copied and circulated, each copier adding their own touches to the manuscript, altering the 
work to the point where actual authorship is difficult to determine (Green cited in Booher, 1996). The first printed text which included gynaecology was produced in Venice in the fifteenth century. The text was a copy of an earlier manuscript by Albertus Magnus and the section on gynaecological conditions had the title: Comments on the Secrets of Women (O'Dowd and Philipp 1994, 9). The title is interesting in that it sums up attitudes to gynaecology that continue today: women's bodily disorders have an air of secrecy, not spoken of except amongst women and, when necessary, their doctors and/or nurses. It seems that gynaecology still carries this aura of marginalisation in today's medical system due to its hybrid nature and concern with the mysterious, and largely secret, dysfunctioning of our female organs.

A difficulty in writing this chapter within the context of my research with nurses, has been the nature of the practitioners of gynaecology. Historically it appears that the roles of doctor, nurse and midwife have been encompassed in one person. The term doctor here is not to be confused with physician. According to authors such as Rowland (1981), prior to the Victorian era, physicians were highly theoretical and academic. These men were often attached to a wealthy family or important people and mainly treated men, not women and particularly not common women. What seems to have remained constant in the development of knowledge related to the body, its ills and their treatment, is that the medical 'theorists' were male. For a man to become a physician he studied at a university and the basis of his learning was text, rather than a living person. As Susan Duncan $(1997,131)$ says of knowledge at this time, "There emerged then a textual canon from which knowledge concerning anatomy and medicine was gained ... medical authority was textual." 
The medical world from the late eighteenth century until today then entered a period of practice based on experimentation; autopsy and dissection became legitimate and an integral part of medical education and experimentation. Women's bodies became a source of knowledge, as Deborah Lupton $(1994,134)$ says in relation to dissection:

... medical writings on the dissection of women's bodies for the purposes of furthering anatomical knowledge positioned doctors as explorers of the mysterious dark recesses of the feminine body, entering unknown territory like colonialists penetrating the wilds of Africa.

\section{Looking back}

Women's reproductive organs, either their normal functioning, as in menstruation and childbirth, or their dysfunction due to conditions labelled gynaecological, were the focus of early writings. Clearly there was considerable sharing of knowledge between the early centres of learning such as Egypt, Greece and Rome, and presumably the adjacent Arab world. ${ }^{2}$ It is also important to acknowledge that while the scholars of antiquity were sharing knowledge, presumably at the same time lay healers, often women, would be sharing their expertise orally and passing on rich, experientially derived knowledge.

According to Michael O'Dowd and Elliot Philipp (1994), the earliest known gynaecological texts are Egyptian papyri. The study of Egyptian medical knowledge has been possible due to the papyri that have been found, translated, and supplemented by archaeological evidence. The Kuhun papyrus of $1850 \mathrm{BC}$, and the later Ebers

\footnotetext{
${ }^{2}$ See Harold Speert's (1996) discussion of authorship of the antiquarian Roman text on gynaecology, initially attributed solely to Soranus, but now thought to be an adaptation of the work of a Byzantian physician, in combination with Soranus.
} 
papyrus (1526 BC - $1505 \mathrm{BC})$, provide details of specific women's conditions such as prolapsed uterus and treatment of symptoms related to uterine infection or malignancy. Treatment for the conditions is described and took the form of prescriptions. The Ebers papyrus contains an extensive pharmacopoeia, but apparently there is no mention of any form of surgery.

Gynaecological knowledge seems to have been consistently well documented. Early Greek scholars such as Hypocrites (c.460-377 BC) and Aristotle (c.384-322 BC) developed theories related to women which often reinforced the concept of the weak and inferior status of women (Porter 1996b; Shildrick 1997). It appears that the Greek writers were the first to describe the theory of the "wandering womb". Harold Speert $(1996,3)$ cites an excerpt from the work of the Greek physician, Aretaeus, describing the uterus thus:

In the middle of the flanks of women lies the womb, a female viscus closely resembling an animal, for it moves itself hither and thither in the flanks, also upwards in a direct line to below the cartilage of the thorax, and also obliquely to the right or the left, either to the liver or the spleen; and it is likewise subject to prolapse downwards; and in a word is altogether erratic. It delights. also in fragrant odours and advances towards them, and it has an aversion to fetid odors and flees from them; and on the whole the womb is like an animal within an animal.

Henry Sigerist $(1951,355)$ attributes this belief that organs, including the uterus, had "a mind of their own" and therefore had to be treated accordingly, to early mythological beliefs that continued to inform healing practices as they became codified. This theory was the basis for the commonly used treatment of fumigation, that is the attracting and repelling the uterus through a variety of methods. Although challenged by physicians 
such as Galen, this theory persisted and the treatment remained a standard therapeutic practice (Dixon 1994) for hundreds of years. According to O'Dowd and Philipp (1994, 49) the work of influential Roman "physician scientists", such as Soranus and Galen, formed the basis of European medicine and profoundly influenced the theory and practice of the discipline for the next millennium (Duncan 1997). It was during this period of knowledge development in Rome that the anatomy of women's reproductive systems were first described by Soranus (Speert 1996), who has been attributed as writing a major four part work on the subject of gynaecology. The first references to the use of the speculum and some form of surgery also appear in writings from this period (O’Dowd and Philipp 1994).

Unlike O’Dowd and Philipp (1994), Rowland (1981) focuses more extensively on the role of women and discusses the role of women in gynaecological practice in the days of ancient Greece and Rome. She cites a number of recorded instances where women have been attributed with knowledge and skilful practice in gynaecology which are significantly absent from the work of O'Dowd and Philipp, who appear to reinforce the male construction of gynaecology. At this time it seems women were respected practitioners and teachers of obstetrics and gynaecology. Rowland (1981) discusses the Greek work of a woman Metrodora on diseases of the womb and refers to several wellknown and documented women, such as Helen of Troy and Cleopatra, who were well aware of the effects of various herbs, and Agnodice and Aetios who were respected gynaecologists in their time. 
The involvement of women in the scholarship of healing related to gynaecology continued into the medieval period. One of the most significant authors of gynaecological literature at this time was the woman physician Trota of Salerno. This woman was a famous writer and practitioner in the field of women's health during the eleventh century (Booher 1996; O’Dowd and Philipp 1994; Rowland 1981). Around the sixth century a medical school was established at Salerno in Italy that became famous throughout the western world until about the twelfth century. This medical school apparently trained many women healers, Trota being the most well-known. Her work Passionibus Mulierum Curandorum, The Diseases of Women, (Mason-Hohl 1940), is considered one of the earliest and most extensive medieval gynaecological texts and is often referred to as the Trotula. According to Elizabeth Mason-Hohl, who published a translation of the Trotula in 1940, Trota drew on the earlier knowledge of Cleopatra, Hypocrites and Soranus. In her introduction to The Diseases of Women Trota, although commenting on the weakness of women when it comes to health, clearly supports the practice of women as doctors:

Since then women are by nature weaker than men it is reasonable that sicknesses more often abound in them especially around the organs involved in the work of nature. Since these organs happen to be in a retired location, women on account of modesty and the fragility and delicacy of the state of these parts dare not reveal the difficulties of their sicknesses to a male doctor (trans Mason-Hohl 1940, 2).

It appears the complete manuscript or certain chapters of the Trotula were copied extensively due to the popularity of the work. However, authorship became disputed due to the belief that the work could not have been written by a woman. According to Rowland $(1981,4)$ a certain Casper Wolff, writing in 1566 , believed that the work must be that of a "Roman freedman of the Empress Julia." And Gill Thornhill (1997) claims 
that even in the twentieth century the historian Karl Sudhoff believed that the manuscript could not have been written by a woman. In fact debate about what has come to be known as The Trotula continues (Green in Booher 1996). This is due not only to the philosophical question as to whether a woman could write such a detailed or explicit work, but also to the difficulties of determining authorship prior to printing, as noted in the introduction to this chapter.

The cures outlined in The Trotula are complex and draw on previous knowledge. They include herbal remedies, the use of other substances such as parts of animals or a variety of metals, and interventions such as fumigation of the uterus. The following description of treatment for "Descent of the Womb" (Mason-Hohl 1940, 13), a prolapse, is an excellent example of the way a condition and its treatment were described in writings from this period:

If it happens after childbirth that the womb descends too low, let oat straw previously moistened be heated and applied as a poultice. At times the womb moves from its place, descends and often it comes out through the vulva. This happens because of softening of the muscles and an excess of the cold humors. A softening and chilling of this sort comes from the cold air entering the mouth of the womb in cases where the woman, uncovered, has placed herself directly against a stream of cold air or has sat a long time on a cold stone. It may even result from a bath in cold water. Because of these things the womb is weakened and goes out of place. Sometimes the exertion of labor causes prolapsus. If the womb descends but does not come out, aromatic herbs should be applied to the nostrils - balsam, moss, amboa, wheat, storax, and the like. Fumigate the woman from below with strong smelling things such as burnt linen cloth and the like. Foment the navel with wool infused with wine and oil. If the womb has come out, let the aromatics be blended with the juice of absinth and anoint the abdomen with these remedies by means of a feather. Then take equal parts of rue, caftoreum, and mugwort and cook them down to one-half. Give this as a drink and cover the abdomen and the navel with cooked cereal. Also if the womb has come out, restore it by hand placed against it and push it back into place. Then let the woman enter water in which has 
been cooked wild pomegranate flowers, roses, pomegranate bark, oakgalls, sumac, myrtle, acorns, leaves and bark of live oak, cypress nuts, and lentils. Put these together in an oakum or steam cabinet and they will help greatly. Galen prescribed that one make for this condition a mixture of bos wood place in oil over live coals; let the woman sit over it well covered that she may receive the fumes within herself. The diet should be cold and styptic without ciminum or other pungency. Of fruits let her eat Syrian figs, medlars, service berries, sour apples, and the like. Let her drink tempered wine having a styptic quality. One well tested recipe for a prolapsed womb is to take the powdered heart of a deer, laurel leaves - one dram of each and one scruple of myrrh; mix them with wine and give as a drink. The womb will return to its place.

This example shows how the work draws on previous knowledge with the mention of Galen's recommendations, and the precise measurements of certain substances, evidence of the importance of empirical knowledge.

Rowland (1981) has translated the manuscript Sloane 2463, written in the early fifteenth century, which is considered the earliest gynaecological text written in English. The authorship of the manuscript is unclear for the same reasons as those outlined above, but it appears to draw extensively on the work of Trota. The traditional cures for women's conditions are described, including quite complex mixtures of a variety of animal and vegetable material, coupled with the traditional methods of cupping and bleeding, and the interweaving of superstition and magic. ${ }^{3}$ Rowland describes the manuscript thus:

Thoroughly domesticated and different from the Latin Trotula, it nevertheless takes its name from the legendary physician popularly associated with gynaecology. Through this work, instructions for treating women's ailments, combining recipes and practices from ancient literary sources with those derived from oral tradition, were widely disseminated, and as the basis for the earliest gynaecological printed text, they dictated childbirth procedures for many centuries (ibid, 48).

\footnotetext{
${ }^{3}$ Both Beryl Rowland in the translation of Sloane 2463 (1981), and Elizabeth Mason-Hohl in The Diseases of Women (1940), provide detailed descriptions of a range of conditions and their treatment.
} 
Rowland notes a major difference in this period in that women were disappearing from healing scholarship, by now the male physician was firmly entrenched. However, although male scholars and physicians drew on the writings of women such as Trota, the actual implementation of treatment was women's work, "Women's sicknesses were women's business" (Rowland 1981, xv). There was also the knowledge that was passed down from woman to woman, something that happened according to Rowland at all levels in society, from the wise woman in the village to the Lady of the Manor responsible for the well-being of those in her service. Managing the treatment and care of people who were sick was clearly positioned within the responsibilities of women. Rowland $(1981,8)$ cites a nineteenth century medieval scholar, Thomas Wright, who wrote on the role of women in western Europe and stated:

The question of allowing women to practice as doctors has been a subject of great discussion of late, but in and before the feudal period it [the practice of medicine] was regarded as one of the natural duties of the sex.

Widespread literacy among women is a fairly recent occurrence and authors writing on the subject of gynaecology and obstetrics in the Middle Ages were aware that few women could read or write. Apparently, in some instances, male writers urged women who could read to make the information available to those who could not, by reading aloud from the texts, Rowland (ibid, 11) cites the author of a manuscript whose advice was to let: "euery woman lettrid.... Reede to other vnlettrid."

It is important to acknowledge that what is known about this early period is dependent on what was written down and on modern interpretations of the texts. Although the 
historical literature related to gynaecology does not appear extensive, it seems that until the late middle ages healing scholarship and practice was an area of interest for both men and women. However, through a process of legislation begun in the twelfth century which licensed medical practitioners (Booher 1996), and which in England in 1421 saw the passing of a law that prevented women practising medicine (Webb 1986), women were gradually barred from the practice of mainstream medicine in most European countries. Although formal development of the theory and practice of medicine became defined and controlled by men, the role of caring for the sick and assisting the well to stay healthy remained the preserve of women. As the power of medicine increased and became professionalised, so it became increasingly dangerous for the women forced to work outside this male monopoly. Lay women who continued to practise as healers during the period between the fourth and seventeenth centuries, risked torture and death by fire, as they were redefined as witches and their work seen as a direct threat to the power of both medicine and the church (Ehrenreich and English 1973b).

Although the burnings stopped in the seventeenth century, these excluding practices remained largely unchallenged until the nineteenth century, when women fought to regain their right to train as doctors and nurses. The enormous changes in medicine that occurred in the nineteenth century led to the paradox of women being excluded and voiceless within their own discourse. They were positioned as objects in a discourse which as the literature shows, was used to control them through physical interventions. 


\section{Recent times}

If like all human beings, he [the gynaecologist] is made in the image of the Almighty, and if he is kind, then his kindness and concern for his patient may provide her with a glimpse of God's image (Scott cited in Dally 1991, 225).

The attitude expressed in this quotation is a leit-motif in the modern development of gynaecology. Exploring the development of modern gynaecological practices during the nineteenth century from a feminist perspective makes grim reading. Discovering the way in which the medical and social discourses of the time, and their discursive practices, enmeshed women and sought to control their power and involvement in society, was a distressing experience. I found it impossible not to return again and again to the violence and fear that seemed to underlie this treatment of women. A number of women authors writing about gynaecology (Dally 1991; Daly 1991; Ehrenreich and English 1973a; Moscucci 1993), discuss the interdependency of the prevailing ideology of women and gynaecological practices. Ann Dally (1991, xvi) sums up the relationship in the following way:

The subject and practice of gynaecology, like the subject and practice of medical history, developed during the second half of the nineteenth century, the period of maximum prejudice against women, when attitudes towards them were at their most bizarre, in a curious mixture of contempt and idealisation. The intellectual inferiority of women was taken for granted and vigorously and jealously promoted.

Belief in the inferior, fragile, inherently sick yet dangerous, nature of women, supported the developing medical specialisms of psychiatry (in the form of the alienists) and gynaecology. The nature of women was centred in their reproductive organs, therefore, control of their nature had to by via these organs, consequently psychology and gynaecology became intertwined. The historian Ben Barker-Benfield (1975, 283) 
makes the link between these attitudes and the development of gynaecology when he writes:

They [male doctors] cited woman as a major source of society's ills, when she should have been the fountain of society's healthy, male future. If, as came to be generally held, women's insanity and nervous disorders were finally functions of faulty sexual organs, why not destroy the sickness at its source?

Attitudes based on these beliefs about women resulted in normal conditions being regarded as manifestations of psychological illness and led to referral to doctors.

Behaviour regarded as socially inappropriate to the passive female role, such as laughing loudly, smoking, talking excitedly and dancing were regarded as manifestations of organic disorder, often of a gynaecological origin, and even as liable to lead to serious disease such as cancer (Dally 1991, 86).

In Britain it was recommended that gynaecologists become part of the medical establishment in women's mental asylums, and examination by the gynaecologist became part of the diagnostic process for mental disorders (Moscucci 1993).

Gynaecology was one of the first major specialisms to develop in the nineteenth century, becoming a separate area of practice long before other, now well established, specialties (Dally 1991). During the nineteenth century gynaecology became wholly the preserve of male doctors. It could be argued that the bodies of women became the site for the development of male medical knowledge as I discuss below.

One of the major factors in the development of modern gynaecology was the progress in surgery, and its subsequent legitimacy as the major form of treatment for women's illnesses (Porter 1996a). Prior to the nineteenth century surgery had mainly involved 
war work such as amputations, or occasionally heroic operations for grossly advanced cases of cancer. ${ }^{4}$ The obvious problems with infection prior to any knowledge of germ theory, pain before the development of anaesthetics, blood loss before transfusion, and the shock that would accompany such operations, led to little surgery being undertaken. By the nineteenth century surgeons were often well educated in anatomy and had often practised a form of surgery on the dead. However, opening the body's cavities was dangerous and although some caesarean sections had been undertaken without the death of the mother this was rare and mortality rates, when this form of surgery was attempted, were often as high as $100 \%$. The common methods for treating gynaecological conditions were more likely to involve the application of leeches, cautery and bleeding (Dally 1991).

In 1809 one of the early successful abdominal operations, an ovariotomy (oophorectomy), that is removal of ovaries, was carried out by an American doctor Ephraim McDowell at the request of a woman patient, Jane Todd Crawford (Dally 1991; Porter 1996a). ${ }^{5}$ McDowell had studied at Edinburgh with the anatomist James Bell who, according to Dally $(1991,13)$ :

... realised that the future of surgery lay with this operation and that the first successful abdominal operation was likely to be for the removal of a large ovarian cyst, but he did not dare do it himself.

\footnotetext{
${ }^{4}$ See Ann Dally's (1991) detailed description of a French woman under going surgery for breast cancer without anaesthesia in Women under the Knife: A History of Surgery.

${ }^{5}$ Ann Dally provides a detailed account of the background of Ephraim McDowell, the circumstances of the operation and the response of the medical profession.
} 
It took some time for the medical establishment in both America and Britain to accept McDowell's reports of the successful operation (Moscucci 1993). McDowell apparently undertook a further thirteen successful ovariotomies (Dally 1991). However, what is particularly interesting is that it appears that the women approached the doctor of their own volition, and in the case of Jane Todd Crawford, went to considerable lengths to obtain the surgery.

In contrast to McDowell is J. Marion Sims, the American so-called 'father' of gynaecology who began practising in the 1840's (Dally 1991; Ojanuga 1993). It is well documented that Sims developed his techniques by experimenting on women slaves in Alabama (Porter 1996a). The women were often brought to him by their owners for the repair of vesico-vaginal fistulas caused by childbirth (Ojanuga 1993). There is no doubt that this group of women provided the ambitious young surgeon with an obedient group of patients on whom he could practise his surgery. Sims subsequently went on to introduce and develop these techniques in his newly established hospital for women in New York. Although perpetrating this experimentation on women Sims went on to become extremely wealthy through his treatment of women and a respected member of the American medical establishment.

Opinions about Sims vary enormously, even amongst feminist writers. For example Mary Daly $(1991,225)$ considers:

J. Marion Sims, known for his hatred and abhorrence of female organs, remedied his problems (becoming very rich in the process) by ruthlessly cutting up women's bodies. 
In contrast to Daly, Ann Dally $(1991,31)$ in her detailed account of Sim's work, although describing him as "proud and self-promoting", attempts to provide a more reasoned discussion of his work, perhaps in an effort to make him generally more acceptable. Dally raises questions to do with the nature of his experimentation on women, and the possible benefits to women of the results of that experimentation. However, the use of the women slaves is impossible to overlook. Their powerlessness and complete lack of voice is appalling even for a time when the great majority of women were subject to oppressive social practices. Durrenda Ojanuga $(1993,30)$ reviewed the ethics of Sim's work and concludes:

... despite his accolades, in his quest for fame and recognition, he manipulated the social institution of slavery to perform human experimentations, which by any standard is unacceptable.

Surgery, as a legitimate treatment for gynaecological conditions, quickly became popular with the development of effective, and reasonably safe, anaesthesia during the 1840 's, in the form of ether or chloroform (Porter 1996a). Many operations for ovariotomy and fistula were carried out on women prior to the 1840 's and the introduction of routine anaesthesia. The rapid rise in the popularity of gynaecological surgery was based on women patients surviving the trauma, men being able to recommend the surgery due to improved outcomes in the form of lower mortality rates, which was important for their careers as surgeons, and women accepting the surgery due to anaesthesia. There is no doubt that the development of anaesthesia, in conjunction with dissection and, therefore, knowledge of the internal female body, led to surgical interventions becoming the main method of treatment for gynaecological conditions, 
either real or constructed. Thus, the specialty became firmly entrenched in mainstream medicine and accepted in society.

These new surgical techniques, particularly ovariotomy and in some cases clitoridectomy, were used to cure what were considered psychological problems and to control the behaviour of women, to “... check women's mental disorder" (BarkerBenfield 1975, 285). Women in the more affluent classes had healthy organs removed for what would now be considered completely spurious reasons. This does not appear to be the experience of working class women whose lives did not allow them to dwell upon their various sicknesses. As Barbara Ehrenreich and Deidre English (1973a, 12), state, "It was as if there were two different human species of females."

Another development in medical practice which extended the gaze of the nineteenth century gynaecologists was the speculum which Speert $(1996,483)$ considers to be one of the "oldest and most frequently modified medical instruments". According to Moscucci (1993) use of the speculum lapsed during the Middle Ages and the Renaissance, but was rediscovered in the nineteenth century during the rapid development of gynaecology. It was at this time that the use of the speculum was given a sexual gloss. The use of the speculum violated Victorian sexual mores and was inconsistent with views on the modesty and chastity of women. Ehrenreich and English (1973a, 32) cite the work of a British doctor Carter, who stated:

... I have ... seen young unmarried women, of the middle class of society, reduced by the constant use of the speculum to the mental and moral condition of prostitutes; seeking to give themselves the same indulgence of practice of solitary vice [masturbation]; and asking every medical practitioner ... to institute the examination of the sexual organs. 
This linking of the speculum and the act of sexual intercourse was the cause of a great deal of debate amongst medical men. On the one hand it was considered an immoral instrument, based on the idea that the use of the speculum was a form of sexual intercourse, on the other hand there were those doctors who felt that accurate diagnosis of specific conditions was important and that the speculum allowed visual examination whereas previously doctors had relied on patient history and very occasionally manual examination. ${ }^{6}$ It is interesting that the New Zealand doctor, Frederick Truby King, when a medical student in Edinburgh, recorded a whole lecture devoted to the different types and uses of the speculum (King 1885 MS1120) and the risk of the speculum introducing "germs" to the vagina was discussed in New Zealand in the 1891 Report of the Dunedin Hospital Inquiry (Appendices to the Journal of the House of Representatives 1891).

There does not seem to be evidence of the same controversy arising in relation to manual vaginal examinations probably due to such examinations being considered unnecessary. Roy Porter (1996b) notes that Queen Victoria's physician only discovered that she had a prolapsed uterus after her death, evidence that Sir James Reid, although her attending doctor for many years, had never given the queen a full examination and certainly not a gynaecological examination. However, a development that may well have had a significant effect on the practice of manual vaginal examination was the development and use of rubber gloves in the surgical setting. In 1890 the surgeon

\footnotetext{
${ }^{6}$ Moscucci (1993) provides a detailed discussion of the nineteenth century speculum debate.
} 
William Halsted instigated the use of rubber gloves (Mount and List 1994). Although Ellis Mount and Barbara List record that Halsted began using the gloves, according to both Porter (1996a) and Charlotte Alderman (1985) the gloves were in fact introduced to protect Halsted's nurse, who also happened to be his fiancee, from dermatitis due to the solution mercuric chloride which was used by Halsted for sterilisation. However, there does not seem to be literature which documents the routine use of rubber gloves by nurses and doctors for examination purposes. Although it appears that manual vaginal examinations were not regularly undertaken, the sexual nature of such an examination with bare hands would not be lost on the Victorian medical fraternity. Once gloves became a part of examination techniques, thereby putting a physical barrier between women and their doctors, the vaginal examination could be interpreted differently in perception and practice, to the act of sexual intercourse. A fact that would, I am sure, have contributed to the current routine practice of including a vaginal examination as part of most gynaecological assessments, whether warranted or not.

Gynaecologists then were a group of male professionals using the bodies of women for experimentation and professional advancement. As Ann Dally $(1991,139)$ states:

The operation of ovariotomy gradually became accepted as the operation by which a surgeon's skill and worth were assessed. Almost any description of a surgeon in the second part of the nineteenth century informs the reader of the date when he 'did his first ovariotomy'. Clearly it was regarded as an important milestone in a surgeon's career.

There is little doubt that this group of men were instrumental in carrying out controlling practices encouraged by the prevailing ideological construction of women, "Sexual surgery became The Man's means of restraining women" (Daly 1991, 225). The 
practices of gynaecology inscribed beliefs about women onto their bodies through surgical practices. However, for me there is a tension when reading of some gynaecological conditions such as vesico-vaginal fistulas, that were a relatively common result after difficult births, and the huge ovarian cysts that rendered the women completely unable to take part in normal life. Surely the development of relatively safe surgical techniques for treatment must have been greeted with relief by many women. The fact that some women chose to go through with such surgery, even before the development of anaesthesia, supports the conclusion that the pain and suffering to be endured was far preferable to living with these debilitating conditions. The ability to correct such conditions must have had a major impact on the quality of many women's lives. There is a sense of loss that surgical practices which could have been used wisely to alleviate the suffering of some women were, and may still be, intertwined with the oppressive practices towards women and glossed with the ambitions of men. ${ }^{8}$ As Mary Daly $(1991,224)$, says:

some specialists...... are at times helpful to women, but such genuine helpfulness occurs in spite of [original italics] the pervasive intent, ethos and method of their professions.

\section{Gynaecology in New Zealand}

The theory, practices and ideology of the British medical establishment were transported to New Zealand through the early settlers and the process of colonisation, which occurred after the signing of the Treaty of Waitangi in 1840 . However, there appears to

\footnotetext{
${ }^{7}$ Ann Dally (1991) provides a graphic and disturbing description of the effects on women's lives of conditions such as vesico-vaginal fistula (23) and ovarian cysts (15).

${ }^{8}$ See Pamela Wood and Lynne Giddings 1991 article: The Symbolic Experience of Hysterectomy, in Nursing Praxis in New Zealand, in which women comment on the positive aspects of having a hysterectomy.
} 
be little written about gynaecology in New Zealand from either a current or historical perspective. A review of Derek Dow's (1994) Annotated Bibliography for the History of Health and Medicine in New Zealand shows that although Dow has a heading Obstetrics and Gynaecology, the literature cited all relates to obstetrics.

There is evidence which shows that the development of gynaecological services for women in New Zealand, followed the British model. Laurie Gluckman (1976) provides some evidence of this link between the practices of New Zealand doctors and their European counterparts. He cites an excerpt from a letter written by the well-known Auckland doctor Logan Campbell, to his father in England in 1841. In the letter Logan Campbell requests that a gynaecological consultation be arranged for a woman returning home. He describes the woman's uterus thus:

[the uterus] appears to be enlarged in the neck requiring application of leeches by means of a speculum as particularly described in a recital of French cases by Balbirnie in his work on the subject (cited in Gluckman 1976, 72).

The application of leeches was an accepted medical treatment in Britain and Europe for many hundreds of years, used for a variety of condition including those of the uterus, cervix and vagina.

According to Robert Fulton (1922) anaesthesia was thought to have been first used by a doctor in New Zealand about 1849. However, Gluckman (1976) records what appear to be first operations using anaesthesia carried out in New Zealand in 1847 , showing the speed with which the new technology reached New Zealand. Interestingly, these first operations were carried out on Maori, a tooth extraction on a prisoner and tumour 
excision from the back of a Maori chief. This, as in the case of J. Marion Sims, raises the question of trying out a relatively unknown technique on disempowered peoples, a theme that has been developed by Tricia Laing in her recent work on the conflation of white women and Maori in relation to health in colonial New Zealand (Laing forthcoming).

State hospitals were established in the North Island from 1846 onwards, and in the South Island in 1852 (Dow 1991). However, the important factor in the establishment of gynaecology was the way in which medical training was established in New Zealand. The first medical school in New Zealand was established at Otago University in 1875 (McLintock 1966), and associated with Dunedin Hospital. However, this School only provided the first two years of training and students were required to complete their education overseas, usually attending Edinburgh Medical School. This resulted in the transference of medical knowledge and practices, including the underlying philosophy, from Great Britain directly to New Zealand.

The transference of medical thinking is apparent in the original lecture notes of $\mathrm{Dr}$ (later Sir) Truby King (1885). Truby King was born in New Zealand, and typically completed his medical training in Edinburgh (McLintock 1966). ${ }^{9}$ His lecture notes include several volumes related to midwifery and gynaecology. There are extensive notes on techniques such as the use of the speculum and the vaginal examination, including the etiquette for

\footnotetext{
${ }^{9}$ Sir Truby King is well known for his establishment of the Royal New Zealand Plunket Society and has been critiqued in recent years for what some authors believe is his programme of eugenics.
} 
managing this procedure, the nature of pathological disorders, and the relationship between nervous disorders and the reproductive organs.

In 1885 the system of medical education changed and doctors could undertake their entire training at Otago University. This led to the need for specialist services in terms of medical staff and hospital resources. Particularly significant in the development of gynaecology as a specialty was Dr Ferdinand Batchelor who came to New Zealand from Britain in 1885 as the first lecturer in midwifery and gynaecology. Dr Batchelor, apparently an outspoken and determined man, was considered "one of the pioneers of abdominal surgery in New Zealand" (Angus 1984, 85). He was extremely influential in reforming Dunedin Hospital (Angus 1984), and was particularly concerned about the lack of a women's ward. He and his wife worked to raise money for the ward which was first established in the Campbell Pavilion in 1893 and subsequently, in 1914, the Batchelor ward for gynaecology patients was opened. John Angus (1984) discusses the establishment in Dunedin of a trained, female nursing staff following the pattern of Florence Nightingale's system in Britain. Presumably, as trained and, after 1901 registered, nurses became part of the establishment they must have been the first 'professional' nurses working with gynaecology patients. This, however, is not mentioned in the history of gynaecological services.

Subsequently, gynaecological wards were established in other major hospitals. However, in 1946 the first hospital for women, National Women's Hospital, opened in Auckland. This hospital, incorporating obstetric and gynaecological services, was the first hospital dedicated to the treatment of women's unique conditions and quickly 
became a major influence in the development of obstetric and gynaecological practice throughout New Zealand (Coney 1988). The hospital became notorious during the 1980's due to the so-called "Unfortunate Experiment", first made public by the feminist writers Phillida Bunkle and Sandra Coney (1987), and which resulted in the Cartwight Inquiry of 1987-88, led by Judge Silvia Cartwright. Briefly, a research project had been established by Dr Herbert Green to try and prove that carcinoma in situ, cancer in the cervix, if left untreated, would not develop into invasive cancer. This idea went completely against the accepted method of treatment at the time, yet Green was never censured by his peers even though the medical fraternity was aware of the study through Green's publications. This lack of censure was due to the importance placed on the notion of 'clinical freedom' by the medical profession, basically meaning as the doctor you know what is right for your patients and can implement different treatment regimes without being challenged by your peers. Subsequently a number of women in the study did develop invasive cancer which led to a number of their deaths (Committee of Inquiry 1988). At no time were the women told that they were in the study, or that there were more acceptable options for treatment of their condition. ${ }^{10}$

Many people, particularly women, found this a horrifying story not only because of the neglect of basic ethical considerations that should be addressed in any research project, but also because of what appeared to be a complete lack of respect for the women involved. Further breaches of women's rights emerged during the inquiry when it was admitted that vaginal examinations and the insertion of intra-uterine devices were

\footnotetext{
${ }^{10}$ See Sandra Coney's publications The Unfortunate Experiment (1988), and Unfinished Business (1993), for a full exploration of both the inquiry and the aftermath.
} 
practised on women under anaesthetic, and that vaginal swabs were taken from baby girls for research purposes without parental consent (Committee of Inquiry 1988).

However, the central issue within the context of my study is the contempt for women and patronising attitudes of the doctors, evident from the submissions of those involved. It seemed to affirm that the discursive practices of gynaecology, so well developed in the nineteenth century, are apparent in the discourse today. The same issues of disempowered and objectified women, either adults or babies, being used by the powerful for self-advancement, is clearly evident. Women were powerless and their bodies used to serve the interests of men. For me the recommendations from the Inquiry make chilling reading. It is not the recommendations themselves, but the revelations which led to the need for such directives to be given to practitioners in gynaecological research and practice. As stated in the Ministry of Women's Affairs submission to the Inquiry:

Ultimately the issues are about who controls medicine and how; about who benefits from it and who are its victims. Thus, as so many witnesses have so clearly stated, the central issue, above all others, is power (cited in Coney 1988, 6).

The implications of the events at National Women's Hospital for the nursing profession relate to our acceptance and silence. As Phillida Bunkle (1991, 383) says:

The Cartwright Inquiry report not only exposed the cervical cancer experiments but examined everyday practices that physicians found normal and nurses justified as inevitable, but which the public found absolutely unacceptable.

The voices of nurses were never dissenting either during the time that the research and other practices were occurring or, unhappily, during the inquiry. We do not know 
whether this lack of nurses willing to come forward and take part in the Inquiry was due to fear of the medical profession or a lack of knowledge of the processes. However, we must acknowledge the implications of our silence for the women who trusted us and who were in our care.

As a feminist researcher the over-riding impression gained from this brief history of gynaecology is that although 'about' women, from the medieval period on, it is a record of the male in gynaecology. Women as nurses and patients have been used as objects for furthering male power and prestige, remaining voiceless within the discourse of gynaecology which should be ours and excluded from decision making about the wise use of technology to improve our lives.

\section{Nursing in gynaecology}

So what is the place of nursing in this re-view of gynaecology? Exploring the formal role of nurses in the history of gynaecology is rather problematic for two reasons. Firstly, there is a difficulty arising from the use of the term nurse. In antiquity the term does not seem to have been used to describe a woman caring for the sick, and in medieval times a 'nurse' would be a term used to describe the woman that was employed to look after the children, a sub-group of which would be the 'wet-nurse' employed to breastfeed another woman's child (Donahue 1985). Secondly, many of the writers describe the early texts as medical, however, they often describe practices that in the world of western medical systems are more within the domain of nurses. As Patricia Donahue $(1985,2)$ states: 
It is difficult at times to distinguish nursing from medicine in this evolutionary process [the development of nursing], since the early stages of each are so closely interwoven. Although some individuals believe nursing began with Florence Nightingale, nursing is as old as medicine itself.

Skills that are now divided between the two separate disciplines were combined in the embodied practice of healers in the past. Practices written up in the historical literature, that are now considered the work of nurses, are those such as carrying out of specific treatments, giving of advice on health related matters for both the prevention and management of illness, and administration of herbal remedies. Prior to the eighteenth century, these nursing practices were carried out by women, often in conjunction with surgery (Green cited in Booher 1996). Male physicians did not consider surgery or the treatment of wounds part of their practice. The only men that did practise surgery were barber-surgeons whose techniques were limited, and those doctors attached to armies, who carried out operations on men injured in warfare (Porter 1996a). However, from the evidence that is available, it seems that having a group of trained women to undertake skilled procedures related to the treatment of sickness and disease, has a long history. Much of this care was carried out by women involved in the spiritual life of a society, with hospitals being established by various orders of religious sisters (Porter 1996a). These institutions were the centres of learning, including medicine, during the Medieval period and it is interesting that when the women's orders were subject to enforced cloistering during the Middle Ages, in an effort to control their power, many towns were left without hospitals or centres for the treatment of the sick. 
As described earlier in this chapter, before the rise to power of scientific medicine and surgery, women were active in providing a wide variety of health care based, it seems, on experiential knowledge, which was handed down through an oral tradition and integrated with knowledge from the largely male writings on the topics of illness. However, as formal scientific medicine became the preserve of men, women became invisible in the development of formal theory related to gynaecological practice.

Florence Nightingale is attributed with developing modern institution-based nursing in Britain. She secularised, professionalised and institutionalised, through a formal system of training, what had been an integral part of women's lives for centuries. With the emergence of Florence Nightingale and her development of formal nursing the demarcation between doctors and nurses became very clear and is well documented. Formal training of nurses developed after the 1860 's and, according to Christopher Maggs $(1983,1)$, by the 1880 's this training had begun to "infiltrate and dominate the entire nursing world". According to Maggs these nurses received a general training that was aimed at equipping them to work in any area in the hospital so although the doctors specialised, that specialisation was not reflected in the structure of nursing in the nineteenth century. A nurse was equipped to work in any area. The type of patient that the hospital treated, rather than a nurse's conscious choice, determined the specialty knowledge developed by individual nurses.

The increasingly hospital-based treatment of illness and disease required the development of a trained nursing workforce which would continue to carry out the orders of medical men and manage the care of patients. For gynaecology to develop as a 
specific institution-based specialism, with its own practices, there must have been nurses working in the hospitals caring for the women patients. In Victorian times as gynaecology developed, nurses must have inhabited a strange and marginal space, they worked within the prevailing ideology of the day yet their very existence challenged the male theory of the time, which interpreted women as sick and unable to work. However, the rise to power of the gynaecologist was dependent on the provision of expert nursing care to support their developing practice and to reinforce their positions of power. What is clear in the literature I have explored is that the positioning of nurses is not referred to by authors who specifically discuss gynaecology such as Moscucci (1993) or Dally (1991), or any other authors who refer to the history of gynaecology.

Nursing training in New Zealand followed the traditional model of training a nurse to work in a variety of areas. There appears to be no New Zealand literature that explores the development of specialism in nursing. This lack in the history of nursing is not uncommon, as Annette Stevenson $(1994,1)$ states:

Despite the burgeoning interest in social, women's, and health history in New Zealand, nurses and nursing have largely been ignored by professional historians.

Becoming specialised was, and still is, the responsibility of the nurse and depends usually on where she chooses to work once her basic education is complete. Often, as in the case of the nurse working in the gynaecology ward, the specialist knowledge related to this area is learnt in the workplace and based on what is learnt in their general nursing education. What is interesting then is how gynaecology is represented to nurses in our literature. 


\section{And the texts}

It is interesting that whereas several recent studies have explored sexist attitudes towards women in the gynaecology textbooks used by doctors in practice and in their medical training (Elder, Humphreys and Laskowski 1988; Koutroulis 1990), this analysis has not been applied to mainstream nursing texts. Ruth Elder et al (ibid) were interested in updating a previous study by Scully and Bart in 1973, whose findings exposed the negative stereotyping of women and sexist attitudes inherent in medical gynaecological literature. It appears from both Glenda Koutroulis' study and that of Elder et al, that although there has been an improvement of attitudes towards women in the literature, there continues to be a focus on pathology, sexist representations of women, including portrayal of heterosexuality as normal, and biological determinism. In conclusion Koutroulis $(1990,83)$ refers to Scully and Bart's argument that "if obstetricians and gynaecologists think of themselves as women's friends then with friends like that who needs enemies?" She goes on to say:

Eighteen years later and in a different society while some positive changes can be discerned, the aphorism still has a regrettable degree of validity (ibid).

A deconstruction of the way women's illnesses are written about in current nursing literature is beyond the scope of this study. However, until recently many text books were written for nurses by doctors, or at best in conjunction with nurses, for example Obstetrics and Gynaecology for Nurses by Gordon Garland, Joan Quixley (a registered nurse) and Michael Cameron (1971), Surgery For Nurses by James Moroney (1966), and Gowland and Cairney's Anatomy and Physiology for Nurses edited by two doctors, 
W.E Adams and D.W Taylor (1974). The fact that by 1974 the Adams and Taylor text had gone into an eighth edition shows the extensive use of these books in nursing courses. Such books were clearly based on the medical model, they are strictly functional and focused on disease. A review of a number of more recent texts now written by nurses, which include gynaecology, make it clear that nursing continues to mirror the medical model in this area. Two examples of recently published and frequently used nursing texts written by nurses are Brunner and Suddarth's Textbook of Medical-Surgical Nursing (Smeltzer and Bare 1996), and Medical-Surgical Nursing: Assessment and Management of Clinical Problems (Lewis, Collier and Heitkemper 1996). These texts are important in relation to the presentation of nursing knowledge and their contribution to the socialisation of nurses. They are large, comprehensive books of the type that most student nurses would buy, and use, throughout their basic education and as reference books during their working lives. Although nurses, both students or registered, may refer to a specialty gynaecological text most would not have such a text for general reference.

The perception of gynaecology gained from nursing texts is that it is only to do with women's reproductive organs, in fact the index entry for gynaecology in Smeltzer and Bare refers the reader to the "..reproductive system, female" (ibid 32[of the index]). Throughout this section on the female reproductive system, as with Sharon Lewis et al, the focus is the disease process, the term patient, rather than woman, is most frequently used, and there are frequent references to the patient's partner. In both texts the treatment for patients is invariably drugs and/or medical intervention usually in the form of surgery. 
This medical approach is also evident in one of the few texts on the specific topic of gynaecology. Ronnie Lichtman and Susan Papera (1990) in Gynecology: Well-woman Care also emphasise the use of medical interventions, although they do consider alternative therapy in some areas such as in the section on perimenopause and aging ibid, 416). The overall impression that is gained from these texts is that although there is now more of a focus on the woman patient, the experiences of women and their responses to gynaecological conditions are not central. It is still a traditional approach with medical knowledge such as pathophysiology and symptoms positioned to the fore.

Although nursing texts devoted solely to gynaecology are rare, there are often sections in books about women's health generally, which address gynaecological problems. The authors of these texts are clearly more woman orientated and address many aspects of women's lives which puts the reproductive problems in context of total health care. However, there is often still a focus on pathophysiology as the most important factor and the treatment again is clearly mainstream medical intervention in the form of drugs and surgery. For example, the text by Karen Allen and Janice Phillips (1997) Women's Health Across the Lifespan, which has contributors from a range of health disciplines is still very conservative in the range of treatment options discussed. The sections of Diagnosis and Therapeutic Interventions are based on an orthodox medical approach.

One exception to this approach is evident in the work of nurses Catherine Fogel and Nancy Fugate Woods (1995), in Women's Health Care: A Comprehensive Handbook, in which there is a section on reproductive surgery. The introduction to this section 
discusses the concerns about the amount of surgery, raising questions about the unnecessary nature of many interventions, and emphasises the concerns of the woman. In the section on hysterectomy Fogel and Woods again raise issues to do with the whether surgical treatment is the most appropriate, citing relevant statistics. They also refer to possible alternatives and stress the need for nurses to discuss these with women facing surgery, and are the only authors I found who mention the value of women getting a second opinion before going ahead with surgery.

Early books written for women such as My Body, My Health: The Concerned Woman's Book of Gynaecology (Stewart, Guest, Stewart and Hatcher, 1981), were written by doctors and present a range of information about women's health issues. They raise the question of the number of hysterectomies but believe that women have made an informed choice and therefore support the decision. All the texts that are focused on women's health include information related to the function, care and problems of the breast. However, it is important to note that in the general nursing text by Smeltzer and Bare a section entitled "Assessment and Management of Patients with Breast Disorders" $(1996,1231)$ is included in the unit on reproductive function, clearly situating women's breasts as part of their reproductive systems.

It seems a review of nursing texts concurs with the findings of Elder et al (1988) in relation to medical texts. Women continue to be stereo-typed in relation to their reproductive role in society. Our nursing texts that present the topic of women's illness in fact reflect a medicalised view of gynaecology. Medical concerns such as pathophysiology are positioned first and foremost, doctors' knowledge being given 
precedence over either the voices of the patients or those of nursing in terms of intervention strategies for managing these uniquely women's conditions. This is not to say that pathophysiological knowledge is not useful to nurses for understanding and informing nurses' practices but this positioning reflects beliefs about knowledge and the power of that knowledge, that do not appear to have been questioned.

\section{In Conclusion}

Gynaecology, the science of women, has a long history and it seems there has always been a particular interest in the health of women. However, the overwhelming feeling gained from my exploration of the history of gynaecology has been the manner in which men have studied and recorded the anatomy, physiology and illnesses of women. The involvement of women either, as patients or nurses, in healing related to gynaecological practice is virtually ignored. As science and medicine emerged in modern form, gynaecological practices which could have been used to alleviate the unique conditions suffered by women, were instead embedded within an ideology which allowed those practices to be used to control the lives of women and serve the interests of men.

Positioning nurses within the service of gynaecology is important in terms of the context within which my research was undertaken. Nurses are rarely referred to in any discussions of modern gynaecological practice, we seem to know nothing of their reality within the discourse and they remain essential yet voiceless. Making explicit their subjectivity within gynaecology guided my analysis of the conversations and work experiences I shared with the nurses. Also important to this research is how my work is positioned within feminist scholarship in nursing and my particular reading of feminist 
theory. My exploration of feminist theory will inform my interpretation of the experience of nurses working within the context shaped by the factors outlined in the above discussion. 


\section{Chapter 3}

\section{Feminist representations within nursing}

he purpose of this chapter is to enable the reader to position my theoretical stance
within the literature related to feminist scholarship in nursing. To achieve this I have undertaken a selective review of feminist scholarship in nursing to explore the relationship between nursing, and feminist theory and research. The chapter is focused on the published work of nurses and is a representation of the inside voice of nursing in relation to feminist scholarship. There is a tension apparent in the literature related to the way feminism is presented as central to nursing, yet it is still clearly marginal in mainstream nursing epistemology. Barbara Keddy $(1992,5)$ states that "the most significant issue facing nursing scholars and practitioners alike in the 1990's is related to feminist research, theory and epistemology". This idea that is taken even further by Carolyn Emden $(1995,35)$ who believes that "feminist analyses are essential to nursing survival". Other authors exploring the integration of feminist epistemology with nursing explicitly raise the issue of nurses' discomfort with the principles of feminism (DeMarco, Campbell and Wuest 1993), and the feminism(s) (Speedy 1997). This review explores some of these themes and focuses on the way feminist scholarship is represented in the nursing literature related to theory, research and practice. It is important to acknowledge that the majority of the publications cited are by nurse scholars from either North America or Australia. This is not deliberate but reflects reality in that there are few publications from scholars in other countries. 


\section{Writing feminism into nursing}

Feminist ideas emerged in nursing literature in the early 1980 's, with the work of authors such as Wilma Scott Heide (1982), Kathleen MacPherson (1983), Christine Webb (1984), Peggy Chinn and Charlene Wheeler (1985), and Mary Duffy (1985). Some of these early writers, such as Webb and MacPherson, were exploring feminist ideas in other disciplines and brought these new approaches into nursing. The work of Heide, and Chinn and Wheeler, reflected their own interests when they addressed the issues of feminist activism and the relationship between nursing and the women's movement. Duffy focused on the bias inherent in knowledge about women derived from male science and explored the way feminist critique can make explicit the implications of this bias. The work of these women can be recognised as the first published writing appearing in mainstream nursing literature that directly addressed feminism and nursing and they have, therefore, made a major contribution to nursing scholarship.

From the time that feminist ideas first began to appear in the nursing literature, a number of authors have discussed the relationship between feminism, nursing and the development of nursing knowledge. In Duffy's (1985) critique of research and science from a feminist perspective, she also explores the effects on women of the power residing in male science. In her writing she called for the politicization of feminist research and for feminists to work to change the nature of science. Elizabeth Hagell (1989) also discusses this critique of science and takes this into nursing by addressing the inter-relationship of science and nursing, using feminist theory as the form of critique. Hagell draws on the work of well-known feminist writers such as Sandra Harding and Ruth Hubbard who critique science as a male gendered enterprise, and 
applies this critique to the development and representation of science within the discipline of nursing. She argues that there is a tension between the reality of nursing practice and nursing knowledge which, she believes, is "very dependent on an empiricoanalytic view of science" (ibid, 230). Specific recommendations are made by Hagell for change and improvement, particularly in nursing education, based on incorporating feminist theory to aid the development of uniquely nursing knowledge. She believes this development will also be assisted by a linking of nurses with the women's movement. However, as a nurse-educator I believe this does not appear to have occurred in nursing education in New Zealand and the political aura of feminist approaches may well preclude an integration of feminist and nursing scholarship in the education setting.

Rosanna DeMarco, Jacquelyn Campbell and Judith Wuest discuss the development of 'feminist critique' as a deliberate strategy for judging knowledge. They note that this has been a central part of feminist writing "from the beginning of recorded and preserved feminist scholarship" $(1993,28)$ and state that:

Although the blossoming of critical examination has contributed to the development of credible nursing knowledge, one aspect of nursing's critique has yet to flower: that is, feminist critique (ibid, 27).

They go on to argue that nurses need to continue to question science and research through the process of feminist critique because of the nature of nursing knowledge, which they, like Hagell, consider is largely derived from traditional medical knowledge. They believe this derivation may prevent us from seeing the androcentric bias inherent in medical research. All research can be subject to feminist critique and the authors detail the actual techniques of this approach, believing that the process can offer:

... a means for nursing to remove the blinders of dominant culture and consider individual research studies and bodies of nursing knowledge for androcentric, ethnocentric and class bias $(1993,31)$. 


\section{Nursing epistemology and feminism}

Although much of modern nursing knowledge may be seen as derived from medical knowledge there has been an attempt to theorise about nursing from within the discipline. However, in relation to this academic development of nursing, feminist theory still appears marginalised or 'other'. A variety of theories such as stress and adaptation theory, interaction theory, even existentialism have been used as the basis for nursing theories (Meleis 1997), yet feminist theory has never been used in this way. Some nurse theorists such as Jean Watson (1990) now address the integration of feminism and nursing. However, in her work there is no recognition of the differing forms of feminism, rather, Watson seems to be referring to one of the central tenets of feminist theory, which is that the personal is political.

Afaf Meleis (1997) is a well-known commentator on theory in nursing. In her comprehensive text Theoretical Nursing: Development and Progress she covers the development of theory and epistemology in nursing, discusses the major nurse theorists, and considers the possibilities for theory development in the future. Meleis considers "feminist perspectives" (ibid, 154) in her discussion of the discipline of nursing, and although she discusses this in the same section as gender orientation she does differentiate between the two. She believes that feminist theorising has the ability to enhance nursing theory and recognises the power of language in terms of maintaining the status quo. Meleis also provides an extensive and up to date bibliography for readers interested in feminist perspectives, citing key writers from nursing and other disciplines. However, the lack of a theory of nursing informed by feminist epistemology may be a reflection of nursing's engagement with post-enlightenment 
ideas and a general waning of interest in grand narratives or all encompassing theory as a part of nursing scholarship in the 1990's.

Two Australian texts edited by Genevieve Gray and Rosalie Pratt $(1991,1995)$ that focus on the development of nursing are Towards a Discipline of Nursing, and Scholarship in the Discipline of Nursing. These authors have a distinctive approach and the contributions from Australian nurses reflect the issues they consider central to knowledge development in nursing. Chapters are devoted to feminist research and Sandra Speedy (1991) and Julianne Cheek and Trudy Rudge (1995) outline different forms of feminism and the principles of feminist theory. Speedy also addresses the feminist critique of traditional, positivist science and research. She goes on to discuss the influence of these on nursing research, particularly in relation to the concept of caring, and finally concludes in relation to feminist research that "there are few other contributions to nursing that have such potential for developing the discipline of nursing" (ibid, 208).

Two New Zealand nurses have appeared in international journals contributing to the dialogue on feminist scholarship, myself (Huntington 1996), ${ }^{1}$ and Jenny Carryer (1995) who discusses the use of feminist research in nursing. However, references to feminist theory and/or research are rare in the New Zealand nursing literature. Two nursing journals are published in New Zealand. Kai Tiaki: Nursing New Zealand is published by the New Zealand Nurses Organisation and although it occasionally publishes smallscale research reports the journal is mainly focused on issues of day to day practice and

\footnotetext{
'In an article 'Nursing research reframed by the inescapable reality of practice: a personal encounter', published in Nursing Inquiry (1996), I discuss the way my work in the gynaecology ward, coupled with my exploration of French feminist theory, completely changed the focus of my doctoral research.
} 
general industrial concerns of nurses. I was unable to find any reference to feminism in this journal.

The second journal, Nursing Praxis in New Zealand, was established in 1985, as a forum for the publication of nursing research and scholarly inquiry. Based on a review of the material published in this journal it appears that few nurses who choose to publish in New Zealand use feminist research approaches or consider feminist theory in relation to nursing practice. Only two articles considered the topic being discussed from a feminist perspective. Jean Dixon's (1990) work places the issue of nurses upholding unethical practices of doctors in the wider context of feminist criticism of both social control over patients and the doctor/nurse relationship. To explore these issues she focuses on the criticisms levelled at nurses for maintaining their silence during the 1987/8 Governmental Inquiry into the research practices at National Women's Hospital, particularly the cervical cancer project of Professor Herbert Green which I discussed in Chapter Two. Although she analyses the background material from a feminist perspective, the specific strategies for implementation by nurses to ensure ethical treatment of patients, although useful, are not specific to women. Dixon $(1990,10)$, when she says "as non-feminists shy away from the term feminism, approaching autonomy for women and patients through ethics is likely to be less threatening", appears to support the idea that nursing and feminism are uncomfortable partners. The only other reference to feminism in this publication is an article by Colleen de Vore (1993). Although the topic of the paper is evaluation in nursing programmes and the problems with measurement, de Vore discusses this in the light of positivism and the manner in which the bio-medical model has been used to guide the development of 
nursing curricula. Her work includes a section in which feminism and positivism are discussed and the feminist critique of this approach is included.

Recently, Jenny Carryer's doctoral research, 'A Feminist Appraisal of the Experience of Embodied Largeness: a challenge for nursing' (1997), has made a major contribution to the establishment of feminist research in New Zealand. Carryer draws on a range of feminist scholars to underpin her research but also incorporates the work of Michel Foucault to include notions of discourse and power. Aspects of her work have been located within the New Zealand feminist (rather than nursing) literature related to the study of the body and women's bodies in particular (de Ras and Grace 1997). Lynne Giddings has also contributed to the visibility of feminism in New Zealand nursing research with her innovative work 'In/visibility in Nursing: Stories from the Margins' (1997). Giddings involved nurses from both Denver, Colorado and Auckland, New Zealand in her project and used a variety of theoretical frameworks, including feminism, to explore nurses' experiences of being different, particularly in relation to ethnicity and sexuality.

When exploring feminism and nursing it is essential to address the work of Wheeler and Chinn as they are considered two of the most influential feminist nurse scholars. Their text Peace and Power: a Handbook of Feminist Process (1991) is the only text by nurses that provides strategies for the practical application of feminist ideas in specific group situations. It is a significant text for many nurses who consider it a handbook for introducing feminist models for managing interaction (Mason, Backer and Georges, 1991). Wheeler and Chinn's text, published in its fourth edition by Chinn (1995) after the death of Charlene Wheeler, and renamed Peace and Power: Building Communities 
for the Future, has been influential in terms of developing a strategy called 'feminist process' that women in "small-group interactions" can use to "enact feminist values" (ibid 1991, xiii). It is important to acknowledge the contribution made by these authors to the development of a feminist perspective in nursing knowledge and to value their work accordingly. However, there are major issues with this text from the point of view of feminist theory. These difficulties are related to the assumptions which underlie the strategies for enacting this process, namely the assumption that these are inherently women's ways of doing and being. The text is celebratory of women and seems to presume an essential women's way of knowing, yet we live and act within a patriarchal system which structures, and strives to shape, all acts. How can we know, therefore, that these processes are women's ways? One could argue that Wheeler and Chinn's model is formed in response to that patriarchal structure and that it encourages binary divisions yet again. Their work subtly supports the construction of women by the male system: everything that is male we are not, everything that is done by men we will not do. Ideas which are consistent with their clear preference for radical feminism (ibid 1985).

The word PEACE in the title of Chinn and Wheeler's texts, is an acronym for the ideals of: Praxis, Empowerment, Awareness, Consensus and Evolvement (ibid, 2), yet disruption and unresolved conflict based on diversity has, at times, led to strength for women. An example of this is the resistance of black women and, here in New Zealand, Maori women, to the form of feminism which they saw as perpetuating the supremacy of white middle-class ideas over their own needs and concerns. I would also argue that many of the skills attributed to women in Chinn and Wheeler's work are used by a variety of groups outside the prevailing white male hegemony, such as tribal groups who practise consensus decision making, for example marae based practices in New 
Zealand. However, there is no doubt that Chinn and Wheeler's work has been valuable for some nurses, particularly in terms of making explicit a process that is different and which provides strategies for 'safe' group interaction. Their contribution in bringing feminism into nursing and developing strategies that make that feminism alive and actionable for nurses, is significant. Throughout their work the authors' concern for women is clear and my intention is not to negate their work but rather in terms of working with developing feminist theory I see it as important to be aware of the assumptions underlying the text.

\section{Feminism and feminism(s)}

In 1985 Chinn and Wheeler, publishing in the journal Nursing Outlook, described different forms of feminism: liberal, Marxist, socialist and radical. The preference of the authors was clearly radical feminism which they considered "the most original approach" as it is "developed from a woman-centred world view" (ibid, 75). Yet in the 1990 's it is still more common for nurses to write about a generic form of 'feminism' rather than articulating a specific feminist position or using the more appropriate term feminism(s) in recognition of the diversity in feminist approaches. In much of the mainstream nursing literature the term feminism is presented in an essentialist form, it is discussed as a particular approach characterised by basic feminist principles which reflect a rather conservative set of feminist ideas. This is in contrast to feminist theorists who acknowledge and debate diversity in positioning while making explicit their own theoretical stance (for example Stanley and Wise, 1993). Except in the work of Australian nurse scholars, which I will discuss further on in this chapter, much of the writing in nursing is out of step with feminist scholarship in which a critical element is the specific lens the author has used to view her work. At the most critical this could be 
seen as nursing being conservative and safe. Those who address feminist theory and research seem either unprepared to take a particular stance, or unaware of the diversity of feminist epistemology. On the other hand it may well be a developmental issue that is inevitable for nurse scholars transferring these ideas into the discipline of nursing. As nurses become more familiar with feminist theory and as feminist scholarship becomes integrated with nursing knowledge, then discussion of the specific theoretical perspectives will become accepted practice.

Even though different feminist positioning was raised by Chinn and Wheeler as early as 1985, a more common approach in the nursing literature avoids specific feminist theoretical positions altogether and focuses on concepts considered common to all feminist scholarship. Jenny Carryer $(1995,181)$, in her discussion of feminist research, acknowledges this by saying that "while it is probably overly simplistic to talk of feminism as a single entity there are tenets of feminism which can be seen as central". These tenets of feminism usually include the notions of oppression, the personal as political and the centrality of improving the lives of women. In conjunction with these basic tenets, many nurses when discussing feminist concepts generally, or their application to nursing specifically, refer to the work of Duffy (1985), who cites a list of eight criteria for assessing whether reported research is feminist research. These criteria were developed by Bernhard and presented at The First International Congress on Women's Health Issues, held in 1984. Bernhard's criteria are:

- the principal investigator was a woman,

- feminist methodology was used, including researcher-subject interaction, non-hierarchical research relationships, expressions of feelings, and concern for values 
- the research has the potential to help the subjects as well as the researchers

- the focus was on the experience of the woman

- the purpose was to study women

- the words feminism and feminist are used in the report

- feminist literature is cited

- non-sexist language was used (cited in Duffy 1985,345$)^{2}$

What is significant about these criteria is that while Bernhard developed them initially to determine which reports published in the journal Nursing Research could be considered feminist, nurses have subsequently used them uncritically as a framework which, if applied, will make a study a feminist project. Reading these criteria in this sense, they seem simplistic and some are inappropriate, yet nurse researchers such as Barbara Parker and Judith McFarlane (1991) and Carmel Seibold, Lyn Richards and Dawn Simon (1994) are still using them in the 1990's.

Not only would feminist scholars find adherence to such a list of criteria as a strategy for ensuring a study is feminist inappropriate, but a number of these criteria are problematic in themselves. The statement that the research has the potential to help its subjects is an example, feminist research by its very nature must be focused on improvement and change for women. The use of the word 'potential' allows the researcher to avoid any responsibility for being active in change. The criterion that the purpose of the research "is to study women", while appropriate for assessing published research reports, is not an approach that feminist researchers would take. Much of the research from a positivist perspective is studying women, whereas in feminist research studying 'with' women is essential and recognises the researcher/researched

\footnotetext{
${ }^{2}$ I was unable to source Bernhard's original conference paper.
} 
relationship and the notion of reflexivity as part of the process that will form and shape the research. The final criterion, that the research is reported using non-sexist language. Although Bernhard may have been concerned with the use of judgmental or oppressive language, much of current writing particularly in postmodern feminist scholarship focuses on the use of language and encourages women to find and express their own form of language. ${ }^{3}$ Woman focused language, that is the deliberate use of words to locate the writing within the context and concerns of women, is a deliberate strategy that must be used, according to many feminist writers. However, it is important to recognise that Bernhard was putting forward ideas that were new to nursing at the time and appears to be the first nurse who actually attempted to assess nursing research from a feminist point of view. Bernhard provided a framework, albeit rather simplistic, that nurses felt they could initially use to explore nursing from a feminist perspective.

When nurse scholars do incorporate feminist ideas into their work it appears to reflect a 'liberal' feminist approach. This seems particularly evident in the work of North American authors. This form of feminism focuses on changing institutions such as health care, law, education and access to employment, within our society, to ensure women have the same options as men (Tong 1992). This perception is supported by Joan Mulligan $(1992,173)$, who states that "at best, most nurses are liberal feminists". Joanne Pohl and Carol Boyd in their discussion of Ageism and Feminism (1993), provide an example from their own work:

Of the many feminist theoretical perspectives (e.g., liberal, radical, Marxist socialist etc.), liberal feminism probably has the closest link to nursing's history. Nurse researchers primarily have studied aging women from a reductionalistic, rational, unbiased, private, individualistic and empirical model. Nursing (along with other social

\footnotetext{
${ }^{3}$ The French feminists particularly focus on language. For a presentation of their ideas see Elaine Marks and Isabelle de Courtivron, New French Feminisms (1981).
} 
science disciplines) expects the findings from nursing research of aging women to be persuasive enough to alter the rational mind and thus cause changes in care and policy. Although there have been numerous studies on aging women from the discipline of nursing, the assumptions that a relatively powerless group of women can change the minds of those holding the health care dollars is never addressed by nursing (ibid, 200).

A further example of this liberal feminist approach with its notion of equality is provided by Carolyn Sampselle $(1990,246)$ who discusses the influence of feminist theory, in the form of specific beliefs and values, on clinical practice and in her summary states:

Incorporating feminist philosophy into practice can make it more likely for women to become full partners in sexual, social and economic relationships and to be valued for a wide range of contributions to society. Such outcomes should enrich relationships for men as well as women because in them resides the basis for true intimacy.

\section{Who is writing feminism in nursing}

Two specific areas that I feel are important to highlight in this review, as they are significant issues in feminist scholarship yet rarely appear to be considered by feminist nurses, are firstly men writing as feminists or using feminist theoretical ideas, and secondly feminist issues for women of colour. Speedy $(1991,191)$, in her discussion "of the contribution of feminist research to nursing research and practice", discusses the debate about who should do feminist research, citing feminist scholars such as Liz Stanley and Sue Wise who are quite clear that men cannot be feminists and therefore cannot undertake feminist research. Interestingly, it is a male nurse-researcher, Sam Porter (1996), who provides a detailed discussion of men in their role as nurses, researching women nurses and their practice. He addresses the role of feminist research and its relevance for nursing research and sets out "four arguments, the acceptance of 
of colonisation, it is rare to find publications that directly address this point of contention. The work of Evelyn Barbee (1994), a black nurse scholar, highlights the way in which feminist nursing literature "remains narrowly focused on White feminist concerns" (ibid, 495) and says that "by essentially ignoring how the realities of Black women diverge from those of middle-class White feminists, nurses reproduce the errors of previous White feminists". Barbee uses her research on Black women's experience of dysphoria to show the usefulness of a combination of black feminist and anthropological approaches to research. Although it can be argued that only feminist nurses of colour can write this text and develop this discourse, it needs to be acknowledged by those of us endeavouring to integrate nursing and feminist scholarship, that there is this significant gap in our developing body of knowledge.

\section{Feminism's visibility in nursing research}

There is an increasing amount of literature published in nursing journals, which explores the application of feminist concepts in nursing research. Some of this literature endeavours to describe the nature of feminist epistemology, methodology and methods although there is little consistency in the use of these terms, which can at times be confusing. A number of authors specifically discuss feminist research as methodology (Carryer 1995; King 1994; Sigsworth 1995; Webb 1984 \& 1993) and outline what is loosely termed feminist methodology, providing guidance and 'signposts' in terms of recognising or applying feminist research strategies. Authors such as Joanne Hall and Patricia Stevens (1991), and Joan Anderson (1991) discuss the specific issues of rigour and reflexivity in feminist research. Their detailed discussion of the issue of scientific rigour in feminist inquiry includes some useful guidelines for the evaluation of feminist studies. 
In relation to feminist research and nursing it is important to acknowledge the work of Patsy Perry (1994) who considers the use of empirical methodologies informed by feminist philosophy in nursing research. The importance of this work is that a significant amount of knowledge used by nurses is developed from research in science and medicine which uses positivist and empirical methodologies. Her work continues and expands the debate discussed earlier in this chapter related to scientific and medical knowledge, and nursing. Since the 1970's feminist scholars have engaged in the debate about the appropriateness of this research, due to the underlying assumptions of objectivity, neutrality and the invisible researcher, and what this means for feminists working in the field of science and technology (Harding 1991). In her very comprehensive article Perry discusses the way in which this type of research can provide valuable information about biological phenomena related specifically to women. She acknowledges, along with many women exploring empiricism and feminism, that science is inherently patriarchal and addresses the difficulties of combining feminist epistemology and empiricism, such as the androcentric and conservative traditions, and notions of objectivity and also considers the post-modern, deconstructuralist views that "the entire scientific tradition is flawed" (ibid, 485).

In addressing the nature of feminist empiricism and nursing Perry also considers the role nurses have in mainstream biological research but argues for inclusion on the basis of taking a holistic view of human experience and endeavouring to include "women and other marginal groups" (ibid, 486). Although Perry can be critiqued for this linking of "women and other marginal groups", which reflects a belief that women are extra and 'other' to the concerns of mainstream science, she has contributed to knowledge about the linking of nursing and feminist epistemology by bringing the debate about 
empiricism and feminist theory into nursing. To practise many nurses require knowledge developed from traditional science research methodologies. The critical issues raised by Perry and earlier by Hagell (1989) and DeMarco et al (1993), need to be considered by nurses in terms of recognising the philosophical underpinning's of science and empiricism and the affects that has on our practice.

Feminist methodology and its application to women-specific issues is also a significant topic in nursing journals. Jacquelyn Campbell and Sheila Bunting (1991) describe in detail the differences between critical and feminist theory, and the application of these approaches to a nursing research project exploring 'Explanatory Models of Women's Responses to Battering' (ibid, 12). Similarly, Carolyn Seibold, Lyn Richards and Dawn Simon (1994) discuss the criteria for feminist method [sic] and report their use of this research approach to study women's experiences of midlife and menopause. Topics such as abortion are explored within the context of a feminist epistemology (Timpson 1996) and Patricia Stevens (1993) uses the specific research approach of "feminist narrative" (ibid, 39) to examine access to health care of marginalised groups such as "low-income lesbians from several ethnic/racial groups" (ibid, 40).

Although some authors such as Katherine Bent (1993) discuss feminist and critical theory and its potential for nurses, generally references to feminist theory and postmodernism are unusual in the work of North American nurses. June Lowenburg (1993, 62), when discussing interpretive research methodologies, does mention the "influence of critical and feminist theory and post-modernism". However, the point that Lowenburg makes is that whereas researchers from the social science disciplines are 
seeing the possibilities of more radical approaches, nurse researchers appear to favour a more structured and controlled approach.

A more common practice in North American writing appears to be the addition of some feminist concepts to traditional qualitative methodologies. A recent work that highlights this more conservative approach is that of well-known authors Barbara Keddy, Sharon Sims and Phyllis Stern who, in 1996, published an article arguing that grounded theory and feminist research can be used together. In this attempt at the integration of a methodology developed in the 1960's by sociologists Barney Glaser and Anselm Strauss (1967), with feminist research, the fundamental issue of language is considered. They pose the question, "however, should the language of grounded theory be changed?" and answer it "we think not" (Keddy et al, 450). The language of grounded theory the authors argue, should stay "stable and separate" (ibid). Such notions are not tenable in current feminist scholarship due to the recognition of the central importance of language in feminist theory. The characteristics of grounded theory, particularly the data analysis, have been described by some writers as becoming over codified as a consequence of positivistic influences, trying to prove scientific merit and coping with inherent ambiguity (Lowenburg 1993). Even Glaser, one of the original proponents of grounded theory, has critiqued recent developments in the methodology as "a return to positivist, verificational inquiry" (cited in Annells 1997, 120). Attributes such as these do not fit with the philosophy of feminist research. It is interesting to note that grounded theory is not even considered in Shulamit Reinharz's (1992) often cited text, Feminist Methods in Social Research, in which the author provides a comprehensive discussion of methodologies that have been used by feminist researchers. This leads one to conclude that Keddy et al are adding feminist concepts to existing methodologies 
without acknowledgment of either the diversity of feminist epistemology or an understanding of the characteristics of that epistemological stance. This approach devalues feminist research, subsuming it perhaps in an effort to subjugate and make acceptable its political agenda.

Although there is some reference to the theories of feminism(s) it seems that research from a specific feminist theoretical position has been unusual until recently. It was not until Australian nurse scholars started writing of their experience and research using specific feminist theory and/or post-modern approaches, that such theoretical positioning started to appear regularly in the literature. Their work, published in journals such as Nursing Inquiry and Contemporary Nurse, has a very different flavour from feminist writing from North America and the United Kingdom. The work of Australian nurses such as Jocalyn Lawler (1997), Judy Lumby (1997), Judith Parker (1997), Patricia Farrar (1996), Trudy Rudge (1996) and Carolyn Emden (1995), reflects a willingness to engage with new philosophies and shows a distinctive application of feminist and post-modern theory to nursing research and knowledge development. The connection of feminism and postmodernism is critiqued by some feminist scholars, due to the debate about this linking (Fahy 1997). However, these nurse scholars are exploring a new dimension in the relationship between nursing, feminism and postenlightenment ideas by their challenging of more traditional approaches to nursing knowledge.

This difference in approach and the embracing of feminism and postmodern philosophies by the Australian nurse scholars, reflects the context within which Australian nursing scholarship has developed. In Australia, between 1985 and 1991, 
nursing and midwifery education was transferred to the University sector from Colleges of Advanced Education. Along with the change went the development of post-graduate studies in nursing. To develop both undergraduate nursing curricula and programmes of advanced study, Australian nurse educators explored the new philosophies and ideologies appearing in education and the social sciences, recognising that traditional North American modes of inquiry did not necessarily suit the development of Australian nursing scholarship (Lawler 1991b). Kim Walker (1995) acknowledges the work North American nurse theorists have done in endeavouring to develop a distinct and scientifically based body of nursing knowledge. However, Walker recognises the possibilities inherent in the newly developing Australian nursing scholarship and states that "only recently have nurses in spaces "other" to those colonised by the North American icons of nursing's intellectual work begun to critique the production of such knowledge" (ibid, 161). This combining of new theoretical developments, such as feminism, critical theory and postmodernism, and nursing, was explored in nursing programmes and developed by nurse scholars in education, research and practice.

The theses by the New Zealand authors Carryer (1997) and Giddens (1997), referred to earlier in this chapter, may also reflect New Zealand nurses increasing interest in these new approaches. This interest may well become more apparent with both the change to Bachelor degree programmes for nurses and a similar shift begun in 1999, of undergraduate nursing programmes into Universities in New Zealand

Although discussion of the usefulness and application of feminist theory, critique and methodology appears in nursing journals, feminist scholarship still appears marginal when reviewing mainstream research texts. There are an increasing number of general 
nursing research texts used particularly by students, which provide information about research in nursing and describe different types of research and their application. However, a review of recent and often cited texts of this nature shows that many either mention feminism very briefly or not at all. For example Laura Talbot, in Principles and Practice of Nursing Research (1995), includes a chapter by Kathleen Knafl and Agatha Gallo on the subject of triangulation in which they briefly mention the different perspective that feminist theory may provide in specific women's research. Nancy Burns and Susan Grove, in their text The Practice of Nursing Research: Conduct, Critique and Utilization (1993, 82), have a passing reference to feminist research that shows a lack of understanding of this approach when they state that "feminist research, which is gaining increasing interest in nursing, uses critical social theory methods and could be considered a subset of critical social theory". Burns and Grove also provide a small section of Published Feminism Research [sic]. However, it is extremely limited, with references dated 1979-1985. The entry ignores the significance of feminist research and the references in no way show the extent of feminist scholarship in nursing. Denise Polit and Bernadette Hungler, in Nursing Research: Principles and Methods (1995), do not mention feminist research at all, yet this is the fifth edition of this text which not only indicates its popularity but is also evidence of the length of time that the authors have been writing about research for nurses.

Texts that focus specifically on qualitative research in nursing again have either the very briefest mention of feminist epistemology and research, as in the case of Helen Streubert and Dona Carpenter (1995), or no mention at all (Morse, 1991). The only exception to this lack of recognition of feminist research and its value in nursing research, is the recently published nursing research text Qualitative Research for Nurses 
by Immy Holloway and Stephanie Wheeler (1996). These authors consider feminist research a legitimate approach giving it the same emphasis as the more traditional qualitative methodologies such as phenomenology and ethnography. They also include

a discussion of the development of feminist research in relation to the critique of mainstream science and application issues are covered in detail. It is clear that whereas nurse scholars are writing and publishing about the relationship between nursing and feminist epistemology and see the usefulness of feminist thought in conceptualising nursing practice and research, mainstream nursing research texts choose to ignore what may be considered an overtly political approach.

\section{Feminist theory and nursing women}

It appears that feminist theory or research approaches have rarely been used to explore or interpret nurses' experiences or practice in acute care settings such as surgery. An extensive review of the contents in recent issues of the specialty serial Journal of Obstetric, Gynecologic and Neo-natal Nursing was undertaken to determine whether such a publication with a specific women focus in terms of nursing practice, presented either feminist research or at least provided a feminist critique in some articles. None of the issues reviewed from 1993 to 1999 had any reference to feminism or feminist research or critique. Although one could argue that virtually all the articles published could be interpreted from a feminist perspective, there were a number in which it seemed a major omission. Two examples highlight this lack of feminist critique or any recognition of broader political implications, related to women's health. First a discussion by Lorraine Walker and Mindy Tinkle entitled 'Toward an Integrative Science of Women's Health' (1996). In this article the authors explore the development 
of integrated care in terms of including childbearing in the "larger context of women's health" (ibid, 381), the goal being that:

If we are committed to health promotion and disease prevention, we should consider it paramount to examine and understand the linkages between childbearing and women's health (ibid, 379).

The article may have benefited from consideration of feminist ideas as it does not address the opinions that women may have about this integration of services for a life normal event with those for women who are labelled as ill. Also, although arguing for an integrated "Science", the authors do not appear to be aware of the critique of science discussed earlier and the issue of the biomedical control of women. Second and similarly, Anne Moore and Melinda Noonan’s (1996) publication entitled ‘A Nurse's Guide to Hormone Replacement Therapy', provides a brief definition of menopause clearly based on the bio-medical model of this event and their discussion of hormone replacement therapy focuses only on the physiological effects of the menopause and their alleviation by hormone treatment. Although the authors address "patient concerns" (ibid, 29) nowhere in the article is there any critique from the feminist perspective of the medicalisation of a natural events in the lives of women and the implications for nurses in terms of being part of the abnormalizing process.

Webb's study of hysterectomy published in 1984, although not specifically detailing feminist methodology, must have been informed by her experience of feminist scholarship. Her research specifically focused on "hysterectomy patients" (ibid, 95) and explored the experiences of this particular group of women with the aim of determining the support which would be of most assistance to them when undergoing their surgery. She also included nurses in this research and concluded that they were unprepared for 
much of their work in this area and in some instances, for example when young women were having abortions, the nurses were quite judgemental.

Judy Lumby's (1997) recent innovative work in which she explored the nature of 'the feminised body in illness', focusing on women experiencing life-threatening illness, appears to be the first such study undertaken from a critical feminist approach. Lumby's exploration from this perspective made possible a "critical awareness of the 'lived' (experienced) female body interacting within the world of illness, disease and health care" (ibid, 131). The possibilities of this use of feminist critique lie in the questioning of what Lumby calls the "presuppositions" on which the concepts of the body are configured and, therefore, which determine practice in relation to the body of women. This dearth of nurse feminists writing in the acute surgical nursing area and especially in the specialty nursing area of gynaecology, is interesting. It seems particularly significant in the light of the work by feminist scholars such as Ludmilla Jordanova (1989), Ornella Moscucci (1993) and Nancy Theriot (1993), who all address the issue of gynaecology and the way women were, and continue to be, treated in the name of science with surgical interventions. It would seem that feminist research which explores nurses, their practice and the reality of the women they care for, is important in acute areas in which the positioning of the medical discourse is so powerful and impacts consistently on the experiences of all the women as patients and nurses in the setting.

In conclusion, it is clear that feminism and nursing have been linked since the early 1980's and the possibilities that feminist theory, critique and research strategies provide, have been gaining in recognition and acceptance. However, although recognising the potential inherent in linking feminism and nursing, nurses seem to have embraced a 
moderate type of feminism in a rather elementary form and not considered feminist theory as a possible basis for the development of nursing theory. There seems to have been a hesitancy in nurses' integration of feminist theorising until recently. Now new philosophical positions that are emerging in feminism, such as postmodern feminism, are starting to appear in the writing of nurses, mainly through the work of scholars from Australia who show a distinct and innovative approach to the relationship between nursing, feminism and post-modernism (Glass and Davis 1998). This distinctive approach reflects a willingness to engage in the debates arsing from recent philosophical shifts. In much of the writing there is a clear commitment to feminist theoretical concepts that show a striving to connect recent philosophical shifts with nursing theory and practice. Australian nurses seem to be using specific feminist theory in research whereas others are still using what are considered basic concepts of feminism, such as the personal being political, the addressing of oppression, and a focus on women's issues. Finally, although a number of nurses have used feminist epistemology in research studies and to explore issues for women, there do not appear to be any such studies which explore gynaecology as a specialty or the practices of nurses in this uniquely female situation.

On the basis of this exploration of the positioning of feminist theory in nursing I decided that it was important to explore my topic of women working in gynaecology from a specific feminist stance. Taking this approach would contribute to the 'movement' of feminist theory in nursing. By this I mean that staying with basic concepts of feminism to guide nursing research could lead to a rather fixed point in the development of feminist thinking in nursing. I came to believe that taking a position from the range of feminism(s), be it liberal, Marxist, standpoint or post-modern, would 
result in a wider variety of interpretations of nursing, thereby contributing to the development of both knowledge and feminist thinking in nursing. The following chapter then describes the exploration I undertook to find the positioning that for me seemed authentic in relation to my ontology and the topic of this research. 


\section{Chapter 4}

\section{An exploration of knowing}

o undertake my research into nurses' experiences of nursing women in the
gynaecological ward from a specific feminist position, I had to address the complexity which is characteristic of feminist scholarship at the end of the twentieth century. This complexity relates to the many different forms of feminisms, the blurring of the boundaries of these different forms, and the current vigorous epistemological debates which are now an essential part of feminist theorising. This chapter explores my development of an epistemological approach that grew out of my immersion in the literature of feminist theory, and particularly my exploration of the linkage between feminist and postmodern ideas. I also identify and discuss specific concepts that emerged from this exploration which I chose to inform my research.

The methodology which is underpinned by my epistemological position is described separately in the following chapter. Although I address epistemology and methodology in separate chapters in the practice of research they are interwoven. However, I feel it is important to discuss the epistemological ideas that inform my research and the current debates surrounding these ideas, before addressing methodological issues and the methods used in this research. As Millen $(1997,1)$ says in relation to her experiences of doing research:

... whilst there is a need to conduct gender-sensitive work, too orthodox a definition of feminist research may inhibit rather than facilitate research which could lead to helpful insights for women. A better strategy might be to site the conflict in epistemology, rather than methodology, and to define feminist research in terms of values which it might uphold rather than techniques it might use. 
I also feel that this separation of epistemology and methodology is important in terms of ensuring that my interweaving of feminist theory, research practice and the topic, is transparent and open to feminist critique, thereby making a contribution to epistemological debate in both nursing and feminism.

The specific feminist epistemology I am drawn to is one which incorporates many aspects of what some authors label as French feminism (Marks and de Courtivron 1981) and others name postmodern (Tong 1992), in conjunction with notions from postmodern theorising (Parker 1997, Shildrick 1997), including ideas from the work of the French philosopher Michel Foucault $(1975,1983)$. Feminism and postmodernism, although at times contesting, have many common concerns and can, I believe, be complementary in a research project. Working with the tensions between these two epistemological positions, although challenging, can enhance the research. The crucial factor is that these ideas are congruent with my personal feminist ontology and have the potential to provide a unique reading of the topic of women as nurses nursing women in the gynaecological ward. The methodology which I go on to describe in the following chapter is at the same time supportive of, and supported by, my ontological and epistemological position.

I believe that the theoretical perspective underpinning research is shaped by the researcher's unique reading of epistemology. If an essential element of feminist theory is recognising that knowing and interpretation are subjective, then it seems that one's interpretation of epistemology is also formed by positionality. I read feminist epistemology in a unique way, distinct from other researchers. Where essentialist terms such as 'woman' and, in the context of my study, 'nurse' are questioned and found 
unreal, then so the term 'researcher' can be subject to the same interrogation. My reading of feminist epistemology is shaped by the feminist ontological position I developed as my research progressed. The subsequent integration of feminism and some aspects of postmodernism, led to a very particular approach that allowed for my exploration of specific aspects of nurses' embodied experience in the area of gynaecology.

When I began this study, although absolutely sure in my mind that I could only undertake the study from a feminist perspective, I was unsure as to the nature of the epistemology. My idea was to undertake a qualitative study informed by feminist philosophy, the exact nature of that feminist philosophy or how it could be presented as theoretical was something that I was looking forward to exploring within the research process. Initially I accepted that the focus of feminism was equality for women, that patriarchal oppression was the overarching practice that constrained women. As I have discussed in the previous chapter, this is a common starting point for many feminist nurse-researchers. I now believe this position reflected a stage in my development in relation to feminist epistemology. As explained in Chapter One, my exposure and commitment to feminist principles was gradual, developing from the 1970's, a time when according to Elizabeth Gross $(1986,190)$ :

Feminists seemed largely preoccupied with the inclusion of women in those spheres from which they had been excluded, that is, with creating representations which would enable women to be regarded as men's equals.

However, there was something about this particular form of feminism that did not seem quite right, although I was unable to articulate just why this was so. When I reflect on my early experiences, I realise that a significant moment of consciousness came during 
my involvement in the movement to ensure women's right to abortion services in New Zealand. Initially I could not understand why men assumed that as women we could not make autonomous decisions about something as serious as abortion, without the intrusion of the male justice, medical and religious systems. The sub-text soon became very apparent - we were not to be trusted.

In retrospect, I also believe that being a nurse was a major aspect of my resistance to what seemed a rather too simplistic form of feminism. Not that I thought that actively addressing women's issues in an effort to change women's lives, particularly in relation to freedom of choice over fertility, the right to equal employment and sharing of domestic work, were not extremely important. The problem was that the focus on these issues alone seemed to leave something unaddressed and, in relation to nursing, did not encompass some of the issues I had confronted. For example, nurses have always been allowed and encouraged to work. We are necessary to the running of the modern medical system, although often underpaid and taken advantage of due to our concern for the people we care for, still the right to work in our chosen profession is not constrained. However, for me there are larger issues to do with power and control that, until recently, went unaddressed. When I became involved in the academic world of nursing, this seemed more evident. Theory in nursing did not address the underlying discourses of power and control that formed and shaped nursing. The grand theories of nursing did not provide me with any entry point in terms of my interest in women and nursing. The generic and ungendered nature of the theories were problematic, they seemed to reflect a neutral subject, unplaced in terms of gender, politics or class, a “disembodied, rational sexually indifferent subject" (Gross 1986, 199), from a feminist perspective patriarchal, and redolent of an effort to join the game of male theorising on 
the meta level. So, although a feminist, I found it difficult to position myself in terms of a theoretical stance. My personal approach was one of commitment to exploring the place of women in the world, how this positioning came to be, and the effects for women. I felt strongly that exploration of this positioning was the domain of women.

Exploration of feminist epistemology during my post-graduate study led me to the realise that my difficulty with the form of feminism I had been exposed to, was due to the underlying assumption that we should try and live in the world like men. That the male way of being and constructing reality was the yardstick against which we should continue to measure ourselves. Equality seemed impossible, something we would never achieve due to our completely different experiences of life. However, Gross whose 1986 work was pivotal to the crystallisation of my position, believes this pursuit of equality was an essential part of the process of women becoming increasingly aware of the taken for granted nature of their undervalued position in all aspects of society. As she (ibid, 193) says:

This aim of equality served as a political, and perhaps experiential, prerequisite to the more far-reaching struggles directed towards female autonomy - that is, to women's right to political, social, economic and intellectual self-determination.

This idea of autonomy, the valuing of women's experiences and their right to construct their world, felt very powerful and I realised that this was the factor that was missing from my previous understanding of feminism. Inherent in the equality argument seemed to be the continued power and privilege of the patriarchy and, as Elizabeth Grosz (1989, 37) neatly states, "If masculinity is oppressive, why aspire to it as an ideal." My early explorations of feminism did not immediately provide me with a framework that was congruent with my instinctive approach to feminist ontology. The transcendence from 
being absorbed by something labelled feminism, which seemed to be presented rather simplistically in the nursing literature and had something inherently lacking, to an understanding of the depth and scope of feminist epistemological theorising incorporating the concept of autonomy, was pivotal to my project.

The possibilities of feminist theorising described by authors such as Gross (1986) and Rosemarie Tong (1992) were extremely liberating, particularly the ideas presented under the names of French or postmodern feminism, or "feminists of difference" (Grosz 1989, viii). The three most well-known women scholars in this group are Luce Irigaray, Hélène Cixous and Julia Kristeva, although their prominence in the English literature may in part be a result of decisions related to who is, or can be, translated. As Diana Leonard and Lisa Adkins $(1996,3)$ say, "There has been a veritable outpouring of publications around their work." Elaine Marks and Isabelle de Courtivron, in their 1981 text New French Feminisms, presented translations of the work of a number of French feminist writers, yet it is the three women named above that are synonymous still with the movement of French feminism. Irigaray, Kristeva and Cixous, although labelled French feminists, do not share a common approach but draw on knowledges that have informed recent philosophical thinking, particularly in France. Grosz (1989, ix), describes this group thus:

They do not present a coherent political or theoretical position, form a 'school' or share a common doctrine. Yet there is a sense in which each is appropriately labelled a 'feminist of difference', insofar as each addresses the question of women's autonomy from male definition. Each remains interested in affirming the sexual specificity of women, rather than seeing women only in their relations to men. Each seeks out a femininity that women can use to question the patriarchal norms and ideals of femininity. Each refuses to accept the preordained positions patriarchy has relegated to women. 
For the French feminists Freud's theory of the development of women, and the subsequent work of Lacan and Derrida, provided the impetus for feminist theorising within the psychoanalytical framework. In her discussion of Modern French Philosophy, Elizabeth Grosz $(1989,33)$ describes the history of these ideas when discussing the work of the French philosopher Jacques Derrida, and his influence in the arena of French feminist thinking:

Derrida here follows Nietzsche's claim that there are two kinds of women: feminists, whose project is simply the reversal of phallocentrism, that is who strive to be like men, to have a fixed identity, a natural essence and a place to occupy as subjects; and women who differ from rather than act as the opposites of the masculine, thus subverting and threatening to undermine masculine privilege.

The writing within French feminism reflected a belief that the pervasiveness of patriarchal power in all institutions in society made it impossible for women to know how their lives could be lived free of oppression, as Faillaize (cited in Leonard and Adkins 1996, 4) says:

They took the psychoanalytical specificity of women for granted, but argued that women had been repressed by patriarchy in such a way that we do not know what women would be like left to herself.

This different view of feminism was immediately appealing, it worked with the sexually differentiated positions of men and women. As Marks and de Courtivron $(1981,36)$ said when comparing French and American feminism:

The French feminists are more convinced than their American counterparts of the difference between male and female; they are more imbued with notions of sexual specificity.

Men and women are different, therefore their realities will always be different. I could not support the belief that the aim of feminist activism, through scholarship or more 
direct action, is to make women the equal of men. As Margrit Shildrick (1997) points out the project of equality has an impossible goal. If women are striving for equality in a male constructed society, even though they may succeed in gaining educational, legal and work equality, it still is not equality if the standards achieved are those set by the male system. As Shildrick $(1997,110)$ says, "There is always implicitly, at least, one who is the point of reference and one who is different, and that latter cannot in any real sense be equal." I believed the emphasis needed to be on women determining their own world and felt the notion of autonomy, being freed from construction by reference to male norms was totally congruent with my personal position.

Another major concern of French feminism is language and the way in which it is used to oppress and exclude women. There is a centrality of language, "both the spoken and the written word" (Marks and de Coutivron 1981, 5). The act of writing is considered essential to making explicit women's reality and to re-working language to try and break from the confines of patriarchal thought. I found the view that it was almost impossible to know how women can act, as even our thoughts and writing are produced in male structured language, extremely challenging (Dallery 1989). I realised the paradox inherent in this theory, that is: if you can only express yourself in male-centred language how can you ever find a way of expressing what is uniquely 'feminine'. But, I also agree with Arleen Dallery when she states that "the hegemony of patriarchy is embedded in language" (ibid, 62). However, I could see that even recognising this is a provocative and challenging act, particularly so in nursing and, more particularly, gynaecology where the whole 'text' seemed to be male, often acted out through the practices of nurses, on female bodies. 
Also, from this perspective, feminist activism includes theory development, based on the premise that otherwise male theory will continue to be used to define and describe the lives of women (Marks and de Coutivron 1981). To me this idea brought action and scholarship together, I came to recognise that theory development is extremely important. If male thought and theory shape the present world, including the construction of women, so feminist theorising must become a powerful part of feminist action. As Elizabeth Gross $(1986,37)$ says:

Feminist theory challenged both the content and the frameworks of discourses, disciplines and institutions, attempting to present alternatives or develop them where they did not exist.

This clarified my thinking and my ontological position: if feminists only sought equality in a patriarchal world then the underlying structure would not change, the desire to become equal with men in a male defined world would seem to reaffirm the 'rightness' of that world. The project of autonomy appeared to go deeper, to question the theories that underpin the structure of our world. These ideas supported my interest in the way male knowledge, and the power that emanates from that knowledge, construct our world, and the way this was played out specifically in the ambiguously female/male area of gynaecology.

As I began to explore a particular feminist epistemology, the symbiotic nature of women's reality and their reality as nurses was very evident. This approach provided an oeuvre or opening through which I could explore women in their role as nurses in a gynaecological setting, not by reference to patriarchal ideas of appropriate nursing behaviour but by giving the 'speaking subject' centrality. Certain specific concepts emerged from my particular exploration of feminist scholarship that had synchronicity 
with the ideas I wanted to explore in relation to women as nurses working with women patients. These concepts are the notion of women as Other, the concept of difference, and a deep concern with the body, or rather women in their bodies. I will discuss each of these notions separately before considering the Foucauldian idea of discourse and addressing postmodernism and its contribution to my research.

\section{The Other}

The notion of the Other in feminist theorising was originally defined by Simone de Beauvoir (1989) in her text The Second Sex, and interpreted as negative, putting women outside the transcending male, and therefore real, world. This text is today considered an "exemplar of modernist feminist inquiry and critique" (Di Stefano 1990, 64), and a turning point in the exploration of the construction of women's reality in opposition to the positioning of men. Naomi Schor $(1994,45)$ considers Simone de Beauvoir and Luce Irigaray "two major French feminist theoreticians of the twentieth century". She notes that de Beauvoir's work was an attempt to expose the manner in which women were made Other, “... the means by which patriarchy fixed women in the place of the absolute Other, projecting onto women a femininity constituted of the refuse of masculine transcendence" (ibid, 48). However, this concept of Other has been reworked by recent French feminist writers (Irigaray 1985b) and has come to be viewed as a space of power and possibility. As Tong $(1992,219)$ says:

The condition of Otherness enables women to stand back and criticise the norms, values and practices that the dominant culture (patriarchy) seeks to impose on everyone, including those who live on its periphery - in this case, women. Thus, Otherness, for all its associations with oppression and inferiority, is much more than an oppressed, inferior condition. Rather, it is a way of being, thinking, and speaking that allows for openness, plurality, diversity and difference. 
Otherness seemed a concept that could be applied to both myself and nurses working in the gynaecological area. It gave me a framework for seeing women as nurses and nurseresearchers, as essential, but marginalised, in the health system. As in many areas, the nurses are central to the running of the gynaecological services but their work is constructed and constrained by the prevailing male discourses of medicine and management. The gynaecological area itself is marginal within the hospital system. Reviewing literature related to both the history of gynaecology and the way gynaecology is represented in nursing, highlighted the focus on medicine and the biomedical construction of gynaecology. In texts which recount and critique modern gynaecology there is little reference to the place of nursing, and the nursing literature reflects a medical model that foregrounds pathophysiology relegating nurses' concerns and women's experience to the Other. Nurses seemed to be Other, working in this marginalised space, a positive space in many feminists' eyes, for it enables creativity and difference to flourish.

I could also be constructed as Other, ambiguous and hybrid, by the nurses in this setting; a nurse yet not a nurse, undertaking research, a practice they would not normally associate with nurses. Yet being Other, working across the boundaries and at the margins, may provide the space for resistance - perhaps both my own and the nurses I worked with, a positive space for re-thinking and re-interpreting our experiences. This concept of Otherness, therefore, was useful in terms of the area of gynaecology, the role of nurses in relation to the power in the institution, and my ambiguous place as nurseresearcher. 


\section{Difference and Différance}

This concept of Other brings with it, from a French feminist perspective, the debate about différance and difference. The way in which these terms are used and their usefulness in feminist theory have been addressed by a number of feminist writers (Diprose 1994; Du Plessis and Alice 1998; Schor and Weed 1994; Shildrick 1997). Although it is the notion of 'difference' that I focus on in this study, I felt it was important to develop an understanding of the variance between the terms. Différance was a notion developed by Derrida (Tong 1992) and intertwined with deconstruction, the meaning of which "is deliberately hard to pin down" (Shildrick 1997, 103). However, this term relates to the fact that within each word is the idea of the opposite, to use the term 'man' alludes to, and is dependent on, the concept of 'woman', the term 'power' has inherent in it the idea of the 'powerless'. It seems therefore that the term différance in Derrida's work attempts to elide dichotomy inherent in these terms and address the gap between (Shildrick 1997). The work of Derrida is pivotal in relation to deconstruction. However, many feminists are unsure about his work and his discussions of femininity. For a number of feminist authors this debate centres on the issue of appropriation of what is named as the 'feminine'. Rosi Braidotti $(1990,36)$, for example, believes that male philosophy has co-opted the word "feminine" as a metaphor for "illness, crisis and discontent", using the term in a way that has no relationship to women and their reality. She critiques Derrida for this male interest in the feminine, saying:

Isn't it strange that it is precisely at the time in history when women have made their voices heard socially, politically and theoretically that philosophical discourse - a male domain par excellence - takes over 'the feminine' for himself? (ibid, 37). 
Shildrick (1997) also believes that on occasions certain characteristics traditionally associated with being feminine are seen as part of a "male ideal" (ibid, 106) but, as she goes on to say, it is important to question whether ".... the feminine in women is ever given the same positive account". So although men may value some female traits when they appear in men, these same traits in women are not valued and in fact are used as a rationale for oppressive practices.

Also, there is a sense that working within a framework that encompasses Derridean theory is a form of complicity with patriarchal thought, as Elizabeth Grosz $(1995,62)$ says:

... his work raises difficult, possibly unresolvable questions regarding the internal and essential implications of feminist theory and practice in an often unrecognised complicity with the very forces feminists have commonly identified as outside of feminism itself - patriarchy, phallocentrism, racism - forces from which feminists have, they believe, separated themselves in order to see feminism as beyond or outside their sphere of influence.

However, recognition that feminism is formed, even if oppositionally, by a patriarchal culture is, I believe, unavoidable, but not necessarily negative. As Grosz goes on to say:

If feminism does not occupy a space outside of patriarchy and phallocentrism, if it is implicated in the interstices of patriarchal functioning, then the security of its identity, the definitiveness of its border as other than outside of patriarchy, its very self-representations as a bounded position separable from patriarchy, are problematized (ibid, 62-63).

But this recognition of the role patriarchal hegemony has had on the development of feminism is not an anti-feminist gesture. It is more a measure of the maturity of feminist theory, able to accept its internal limits and to use them in enabling and productive ways. The link between these ideas and my study with the nurses in the 
gynaecology setting is that nurses and their work are, to a certain extent, constructed and formed by reference to male medical hegemony and discourse. I believe it is important to acknowledge this. In the very same way that recognition of the manner in which feminism is influenced and formed by patriarchy can be a measure of maturity, so recognising that nursing is influenced by the nature and practice of medicine, can be a measure of maturity. If we can incorporate the reality of our relationship with medicine, including the tensions that this brings, into our reality in an enabling way, it may well give rise to a more productive way of practising nursing.

Difference (rather than différance), does not focus on the gap between, but rather on actual difference in identity and positioning, and the effects of totalising theory in relation to the experiences of minority groups within feminism. These effects, which result in the lack of recognition of obvious differences between women became oppressive in themselves, blurring the vision of feminism so that one experience of oppression was thought common to all women. The term woman "reflected and universalised the experiences of white, middle-class, heterosexual, first world women" (Jeffreys, 1991, 4). This situation ignored the role white, educated, middle-class women had in oppressing women who were not part of this more powerful group (Haraway 1990), and who, therefore, had little voice in the development of feminism and feminist theory. Women who considered themselves members of minority groups, due to different ethnicity, ability, sexuality or economy, "at the bottom of a cascade of negative identities" (ibid, 197), saw themselves as being placed outside mainstream feminism, marginalised within a feminist discourse that really spoke of white middle-class women's concerns (Jeffreys 1991). These women pointed out that their experience within the patriarchal hegemony could not be encompassed within white middle-class 
concerns. ${ }^{1}$ These ideas of difference can now be seen as transferable to individual identity no matter what more obvious group a woman identifies with, within that group her identity will shift and change according to the situation. As Lynne Alice and friends (1998, 146) say:

Difference as identity is the idea that lived experience is saturated with differences and that these simultaneous social fracturings, which we call sex, race, class, colonialism, nationality, and so on, shape constantly shifting frameworks of identity that can only ever be multiple-identities.

Recognition of this shifting of identities destabilised the meaning of the word 'woman'. Did women, as a concept, actually exist? If not, could women be called together to work towards a common goal of liberation, the diversity inherent in the term women also meant there would be no coherence in the term liberation. In modern feminist theory then, there are two main points of view in relation to this interpretation of difference: standpoint feminism and postmodern feminism, although it is important to recognise that categorising theory is an impossible and maybe irrelevant task, and many feminists would actively resist being labelled in this way.

Feminist standpoint theory believes that a beginning point for theorising, is the experience of being a woman. As Sandra Harding (1993, 140), explains:

Standpoint theories show how to move from including others' lives and thoughts in research and scholarly projects to starting from their lives to ask research questions, develop theoretical concepts, design research, collect data and interpret findings.

\footnotetext{
'See Patricia Maringi G. Johnston's (1998) chapter "Maori Women and the Politics of Theorising Difference" in Rosemary Du Plessis, and Lynne Alice, (Eds) Feminist thought in aotearoa new zealand, [sic], for a discussion of these issues particularly in relation to Maori women and their experience of colonisation.
} 
Harding (1991) is concerned with the relationship between feminism and science. She clearly locates standpoint theory as oppositional to traditional science and the call by feminists empiricists to add women into all aspects of research currently framed by male values and practices. Although this inclusion may be supported by some women, Harding $(1992,63)$ believes "feminist empiricism tells them that the way they do science and the content of their work is not, and should not be, affected by the fact that they are women". From a standpoint feminist position this will, inevitably, leave the project of science largely unaltered, it will remain "science-as-usual", still focused on male determinations of what is, and what is not, considered appropriate for knowledge development. Standpoint feminism locates science within a social context, believing that changes will not be made in science unless they occur within society. It is hard to imagine that androcentrism in knowledge development can be eliminated without recognising it exists and requires addressing in all areas of society.

However, the idea that women's experience is a valid starting point, often leads to criticisms of essentialism (Millen 1997). Essentialism is "the attribution of a fixed essence to women" (Grosz 1994a, 84), often associated with biologism or the notion that there is something universal in our biological experience and, therefore, in our lives generally, something that is natural to our way of living.

The belief that all women can in any way share a common or unitary experience is fraught with difficulties, the most frequent challenges to feminist standpoint theory being based on the obvious divisions of class and ethnicity, and the effects these divisions have on women's experiences. As Naomi Schor $(1994,45)$ says: 
Essentialism, according to this critique, is a form of "false universalism" that threatens the vitality of the newly born women of feminism. By its majestic singularity Woman conspires in the denial of the very real lived experiences - sexual, ethnic, racial, national, cultural, economic, generational - that divide women from each other and from themselves.

However, Harding $(1993,141)$ addresses the difficulties inherent in starting from women's actual experiences when she says, "What "grounds" feminist standpoint theory is not women's experiences but the view from women's lives." She acknowledges that you cannot start from women's lives as though women were a homogenous group, undivided by factors such as ethnicity and class, and states, "We can all learn about our own lives at the center of the social order if we start our thought from the perspective of life at the margins" (ibid). Millen $(1997,12)$ also supports the non-essentialising nature of standpoint feminism when she argues that:

... criticising FS [feminist standpoint] theorists as essentialists amounts to a failure to understand that they are discussing the incorporation of the feminine, rather than of womanhood.

In fact it is the inclusion of the feminine, the integration of the women's view into epistemology and theory that governs our world, that is the commitment inherent in feminist standpoint theory.

Postmodernism recognises the plurality of subject positions and believes there can be no woman's view to use as a starting point. Subjectivity "is not the manifest property of the inner self but merely a more or less unstable effect of power" (Shildrick 1997, 149). This idea of a constantly shifting and changing subject does not allow for any conception of a shared starting point in terms of experience, reality or concerns. Alice $(1998,138)$, in her introduction to a discussion of sexuality, finds the challenges of 
postmodernity enlivening, being "dissatisfied with how familiar and convenient some of the boundaries of feminist thinking have become". For some authors the similarities between feminist theory and postmodern discourses, such as the holding of contradictory "notions of the self, knowledge and truth" (Flax 1990, 40), are so evident and so strong that they seem to be all part of the same shift in philosophical thinking that has occurred in the latter part of the twentieth century. For example Jane Flax $(1990,40)$ states:

As a type of postmodern philosophy, feminist theory reveals and contributes to the growing uncertainty within Western intellectual circles about the appropriate grounding and methods for explaining and interpreting human experience. Contemporary feminists join other postmodern philosophers in raising important metatheoretical questions about the possible nature and status of theorizing itself.

She believes that "feminist theorists enter into and echo postmodernist discourses" (ibid), a view that seems to firmly locate feminism within the postmodern.

My reading of these differences led to the conclusion that although the debate is important in terms of determining the nature of feminist theorizing, elements of both points of view are useful and not incompatible. I consider taking women's lives as the starting point for theory and research, to include the feminine, as extremely important. And, in an effort to recognise and work with diversity, it is important to accept that the position and identity of the individual woman will shift, will be unstable at any given time. Also, although the commonalities between postmodernism and feminism can be identified, I believe that the linking of feminism and postmodernism needs to be approached with caution. As Nancy Hartsock (1990, 163-4) asks:

Why is it that just at the moment when so many of us who have been silenced begin to demand the right to name ourselves, to act as subjects rather than objects of history, that just then the concept of 
subjecthood becomes problematic? Just when we are forming our own theories about the world, uncertainty emerges about whether the world can be theorized. Just when we are talking about the changes we want, ideas of progress and the possibility of systematically and rationally organizing human society becomes dubious and suspect.

Difference, lived difference, with its recognition of diversity and different positionings, supports the exploration of difference rather than homogeneity, in the practice of nurses. Also, I feel that the notion of essentialism is important to confront when exploring nurses' practices. The term nurse, like woman, is a highly essentialising label under which a range of characteristics, expectations and practices are subsumed. Destabilising the term 'nurse' results in considering nurses as individual women and accepting their practice as highly idiosyncratic. Starting with their positioning in the role of nurse yet realising it as a constantly shifting identity seemed to incorporate recognition of difference and essentialism.

\section{The Body}

Feminist writers are now struggling to reinterpret and re-centre the body. Grosz (1994b, 3) describes feminist understandings of the difficulties with the body as "a conceptual blind spot in both mainstream Western philosophical thought and contemporary feminist theory". Yet addressing 'the body' is a fraught situation, leaving the writer open to charges of biologism, naturalism and essentialism, of believing there is something that all women share that underpins life as a woman.

For many feminists this attention to the corporeal body is an essential part of reclaiming autonomy as women. We have traditionally been defined by the link to our bodies, bodies that have been interpreted negatively as in the mind/reason versus body, split. 
We are unable, nor now want, to transcend our material reality but rather seek to affirm our embodiment (Shildrick 1997). Women's bodies have been denied, ignored and used as weapon against us to support the oppression of women through the negative interpretation of our biology. As Susan Bordo $(1989,14)$, says "... the discipline and normalisation of the female body ... has to be acknowledged as an amazingly durable and flexible strategy of social control." The displacement and denigration of the body was an inevitable consequence of the elevation of reason. From the beginnings of western philosophy the male mind was considered superior, the body being "regarded as a source of interference in, and a danger to, the operations of reason" (Grosz 1994b, 5). The binary nature of man/woman and mind/body, resulting from early philosophical thought and extended by Descartes, results in a superior/inferior dichotomy. In this system women's bodies are defined as doubly inferior by nature of being oppositional to both men and mind.

Modern feminisms struggle with the notion of the body, which has led to a complex array of attitudes and positions. Grosz's (1994b, 15) work provides a way through this complexity. She describes three distinct categories of feminist theorising about the body - egalitarian feminism, social constructionism and sexual difference - while recognising that these categories often overlap and that the feminists may in fact be part of different categories at any one time.

Egalitarian feminism has a project of equality and while some feminists within this category regard the body as negative, others consider it positive. The negative view regards women's bodies as being an element of women's oppression, the biological function of reproduction ensures that whatever equality women gain in the public sphere 
will never be reflected in the private sphere. The role of mother, or potential mother, is considered a major limiting factor in women's lives. The positive view relates to the belief that women's bodies give women special insight or knowledge. However, both these seem to accept that the role of childbearing hinders women from full citizenship and that it is this biological function that must be modified.

The social constructionist perspective, accepting that the sexually differentiated body is a fact in western culture, focuses on minimising biology rather than attempting to overcome it. In opposition to those feminists described above, from a social constructionist point of view biology is not the problem, how society constructs women on the basis of biology is the locus of oppression. Changing culturally determined attitudes, beliefs and values about the body will change the experience of women.

Feminists who are located in the sexual difference group believe in the cultural positioning of women and that consideration of the 'lived body' is essential. From this perspective the body is discursively constructed and "is regarded as the political, social and cultural object par excellence" (Grosz 1994b, 18). Men and women are seen as fundamentally different, a difference that is unable to be changed, "eradicable". This approach does not, however, result in an essentialist belief in a universal experience of being a woman, multiplicity and diversity of experience are recognised as fundamental to women's embodied lives. As Grosz (ibid, 19) says, for theorists committed to this view, the body:

Far from being an inert, passive, noncultural and ahistorical term, the body may be seen as the crucial term, the site of contestation, in a series of economic, political, sexual, and intellectual struggles. 
However, writers such as Susan Bordo $(1989,27)$ critique French feminists located within this group, by arguing that:

French feminism has provided a powerful framework for understanding the inscription of phallocentric, dualistic culture on gendered bodies. But so far, French feminism has offered very little in the way of concrete, material analyses of the female body as a locus of practical cultural control.

The politics of sexual difference in relation to the body, seemed useful for exploring the place of nurses in the gynaecological area. Women as nurses reflect the characteristics of women's bodies described by Grosz (1994b, 18) thus:

On one hand it is a signifying and signified body; on the other, it is an object of systems of social coercion, legal inscription and sexual and economic exchange.

The nurses are the site of contestation, they are at the same time involved in the construction of themselves and the women they nurse. They work with the diversity of women in a configuration of discourses that often constructs both the nurses' and the patients' experiences as universal. They struggle with a multiplicity of positioning effected by the cultural discourses of nursing, medicine, management and cultural expectations.

In most areas where nurses practise, the body is the focus of their work, even in psychiatry where the deviant body may be the physical manifestation of the deviant mind. However, compared with the extent and variation of literature related to women and their bodies in feminist writings, until recently the topic was rarely discussed in nursing literature. This situation has changed with the publication of the significant text The Body in Nursing (Lawler 1997). However, how nurses confront the experience of working specifically with women's bodies does not appear to have been considered by 
nurses, yet nursing practice is made real through the bodies of nurses. Nursing practice is embodied practice. According to Susan Bordo (1989, 14), Foucault "consistently reminds us of the primacy of practice over belief", and nursing is, in fact, what is practised, made real through the bodies of nurses and experienced by the person, not that which is theorised. This is the reality for both the women nurses and patients in the gynaecological area, where the situation of nurses working with women's bodies is unique. This uniqueness is due to nurses being continually confronted with both the feminine body in discourse and the biological entity, both permeate their practice. Nurses are influenced by and respond to the representations of the feminine body in the prevailing discourses in our society. Therefore, the dominant discourses in the areas of health, illness and women will, through the embodied practice of the nurse, directly affect the experience of the woman being nursed.

The postmodern idea of the body as text, having multiple identities and being discursively constructed, is congruent with my position in relation to feminist theorising about the body. Judith Parker (1997), in her discussion of nursing and the body within the postmodern, notes the similarities in positioning of both the body and nursing which she describes thus:

... I am suggesting that in postmodernity both nursing and the body are characterised by collapsing hierarchies and polarities with the emergence of heterogeneities, pluralities and a concern with surfaces (ibid, 12).

This situation Parker sees as positive, the changes that postmodernism brings to the representations of bodies and nursing can lead to "new understandings". She also states that "nursing, like the body, can be thought of as having been colonised by the objectifying and rationalising impulses of modern medicine within the context of the 
institutional structures of the health system of modernity" (ibid, 21). Therefore, consideration of the body from a postmodern perspective would also relate to the nurses' positioning of themselves in relation to medicine, how they view this relationship and how they manage it.

\section{Discourse}

The dialogue between feminism and the writings of the French philosopher Foucault (Hartsock, 1990) also provided me with valuable ways of considering nursing in the area of women's illness. Authors such as Irene Diamond and Lee Quinby $(1988, \mathrm{x})$ note the similarities and "convergences" between feminist theorising and Foucault. Both are concerned with the body as the site of control and domination, how power is constituted and maintained, and the relationship between power/knowledge and universal claims to truth. Although Foucault did not align himself with postmodernism (Foucault 1983), many of his ideas have been incorporated into postmodernity and the concept of discourse (Foucault 1977, 1990) is one of the most influential of these ideas. Foucault is considered to be the first scholar that linked discourse and power in terms of the discursive structure of power and its possibilities (McHoul and Grace 1995).

Nancy Fraser (1991) discusses the different approaches that have developed through the French concern with theorising about language. The approach she labels as a "pragmatic model" (ibid, 101) recognises the multiplicity of discourses in any given situation, and the fact that individuals move and shift between these discourses, having "a plurality of communicative sites from which to speak" (ibid, 107). Her discussion included the following definition of discourse which fitted with my project of exploration of nurses 
at the intersection of the myriad of discourses that continually formed and re-formed gynaecology:

Discourses are historically specific, socially situated, signifying practices. They are the communicative frames in which speakers interact by exchanging speech acts. Yet discourses are themselves set within social institutions and action contexts. Thus, the concept of discourse links the study of language to the study of society (ibid, 107).

This interpretation of discourse shows that language is the medium through which practices become real, and the over-arching power and influence of these languagestructured practices. Susan Bordo $(1989,15)$ believes that as women we should develop a discourse "that will enable us to account for the subversion of potential rebellion" and "allow us to confront the mechanisms by which the subject becomes enmeshed, at times, into collusion with forces that sustain her own oppression".

\section{Postmodernism}

There is a considerable debate in the feminist literature about the linking of feminism and postmodernism (Alice 1998; Braidotti 1990; Flax 1990; Shildrick 1997; Stanley and Wise 1993; Strickland 1994), and it is clearly a debate that will continue, adding to the diversity and energy of feminist theorising. Strickland (1994, 266) defines postmodernism thus:

Postmodernism rejects humanist appeals to a universal subjectivity or human condition. ... Instead postmodernism offers a theoretical celebration of 'difference', partiality and multiplicity. It opposes the search for coherence and a desire for 'the right answer'. It suggests instead the continuation of 'conversations' - conversations having no given goal or end, and not aiming at a single representation of reality.

As with the work of Foucault, there are many points of similarity between feminism and postmodernism. However, for my research I particularly focused on their shared 
concern in relation to power, particularly the power invested in the academy which validates knowledge, and which in the past has valued and reified the concepts of neutrality, objectivity and generalisability. Both feminists and postmodernists regard these claims as spurious, reflecting the views of powerful men, universality being no more than the imposition of the ideals of masculinity (Flax 1990; Nicholson 1990). Modernist claims to universal truths and the place of science have been challenged and reinterpreted as a male instrument of power responding to the historical imperatives (Parker 1997).

A concern with power has been at the very heart of feminist thinking for many years. What postmodernism has contributed is the notion of power being seen as discursively constructed. Rather than being an oppressive force that requires a victim, this notion of power acknowledges the shifting, changing nature of power. Shildrick $(1997,115)$ notes "...what becomes possible is to speak of power, not perhaps in the sense of monolithic structures, but as a field of forces held together in shifting but temporally analysable contestable configurations". The power relations within a hospital and within any specific area of the institution can, therefore, be considered as formed by many discourses, medicine, management, patients, and nurses. Annette Street $(1995,51)$ addresses this directly in nursing and nursing research, thus:

Nurses find themselves continually enmeshed in contradictory and fluid power relations with medical staff, patients and clients, their families and significant others, and with other members of staff. Nursing research needs to take account of these relationships as well as highlighting the power relations exercised in the context by the presence and interventions of the researchers.

Also, postmodernism, while acknowledging the pervasive and inevitable existence of power, recognises fluidity and allows for exploration of the shifts and changes in 
structure. Susan Bordo $(1989,15)$, in her discussion on the usefulness of Foucault's concept of power, supports the view that power need not be seen as negative, stating that ".... we need analytics adequate to describe a power whose central mechanisms are not repressive but constitutive". As Foucault $(1990,136)$ says, "A power bent on generating forces, making them grow, and ordering them." We need to analyse power from our position below, to question the practices that seem to have us accept, as women, norms and practices that support oppression (Bordo 1989).

It is quite evident from the literature that feminist theorists have an ambivalent relationship with Foucault, some rejecting many of his ideas. For example Nancy Hartsock (1990) criticises Foucault's theory of power on the basis that all theories of power grow out of, and reflect, certain epistemologies. Consequently a theory of power for women, although again having to confront the idea of 'women', will not come from "the perspective of the dominator" (Harstock 1990, 165), and Hartsock goes on to outline areas that need to be considered when exploring a theory of power for women. However, although I acknowledge Hartsock's argument and agree that a theory of power for women must come from feminist epistemology, still I believe that the notion of power as it is formed by the inter-play of competing discourses and the concept of resistance to those discourses, as described by Foucault (1990), is very useful for exploring nursing practice in a particular area. Consideration of the nature of power in my research with the nurses in the gynaecological ward seemed essential in relation to how we see ourselves as nurses, how we see our practices in relation to other discourses within the hospital setting, and the influence we think we may, or may not, have in given situations. 
It seemed to me that postmodernity's recognition of partiality, "with its apparent attention to difference, diversity and locale" (Strickland 1994, 266), and the inability of one to speak for another, fitted with feminism's concern with the avoidance of universalism. However, there are still differences between feminism and postmodernism, particularly in relation to difference, as discussed earlier, and the feminist critique that confronts the extent to which recognition of difference and plurality in postmodernity can be an end unto itself, avoiding any action or change in the power relations inherent in the concept (Strickland 1994). This is problematic due to the usefulness, in the past, of the collective term 'women' as a unifying label for the purposes of action focused on change in women's lives. Now recognition of the individuality and difference of women's positioning, and how this can be interwoven with collective action, is being debated within feminist theory (Lorde 1992).

However, for me the combination of feminism and postmodernism was one which enhanced the research process. Postmodernism allowed a different way of looking at practices rather than just the nurse as oppressed, because of the consideration of the discourses enmeshing and inscribing the practices. Nurses shift within and between discourse on an individual and group level. Many individual nurses may not see themselves as oppressed but may recognise that their position changes in relation to situations and events. In terms of the plurality of postmodernism nurses work across many boundaries as Judith Parker $(1997,22)$ says:

The nurse in this sense is hybrid, able to speak the voices of medicine, nursing, institution and patient. Rather than being confused or disorientated by this multivocality, the nurse can assume a position 
'in-between'. It is from this place that new understandings and previously hidden dimensions of nursing may emerge. ${ }^{2}$

This journey through certain areas of feminist epistemological thinking enabled me to develop a specific approach for exploring the way that nurses positioned themselves when working with women in the gynaecology area. Although I would not at this stage name myself a 'postmodern feminist' or a 'standpoint feminist', a combination of feminist theory and postmodern ideas will inform my exploration of the reality of nurses in the gynaecology ward. This exploration has clarified my focus on the subjective reality of women working as nurses within the discourses that support and maintain gynaecology as we know it. Nurses can be seen as enmeshed in a service with a long history of being structured by male medical practices which function to disadvantage women, including themselves. Although their work as nurses can be interpreted as discursively constructed they are embodied as women and I became intrigued about the implications of this in the day-to-day world of practice. Thus the feminist notions of the Other, difference and the centrality of the body, linked with notions from postmodern thinking, provide a specific lens through which to view the actual process of interpreting the texts resulting from my time with the nurses. My epistemological reading provided me with a philosophical base from which to embark on the physical experience of being with the nurses. Developing the actual methodological strategies to explore the reality of the nurses became the next consideration in my study.

\footnotetext{
${ }^{2}$ I interpret the idea of speaking the voice of the 'patient' here as referring to the nurse's role as advocate, for example in the situation of unconscious, confused or seriously disabled patients.
} 


\section{Chapter 5}

\section{Feminist methodology: one woman's way}

feminist research project accepts certain philosophical principles which are
made explicit and adhered to throughout the study. It is the commitment to these principles that makes the research feminist. The theoretical position taken by the researcher shapes the study as feminist and this position is supported by the explicit strategies chosen by the researcher when undertaking the research. Feminist research does not require the researcher to adhere to a specific set of research strategies, as Shulamith Reinharz $(1992,243)$ says:

Clearly, there is no single "feminist way" to do research. There is little "methodological elitism" or definition of "methodological correctness" in feminist research. Rather there is a lot of individual creativity and variety ... Feminist research is amoeba-like; it goes everywhere, in every direction. It reaches into all the disciplines and uses all the methods, sometimes singly and sometimes in combinations.

Feminist research, in which women explore the lives of women, has developed in response to positivist science and its fundamental commitment to concepts such as objectivity, neutrality, and truth (Nielson 1990). Feminist research is fundamentally value based. Women's reality and the experiences that shape that reality, are considered different from those of men, and there is a fundamental belief in the oppression of women, although this will be experienced differently, reflecting the difference in each woman's positioning (Stanley and Wise 1993).

This chapter describes then the methodology I used to explore the topic of nurses nursing women in the gynaecological ward. The chapter reflects the feminist principles I have 
adhered to when doing my research and consideration of the ethical issues is interwoven throughout. I have included a description of the context within which the study took place, the participants, and the methods used, including the factors which affected the implementation of my research strategies. Specific strategies for addressing authenticity are also described and discussed. Reflexivity is of central concern in feminist research. Reflexivity is defined by Mary Fonow and Judith Cook $(1991,2)$ thus "by reflexivity we mean the tendency of feminists to reflect upon, examine critically, and explore analytically the nature of the research process". I have endeavoured to integrate the notion of reflexivity throughout my work and in this chapter I do so by addressing issues related to the research process as they arise.

In accordance with accepted feminist research practices and as part of the reflexive process, the researcher is included as a participant in the study. Throughout this study I shared the experience of being a woman and a nurse (although I am not an expert in gynaecological nursing). Sharing these characteristics allowed for the establishment of a reflexive dialogue between myself and the participants, which incorporated disclosure and the sharing of knowledge. As Cook and Fonow $(1990,73)$ state:

Understanding the common experiences of women researchers and women subjects in a society characterised by a marked degree of gender asymmetry enables the feminist researcher to bring women's realities into sharper focus.

In this research I believe my positioning allowed me to bring the nurses' reality into "sharper focus".

As feminist research is multi-disciplinary in its approach to methodology the choice of specific methods is made based on the disciplinary background of the researcher, the scope 
of the project and the strategies which seem most appropriate for the topic being researched (Jayaratne and Stewart 1991; Reinharz 1992; Stanley and Wise 1993). For me, an important methodological issue was to choose strategies that would capture the textuality: the lives and experiences of the nurses' embodied practice. During my refresher experience when I worked alongside registered nurses in the gynaecology ward, I was confronted with the complexity of nursing practice and it was apparent that action, reflective thinking and context all interacted to shape practice. This situation persuaded me that a research design that allowed for the observation of nursing practice, in-depth discussion of issues, and the examination of the philosophies shaping the context, was essential. Therefore, to explore the experience of nurses nursing women in the gynaecological setting, I used a qualitative research design informed by my feminist theoretical position, and chose the data collection methods of participant-observation with indepth interviews, supported by a personal journal and fieldnotes.

As a feminist researcher, I was very aware of the notion of reciprocity, that the nurses were making possible this research, through which I would gain a post-graduate degree. Because the nurses were busy and their work at times stressful, I felt strongly obligated to them and wanted to offer something back to show my appreciation. I also felt that this was important in terms of the power implications for research participants, I was coming in as the person with research knowledge but perhaps the nurses could find a use for my knowledge that was important for them. I also felt that offering my research skills for the nurses to use contributed to the transformatory possibilities of the research in that nurses could develop knowledge about the possibilities of nursing research, an activity not normally undertaken in the gynaecological area. This knowledge could also give them power in terms of exploring some aspect of their practice that was important to them in this 
area. Therefore, at the time of discussing the proposal with the nurse leader in the area, I asked if there was any way in which I could be of assistance to the nurses. I discussed with her the level of my research knowledge and on the basis of this I was asked to assist the nurses with a small research project of their own, asking the women using the service what they felt about the nursing care they received. In this way I could contribute by making my research skills available to the nurses and enabling them to carry out a project they considered important for developing their practice. It was organised so involvement in the nurses' project occurred outside the time I was in the area for the data collection part of my research. This enabled me to focus on the needs of one project at a time.

Throughout the study I endeavoured to be as accessible as possible to enable the nurses to raise any issues with me about the nature and purpose of the research, and I was honest and open about the decisions made regarding the research and about my own limitations. I constantly reviewed my own behaviour to ensure I treated all the women I was in contact with, with respect and that I did not undermine their knowledge and expertise in any way. I was determined to show by my interest that I valued their work in this area. As part of this, the contribution of the participants will be recognised in all subsequent publications which report the findings of this research.

Feminist research of any sort considers the participants in the study as co-researchers, and strives to ensure, as far as possible, that they are active and equal members of the research process (Fonow and Cook 1991). This approach, with the emphasis on non-hierarchical and collaborative relationships, means that the participants must be consulted throughout the study. I attempted to foster a consultative and collaborative approach, which was possible during the data collection and analysis phases, when there was a sharing of 
information and discussion of the emerging areas of interest. However, I am responsible for the interpretation and final overall preparation and presentation of the thesis, something of which the nurses were well aware. Although they had collaborated, the study was in reality 'mine' as I had chosen the topic, determined the theoretical orientation and the appropriate methodological strategies. I do believe that the relationship between us was relatively reciprocal, particularly as I was not an expert nurse in the area and was content to assist the nurses at their direction in everyday, practical aspects of their work. The fact that I am a registered nurse and a nurse-educator was consciously managed when I discussed my research with the nurses. At the time of undertaking the research I was not involved in teaching any of the registered nurses from the ward.

\section{The locale}

This research was undertaken in the gynaecology ward of a large urban hospital in New Zealand. The ward is situated in a block that currently includes post- and ante- natal wards, delivery suite, the neo-natal unit, several medical wards and the gynaecology ward. The rationale for putting the childbirth facilities and gynaecology services together is the link with women's reproductive systems, either functional or dysfunctional. However, in reality it appears that it has more to do with the needs of the doctors. The situation of this ward can be reinterpreted as an example of the institution being arranged to suit the predominant discourse, that is the doctors and particularly the needs of the specialist obstetrician and gynaecologists. Because of the conditions that result in women being admitted to the gynaecology ward, a large percentage of the patients go to the operating theatre for surgery. Gynaecology is, therefore, considered a branch of Surgery. However, because the gynaecologists are also obstetricians a lot of 'their' patients are in the obstetric areas of the hospital. When a specific Women's service was 
established in a separate building in this particular institution it was thought it would become a centre for all women's health services and, therefore, gynaecology was located in this particular building. However, all women's illnesses that required surgery, particularly breast surgery, were never relocated.

The interesting factor in all of this is the requirements of the surgeons. Either the surgeons involved in breast surgery would have to walk to another block to see the women, or the gynaecologists would have to walk to the surgical area to see the gynaecological patients situated away from their obstetric patients. As a consequence, it appears women needing breast surgery stayed in the general surgical wards so the general surgeons would not have to walk across to the Women's block, and women requiring gynaecological surgery stayed next to the obstetric wards so the gynaecologists would not have to go across to the main hospital. However, the result is that the women having surgical procedures and the nurses that accompany them from the gynaecology ward, must go across to the operating theatres situated in the main hospital block. This journey takes 20 minutes in total, involves going down to the bottom of the block and through an underground tunnel (not pleasant during the night). Now, due to the reduction in inpatient obstetric care and the relocation of medical wards in to the block, the lift service has improved. Initially the journey involved three trips in lifts all adding to the discomfort of the women. The time out of the nurse's day, if she has four women going to theatre, is considerable and impacts dramatically on her practice. Needs of the women, either as nurses or patients, seem subsumed by medical and institutional needs.

Women are admitted to the gynaecology ward for either acute or planned admissions. A woman who has a planned admission is usually having surgery and has been through 
the pre-assessment clinic, where a routine physical check, including tests such as blood typing, is carried out. Once a woman has been notified of the date of the planned surgery she arrives in the ward at the specified time.

At the time the research was undertaken, women who were acute admissions to the ward had usually consulted their General Practitioners due to symptoms such as pain and/or unusual vaginal bleeding. However, as a nurse remarked, any condition that could be connected to a woman's reproductive organs, no matter how remotely, seemed to result in their being admitted to the ward. The reason for this may be that women being admitted acutely to the gynaecological ward do not go through the normal process of being seen in the Accident and Emergency Department first. This change was made in recognition of the very personal nature of gynaecological conditions. It was considered inappropriate for women to have vaginal examinations and be asked very personal questions related to their reproductive systems, in the essentially public space of the Accident and Emergency Department. Until recently the standard process for women being admitted acutely, was that their General Practitioner contacted the doctor on call in the hospital, discussed the woman's symptoms and if they agreed she required hospital services she was told to go directly to the ward. At times, particularly if the doctor on call was busy, s/he forgot to inform the nurses on the ward and they were frequently put in the difficult and embarrassing position of knowing nothing when a distressed and anxious woman arrived in the ward. This process was under review at the time of the research and subsequently a women's assessment service has been established, where women are assessed before arriving in the ward. This has resulted in a lessening of stress for the nurses in the ward in that a number of women do not have to be admitted, but can be treated in the Assessment clinic. However, this new service is 
not available for the 24 hours consequently after hours the women still go directly to the ward.

At the time I undertook the study the ward was staffed with fourteen FTE (full time equivalent) women, staff nurses. In fact this was made up of one Charge Nurse/Nurse Leader, ten full-time staff-nurses, six part-time staff-nurses, one part-time enrolled nurse and one hospital aide. Also, there is a ward clerk responsible for the management of documentation including patient records, and general duties such as answering the phones, and one regular cleaner. Both the ward clerk and the cleaner are women. The doctors are arranged in three teams headed by the gynaecologists and include registrars, house surgeons, trainee interns and the occasional fifth year medical student. There are seven gynaecologists two of whom were women. This has recently changed and there is now only one woman. The registrars, house surgeons and interns all rotate for periods of time and can be all men, all women or a mixture of both, depending on their rostering.

\section{Meeting Rose, Sarah, Rachel, Alice, Henrietta, Isabelle, Audrey and Bridget}

The women in the research were registered nurses who worked in the gynaecological area and were willing to be involved. When undertaking qualitative research determining an appropriate number of participants requires careful consideration (Sandelowski 1995). Although qualitative researchers are not concerned with generalising their results to larger populations, still there is a need to ensure that the number of people involved in the study will provide the range of data needed to meet the aims of the research. Margarete Sandelowski $(1995,180)$ raises the issue of having too large a group of participants which she feels may be inappropriate due to the "microanalysis demanded by certain kinds of 
narrative and observational studies". In reality this concern for the appropriate number of participants is then mediated by practical considerations such as the number of, in my case, nurses who where willing and able to take part in the research.

Initially I thought that it would be more appropriate if the nurses in the study had worked in the area for some time. However, once working in the area I realised that the important issue was to have nurses who wanted to be in the research, and that all the nurses, no matter how long they had been in the area, had their own thoughts and opinions which they could contribute to the study.

The idea of the study was first explored as a possibility with a senior nurse in the area. It was important that research would be considered worthwhile by the women who worked in gynaecology and that, in principle, they thought the research could be useful to them as nurses. I was drawn into the area and felt very clear about the possibilities of research but could not proceed unless the nurses also felt positive. I was aware that the way I presented the study would influence their views but repeatedly I was told that they would be pleased to have the research being undertaken in their area. The idea that a nurse wanted to explore the practice of nurses in the area for a major post-graduate research project seemed important in terms of validating their work.

Once the nurses agreed in principle, I went through the formal channels required of any researcher. I gained consent to undertake the study from the Victoria University of Wellington Human Ethics Committee. On the basis of this consent I approached managers of relevant hospital services to request access to the gynaecological area. This access was granted on the basis of the proposal and I then submitted my proposal to the local Regional 
Ethics Committee of the Health Funding Authority and, after gaining permission from the Head of the Obstetric and Gynaecological medical team and making several minor alterations to consent forms, approval to proceed was granted. A copy of the approved proposal was also given to the Charge Nurse of the area.

Once I had formal permission to proceed with the research I arranged with the Charge Nurse to visit the ward to explain to all nurses the nature and purpose of the study. The most convenient time to do this was at the nursing handover between morning and afternoon duties. Also, because the nurses working on this ward were all expected to rotate their duties, including night duty, most nurses would be on a morning or afternoon duty over a period of a month. I attended the afternoon handover on a series of occasions and discussed my project, what I would be doing and what I hoped to achieve. At this time I also handed out the information sheet I had prepared for nurses (Appendix I), and showed them the consent forms (Appendix II). As the researcher I was working at following accepted practices for gaining consent but I realised that this seemed much more of an issue for me than for the nurses, as I recorded in my journal:

As I said I would, I discussed my project with the nurses at changeover meetings. I showed them the information and consent forms. At the end of the meeting they were chatting away to each other and busily signing consent forms in a very offhand way! I then realised I had a problem about who had witnessed who, another Ethics committee requirement. The charge nurse then said: oh well, I'll sign them all, I know you told them and they weren't made to be part of it [the research]. Because of this I will ask each nurse again when I work with them or interview them, to sign another consent form (Journal 1996).

When I started my six week period of data collection I approached individual nurses through the intermediary of the Charge Nurse, she would approach the nurse for me to see if she would agree to be a participant. On reflection, I should have asked a staff nurse to 
make this initial approach, particularly to the more recently graduated nurses. The experienced nurses were very clear about their support of the research and I felt they had the confidence to choose not to be in the study if that is what they preferred. However, for the newer nurses, being asked by their Charge Nurse may have had an element of coercion about it, they may have felt uncomfortable about refusing. As I noted:

There is a power issue in terms of the nurses who are positioned in a more vulnerable place compared with the more experienced nurses. I think it is an issue you have to think of carefully when choosing an intermediary. If you choose a person who has some seniority, and therefore some power over the person it may be even more of a problem than if the researcher asks directly. The best thing would be to ask an equivalent staff nurse to ask for you (Journal 1996).

Because of this I endeavoured to check out regularly how each nurse felt about her participation, particularly as being in the study would involve me working alongside the nurse. This was something the experienced nurses did not appear to be the slightest bit bothered about but which I thought the new nurses might find difficult due to feelings about having their developing expertise 'evaluated'. The hesitancy on the part of these nurses related to their beliefs about whether they 'had anything to say', and the value of their contribution, they felt being asked to be part of the research was positive. In fact they were just as perceptive and able to express their thoughts and feelings about their work and the gynaecological area generally, as the more experienced nurses.

The number of participants in the study was dependent on the registered nurses that were willing to have me work with them during their normal duty time. All of the nurses that were part of the information giving sessions were interested in the research which I felt was very positive. Subsequently, I chose to approach particular nurses on the basis of their willingness to be part of the research and because of their experience in the area. I also included two recently graduated nurses in the study as I believed they had the ability to 
contribute valuable insights due to their newness to the gynaecological area. As a result I had eight nurses in the research which, in relation to Sandelowski's (1995) discussion, seemed an appropriate number of participants who could provide the relevant data for the study I was undertaking.

The New Zealand health system is small and separate gynaecological services are only available in some hospitals, therefore, in the interests of confidentiality the name and location of the hospital have not been included. Also, to try and ensure that the nurses would not be identified, their names have not been used in any documentation related to the research, and personal details, such as age or ethnicity, were not recorded. Nurses were asked to choose a name for me to use as a pseudonym throughout the research and any subsequent publication. Most participants were a bit unsure about choosing their name and several put a lot of thought into the choice. My participants subsequently became known as Rose, Sarah, Rachel, Alice, Henrietta, Isabelle, Audrey and Bridget. No participant was aware of the name that another had chosen, although it was impossible for the nurses not to be aware who was formally taking part in the study due to their close working relationships. By the end of the research three nurses, Rachel, Rose and Bridget, were no longer working in the area and two of these were not contactable for the final stages during the writing up of the work. Participants gave permission for me to quote verbatim from their transcripts to support conclusions being drawn from the data. However, if a nurse used the names of patients or doctors, or included any other identifying details in their interviews, these were all changed and other health professionals are only referred to by their designation, such as trainee intern or house surgeon. 


\section{Being with the nurses}

Determining the specific methods for this study was a challenge. Neither feminist nor postmodern literature provides a neat package of predetermined research methods. Also, in nursing research there is no specific methodology that is characteristic of the discipline, instead there is the possibility of choosing from a wide range of social science methodologies and methods to undertake a study of this nature. Finding the most appropriate way of exploring the area under study is turned back on the researcher. For me it seemed that the research techniques of participant-observation and in-depth interviewing, which are frequently used by feminist researchers (Holloway and Wheeler 1996), would be most appropriate for my project. These strategies allowed me to immerse myself in the work of the nurses, to see what their working reality consisted of and to talk at length and confidentially with particular nurses, to explore personal thoughts and experiences.

Participant-observation seemed appropriate for my research as it would provide me with the opportunity to understand the context within which the nurses worked. Carol Grbich $(1999,124)$ describes the data gained through participant-observation as "firstorder data" as the researcher is collecting the data as it occurrs. This is differentiated from the data gained during an interview which reflects the participant's interpretation of any given situation. For the purposes of my study I felt gaining my own perspective of the context was important and would also inform the interview process through the questions raised during my observation. I was not undertaking traditional participantobservation used most often in ethnographic studies where the aim is to develop a dense description of culture, rather the data gained through my time of being in the ward 
would be used to add another dimension to my understanding of the nurses' reality. This led to my spending six weeks with the nurses at times that were suitable for them.

To support my strategies of in-depth interviews and participant-observation with the nurses, I also wrote up fieldnotes related to each period of participant-observation and kept a personal journal for recording my interpretation and analysis of the experience. Using multiple methods of data collection ensured that major aspects of the topics were explored and this triangulation of methods can support the validity of the conclusions drawn from the data (Denzin and Lincoln 1994). The journal was invaluable for highlighting issues that I would then 'check out' with the nurses the next day, and for my early speculation about the data which began the analysis process. As a nurse I was readily accepted in the area and was included in many of the nurses' general discussions about their work and their feelings about practising in the area. Talking to nurses that were not formally in the study was an inevitable part of my involvement as a nurse-researcher in the area. Notes related to these discussions were included in my journal but no direct comments from these nurses were used. When recording fieldnotes or journal entries I would often include interpretive notes in relation to my own feelings about the situation I was discussing and any impact on me as a researcher. Consequently these writings often contained the beginnings of my analysis.

\section{Nurse-researcher as participant-observer}

Participant-observation, usually associated with anthropology and ethnography (Atkinson and Hammersley 1994), is used by researchers in many other disciplines including nursing (Christensen 1990; Clare 1991; Street 1992). Although it is usually thought of as a data collection method, authors such as Paul Hammersley and Martyn Atkinson (1994, 249) 
believe that it is impossible to separate oneself as researcher from the world and therefore "from this point of view participant observation is not a particular research technique but a mode of being-in-the-world". Annette Street (1992) and Judith Christensen (1990) both used participant-observation to explore nursing practice in acute areas of large hospitals, Street as part of a critical ethnographic study, and Christensen to develop grounded theory related to nursing in the acute surgical setting.

Participant-observation is considered as being on a continuum, the complete observer at one end and the complete participant at the other (Reinharz 1992). For this study, the role of participant-observer was most appropriate due to my, like the participants, being a registered nurse. Also, because I had previously worked in the area, I thought it would be impossible for us all to pretend that suddenly I was not a nurse. I worked alongside the nurses which enabled exploration of practice and, in return, was of assistance to the nurses, thereby contributing to the development of a more equal and reciprocal relationship in accordance with the principles of feminist research (Stanley 1991). My earlier refresher experience was structured in this way and the registered nurses whom I worked with were positive about the experience.

My participant-observation took two forms, at times I would be in the ward and not be working alongside any particular nurse, and at other times I would formally negotiate to work with the nurses in the study. The nurses were very welcoming when I was in the ward and included me in the rituals of morning and afternoon tea, the between duty handover, and some teaching sessions arranged specifically for the nurses. To work formally with a nurse I discussed when it would be appropriate to work with her in relation to rostered duties, and any other responsibilities she may have, such as helping in another 
area or attending inservice education. When arranging to work with the nurse I would again verbally check consent, and that she was comfortable about my being with her, I would check this again at the actual time we worked together.

It was clear from my first few occasions of working with the nurses that my presence altered their way of working in that they had to allow for my presence in all their activities. I made it as clear as possible to the nurses that I respected their knowledge and expertise in working with patients, and that at any time they could ask that I did not accompany them or that I leave a situation where my presence was inappropriate. In fact the nurses did not ask me to do this. However, this may have been because on several occasions I immediately saw that my presence was making a situation awkward, that I was intruding and my presence could influence the care of a patient by preventing a relaxed and intimate exchange between the nurse and patient, and I withdrew. On several occasions when patients were upset I was aware that they were visibly trying to 'pull themselves together' when I entered the room, a situation that made me feel very uncomfortable due to the strain it could put on the women. This was a dilemma in that I was there to observe the nurses' practice yet it was absolutely inappropriate at times. This made me question whether, because of the ethical implications, we can ever research these intimate moments in nursepatient relationships, which has important implications for the exploration of the hidden moments of nurses' work. Whenever the nurse I was working with was involved in patient care she would verbally explain to the patient that I was doing research, that I was interested in the nurse's practice, and ask the patient if she agreed to my presence. 
The more experienced nurses had little trouble in accommodating me in their working day. However, for the new graduates it was more difficult. I noted an example of this in my journal:

Isabelle stated that she was nervous and she did seem to have more trouble with where I fitted in terms of the whole business of herself, me and the patient. Several times she asked for my advice, luckily about things that were ok such as blood pressure readings and assessing a wound. I asked her for information to try and make the relationship seem more equal and it felt as though things were easier at the end (Journal 1996).

Because of the strain that my presence put on the nurses, particularly the newer nurses, I did not work with the nurse for a complete duty, rather I would work with them for a period of time often during the busiest part of their day, and discuss issues as they arose. However, although not remaining with a nurse for the whole duty, I usually stayed in the area at least for the period of a complete duty. The times I did not stay were when the ward was very quiet with few patients, and little patient care was being undertaken by the nurses.

The use of participant-observation led to some very real ethical issues. As a nurseresearcher my use of this form of data collection placed me in a very ambiguous position. Sally Borbasi (1994, 1995), Jocalyn Lawler (1995) and Trudy Rudge (1995) discuss the difficulties of this positioning and believe that nurses are in a unique situation when undertaking research in the clinical setting. As Lawler $(1995,57)$ says:

Nurse-researchers, compared with researchers from non-practice disciplines, operate from a qualitatively different base and within a more open set of parameters when they enter a given field to conduct research, particularly a clinical setting; this can be both a strength and a source of discomfort.

I was a nurse working alongside nurses, the nurses and I had to work with the ambiguity in my roles which led to some interesting points of construction. Initially I was anxious 
about the role of researcher versus practising nurse, although from a patient safety point of view I was very clear that I was not in the area as a practising nurse as this could have raised serious legal implications for both myself and the ward. Although a registered nurse with some experience in the area I was not an official staff member, I was a sort of hybrid nurse, a marginal occupier of the role. The nurses considered me a nurse, and it was quite clear that although I was carrying out research, I was firmly constructed as a temporary member of their group. This was born out by Audrey when, in response to a doctor's query about my presence, she replied, "Oh don't worry about her, she's one of us."

One of the important aspects of my nurse-researcher role was the familiarity with which the nurses treated me. Once I had established a rapport with the nurses and other workers in the area such as the allied staff, I was considered to have the same rights as the nurses in terms of being party to their personal and work related discussions and their sharing of confidences. However, my position as a nurse and a researcher meant I was also marginal and Other even within the nursing structure. I worked in the space between self and other, a situation Michelle Fine $(1994,75)$ describes as the "hyphen", a difficult position "uncomfortably engaged in ethical decisions about how deeply to work with/for/despite those caste as Others and how seamlessly to represent the hyphen". I was at once a researcher and a nurse, in fact more often constructed as a nurse, by the nurses in the area. The role of researcher was marginal and could have been considered deviant by the nurses, not what a nurse does. However, their construction of me in a nursing role made me 'knowable'. This led to an issue related to the ethics of participantobservation in such a setting. I was in a privileged position, constructed as a nurse and therefore immersed on a daily basis in the concerns and practices of the nurses which led to my knowing confidential information related to the patients who were not part of my 
study, details about current management issues in the area and a variety of daily concerns. This situation was impossible to avoid, particularly as I had been asked to assist with research guidance related to the nurses' own research project. My strategy to deal with this situation was to be very clear about what I collected, what became the textual data for this study.

Slowly, after several periods of time spent in the ward, the nurses came to fit me into a position that they found acceptable. A journal entry (1996) shows the way this was managed, and the manner in which the role I made for myself was accepted by the nurses:

I have been in several situations where my not being a member of the nursing staff has been obvious but I don't feel it is a problem. The nurses now joke about it, as one nurse I was working with yesterday said: oh, she's a polytech, you can't ask her anything. It sounds rather unkind but in the context it wasn't and caused a great deal of laughter. Even a member of the non-nursing staff passed the comment that a visiting registered nurse was great to have around: she was like Annette only she worked! I replied that I was exhausted after watching someone doing a dressing! Again the exchange could be interpreted as a bit "rough" but was very funny, provided a great deal of hilarity and showed a relaxed acceptance of me. I have had no trouble drawing the line as nurse and/or researcher so far. I will fetch and carry for the nurse I'm working with, I make beds, get fluids, help women in and out of bed and to the toilet; in other words I assist with body type care, no technology. Any situation where I think I would be unsafe, put either the woman or the nurse at risk, I just say that I can't do it as I'm not there as a nurse, and that both the nurse and I would be in strife if anything went wrong. The nurses seem to respond positively and are clear what I am doing in the ward. Working alongside them is a real pleasure.

I was also very aware of the ambiguity of being a nurse and a researcher in my own mind.

This became especially obvious at times like duty handovers, when the nurses went through the details of patient care. I would mentally slip and slide between researcher and nurse, starting off by observing the handover process as an example of nurses reflecting their reality and beliefs about the women they cared for, but quite quickly I would be 
drawn into the detail of nursing women with particular conditions and pondering the appropriate strategies for care. This also occurred when working with the individual nurses, I would be a researcher at one moment but the next would be drawn into the intricacies of a new technology, or a new way of treating a certain gynaecological condition, or be having a long conversation with a patient about topics such as the problems of settling children into school. This also seemed to relate to the self and other dynamic: which was my 'self' and which was my 'other'? As a woman researcher, exploring the practice of women as nurses caring for women, I found my position to be a slippery one, one moment experiencing myself as researcher, the next as a nurse working in the area, and the next empathising with the personal experiences of the women. This highlighted the inadequacy of notions of objectivity and neutrality, I could not conduct this research in any way other than located as a woman connected to the reality of the lives of the women in the study, a position that irrevocably mediated my conclusions. As Anne Williams $(1991,74)$ says in relation to her research with nurses:

Boundaries between researcher and researched are not so easily drawn in my experiences of fieldwork, nor are they, I would suggest, so easily drawn where ethnographers share sex, race or occupational backgrounds with those researched. Of course there will be differences. Nevertheless there will clearly be important similarities of experience and orientation which, when taken into account, will challenge taken-for-granted assumptions about where boundaries between researcher and researched should be drawn.

On a number of occasions, I was involved in quite lengthy discussions with nurses who were not being formally interviewed for my research. Speaking of events related to their immediate experience was important for the nurses and I could not withdraw my support under the guise of being a researcher and only interviewing certain staff. For me, being able to undertake the study was dependent on the good will of all the nurses and I could not have functioned in the area if they did not feel comfortable about my presence. In 
return, I respected their wish to talk, to discuss and to explain important elements of their practice, their comments were insightful and added to my knowledge and understanding of the area. My attention to all the nurses' experience was an important part of the affective: the relational, dimension of the research.

As a participant-observer in the gynaecological area, part of ensuring that I was accepted by the nurses and the patients was attention to how I presented myself. The nurses in this area can choose to wear their everyday clothes, rather than a uniform, on duty. The more mature nurses who have worked in the area for some time usually wear a uniform because they are used to it, and felt it was more 'hygienic' in relation to getting material, such as body products, on their own clothes. The younger nurses wear their own clothes more frequently, the decision often being made on the basis of practicalities such as just climbing into a uniform without thinking for a morning duty, but being able to take the time to choose clothes when coming on duty in the afternoon.

Whatever they wear, the constant in the nurses' presentation was their New Zealand nursing medal, the distinctive five-pointed star, which all wear pinned to their clothes and which singles them out from other personnel. I decided that I would wear casual clothes which suited the culture of the area and which did not make me stand out in any way. I also had to decide whether to flag my identity as a nurse by wearing my registration medal as well as the name badge I was required to wear. I thought about wearing my medal for it would show that although a researcher I was a registered nurse. However, I finally came to the conclusion that wearing the star would be highly inappropriate for a number of reasons. Although $\mathrm{I}$ had been given permission to be in the area, it was as a researcher, I had not been given permission to be there or act as a nurse, yet seeing the badge could set 
up expectations related to my ability to perform nursing tasks on the part of the patients and other health professionals. This would not have been acceptable as, although I helped out with the basic work of the nurses, I was not there as a staff member, with all the legal coverage of indemnity insurance and Accident Compensation Cover. If I did undertake a nursing procedure requested by a nurse or a patient, which resulted in some harm to either the patient or any staff member, I could have put the staff, particularly the nurses, at serious risk of censure for using a non-staff member for clinical procedures. Ethically, I believed that for the safety of all it was better that although I was frequently introduced as a nurse and identified myself as a nurse, I did not make it apparent by wearing the registration medal.

I was clear that I was not interested in the doctors other than in the way they impacted on the nurses, a situation that seemed to encourage my acceptance by the nurses. I deliberately avoided establishing a relationship with any medical personnel, other than the purely functional to meet the needs of patient care, wanting the nurses to see that my focus was on their reality. This was important to me not only in terms of validating the nurses as central to my research, but also reflects my feminist beliefs in relation to positioning myself clearly as a nurse. As I wrote at the time:

Some of the docs are still a bit mystified [about my presence], but naturally not one has asked me what I am doing, a situation that rather appeals in a way as, although they will be "present" in the study, it is not about them per se, and their natural "distancing" has helped with that (Journal 1996).

\section{The interview experience}

Although I have used the term 'interview' to describe my one-to-one discussions with the nurses, in reality there was considerable individual variation in the process. This raised the issue of categorising these interactions, and whether researchers who are exploring issues 
in depth can ever really ensure, and therefore describe, consistency related to such interactions. The interviews were really extensions of the dialogue I established with the participants and a number of the other nurses, just by being present in the area. The interviews were very much part of the whole process of data collection in that a considerable amount of informal discussion had already been held with the nurses during my involvement in their daily lives on the ward. The interviews and allowed them to talk more freely and at length about their work and their concerns. After the discussions we would often talk further about some of the issues raised, when I was next in the area.

In-depth interviews with the nurses required further written consent. Nurses were asked to sign the consent form after they had read the information sheet and had a chance to discuss any aspects of the research with me. An interesting issue arose with the consent form as I had included a space for a witness to sign, as well as the participant and myself. However, several nurses were very off-hand about this and commented that it was unnecessary, one in particular felt that she was quite able to make the decision on her own without a witness having to agree that no coercion had taken place. Subsequently, I said to the nurses that if they would like to, they could have someone with them when I discussed the project individually and the consent form was signed. At every interview, as on the occasions that I worked with nurses, oral consent was again sought. I explained and reinforced whenever appropriate that participants had the right to withdraw at any time without prejudice. Also, I considered it inappropriate to request in-depth discussions with nurses who were very busy or in stressful situations.

The interviews were very unstructured in that I would commence the session with no specific 'research questions' for each nurse to address. Anne Opie (1992) suggests that the 
issues of empowerment must be addressed in the interviewing process if appropriation of the participant's reality is to be minimalized. I felt that using an unstructured interview approach would allow the greatest freedom for the participant and, therefore, contribute to the nurse's feeling of having some control during the interview process. However, as I worked alongside the nurses in the area, certain issues emerged and would recur in my informal conversations with them. These issues seemed to be of concern to most of the nurses and I would, therefore, at some time during the interview, ask each nurse what their thoughts were about these particular areas. This discussion allowed me to clarify these issues, discuss them in detail and gauge the impact on the nurses. Although the interviews often began with a general discussion of how the nurse came to be working in the gynaecological area, the dialogue from then on became very exploratory with both the participant and myself raising and discussing areas of interest. I also found it important to raise general issues from interviews with other participants, and to explore issues raised in previous interviews with the same nurse. Because of this approach the interviews were what Opie sees as "responsive to individual preoccupations". Opie goes on to say that this gives the interviews a "therapeutic dimension to the process which I would also characterise as empowering" $(1992,64)$. Characterising this provision of time and space for a woman to speak about their reality as empowering is questioned by feminist writers such as Daphne Patai $(1991,143)$. Patai raises the very important point that the interview cannot be seen as a "bracketed moment" (ibid, 144), separate from the issues of power throughout the research. As she says, "By abstracting the interview from the larger social context of the real world, we are in effect returning to discarded research models that situate our research practices outside of reality" (ibid, 145). However in relation to the interview process in this research, being involved gave the opportunity for nurses to speak, something they commented on in a very positive way. It seemed that the positive feelings 
generated by this involvement, although not necessarily empowering, supported the transformatory notions of feminist research in terms of valuing the nurses' insights and experience.

The interviews were held at a time and place that suited the participant, either in a quiet room in the hospital before, during or after a duty, or in the nurse's own home. The interviews were taped, a situation that did not seem to cause the nurses any concern. There was little discussion of the presence of the tape recorder and a number of the nurses wanted to ensure their voices were loud enough for the tape and could be clearly heard. The length of the discussions varied from approximately half an hour, to about an hour and a half, with most of the interviews being around an hour. I had no fixed idea about the length of the interviews and the first three interviews happened to be with senior nurses who had a lot to say. However, the interviews with the newer nurses were not so long and there was a point at which I could sense it was time to stop. I noted my thoughts about the interview process in my journal thus:

I think it may be that different approaches are more appropriate for different people. For example I was unable initially to find a way of gaining perceptual data when I talked to a new nurse and shorter interviews allowed me to go away and reflect on this. I could explore whether it was a problem or more an indicator of something such as where the new graduate is herself in terms of her brief practice experience, her life experience or just an individual difference. I now feel the best approach is to be more intuitive about the process. The interviews will perhaps just fit the situation as it develops, all the senior nurses said how nice it was to talk about their views on nursing in this area (Journal 1996).

At times I realised I could have managed the interview process more competently and an entry in my journal when I began interviewing highlights a particular difficulty and my response: 
There are areas [in the transcript] where I am trying to formulate a question or elicit certain information, that just seems a clumsy mess, I need to be more patient after making a statement rather than trying to reword it in a hundred different ways. I realise this is a "clue", if I say something and the nurse does not respond easily, rather than rewording it may be better to verify the authenticity of the issue itself (Journal 1996).

The interview has been of concern for some time in feminist research and the work of Ann Oakley (1981) is often cited as raising the issue of unequal power relations in the interview process and the implications for the feminist researcher (for example Patai, 1991). Oakley points out that researchers are often required to comment on the detail of the interviewing process but rarely address the interaction between researcher and participant. One way that feminist researchers have sought to ameliorate the potential power imbalance in the interview process is to be open to questioning from the participant and to contribute one's own experience where appropriate (Phoenix 1995). I was very aware of this literature when I began interviewing participants and I was prepared to share any ideas, or thoughts of my own, and answer any questions that the participants put to me. However, my experience of interviewing the nurses in my research was a challenge to my careful consideration of the relationship.

The first three nurses that I interviewed were very experienced in the area and were not at all concerned about being involved in an interview-like situation. It quickly became clear that I was not considered knowledgable about the area, and that they were the experts. Although I did contribute at times during the interview, once the nurses were talking about their experiences they had no trouble sharing their feelings and experiences. The interviews with these experienced nurses were long, and they controlled the information sharing. The recently graduated nurses were more hesitant during the interview process and expressed some nervousness, mainly about the worth of their contribution, and in these 
interviews my own contribution was greater. It was important to reinforce the unique contribution they could make in relation to the freshness of their experience. Because these nurses felt slightly less at ease I carried out several short interviews, the long interviews that I experienced with the other nurses would have felt very uncomfortable for us both and I wanted to avoid any feeling they may have of being pressured. Checking consent at each of these interviews was important to stress the control that they had over the process, although I think in reality the nurses probably would have felt uncomfortable about withdrawing.

Once the interviews were completed they were transcribed. This was undertaken by a woman who had no experience or connection with the area. She was required to sign a confidentiality form and to delete the interview from her computer once it had been safely transferred to my own data base. I then reviewed each interview transcript word for word with the tapes to totally familiarise myself with the material before beginning the structured analysis and to ensure they had been correctly transcribed before returning a copy to the nurse for checking, a process discussed in detail further on in this chapter. Individual nurses in the study only had access to their own material.

The comments made by several of the nurses after the interview was complete, reflected the notions raised by Sally Hutchinson, Margaret Wilson and Holly Wilson (1994), in relation to the benefits to participants of being involved in in-depth research interviews. The nurses frequently stated how nice it was to talk about 'their nursing', how they never got the chance to talk, and that thinking about what they did was interesting. Several of the nurses had recently been involved in further study and were very interested in their own experience of being in a research project. Although I do not believe that interviews can be 
truly reciprocal and that there will always be great diversity in any interviewer/interviewee interaction, it was an important realisation that for the experienced nurses, in terms of knowledge about gynaecology, they definitely felt the power resided with themselves.

\section{Exploring the texts}

As Susan Strickland $(1994,270)$ points out:

Obviously all knowledge is a product of certain specific circumstances the product of a relation between a knower/knowers in certain particular social and political locations, and the "world" as it appears to her/them, mediated by the concepts, codes, discourses at her/their disposal. Any knowledge-claims should thus be seen in relation to the context of their production and not in isolation, as though made "from nowhere".

I believe it is important to acknowledge the difficulty of analysing data when focusing on the textual representation of a lengthy research project of this nature. Even my own writings reflected my position at a particular point in time, a point in time in a way now removed from the final written production of the research. And, certainly, some organisational aspects of the area in which the research was undertaken have changed since I was involved in the formal data collection phase of the study. Therefore, my research findings reflect my interpretation of a situation which I explored with a group of nurses, in a particular context, at a particular time. Returning to the ward at intervals subsequent to the formal data collection period has been extremely important and has allowed me to continue to check the focus and currency of my analysis with key nurses in the area.

The concepts outlined in the epistemology chapter were those I used to explore the texts produced from the interviews, field notes and journal entries. Analysis of my participantobservation fieldnotes and the interview transcripts began when the research began and 
this analysis shaped the research, progressively refining the focus of the study throughout the process, which is an accepted practice for researchers involved in this type of fieldwork (Griffiths 1991). All the data, including my own reaction to the area, was subject to this theoretical reading. The work of exploring the texts resulted in the emergence of three major areas which I have entitled: women working with women, who cares, and power and resistance - nurses working with/in medical discourse. These areas are discussed in three separate analysis chapters which follow.

Analysis of the data in this study was undertaken manually, that is without the use of qualitative data analysis computer software. Initially I did consider using one of the wellknown computer packages such as The Ethnograph, as I thought it could assist with managing a large amount of data. However, eventually I decided otherwise. At first I felt that as a novice using the software I could find myself working the data to fit the requirements of the analysis package. As I explored the option and realised that the analysis software was in fact a system for managing, sorting and coding the data, rather than analysis (Coffey, Holbrook and Atkinson 1996), I felt that for this study I could manage using the capabilities of the word processing software with which I was already familiar. And, as Amanda Coffey, Beverley Holbrook and Paul Atkinson (1996, 8), say, "it is important to avoid the misapprehension that coding and computing lend a scientific gloss to qualitative research". At the point where I began constructing the analysis chapters I was absolutely immersed in the data. Through editing and reading, I knew the interviews and the records of my own observations thoroughly and, as mentioned above, I continued to visit the ward at intervals to explain my progress and to 'keep in touch' with the nurses and the area generally. This enabled me to keep the scene of the research clearly in my consciousness. 
As the researcher I felt I was responsible for constructing an account of nurses' perceived reality in the gynaecological ward which resonated for the nurses. Nicola Armstrong and Rosemary Du Plessis $(1998,109)$ suggest that "the researcher is identified as actively constructing research narratives, rather than as engaged in the transparent transmission of "authentic" or "true" accounts of "real" experiences". In the analysis I endeavoured to avoid what Anne Opie $(1992,53)$ calls the "textual appropriation of the researched", and to attend to "difference as a means of fully representing the complexities of the social world". I took this idea beyond application only to the words of the participants, applying it to my own written words, in other words I tried to represent my own 'differences', my own shifts and changes in thinking. Important then, after the analysis, was to produce a text which showed elements of difference, which made my strategies of interpretation and conclusions, transparent and available to the reader. The difficulty is what is excluded. However, in line with postmodern notions, I believe that research can only ever be a partial representation (Strickland 1994). Surfacing certain issues through a particular lens, in my case that of feminist theory, still has transformatory possibilities for theory development and clinical practice in nursing.

My strategy for managing the possibility of appropriation of the other in analysis, involved working with the text in a way which avoided constructing a universal, cross-surface, representation of experience between nurses, the identification of unifying and consistent themes between participants was not the object of the analysis. What I wanted was to allow for difference and to express the nurses' unique interpretations of specific issues. Similarity in the nurses' experience of the major discourses that shape their lives in this setting was the starting point, but how these discourses were interpreted, constructed and experienced by each nurse, was different. For example, all nurses shared a relationship 
with the doctors in the area but how that relationship was felt and how it affected them was different for each nurse. However, I believe that some degree of appropriation can never be completely avoided by the very nature of research, the researcher in the end is responsible for preparing a text which must meet the academic criteria for, in this instance, a doctoral thesis

\section{Managing authenticity}

In contrast to the misleading and unattainable ideal of transcendent reason and a view from nowhere, feminists have argued that all knowledge is situated and limited by its positioning; that it reflects our social experience, our understanding of our interests and our values; that objectivity seen in terms of political and personal disengagement and value-neutrality is neither possible nor desirable (Strickland 1994, 265).

Because of the issues raised by Strickland, validity is a problematic concept in feminist research. As Caroline Ramazanoglu (1992) points out there is no consensus amongst feminist scholars on the strategies to be used to validate experience, yet women's lives and experiences are at the heart of feminist research. However, validity or authenticity in feminist research must be rigorously addressed and relates to the methodology and the extent to which the research can represent the participant's reality (Fonow and Cook 1991; Lather 1991). Validity in this instance does not relate to issues of replicability as in positivist science, rather my endeavours were focused on ensuring that, although partial, the study had authenticity in relation to the theoretical exploration and the reality for the nurses. It is, therefore, the responsibility of feminist researchers to draw on strategies that are congruent with the principles of feminist research and which, through the process of ensuring transparency, allow the study to be judged in relation to appropriate criteria for this form of research. 
So who in the end is the judge of my work? Who are the people that confer legitimacy? For me as a feminist researcher of women as nurses, it must be the nurses. Although the work will be judged for its academic merit, the final arbiters of the usefulness of my contribution to nursing knowledge will be nurses. I also have a role in legitimation and establishing authenticity in terms of feeling I have represented the voices of women as nurses. For me, the following strategies derived from Patti Lather (1991), and Fonow and Cook (1991), provided a framework for establishing authenticity which incorporated feminist and qualitative research principles. Under each heading I have detailed how I addressed the criteria, and the reality of my engagement with the process.

\section{The nurses' validation}

In reality, asking the nurses to review their transcripts to ensure they felt the material represented their views was not the straightforward process that is discussed in many research texts. After the verbatim transcription of the tapes, I prepared a transcript for the nurses that had minor alterations: some repetition of phrases, for example 'you know', repeated 'ums' and 'ahs', were removed, and the term 'yeah' was replaced with 'yes'. Occasionally it was necessary to insert or delete a word to clarify the point being made by the nurse. Even though these changes were made the nurses nearly all commented on how badly they felt they expressed themselves, it was often the first comment made when discussing the transcription. This was a concern as I felt it had the potential to make the nurses feel inferior about their 'talk' even though I had largely left my own voice unchanged to show the consistency between my own messy use of words and expressions, and that of the nurses. I think this is a very important issue for feminist researchers in the interview setting. Completely editing the transcripts threatens validity of the text, yet subtly ensuring the participants are confronted with what they consider their inadequacy, 
can contribute to a perceived lack of ability and knowledge on their part. This is an important dimension of the power issue in the whole interview process, that is in the reproduction of spoken English as text. As I have written above, in my experience the interview process did not appear to have some of the issues related to power that other feminist researchers have documented, however, returning the transcripts certainly had the potential to underscore the perceived gap between academic nurse and clinical nurse, and make the nurse participant feel unequal.

The other important point that is problematic, is that several of the nurses did not want to read their work. I returned each transcript to the nurse in private and encouraged them to read it at their leisure and to discuss it with me when they felt able. Several nurses were quite clear that they felt they did not want to do this, their reasons remaining private. I felt that this was their prerogative as they owned the material. Again, I felt pressuring them to do this for my reasons was not respecting their feelings and their desire to manage the process of the interviewing in the way they wished. I managed this by discussing the issues that I saw arising from the data collection with them, even though they had not read their own material at the time. The major areas that I wanted to address and the ideas I had in relation to those areas were discussed in detail.

After the initial analysis and the preparation of draft chapters I returned to the area and gave oral presentations of my findings to the nurses. These presentations were done over several days at the duty handover time, to all nurses who were interested. This allowed the nurses who were part of the study to remain anonymous if they so wished, and also was part of validating my analysis by asking if the issues raised resonated with current experiences of nurses in the area. The nurses were consistently positive about my analysis. 
The three major themes of being with women, coping with the emotional nature of their work and the relationships with the doctors, were introduced with some discussion as to how I chose to focus on these areas, including my initial reluctance to explore the nurse/doctor discourse. The nurses at the meetings felt these were genuine issues for them and that exploration would be useful for their practice.

\section{A feminist researcher's view}

All my work was subject to the scrutiny of my research supervisors, one of whom was an experienced feminist scholar. She, along with the participants and myself, were involved in the validation of my interpretation of data, a process of triangulation which enhances the validity of the work. A fellow nurse researcher was also invaluable throughout this process in terms of working through my developing ideas of analysis, she would challenge and critique my thinking in terms of the relevance for nurses. I endeavoured throughout the research process to maintain feminist research principles as my reference point, by this I mean that I would constantly test my ideas against my reading of methodological issues raised by feminist researchers, particularly in relation to power, and by valuing the participants and placing their experiences as central. An example of this is the notion of the nurses' relationships with the medical world. This was an area that initially I was not particularly interested in, there has been a lot of research on this subject from a variety of disciplinary perspectives, as I discuss in chapter eight. However, it soon became very apparent that the nurse-doctor relationship was of central concern to the nurses, they wanted to talk about it and talk about it in detail. I had to reframe my own expectations about the areas that I wanted to concentrate on, and address the nurses' concerns, shifting this issue from the periphery to the centre. This process, although at times personally challenging, ensured that I remained true to the data and the concerns of the participants. 


\section{Maintaining the principles of feminist inquiry}

The supervisors of my research contributed to this aspect of validity by critiquing my feminist positioning, particularly in ensuring that the feminist underpinning of the research was a consistent thread throughout the study. My critique of my personal feminist positioning was also an important part of this, if I believed that feminist critique has a vital contribution to make to nursing scholarship then I felt I must critique my own stance where relevant. Again, the strategy outlined above, of consciously 'checking' my thinking and behaviour against accepted feminist research practice, was critical. Although this criterion relates to having an independent researcher challenging the feminist stance of the research, an unexpected and very positive element in validating my research was the feminist stance of one of the senior nurses involved. She named herself as a feminist and would discuss the issues I raised and those she felt were important, often taking a critical feminist stance. There was no doubt that this nurse felt I was a feminist, that my interest in women, power and nursing reflected feminist principles and that my behaviour and talk reflected feminist ideas.

\section{Ensuring transparency}

The final presentation of my research is written to make explicit not only the research methods, but my positioning in the world and within the research and, specifically in relation to the methods, the reason for their choice. However, it must be recognised that this thesis has been written in a manner that is required by the academy, much of the writing may be difficult for nurses to access. In acknowledgment of the transformatory requirements of feminist research, to make the feminist research process visible I will endeavour to publish my experiences of undertaking the study in ways that will be more accessible to a wider audience of nurses. Although the aim of feminist research is not 
replicability, detail of the research may well assist other feminist researchers, particularly in the discipline of nursing, in the development of their work. The limitations of both my chosen approach and my knowledge are honestly and openly acknowledged.

\section{Contributing to knowledge}

Throughout the time that I have been involved in this journey of exploration I have contributed to the knowledge about both feminist research in nursing and nursing issues in the area of gynaecology, through presenting papers at four conferences and publishing two papers. My commitment to the transformatory and consciousness raising elements of feminist research require me to publicise the results of this research in appropriate media including public presentations. However, I also wanted to make the results known to nurses practising in the area. The first presentation of the results, therefore, had to be to the nurses in the area where the research was undertaken. There were several ways this could be managed and with the support of the nurse leader in the area I have been able to make a positive contribution to knowledge, informed by feminist theory, in gynaecology at a very practical and practice-based level by presenting the initial findings at the first regional study day held for nurses working in gynaecology.

\section{Closure?}

Attending to the closure of the relationship with the nurses in the study and leaving the area is important in any qualitative research (Bernard, 1995). However, this has not been difficult for me as there has not been a point at which I ended any involvement with the area, in fact, I wonder if I will ever terminate the relationship while there are nurses who have been part of this study, working in gynaecology. Because of my role as an educator my continuing involvement in the area is legitimate and my fascination with gynaecology 
is still evident. On completion of the current study into the nurses' experiences I would like to focus on the women as patients, so remaining connected to the area is important. Although I do not visit the area all that frequently, the nurses seem to accept me as part of their world. The nurses I know are always welcoming, interested in the progress of my research and several often mention their interest in the final report. Holding meetings to discuss my findings, as part of the analysis process, has also involved the nurses that are new to the area and raised their awareness of my research, several have mentioned their interest in the project. However, my enmeshment in the ward is certainly less intense and when the data collection phase of the study was completed I discussed with the nurses the fact that I would not be in the area in the same way. As the nurses are busy and mainly focused on their everyday work this did not appear to cause any difficulties. Completion or closure has occurred in relation to my activities of formal data collection, but not in relation to my connection with the nurses themselves.

\section{The nurses' voices}

This chapter has described the methodological structure which shaped my experience of being with the nurses during this research. What follows in the next three chapters is my interpretation of three key areas that shape the nurses reality of working in this particular gynaecological ward. All the data for this research was collected in 1996. Consequently, so as not to impede the reading of the text, I have not included the date with each separate quotation from either the nurses or myself. The key areas addressed were raised and discussed by all the nurses although their experiences in relation to the areas differed. First in 'Women working with women', the nurses' relationships with the women they nurse and with each other is addressed. The relationship between woman and nurse is positioned first as whenever I talked to nurses about their work it was the interaction with their 
women patients that was spoken of first. The second chapter, 'Who cares?', explores the emotional nature of the nurses' day-to-day work and the way this can impact on them as women and nurses. Finally, the chapter 'Power and resistance, nurses working with/in the medical discourse' considers the way the nurses managed their close and at times stressful relationship with medicine as a discourse in which their practice is embedded and with individual doctors. Throughout these chapters the voices of the nurses are heard along with my own, to portray to the reader a sense of their world as it was at that time. 


\section{Chapter 6}

\section{Women working with women}

I really like relating to women, I suppose because I'm a woman myself I feel I can empathise in a number of instances because that's been my life experience too. I feel very much that, particularly in the gynae situation, when a woman comes in to hospital ... I want to make her as comfortable as possible and give her the best time because I think a lot of women need some pampering. I know that isn't necessarily what nursing is about but ... I do feel that this is one opportunity when some women have the opportunity to only think of themselves and to be looked after (Bridget).

It's very different nursing women as opposed to men. Men basically, will just do what you tell them. If you say: 'I'm sorry Mr Jones, we have to cut your arm off and here are six pills you have to take, he'll take those six pills and say: what time is it? Whereas women want to know a lot ... they want to know why things are happening, they want to know what will happen if they don't have this done ... what does this entail ... on the whole they are a lot more demanding I found. But I love this area, it's great (Sarah).

his chapter explores the relational work of the nurses with each other and the
women they nursed. This work is to do with connectedness, the connections with others that nurses sustain and work with in their everyday practice. It is a cornerstone of the nurses' work. The notion of being with women in their roles as patient and nurse, as a central concern in the day-to-day reality of the nurses, arose from my experience of working with the nurses and the conversations, both formal and informal, that occurred with nurses throughout the research. Specific elements of this concept emerged from the data gathered during the individual discussions with nurses when they raised their relationships with doctors, patients and other nurses. The nurses also identified their relationships with doctors as a major issue in this setting. Because of the way this relationship with medicine impacted on the nurses and their work it is discussed in detail in Chapter Eight 'Power and resistance, nurses working with/in the medical discourse'. 
This chapter then explores the two key relationships, being with the women nursed and being with each other as nurses.

When in the ward I quickly came to recognise that relationships are of central importance to the nurses and impact greatly on their working lives. The importance of this was supported with reference to the nurse-patient relationship, by the nurses themselves, as Rachel explains when describing her first impressions of the ward as a new graduate:

When I first came here it was manic, like crazy, people had such a hectic work schedule, busier than a lot of other wards I'd seen, but people were still really dedicated to their patients and that was what I was really impressed by, the nurses up here were really, I thought, good advocates for their patients, really interested in their total wellbeing and it just really stood out, I guess because it was an area I was interested in.

So much of the nurses' work is bound up in establishing and maintaining relationships with people, and a lot of energy goes into this work. The skills element of the nurses' work is seen by them as essential to their role and a marker of their confidence and competence, as explained by Bridget, a senior staff member, describing her introduction to the gynaecological area:

I had I think two or three days orientation, one of which was with a full-time preceptor ... we had to catheterise a patient and she said would I like to do it, and it was an absolute joy to be able to do a catheterisation and feel shucks, I haven't lost that [skill].

However, although expertise in tasks is the explicit part of the nurses' work, it is enveloped in relational work. The relational work is constructed on a moment by moment basis, the positioning of the nurses being influenced by their subjectivity in relation to the particular events, "multiple and fragmented within a particular moment" (Court 1998). The discourses that structure the functioning of the area, nursing, 
medicine and management, and the practices inherent in the various discourses which make the area specifically gynaecological, also influenced their relational work. Nurses' relational work is on the obvious level of nurse to patient, nurse to nurse and nurse to doctor, connections that were discussed in detail by the nurses, relationships that they clearly saw as part of their working world. Management, rather than having a continued, separate presence was mainly seen as embodied in the nurse leader of the area. Management requirements were channeled through her, although there were people that appeared in the ward from time to time who carried out management practices.

When the nurses discuss the relationships that they feel structure their work, it is the patients that they focus on first. For the nurses, their relationship with the women in their care frames their perception of their practice. For some it is the reason why they have chosen to work in the area of gynaecology. For example Sarah said:

I'd worked in urology for three years, I really enjoyed working with predominantly men but I thought it would be quite interesting to work entirely with females. I like surgery as opposed to medicine and I really just came here to see how it would be, if there was a big difference between nursing women as opposed to men.

Although Sarah did not have a clear idea of what the work in a gynaecological area would entail, she saw a difference in terms of the patients related to gender, and the difference between men and women. She wanted the experience of what she thought might be a different type of nursing, to see if there was a difference in nursing relationships working with all women rather than men:

[I] had no idea of half the stuff they do here, especially with regards to the terminations ... don't know that I thought much about it to be honest. It was just looking, just ... I was looking at comparing men and women, nursing women to men really. 
Other nurses talked about their commitment to women's health and linked this with their interest in women's issues generally. As Rachel, a relatively new graduate and staff member says: "I've an interest in women's health and feel quite passionately about women - about women's health and women's issues." Isabelle, also a new graduate, reflected an interest in women's health coupled with a commitment to people which, in addition to her student experiences, led her to the area:

I asked to be sent to women's health as part of my training and I came to [this setting] for six weeks and loved it. It was my best placement, I just loved it and the people here and it was really where I wanted to be but I was told it was really hard to get in to as a new grad.

This desire to work with women was one of the most common reasons stated by the nurses for working in the area. The nurses were clear about their choice, although they may not have been sure about the actual type of work, choosing a woman only area of practice was quite deliberate. Some nurses, such as Isabelle and Rachel, were clear that it was women and women's health that was the attraction, others such as Sarah were more intrigued by the difference between men and women. However, having a relationship with acutely unwell women, was a deliberate choice for the nurses in this research and was a continuing source of satisfaction. As Isabelle says when describing the nicest thing about working in the area, "It's the women, I have just met so many amazing women being here."

However, there is also a connection less spoken about and that is the relationships the nurses have with each other. This relationship was extremely important, the closeness providing support that the nurses considered essential to their daily work and which coloured their feelings about the area. As in any close human interactions that occur on a regular basis, there were specific instances mentioned by the nurses when relationships 
with each other had been more difficult, but these seemed to be managed in an informal way and did not ultimately affect the collegiality of the group. Therefore, relational work occurred on a micro level with individual nurses and patients, and also on a more macro level with the discourses structuring the world of gynaecology in this particular setting.

\section{Being with women as patients}

Being with women relates to the closeness inherent in the nurses' work with women in the gynaecological setting. This closeness is on a very physical and corporeal level as the nurses' practice involves a great deal of intimate work with women's bodies. Being with women requires the nurses to work extensively with the reality of women's bodies, intimately touching them, exploring their functioning and assessing and working with the fluids, including tears, leaking from bodies. Nurses, through the very nature of their practice with women, have always worked with the reality of the lived body (Grosz 1994b). An entry from my field notes describes a specific situation which, although quite every-day in this setting, exemplifies the nature of this reality:

The woman had come back from theatre, she had a PCA [patient controlled analgesia] and was rather nauseated, vomiting a bit and itchy from the morphine. However, she was keen to PU [pass urine] as she hadn't since her return and someone had mentioned a catheter which she was definitely not keen on! She had been drinking gallons so Audrey disconnected the IV [intravenous infusion], and I helped get her up to try and go on a pan by the bed, with no luck. Then she thought she could manage a shower if she could sit down while doing it, apparently it often helps with passing urine. She needed a lot of help due to it being her first time up. She finally managed to PU which I measured. Once back in bed I checked her wound which was oozing slightly, her pad had to be checked too [for blood loss]. Audrey did her recordings and reconnected her IV. 
Throughout this situation focused on body management, Audrey and I were present with the woman, touching and assisting her throughout the process, intimately aware of her body and its functions. I recorded my reflection on this moment thus:

The interesting thing for me today was the emphasis on bodies and body fluids. In a sense there is something almost medieval about it, I have an image in my mind from a film, of a medieval woman inspecting urine, vomit etc. There was the same emphasis on the visual responses of the body to trauma, the trauma of surgery as well as the initiating condition that caused the woman to have surgery. What we, as nurses, were doing was assessing and recording the body fluids to gauge the overall condition of the body. There is something about the smell and closeness of sick bodies, I think you do have to be able to cope with that and get used to it ... there is a choice that you have to make as a nurse, do you actively enter into that body contact with the patient, or do you stand back from it. You can decide to nurse with varying degrees of involvement in the intimate side of body work but in this setting it's unavoidable.

For the nurses I worked with this intimate work appeared to be governed by their respect for the woman's body. Although unspoken, there was a relationship between the patient and the nurse, not only due to the expected and powerful positioning of the nurse, that allowed for intimacy. It seems there are shared feelings related to women and their bodies, Sarah shows this shared subjectivity when she connects herself to her patients when describing her practice:

When I am looking after someone I pretty much think if that was me how would I feel about that ... I just think how would I feel if that was me having - losing my baby and having some strange doctor do this or what have you ... or being told: oh, we're just going to take swabs now and just thinking: oh my god what does he think I've got.

The nurses recognised the difference and diversity of patients but within that framework still related to them on the level of woman to woman, connecting their own feelings about how they would like to be treated to the patient's experience as Sarah goes on to say: 
... you can't nurse Mrs Jones the same as you can nurse Mrs Smith because they may be a different age, a different culture, a different religion. You've sort of got to take into account everything, their families, the whole thing and, yes, I basically just look at them and, and treat them as I would like to be treated.

Throughout the woman's stay in the ward the interactions that require the nurses to work closely with the women's bodies are often managed in a way that endeavours to preserve for the women their sense of privacy, and therefore ownership, of their own bodies, in the face of what was seen as an overpowering and objectifying medical discourse. Sarah stated strongly that women felt:

... very, they feel very invaded ... their space is very private to them ... I'm a lot more aware of women's privacy here than I was there [in a previous area] ... but vulnerability as well.

The nurses, within a very short time of a patient's admission to the ward, establish an intimate relationship with the woman's corporeal body. Intimate practices which occurred frequently, such as assessing vaginal bleeding by checking and changing pads, were managed by the use of techniques which preserved as much as possible, the woman's privacy, and made an unnatural and potentially invasive-feeling procedure, as manageable as possible for the woman. Techniques used by the nurses I worked with to manage invasive practices included ensuring the woman was covered and the nurse averting her eyes while carrying out the procedure, yet maintaining contact with the woman by talking quietly, but matter-of-factly, about what was being done. The intimacy of the procedure is very evident and the nurse is very aware of the need for sensitive handling as the woman is exposing herself to a stranger, even if that stranger is another woman and one sanctioned to perform this type of work.

It seemed that the nurses supported the identity of the patient as a woman when attending to intimate bodily practices. When reflecting on the feminist attention to the 
body as I discussed in Chapter Four it seems that while there have been attempts in the past to transcend the centrality of the body (Shildrick 1997) nurses could not avoid addressing the positioning of the corporeal body. Their work does not allow them to transcend the reality of the body for the women patients.

Also, the nurses confronted the cultural positioning of the woman's body (Grosz 1994b). On the one hand it could be argued that in this situation the nurses did adhere to an essentialist construction of the body in that they assume all women would want their privacy guarded in relation to such intimate practices. However, the cultural construction of women's bodies meant that bodily practices of this nature were considered private, to be attended to discreetly to make the situation safe for the woman. Interestingly, also inherent in this management of the body was an element of secrecy around 'women's problems', an element that has long been a part of gynaecological practice as raised in my exploration of gynaecology.

Conversely, medical practice appeared to be focused on the physical, treating the body objectively, although maybe the distance and impersonal nature of the doctors' approach was a safety mechanism, especially for the inexperienced. This distancing behaviour could make the intimate and vaguely sexual nature of the examinations, manageable for doctors, particularly male doctors. As Sarah described, "She's [the patient] on the ward five, ten minutes and then some strange doctor comes in, does a vaginal examination then he rushes off." The nurses did not work with the woman's body in this detached way. It did not appear, from my observation during the numerous interactions I was privileged to be part of, that the nurses in any way treated the women's bodies as objects. Nurses like Sarah were very conscious of the way women experiencing 
gynaecological procedures may feel, saying that compared to other types of operations or medical interventions "it's [treatment in this setting] a lot more private, it's a lot more personal". The way they endeavoured to ensure as much privacy as possible seems a subconscious recognition of the patient's continued ownership of her body within the unnatural and potentially depersonalising environment of the hospital and the gynaecological ward.

The secretions of women's bodies, the blood, the oozing of fluid from wounds, the urine, are part of everyday work for the nurse. She not only works with the external body of the woman, but also the products of the internal workings of the body. Although the doctors work more intimately with the internal organs of a woman's body, the nurse works with the bodily secretions that come to the surface. Assessing the meaning of secretions, what was significant and what was not, was something the nurses had to learn quickly, as Sarah explained:

I hadn't been here that long, it was I suppose two or three months, and they said: oh we're sending somebody up who's bleeding heavily, and I thought: yes, okay, and I went to pull back the blankets and she was just in a pool of blood and it had started to set, it was just like, like I'd never seen bleeding like that in my life, oh god, I didn't know anybody could bleed that much ... and obviously it had only been since she arrived ... and still be okay, [she said] I am feeling a bit weak actually, oh the tummy pains have eased off. I thought: oh goodness, there is a lot of blood there.

As Sarah describes above, a woman can lose a lot of blood but still be alright, being able to compensate for that loss. Having to deal with this type of situation added to Sarah's knowledge and confidence about the meaning of certain body products.

Initially I saw nurses' work with the products of the women's bodies as an extension of Michel Foucault's (1975) notion of surveillance discussed in his Birth of the Clinic, and 
particularly the concept of the normalising medical gaze. This describes a process by which the medical profession knows the body. This process objectifies, in this case, women, and reduces them to measurable data. Authors such as Carpenter (1993) and Carl May (1992) specifically discuss the role of nurses in the control and management of patients bodies in the hospital setting and consider nurses an integral part of surveillance. Secretions, which represent the workings of the individual body, are used to determine whether those workings are considered normal or not. The nurses' work in the gynaecological area reflected the medical construction of the body, measuring and recording of body products being part of the biomedical, reductionist process of normalising the female body. The norms, constructed by medical science, are the reference points for the nurses. However, these norms are interpreted by the nurse on the basis of her previous experience and knowledge, which at times leads to her conclusions about appropriate management being at odds with that of the doctors. Sarah graphically describes a situation where she felt that a hysterectomy may have been avoided:

He's [a doctor] so gung-ho, he just loves to get in with that knife. Once he did an "emergency" hysterectomy on a weekend. The woman came in with PV [per vagina] bleeding and she was hosing but we managed to get it down to a manageable level, but would he wait one more day - no, off she went for an emergency hysterectomy on Sunday pm.

Yet the nurse in this setting does consider it part of her role to assess these secretions, to interpret them in the light of the knowledge she has of the patient, of the condition the patient is experiencing, and of any procedures that the woman may have undergone for the management of her 'condition'. The nurse is an extension of the medical gaze in that she is the person that works with, and is responsible for, the day to day management of the woman's embodied experience, she is central to the determining the trajectory of the woman's gynaecological experience. Yet on further consideration, there is far more 
complexity in the situation. The one to one relationship between the patient and the nurse, makes the notion of the gaze rather superficial - perhaps more suited to medical relationships with patients. The woman to woman nature of the interactions seems to point to a connectedness that is more subtle and intimate than the distance and objectification that seems inherent in the medical gaze. Foucault's (1975) notion of the gaze seems only partly transferable to nurses. Maybe our attempt to use this philosophical notion as a starting point for analysing the practice of nurses is another attempt to use theory developed by a male, to explore female practices. Seeing the nurse as closely tied to the medical profession in thought and action may well prevent us from seeing the difference. Although the nurse requires a patient as the focus of her work, the relationship between nurse and woman patient is complex. This complexity is due to the fact that the individuality and difference in nurses and patients leads to diverse and unique connections between them, this diversity resists the notion of some essentialist and uniform practice of nursing, instead making each interaction unique.

Nursing could be constructed as Other in the male milieu of the medical system and the hospital, enmeshed in the medical construction of gynaecological practices. Nurses' work is pivotal yet goes unrecognised. As Rachel says, "I don't think the work that I do is respected and appreciated, or even the value of the work that I do, I don't think is recognised." The discourse of nursing is positioned as Other within the culture and power relations of the hospital. However, the individual nurse disrupts this positioning at the bedside, as Rachel goes on to explain:

One thing that I really notice is that it doesn't matter how busy and how big our workloads are, you know, how tired or how hungry because we haven't had anything to eat since we started at the beginning of the morning or the afternoon, we still manage to have good relations with our patients and our doctors. 
The nurse because of her relational work and subsequent rapport with the women, crosses boundaries between self and other. She works across the "hyphen" (Fine 1994), connecting herself with the woman she is nursing as a woman, rather than a patient, relating to the women on an individual level, supporting their decisions and joining the self of the nurse and the Other of the woman. Nurses are working with a reflection of themselves, particularly if the women have specific points of connection with the intimate lives of the nurses, as Rachel described:

Well, recently we had a young woman in who was fifteen, with ovarian cancer and she didn't have a very good prognosis and that's the age of my sister and she actually reminded me of my sister, some aspects about her reminded me of my sister and I actually found that quite hard.

Isabelle also found the connections between her own life and her patients, painfully clear during her very early experiences in the area:

I remember when I was training here there was a lady who was the same age as me and she had eight children and she had ovarian cancer and ... it was the first time I'd ever come across anybody that was ... I could really just relate to her having children, being the same age as me and she was dying and, and I was just absolutely horrified ... I showed an interest and at the same time I was devastated of course ... why was this happening to somebody so young.

The nurses acknowledged their role in connecting with the patients through the use of the term 'partnership'. This is a term often used in nursing education and practice to label an approach to the relationship between nurse and patient that is characterised by working together for the good of the patient. Partnership is used in connection with the nurse-patient relationship, it is not a concept that any of the nurses used to conceptualise their relationships with the doctors. Although it is an ideological concept, born of the change in nursing in the 1980's and formalised by authors such as Judith Christensen 
(1990), nurses use it to describe a form of relationship that they feel is important in their work. Bridget clearly articulates her view of partnership when she says:

My philosophy is that I hope to stand with and by, a patient and to walk with her through this part of her health experience, to work in partnership with her. I realise now that the patient actually has a lot of work to do, which I can hopefully assist and enable and support her in doing and in the whole experience supporting her. I hope to express a degree of compassion that will make her feel she's understood and if she needs someone to stand up for her, that she can have the confidence that I'll be able to do that as her nurse.

In reality, in this busy setting a relationship based on partnership is often difficult for the nurses to develop, at times leading to feelings of unease. The stress of being unable to do this at times leads to internal feelings of dissatisfaction and frustration, a sense that they are not working with women in a way that they would like, as expressed by Rachel:

Well often I feel dissatisfied going off duty for various reasons. Often it's to do with time constraints and I often feel that I haven't been able to do as good a job as I would if there was more time which is really frustrating. I just like them [the women] to feel well heard and feel that I've spent some quality time with them. Often I feel that some people get neglected because they're not as acute as others and it's matter of time and priority and I might poke my head in a few times and, you know, chat to them for a second but ...

The frustration felt by nurses such as Rachel may be part of their desire to extend practice, to increase the conscious relational aspect of their work and to make this an essential element in their practice, acknowledging the reality of the woman they are nursing.

Some of the experienced senior nurses embedded their work in beliefs about the freedom of women to be part of the decision making process. The nature of the gynaecological area, its construction of women's' illnesses, was not questioned. However, the nurses, particularly those more experienced, are clear that they are 
working with women in a patriarchal environment. Consequently, although they do not articulate the notion of the discourses that structure the area, they are clear about working within a hegemonic structure that has the potential to be unsafe for the women in their care. Alice and Henrietta when discussing the gvnaecological area generally 
and medicine. I have not heard of, or experienced, any situations involving male patients and their doctors, where any sort of specific chaperoning practices are used, it appears to be a practice that is related to the examination of women only. It is an ambiguous concept that has inherent in it the protection of both the woman's body and that of the doctor, the nurse being there to protect, through her presence, both people. Initially, the idea was that the women were being protected from any indecent practices, and the doctor was being assisted and protected from any false accusations of indecent practices, the physical presence of the nurse being used as a tangible embodiment of this protection. Today, the role of chaperone has become more problematic. Some of the nurses were very much against the presence of the nurse being used as a form of protection for the medical world, believing it has connotations in terms of the status of the nurse, beliefs about her work and the appropriateness of being 'used' by the doctors, merely because of the history of the roles and relationships between nurse and doctor. As Henrietta, who had a particular concern for this role, said:

When I first came ... the word chaperone was not used very often, you were there to support the person you were not seen as somebody there to support the doctors and protect the doctors from the women, it was their responsibility. Now I find it creeping more and more, I need a chaperone the doctors will say, and because the young ones don't know where we've walked they sort of don't pick up the ...

It was a situation I saw frequently, the body of the nurse being used to protect the male institution of medicine. However, if this idea is reconstructed as support for the woman undergoing the procedure, the situation seems to become more acceptable for some nurses, yet in a way it is more difficult, for the notion of the nurse's presence has not changed in the eyes of the doctor. Although the acceptable and outward reason for the nurse's presence may be stated as support for the woman, one of the unintentional spinoffs is that the doctor does have a witness to his/her actions when undertaking intimate 
procedures. The relationship the nurse has with the patient makes it difficult for her not to be there when procedures such as vaginal examinations are being undertaken. In fact she considered giving the woman support by her presence a very important part of her role in this setting. Where this role concerns some nurses, others felt that as they are there mainly for the woman, if it helps the doctor then they are all part of the same team, and ensuring the safety of the woman is an essential part of nursing practice.

The difference in the management of women's bodies by doctors and nurses was quite clear, and the nurses felt there was something different in how they worked with women's bodies. How each nurse constructs this relationship during examinations and procedures depends on the individual nurse. This difference again reflects the diversity of practice and the shifting subjectivity of the nurses in the moment, a situation which Marian and Helena Court $(1998,128)$ believe can "be marked by conflict and contradiction". This was evident as some nurses do still construct their position as supporting role where they will do a variety of tasks for the doctor, adding to the efficient carrying out of the medical tasks. Other nurses felt that parts of that role was demeaning, acting as the 'doctor's handmaiden', adding to the inequality of their positions and saw their main purpose being to help the woman through what the nurse recognised as potentially a demeaning and devaluing process. The nurse in this role could be seen as enacting the discourse related to male constructions of the untrustworthiness of women. The chaperone is needed because women are considered powerless, weaker and less able to protect themselves, yet also more devious, more likely to falsely accuse a doctor of inappropriate actions, not something that it seems anyone would consider happening if the patient were male. In a situation where most women would feel extremely vulnerable, the doctors are in fact constructed as 
vulnerable, open to the exploitation by a devious and untrustworthy woman, reflecting a belief about women that the nurse is supporting by her presence for chaperoning purposes. Yet, the safety of the woman in terms of her body and her feelings may be assisted by the presence of the nurse. The woman may feel that the nurse's presence is reassuring for the very reason that she is a woman, a competent woman that is not phased by the intimate process being undertaken, a woman who has been through this many times before, who has an intimate and reassuring knowledge of bodies in all their variety. This may contribute to making the woman feel more able to cope with what can be a very exposing and potentially depersonalising experience.

Ensuring the safety of the embodied woman, as part of protecting the whole woman, emerged as an important aspect of practice in this setting. Perhaps protecting the body as the corporeal reality of the woman herself, may be something that we have not yet considered or articulated. In feminist terms, the inscription on the body of discourses, particularly of medicine in this setting, may be a process that is worked with by the nurse in the interests of the patients. We have a sense of working with the whole person, that is, we want to be seen as working with a person and not merely focusing on the condition and its management, but we have yet to consider the depth and meaning of our role in body work. In the gynaecological setting safety of the woman's body, the lived body of feminist theory, as part of total safety, seems a central concern for nurses. How the nurse manages the lived body of the women, how she relates in her practice to that body, is a significant part of her work. Maintaining the safety of the body, due to the invasive nature of practices in gynaecology, and the ability of these practices to disrupt the woman's bodily integrity, is an element of practice that, although unspoken, is an important focus of nurses' work. It would be impossible not to relate to the physical 
embodiment of the particular gynaecological condition that a woman was experiencing, how this illness appeared through her body and the physical manifestations were directly related to her safety, her total safety. Managing the physical procedures was an element of body safety that incorporated the safety of the woman's total being.

The nurses I was involved with worked hard for the patients in their care. At times this work is very demanding yet their underlying concern for the women is evident, even when they feel undervalued and stressed by the workload. Essential for coping with their work with patients are the relationships the nurses have with each other.

\section{Being with women as nurses}

Although the relationships with patients and doctors are most frequently discussed by the nurses, their relationships with each other are of central importance in terms of providing a safe environment for themselves, in what they see as the high tension area of gynaecology. Jocalyn Lawler $(1997,33)$ comments on the way that a patient can be seen as "captive in the dysfunctional and/or sick(ly) body" and makes the important point that the "nurse is captive with the patient", for long periods of time. It became apparent through my being with the nurses that they are also captive with each other, in the same way they had to interact, connect and 'be' with each other for longer periods of time than they would with many other people in their lives. The nurses worked as individuals yet identified very strongly as part of the team of nurses, the group was important. They socialised with each other and were very aware of each others' lives and concerns. Sarah, an experienced nurse who has worked in a wide variety of settings, describes her view of the nursing culture:

Well I think we've got quite a good atmosphere, I think this is one of the best wards I've worked in actually, for friendliness and support 
and things like that, and there's no cliquiness, there's no little groups. Other wards I've worked on there's little groups that go out together and talk together ... there's none of that here. And there's nobody that doesn't get on, I mean, every now and then so and so has a little ruckus, but it's nothing, it's just day-to-day life really ... I think we have to be there for each other. I think we have to support each other the emotional thing ... when we go through a run of lots of people with cancer ... everybody comes on [and says] oh my god, this is just too much, but we'll go out for drinks or have a coffee or ... people tend to stay [on the ward] a lot later than they need to and will sit and talk till midnight if required, that's sort of how we do it. And we might not be talking about the ward, you'd just be having a rest and time out and sort of winding down before you go home. I've never seen that [elsewhere], as soon as you've finished your reports and read them, you're out of there, in every ward I've been in, this is the only one where people stay around.

Support was a word that frequently arose during my discussions with the nurses. It was provided informally through the relationships they had with each other, and the recognition of shared concerns related to nursing women. Nurses such as Alice acknowledged a very tangible feeling of support:

The ward staff are generally pretty good to each other, pretty kind and pretty aware when someone's putting a lot of themselves into their work at a particular time and quite generous emotionally to each other I think. I think we're an unusual ward in that. [Another nurse] who's just come to the ward said that we're unusual in that people don't seem to want to fly off the moment they've said report. Quite often, they hang around and chat and she said there aren't the cliques that you find in other places.

Yet nurses such as Alice who had worked in the area for some time were also quite open about some of the difficulties that inevitably occurred in the work environment. At times the nurses themselves was seen as a problem that had to be worked with, their practices considered negative and hard to accommodate. As Alice explained:

I find the pettiness amongst nurses very hard, very hard, that they don't support each other. Like [the charge nurse] used the term horizontal violence and I find that very difficult to cope with and impossible to do anything about, I don't know what you do about that. 
However, even for Alice her overall impression of nurse to nurse relationships was one in which the positive aspects out-weighed the negative:

I think we have fun here. I do think we're a fun ward even though we've had our problems and they've been serious and not fun, generally we're a fun ward ... we can laugh at ourselves. We like to learn as well, we get a lot of staff who like to learn and we have a really strong and broad knowledge base amongst the staff. We are individuals and practice as individuals and are quite good at acknowledging that without pulling people down for practicing differently to the way we do.

For the nurses that were new to the area, feeling supported by their colleagues was essential to coping with the demands of the work. Isabelle described the way she felt that other nurses cared for her:

That's the good thing, they [the other nurses] make you feel like you can say if you think you are overworked. They say: say if you're overworked, and I think knowing that and feeling that you can say, speak up and say: look I've got a full work load already, I just can't take any more, and that's okay.

Again, this varied from nurse to nurse and for some becoming a member of the group or team took time and the support, although acknowledged, did not always help initially, as Rachel says of her early feelings:

It's taken a long time to feel as though I belong to the place, like now I feel part of the place and feel quite comfortable with my colleagues but it took ages because I really felt as though I was being judged a lot. Not that I was, obviously I was supported but I felt it, it took a long time to feel comfortable.

Yet Rachel was also clear that fitting in was essential for her own safety, "it's really important because it really keeps your sanity, really, to have the support of your colleagues, especially with the difficulties we have around here." Overall, she had a sense that "we're loyal to each other in terms of a united sort of approach to [the area]". 
There was a feeling amongst the nurses that the relationships they had with each other were unusual. While they recognised difference and individuality, the group cohesion was extremely important. Interestingly, Isabelle related the supportive culture of the nurses to the fact that they were all women. When asked about the relationships between the nurses she says:

Oh it's good. What makes it good? I don't know, it's just like we're a team, and I think that everyone enjoys their work and ... I think because we're all women ... that we're all quite sympathetic too and we all, we all feel the same sort of ... there's nobody here that isn't understanding and ... that would be just blase about things, they all really care.

Although there was some consensus in the feelings the nurses expressed for the area still there is a great deal of individual diversity, obviously in their personalities, but also in the way they practise, the organisation of their practice and their thinking about gynaecological work. Although it is obvious that each nurse will work differently, the notion of an essential nurse became redundant and problematic. The more I worked with each nurse, the notion of some bland and unitary practice of nursing was less and less appropriate. Feminist theorising in relation to difference (Grosz 1994a, Millen 1997) supports the notion of avoiding essentialism in relation to women's experience and this, it seems, applies also to the roles within which women work. Although society may consider those such as nurses homogenous, in reality no such generalisation is possible. The diversity between nurses became clearer and clearer, the only unifying element of their practice being the skills and the following of various required hospital protocols, yet even these became obviously idiosyncratic as my familiarity with their work increased. Basic concepts related to skills were observed fairly consistently, for example the principles of asepsis when doing a dressing or a catheterisation, but the framework within which skills were carried out varied enormously. If a nurse went in to 
do a wound dressing, then that process would be accompanied by the practices of relational work manifest in the verbal explanation to the woman, the physical organisation of the environment appropriate to the task in hand, and the body language of the nurse, but how they managed these aspects of the work were totally individual. Although the nurses I worked with did work differently, they were all governed by the busyness of the ward, consequently at times nurses would 'speed up' their approach as the requirements of the pressure of work building up did not allow for the usual calmness. This idiosyncratic approach to practice supports the difference of the nurses in relation to each other and their preferred way of working. The negative side is that there is very little in the way of professional review of practice, to ensure that basic principles related to accepted care and treatment in particular areas, for example wound care, are adhered to in the interests of patient safety. Thus the nurse is responsible for her own practices, but rarely gets a chance to see another nurse working with the patients as part of a learning process. As Bridget pointed out:

I actually don't know how other nurses practice. I was asked to write a reference for a nurse last week and I found that quite difficult, I can only answer from what I hear her say in hand-over and the kind of incidental remarks that'll get passed and by appreciating how she approaches ... in this case she's a senior nurse ... the difficult patients, when I say that not difficult but more complex patients. I make an assessment and an assumption, but how a nurse actually relates one to one with the patient, no I can't tell you that.

Within the practice of nurses there is the need to support and develop individuality and diversity of approach. However, because there are safety issues and the potential inherent in practice to seriously harm women, then difference must be accommodated within a framework of strategies to ensure safety and competence. 
The nurse leader had a significant role in forming the nursing culture of the area. Her relationship with the nurses was crucial and she fostered a particular view of the way nursing work should be carried out in a gynaecological setting. Her philosophy reflected her beliefs about nursing and women's concerns and was considered quite radical by many nurses, and within the institution as a whole. For some nurses it influenced the feelings they had towards their practice, as Rose said:

I know my practice has changed since I've come to this ward, but I'm not sure whether that's because I'm working with women or it could be the philosophy of this ward or the philosophy of management. I've been very influenced by [the nurse leader] being very woman-centred and giving them choices and working in partnership with them [women].

The influence of this nurse was felt by all the nurses in the study, and from casual conversations with many nurses she was considered pivotal to the ward. Although there had been problems with the nursing management, according to Alice these had been addressed:

We've done a lot of work with her [the nurse leader's] role, with the staff and her role which means she is here a lot more now and staff appreciate that and it's changed the ward really. It's been good. There was a time when she was away a lot, at a lot of meetings and training things and management stuff and we rarely saw her and there was a feeling that there was nobody taking control.

Now that these difficulties were apparently resolved, the nurses were strongly supportive of their leader. As a nurse-researcher in the area this was a feeling that was very evident from my first experiences in the ward. As I have discussed in Chapter One the informal discussions I held with the nurse leader prior to formally beginning this research were pivotal to my recognising that this ward did have a unique culture which was influenced by a women-focused, clearly articulated philosophy that the nurse leader endeavoured to enact. Her skill when relating to women was recognised as one of this nurse's greatest 
strengths and all the nurses were extremely respectful of her approach, as Isabelle explains:

I feel good when [the nurse leader] is around, she's always been excellent to me ... and I think she's got great management skills really ... she's just got so much knowledge, I mean it's just great being in a room with her and with a woman and just, just listening to her and what she's got to say. She's just got so much knowledge and that's really good for me. I wish I had more time like that so I could learn more, but she's got a wonderful way. She's really ... very quiet sort of, gentle sort of ... way with people and I think it's really comforting for someone, especially if they've just lost babies ... I mean sometimes the ward can be really rushed, you know, just running, running, running and she always makes sure everybody sits down for a cup of tea and things like that ... she's not like the big boss, she's just one of us really and I always feel really comfortable about asking her anything.

This nurse leader's position singled her out as different and she encouraged independence and difference within the nurses. This conscious approach to nursing women and to supporting their individual realities was something she expected to see in the nurses. Autonomy of practice was encouraged, diversity and difference being accepted. As Alice said, "I guess we have a leader by example but most of us look at her example, see that it works for her, and do our own thing." An approach that the nurse leader herself supported in her comments:

I don't think people can grow by being managed, they've got to have room to grow, room to manoeuvre, and, and their own practice has to grow. I mean the way I do things is not how I expect other people to do it and I don't see myself as an expert ...

In this way she also supported the choices, diversity and individuality of the women as nurses, as well as patients. This approach was apparent from concrete examples such as the choice nurses had over wearing uniform or their usual clothes, the questioning of what nurses thought were the underlying reasons behind certain strategies and actions they were asked to undertake, and the example she set by her own actions in terms of 
making appropriate decisions without reference to medical power. This was always undertaken with due consideration of the safety aspects of her decisions. As Alice said during our discussion about holistic nursing:

I think we do it really well here and the ward lends itself to it. [The nurse leader] is just such a superb example of a manager, or charge nurse, or whatever you want to call them, for letting people develop and grow, and allowing the whole ward to have its own culture.

However, the more experienced nurses, familiar with the workings of the area and the management of acutely unwell women, found some of her practices difficult. While admiring her skills and her confidence they were clear that they managed situations differently, as Bridget described:

She is always very strongly on the patient's side and that comes out ... she obviously puts the women first and the new staff see that. She is very much non-task orientated, I'm critical of that sometimes, I think that sometimes, personally I feel that everyone needs to have their vital signs taken. I am more cautious. She feels well, she can assess, and quite rightly, that a patient isn't febrile, she's perfectly alright, so you don't need to take a temperature for instance, whereas, I would feel well, she's come back from theatre, I should take her temperature because it's a baseline even though I'm quite confident she isn't febrile.

Sarah also described the frustration she experienced at times but was clear that this should be seen in relation to the immensely valuable work of the nurse leader:

Sometimes she'll look at the [patient] board, you'll say: I think we need an extra person on this afternoon, she'll look at the board and say: oh why we are baby-sitting her, she's going home, she's fine, she's fine, and I sort of think: where are you, she might be nothing but she has just lost her third baby in a row and I've just spent two hours in there, as the duty goes on I think people get a bit frustrated with that. But then having said that, somebody will walk in to the ward an absolute shambles, just crying and within ten minutes of talking with [the nurse leader], they'll be together, they'll be reassured .... if you have a problem, you just go and say: oh, look I'm really finding it tough, she'll have the problem sorted in fifteen minutes, whatever it is. 
Some nurses found the culture fostered by this philosophy difficult to work in initially. The encouragement to make their own decisions, to decide when and what were appropriate nursing actions based on their own assessments, rather than referring to a standardised set of protocols, led to the feeling, for some, of insecurity. The apparent lack of structure in terms of clearly stated directives could make some nurses feel unsafe at times, as Rose explained:

I think it would be scary for ... I think for new grads it's scary from the feedback that I get. The one criticism that they tend to make of this area is that we don't have protocols, they don't know what's right and what's wrong. It's not black and white but I don't think in this area it always is black and white, you're looking at the whole picture so ... in some areas it can be black and white like if their temperature is 38.5 you call the doctor ... and a lot of people want that for their security. They want to know that you take recordings four hourly and that's correct but it's not always as clear cut as that. It really depends on what's happening to that woman at that precise moment.

For most nurses the differences must apparently be accommodated in the interests of the smooth running of the ward. If the differences become too uncomfortable then the nurse may well decide to take herself out of the position and leave the area. To maintain her confidence and integrity, this may be seen as a necessary action. As Alice pragmatically pointed out, "Without kind of being ... no-one is forced out, but if it becomes evident that your style is never going to fit, you do leave because you want to go somewhere where you are more secure." The culture of the area, although supporting difference, did not suit every nurse and there were situations where the nurse did choose to leave. However, this led to feelings of concern on the part of the nurses, as expressed by Sarah when she worked with a nurse who was definitely uncomfortable in the area, "I knew I was just not getting through to her at all ... she just got quieter, she was never very vocal but she's just got quieter." 
While recognising the difficulties, other nurses flourished, feeling valued by the independence fostered by the senior nurse's woman-centred approach. Nurses were encouraged to develop their independence and value their own decision-making abilities. As already noted in this chapter the nurses felt closely linked to the woman's experiences and similarly the nurse leader who was responsible for the nurses, connected her own feelings to those of the nurses. When reflecting on her role she stated:

Supporting them [the nurses] through things and getting the information when they want it, because I've got the time and they're busy at the bedside, and I would see that there are resources they need or whatever they think that they need I can put in place for them ... emotional support mostly and supporting them through. I always think of the nurses in the middle and around them ... you can see I'm a gynae nurse because I think in circles ... all combining to keep the nurses happy at the bedside so they can look after the clients, and I suppose the tightest little circle is the client. But you can't have happy clients unless you have happy nurses, I suppose that's my philosophy and also I would also like to think that I treated them the way that I would like to be treated, so yes that's my philosophy.

The relationships the nurses had with each other were pivotal in their feelings about the their nursing and the gynaecological area generally. It appears that difference is tolerated and actively fostered by the nursing discourse in the ward. Although some nurses felt this could at times be difficult, for most it gave them a sense of being able to consciously practise in a way that they would prefer.

I believe that the nurses connected with the women in their own individual way. They worked with the reality of women's bodies and the practices that they are subject to as part of the experience of being a patient in a gynaecological ward. Because they were working with women's bodies the nurses were in a very vulnerable position in relation to their own embodied safety. The impact of the work that they did with women's 
bodies did not allow them to avoid the reality of the lives and for some the suffering, of the women, a situation that affected the nurses greatly at various times. This emerged as an important issue and I realised how the work affected the nurse required exploration. This exploration is the focus of the next chapter. 


\section{Chapter 7}

\section{Who cares?}

When I'm actually physically at work is when I notice I feel stressed and run-down and tired by work, but when I'm not at work I don't feel like that ... it's not so much physical tiredness, I don't feel physically tired, it's definitely the emotional bit, I just find it draining. It is the emotional energy, it is the type of energy that is very draining (Rachel).

It's the grief, it's the grief in this ward, it's just terrible and just trying to sleep and having to cope with that everyday (Isabelle).

s I became immersed in the nurses' world of clinical practice the personal
impact of their daily work surfaced as a major issue. The feelings expressed by Rachel and Isabelle were common amongst the nurses I worked with in the gynaecological area. The stress of working with grief and loss as part of their everyday practice was something all the nurses acknowledged. This chapter explores this aspect of practice. To illuminate the issues for the nurses I have focused on two particular instances, coping with nursing woman experiencing mid-trimester terminations, and nursing women with cancer.

When I worked in the area prior to undertaking this research I became aware of the burden society places on nurses by just expecting them to integrate and cope with situations that have the potential to cause the nurse considerable psychological trauma. At this stage I did not formulate these thoughts into a particular conceptual interpretation, but realised that we expect nurses just to accept whatever they are exposed to during their work. It seemed that in acute settings such as gynaecology we have not recognised how our work can impact on our well-being which ultimately 
affects our practice as nurses. This element of nursing seemed to be ignored. Or perhaps it is taken for granted, assisting people through complex and traumatic events is an inevitable part of nursing practice and nurses should be able to cope emotionally with these events. I began to feel that not recognising that much of a nurse's work could result in serious and negative effects on her as a person was a form of oppression, an idea that was very uncomfortable for a feminist nurse.

During my early experiences in the area I became aware of a specific service which highlighted the notion of practice affecting the nurses. The service was that of midtrimester terminations, that is terminations of pregnancy between twelve and twentyfour weeks, which in New Zealand are carried out for both foetal abnormality and social reasons (Contraception, Sterilization and Abortion act 1977). When I returned to the area to undertake my research I was again confronted with the way mid-trimester terminations affect the nurses. However, as the nurses talked about their practice and the way they felt about their work, I realised that many women patients experienced loss and grief as part of their gynaecological experience and it is this aspect of practice that affects the nurses deeply.

As I became involved with the nurses and heard their formal and informal stories and anecdotes, the importance of exploring the traumatic areas of their practice became unavoidable. Not to address this aspect of the nurses' work would, I felt, be unethical. The aspects of subjectivity raised by Renato Rosaldo $(1995,171)$ and the specific notions of "passionate concern" and "ethical engagement" she describes, were particularly relevant to this exploration. I acknowledge that an obvious concerned connection with the reality of the nurses impacts on my interpretation of this aspect of 
their work. However, I felt that once I was made aware of the effects of this aspect of practice I must provide a place for the voices of the nurses to be heard.

Trauma from practice in acute settings was something that I had not considered previously and which in my area of nursing education we do not seem to address even though research by authors such as Pam Smith (1992) highlight the way in which exposure to practice affects nursing students deeply. Because of this I questioned our preparation of nursing students, whether we acknowledge the potentially harmful and unsafe situations some will be exposed to, and in which they may have to practise. During a nurse's education we may explore the topic of death, but I wondered how well we prepare them for the serious mental and emotional impact they can experience due to the sights they will see, or as a consequence of some actions that are expected of them. Also, do we make them aware that their close involvement in a patient's emotional state of being may be extremely stressful at times?

By entering the nurses' world I gained an understanding of the complexity of practice in gynaecology that in my experience was not apparent in other settings. The complexity was due to the nature of the conditions labeled gynaecological, most of which are very emotional as well as physical experiences for the women patients. And, as discussed in the previous chapter, the nurses get drawn into the emotional state of the women they are nursing. To be admitted to the gynaecology ward means that you have something wrong with the parts of your body and their functions, which in our culture define you as a woman. All acute hospital admissions have an element of anxiety but often the outcome can be positive, a situation that appears to happen rarely in this setting. As Henrietta explained when discussing the positioning of gynaecological facilities: 
... it's for the womens' interests that it's [gynaecological services] kept separate, because, just the nature of the work, most people I think, most cultures, I think even our hard-nosed culture, looks on our reproductive organs as being ... sacred, and for quite a lot of women the removal of them causes quite a lot of grief. I've actually read figures where you have a cholecystectomy, and a few people feel depression after that, but having your uterus taken out, or your ovaries, or your fallopian tubes, it's something like seventy-something percent of women suffer some sort of depression.

Jane Hall's $(1996,1997)$ work on Nurses as Wounded Healers, has been particularly useful in exploring this hidden aspect of nurses' practice and provided a way of conceptualising the effects of a nurse's work on her own being. Hall's work was illuminating in that she discussed the betrayal that nurses can experience due to the impact their work environment has on their ability to practise in the way that they would want. She also considered the way in which being part of the patients' experiences affects the nurses, "for as the physical and emotional depths of a patient are affected, the nurses' own depths are also touched" (Hall 1996, 15). Working in the gynaecological area had the potential to impact on the nurses more than ever as a result of their nursing women, that is nursing a reflection of themselves. They worked with women they could identify with and their discussions showed that they recognised that this element of their practice could be problematic. Could these factors lead to the nurses becoming disconnected from the women as a way of managing their own feelings? As I noted in my journal:

The reality of working with women and entering into their state of being could be too damaging for the nurses' psyche. Perhaps distance is the only form of protection in the gynae setting.

The nature of the work in the hybrid service of gynaecology requires the nurse to have the skills and knowledge to care for women experiencing major surgery such as hysterectomy, as well as a variety of pregnancy related conditions. This is a situation that, as I discussed in Chapter Two, has been part of the service for much of the history 
of this specialty. For the women patients, these uniquely female experiences often involve psychological as well as physical trauma. Hysterectomy, ectopic pregnancy, miscarriage and procedures for the termination of pregnancy, are all very emotional events in a woman's life. As Sarah commented, "There is a loss, there is a loss. And ... and to a lot of women they are losing part of them that makes them feel feminine, not physically, but it's part of them." These events are often multi-dimensional in nature and a woman can be pregnant as well as going through surgery, or she may have to make a painful decision related to the termination of pregnancy. This requires the nurses to be competent and able to manage a wide variety of clinical situations. As Rose says:

... it's quite a specialised area ... because it's not really ... there's a bit of surgical and a bit of medical but there's ... it's all intermixed, it's not clear cut. Something like urology, it's quite clear cut like it's usually just surgical, and medical you're treated with drugs and there's not that intermix, or even the possibility that when you've got pregnant women as well, no you can't take them to theatre, no we can only treat her with a limited amount of drugs. I think that combination of different skills that in other specialties you may not have to call into play for ages and ages, then suddenly you get somebody who's really wheezy and asthmatic because of something that's happened to them. So you've suddenly got to pull your experience out of nowhere.

The multi-dimensional nature of the work means that the nurse cannot always be certain she will have the knowledge required to care for the woman. This makes day to day practice difficult. As Rachel said, "Nothing's easy, in this ward nothing is easy." Anne McQueen's (1997) research into nurses working in gynaecology supports this interpretation of the area having a significant emotional dimension. She identified a number of areas that the nurses identified as requiring "emotional work" (ibid, 236) and concluded that nurses' feelings need to be legitimised and acknowledged.

Emotional work was identified as early as 1983 by Arlie Hochschild in his work with flight attendants and the aspects of their work that involved emotional labour. Although 
these ideas have been applied to nursing by authors such as Katherine Froggatt (1998) and McQueen (1997), still it appears that there is little application of these ideas in the actual work situation. Nurses still appear unsupported with little space, other than that created through their own strategies, to manage the emotional impact of their work.

It is not only specific practice requirements that affects the nurses, but also the shaping of gynaecological services by the discourse of medical management impacts on them at a personal level. The actual way gynaecological services are provided intensifies the emotional experiences for the nurses. As I explained in my discussion of the service organisation in Chapter Five, a woman who has an acute condition or symptoms related to her reproductive system can be admitted directly to the gynaecological area. This can be very positive as Henrietta explains:

And we acute admit as well, which makes us rather unique around the region, again I think it's probably .. some of it's doctor driven because they can't be running over to A\&E which is so far away .. it takes about ten minutes to get there, so they could have seen the woman and assessed them and done what they need to do, and also again, you'd have women down there [in A\&E] and having VEs [vaginal examinations] with just flimsy curtains being around them, and drunks on Friday and Saturday nights who are likely to ... nosy their way into the cubicles, so yes, a gynae ward is, I think, a nice place for women to be.

However, a result of this admitting procedure is that women who are often in considerable and increasing distress can wait for varying lengths of time to be assessed and admitted, depending on how busy the gynaecological area is and how quickly the doctor can be available. This situation becomes very difficult for the nurses because they recognised that the women and their families are becoming increasingly upset, and their feelings are often directed towards the nurse who is highly visible. This situation was raised by nurses in McQueen's (1997) research and may be a common occurrence 
for nurses working in acute areas where stress for patients, families and staff is high. In response, the nurses experienced a corresponding rise in their own discomfort and distress. In this situation, the nurse is at the intersection between the practices of the medical discourse and the individual woman, the nurse is "hybrid" as referred to by Judith Parker $(1997,22)$. However, there are times when this ambivalent space that the nurse inhabits becomes too uncomfortable, as Rachel described:

Yes, [you're] caught in the middle. It is really, really hard and personally I've never found a good way to handle the situation. And often if you ring the doctors and they're busy and can't come to see the patient, they're highly stressed so consequently it doesn't actually do a lot of ... like it just creates a lot of friction between nurses and the medical staff and doesn't actually get anything done. And that can be really difficult and often the people's partners or family, they get really annoyed and it gets quite difficult to explain to them why this person's been waiting here.

The accepted rituals of medical discourse and the power it wields over the actions of both nurses and women in the situation of waiting for medical decisions that everyone accepts must be made, leads to distress for both women, patient and nurse. The implications of medical control were put into the perspective of a woman's reality by Henrietta when she said:

Their [the doctors] view is worst case scenario every time, they forget that in ninety-nine of these hundred there's going to be no worst case scenario and does everyone else have to be punished for the one that is going to go astray, and it is a punishment because, because women are special. A man that goes into hospital will have his wife who will probably pack his suitcase, have his ... having the kids at home having their meal, she will also come and visit him. The wife going into hospital, she knows there is chaos at home, that the food is not going to be bought, that they'll possibly be fed if there's anything in the cupboards but it might be a can of baked beans, but the clothes aren't going to be clean and ready for the kids to go to school in the morning, that the lunches might not be ... I mean there's a new lot of men that are coming through that can cope with that. Not that many ... And there's an awful lot of single mums out there who are coping with the whole thing by themselves, and the doctors keep saying they're practicing holistically, but it's a laugh. 
Whether medical practices are essential of not, they are supported by the power invested in the medical word. The positioning of the nurses between the understanding of the woman's situation and the requirement to support medical practices was highly stressful for the nurses and means, as Henrietta said:

We sort of see ourselves as the meat in the sandwich yet again, here's a woman that wants to go home and she needs the doctor to give her the ok. She doesn't want to go without his sanction, and it is for a lot of women, the doctors right.

This situation of being caught between discourses caused a constant tension. As Parker $(1997,28)$ describes it, "Here nurses may be uneasily positioned in the present at the edge of beyond, in a disorientated and disturbed space."

These aspects of the service made the environment emotionally challenging for the nurses. This was then compounded by the actual services provided and the effects this had on the women patients. Working with the women's grief and loss are part of a nurse's work and the fact that it is women experiencing these feelings made a difference, as Rose explained:

I suppose with all nursing you have to deal with things all the time, like if there's grief and loss, but I think here ... I don't know whether it's because you're a woman in a woman's area that suddenly ... or you just get to a certain age where that becomes an issue. And also, in some things like infertility where that ... like I've got no desire to have children at the moment but if I was told: sorry you're infertile, well then that doesn't give me an option and suddenly things might change. So I think it's probably because you can relate in a way to some of the issues or you could try to search perhaps in yourself for how I would feel in the situation or things like that.

It seemed that the nurses had little preparation for the reality of working with women experiencing emotional trauma through their gynaecological experiences. As Sarah discussed, they were on their own when it came to developing the confidence necessary to cope with the woman's emotional state: 
We came from surgery, we knew how to look after a post-op patient basically but not emotionally ... it was basically just by experience really. I suppose it took me about four months to start feeling a bit more comfortable in the ward but I used to hate getting an admission that was a threatened miscarriage because I knew it was probably going to be emotional. I'd much rather have an abdo [abdominal pain], or ... or something, but I knew that I would ... a threatened miscarriage would be, could be, traumatic.

Lack of preparation for the emotional nature of the work was identified by nurses in gynaecology as an issue in practice as early as 1986 when Christine Webb (ibid, 93) undertook her research 'Women as gynaecology Patients and Nurses'. It appears little has changed and that still nurses are expected to work unsupported in this area, their voices unheard and unheeded.

The two situations which follow were identified by the nurses in this research as being particularly difficult for them to integrate into their day-to-day practice because of the feelings they engendered. These situations illuminate the effects of these practices on the nurses involved.

\section{Coping when women are having mid-trimester terminations.}

A specific clinical situation that epitomised the emotional labour of the nurses was that of mid-trimester termination. Being involved with nurses assisting women through the termination was pivotal to opening up this aspect of nursing in the gynaecological area. It had an immediate impact on me and made me confront serious issues to do with my own positioning as a feminist nurse-researcher, as well as the reality of the nurses' working world. I subscribe to the feminist tenet of the personal being political which according to Liz Stanley and Sue Wise $(1993,63)$, includes the recognition of women's experience and the acceptance that these subjective experiences, which are "rooted in 
the particular", are valid and undeniable. This particular situation of nursing women through mid-trimester terminations made me aware of how my personal positioning as a feminist nurse-researcher required me to acknowledge how poorly we prepare nurses for practice situations that are so emotionally draining. Making explicit the reality for the nurses could then be seen as a political act.

Until I worked in this area I, along with many of the nurses it seems, had never given a thought to where, or how, mid-trimester terminations were carried out. However, soon after I began my research in the area a woman was nursed through such an experience and so the occasion naturally arose for the nurses to discuss their feelings with me, feelings of ambivalence and, at times, very real distress. The ambivalence occurs through the distress at being involved in the death of a baby, while holding the belief that women should have the right to choose the option of mid-trimester termination. I realised that nurses were just expected to cope with such situations, that society made the law which affirms a woman's right (if she meets certain criteria) to choice in relation to continuing a pregnancy. However, to make that right a reality, nurses are required to be there and, therefore, experience the termination along with the woman. Society in New Zealand, through the legal process, has sanctioned termination of pregnancy and provision of this service is dependent on nurses. Members of society can distance themselves from the reality of the situation and rely on nurses to actually implement the service. The provision of this service became absorbed into nurses' clinical practice, an unseen aspect of a nurse's work, another element of the nurse's hidden work with the physical body discussed by Lawler (1991). 
Women in New Zealand may have terminations up to twenty-one weeks into their pregnancies and at no stage is there a differentiation between termination for foetal abnormality and termination for what is very broadly interpreted as the physical or psychological health of the woman (Contraception, Sterilization and Abortion act 1977). Early terminations are carried out by suction curettage often in separate facilities, which, although traumatic, do not require the delivery of a foetus. A mid-trimester termination of a pregnancy is carried out after fourteen weeks when a requirement of the termination is that the woman goes into a chemically induced, active labour. Although the provision of services varies tremendously throughout New Zealand, for a midtrimester termination the woman is usually admitted to hospital and labour induced using drugs such as prostaglandins occasionally in conjunction with syntocinon, to speed up the labouring process. The woman can labour for one, to two and a half days and is cared for throughout the procedure by the nurse. The result of labour in the second trimester is a foetus recognisable as a human being. Use of the term 'baby', or 'wee one' by the nurses when discussing terminations made it clear that the nurses could in no way distance themselves from the fact that they were involved in the death of a human being. The way this experience is managed requires the nurse to carry out a variety of actions, with great sensitivity, and which quite clearly support the recognition that this is a human being.

Being with a woman through a mid-trimester termination was one of the most traumatic experiences for the nurse in the gynaecological area, the trauma of the event is something a number of the nurses carried with them on a daily basis. It is the most frequently referred to painful experience for the nurses. The examples they used to illustrate their personal stories make me seriously question how we can just expect 
nurses to 'get on with the job' in this situation. I do not think other professional groups in society cope with events such as these in the way that nurses are required to, that is in a sustained and intimate manner. Sarah's story of her experience, one of the most graphic and most harrowing, epitomises for me, the reality of this nursing:

I can remember the first one [mid-trimester termination] I saw. A [another nurse] and I were on at the same time, we hadn't been there very long and B, do you remember B? It was her patient, because A and I hadn't been there very long and we weren't happy to look after her. B came from a Christian background, was very unhappy about looking after her, but A and I just weren't happy to do it. B had taken somebody down for scanning and her lady rang the bell and A said: oh I can't ... I'm not going in there by myself ... The lady was on ... she said: oh look I need to go to the toilet. And we both looked at each other and so we put the pan down and she said: oh something has just happened. And I said: oh that's fine. She was very relaxed. But the scariest thing was ... was I'd been told that the cervagem kills the foetus. The foetus, when I had a look, I said: oh just move forward ... and the foetus was still wriggling, it hadn't died. So I thought oh my god, and the first thing that crossed my mind was: am I supposed to take this to neonates? And then I thought: don't be silly. And then she said: can I have a look, can I have a look, and I said: oh look it's a bit bloody at the moment, I'll just go and clean it up and then bring it back, thinking: gosh she can't look at this. Because it was a social termination but even still it would have been mortifying. I mean, just ... its little arms and legs and diaphragm was going up and down but it wasn't breathing, but it took a couple of minutes for it to stop wriggling in the sluice room. And so A stayed with the woman and I took the wee one out and we just popped her back to bed and I bought the little one in when she was ready to see it.

An experience such as this was so immediate and unexpected due to lack of preparation, it affected the nurse deeply. When I asked Sarah how she coped with the situation she said:

Well, I didn't say anything for a while 'cause I was just so shocked, I thought ... at first I thought I was going to cry and I thought oh ... this is ... stop it, stop it, and nobody was around because B was off the ward and I thought well maybe ... maybe I got it wrong, maybe it ... maybe it didn't ... maybe cervagem doesn't kill the baby, maybe I just thought it did and ... I took the wee one [out], and then when A took the little one in to her, A and I left her alone and I came upstairs and I said: it was moving, she said: what, and I said: it was moving, that's right. I was really shocked. I didn't want to look after ... I didn't want 
to do it for a while anyway because I was so scared ... I won't know what I'm doing, I won't know what I'm doing, and I won't know what's normal.

The impact of this event on Sarah was clear, she felt unsure about the actions required of her, the trauma caused her to doubt her abilities and decisions, and her emotional distress is evident. Therefore, this clinical situation had the potential to cause a great deal of distress to both the women patients and the nurses involved. An example of this was given by Bridget when she described a situation that still, after a number of years, caused her pain:

Sometimes the terminations do not go smoothly and it's pretty horrendous and particularly for the young staff. I'll never forget one that I felt so awful about it. This young woman, it was an abnormal foetus and this young couple, and they were distressed about having the termination and I put a pan in the toilet and I said to the woman: you may feel that, you know, you're going to have a bowel motion but in fact it may be that you're going to deliver the foetus and, anyhow, she decided that she felt like that and she'd go to the toilet. She went to the toilet, nothing happened so she got back to bed and as she put her foot on to the stool to get back into the bed, she delivered and the baby fell on the floor, and it was so awful and I felt so terrible. Because I felt I hadn't managed her properly. I hadn't insisted that she wait on the toilet. She wanted to get back to bed and, oh, I just ... I really felt awful. I can still hear the noise because it was just awful.

Sarah's and Bridget's experiences were so graphic and were told in a way that showed the effect these events still had on them a considerable time after they had occurred. Their feelings of distress were so evident that I could not help but reflect on the way we unthinkingly expose nurses to situations such as this, with little or no thought as to their psychological safety. Wounding (Hall, 1997) of the nurses through their direct involvement in this process seemed almost inevitable. Active participation in this aspect of practice with so little support must affect the individual nurse. 
When a nurse works with a woman experiencing a mid-trimester termination she is involved in a multi-dimensional situation. She is supporting a woman through a uniquely female event which New Zealand women have fought to have made freely available. A fundamental principle underlying the provision of the service is acceptance that women have the right, although not completely without medical surveillance, ${ }^{1}$ to make decisions about their health and well-being, particularly in relation to fertility. It is clear that this was a major reason that the nurses, even though finding the provision of care difficult at times, believed that it was an essential part of their practice in the gynaecological setting. They did not reflect the seemingly judgemental attitudes that were expressed by nurses in Webb's (1986) research nor the more neutral feelings reported by McQueen (1997). As Bridget exemplifies:

I also know I haven't the right, and I, I couldn't, I can't walk in another woman's shoes. I know what it is like to think that you're pregnant and not want a pregnancy ... and I just feel that those women deserve to be looked after in the very best way they can. I also feel very strongly that we need to provide a proper, safe termination ... medical situation like the clinic or in here.

The experience is always very emotional for the woman, the reality of the event often catching her unprepared and leading to the woman requiring a great deal of support from the nurses. The actual physiological event that is taking place again requires complex nursing management, for example the induced labour requires monitoring and the accompanying pain must be managed. Women taking prostaglandins frequently experience uncomfortable side effects such as nausea, diarrhoea and palpitations, all of which involve the nurse in continual assessment and management. The procedure, although involving a woman that is well, requires much of the nurses in terms of psychological and physical knowledge, and clinical expertise. The nurse is required to

\footnotetext{
${ }^{1}$ In New Zealand two doctors or certifying consultants are required to approve the termination.
} 
draw on these skills to ensure that the woman is nursed in a supportive and sensitive manner, and they must remain emotionally connected to the woman throughout, as Rachel explained:

I mean we have a lot of miscarriages and recently a lot of terminations at 20 weeks. I just find them tiring really, because it's really ... you spend a lot of time with that one person and often it's that person and their partner and it's on quite an intimate, intense level so I find it quite exhausting.

If the nurse distances herself emotionally or physically from the woman this would add to the trauma the woman is already experiencing. After the woman has delivered, the nurse is involved in the actual management and disposal of the foetus. She cleans the foetus, transfers it to a basket if the mother wants to see it or deals with it according to the hospital protocols. This often occurs after a lengthy period when the woman and the nurse have been intimately connected through decisions being made about whether the mother wants to see the baby, name it, photograph it, and/or take it home.

The physical experience, the psychological distress and the decisions that are made are all obviously extremely distressing for the woman, but it appears that no-one has considered this from the nurse's perspective. The woman may go through this process once in a life time, the nurse will go through it a number of times a year or, as happened recently, up to three times in a week leading to the nurses making comments about feeling like a mass murderer. If a nurse holds definite views about issues such as termination of pregnancy, then a situation such as mid-trimester abortion poses no dilemma. You simply will not work in this area of practice if you do not support abortion. In some ways polarised views can make life, and nursing practice decisions, easier. It is nurses that continue to work in the spaces created by polarised views, that struggle with the complexities of such work and try to accommodate the requirements 
of society, the patients and their own beliefs. It is these nurses who face the tensions and personal dilemmas inherent in such emotionally charged work. As Bridget said:

I do struggle with it. I have struggled with it. I struggle with it on a spiritual level because, as a Christian, I do feel that it isn't the right thing to be taking a life. However, on the other hand I struggle with the fact that there are many kids out there ... who are, and this sounds judgmental, but the reality is that they are not receiving the kind of parenting that enables them to have a secure, stable homelife to nurture them through their childhood and I do feel that some children probably have, should have the right to say no, I don't want to be born.

Rose goes on to explain that nurses who were prepared to work with women in this way have to confront their own beliefs in a manner that may not be required in other areas of practice:

I think you have to look in to your morals and things like that because you're dealing with pregnancies and that can be miscarriages and terminations, and those terminations can be for social reasons or congenital abnormalities. So I think you have to look at your beliefs and things like that and whether you're comfortable nursing women like that or whether your beliefs are going to stand in the way of you caring for those women, and with that there's your own sexuality and self-image and those kind of issues ... In a way you have to be comfortable with yourself and how you feel about yourself and whether it does bother you if a woman is having a termination ... or whether your religious beliefs or whatever ... and whether having to do all that is going to affect you or affect the way you will care for those women. I think those are the things you have to deal with and you have to know when you come here that those are the kind of things that you're going to have to deal with.

However, there is a problem when nurses work in the area but have the right to decline to care for patients that are under-going mid-trimester terminations. The nurses recognised that you should be able to refuse to be part of the practice. However, as Sarah said, this places a strain on others and requires those who will nurse the woman to be involved on a more frequent basis:

I think that you shouldn't have to look after people like that, but I think it makes it quite hard on the staff if you get three or four people 
that won't do it, which is what happened when I first arrived here. There were quite a few staff that wouldn't look after mid-trimester terminations and so the same staff were doing it all the time and they resented that. They resented ... oh god I'm the only one on that's going to do that and so it'll have to be me and I've just done the last three.

The explanation of mid-trimester terminations, what it means in reality for practice, was not explained to the nurses when they applied for a position in the area. Although they may be asked whether they minded nursing women who are going through the experience, they were not told in detail about the nursing responsibilities that would be part of their practice, to enable them to make a well-informed choice. Sarah describes her early experiences thus:

Well when I first started working in this ward I had ... I was just so blown away by what, what I saw in the ward. The first day I arrived we were being shown around, by [two staff] and the photographer was taking a photo of a foetus, and I thought it was a baby bird ... I honestly thought ... it had been in the fridge all weekend and it had dried out, so there was this little thing on the floor and a flower beside it, on a bluey [small absorbent sheet]. I just never thought, and I just carried on "cause she said: this is the sluice room, and I said to [another new nurse]: what are they doing? And she said: well I think it's a foetus. I had never thought, I'd never actually thought about how I'd get to see them and ... I don't know what I thought. I didn't know about mid-trimester terminations ... I found that quite shocking really and that was probably a big stress when I started actually. I didn't know that, that people had mid-trimester terminations and I didn't know that I would be a support person, that, that's what we did, we were there as a support person ... I didn't actually know that that's what happened. I don't know what I thought, I think I just assumed that they went to theatre and that was that.

Isabelle also stated that she was not clear about the reality of the terminations, "I knew that there were terminations but not so late on. No I had no idea about that. That was a real shock." Although she had not yet had to care for a woman going through this experience, now that she knew what it entailed it raised a real dilemma for Isabelle and she had to confront her own opinions about terminations: 
There's been a few here but I haven't ... I don't know. I don't think I could cope, 'cause the last time we had one of those, a woman on the ward I think she was 20 odd weeks, it was just awful. I had a real problem with it.

The only way out for Isabelle was to avoid looking after a woman in this position. She went on to say 'If I couldn't [avoid it], then I'd look after her and I'd look after her like I look after everybody else." She acknowledged her feelings openly, however, when she said, "It's awful 'cause the babies come out so beautiful and perfect and, it's criminal to me it really is." As Sarah points out, if you have these feelings it would not be in the woman's best interests to be involved in her care:

I don't think you could nurse somebody if you felt ... if you were ... if you had strong beliefs that it was immoral and things like that. I think it would be terribly wrong of you ... because they would have to know ... people aren't silly, you can pick up vibes.

However, even for nurses like Bridget who are clear that it is the woman they focus on in relation to terminations, it is still not easy and leads to questioning of their feelings:

How do I deal with it when I've taken someone through a late termination? Um, I think I've put it in the too hard basket. I ... sometimes I feel sad but I guess I actually quite often feel concerned that I don't feel sadder about this foetus lying on the bench. I feel I should feel more distressed than I do. I talk about it with my husband, no names, but I will talk about the fact that ... but it ... even with late terminations my feelings are much more with the mother than the baby. So yes, my definite emphasis is on the mother.

I felt that this separation of the nurse from the reality of the foetus lying in front of her was a realistic defense mechanism that made the process more manageable. The nurses' feelings are for the women, yet their accounts of working with women show the way it also makes them feel. As Sarah said:

I find it very hard [mid-trimester terminations], we had a very young girl, she was eighteen and that's probably the worst one I've ever seen, and that was hard. I don't know how she'd get over that really. Even though she'd been told and she knew what to expect, she had no 
idea, and as soon as the pains started coming, well she just couldn't cope and it was a long labour. She was in pain for twelve hours, it was just awful.

We are required by law to provide a service for the women of New Zealand, yet due to the nature of this service nurses, also women, can suffer. The issue, then, is how we care for and support both the woman and the nurse who is working in this multidimensional and often emotionally exhausting situation, which has the potential to be psychologically unsafe for both.

The fundamental tenet of feminist praxis, of placing the woman as central to all other considerations, can be applied in this setting and is, as previously stated, the reason nurses gladly support the woman through her termination. However, on closer examination this is problematic. Placing the woman patient as central is obvious but what of the nurse, she is also a woman. My concern is that as feminist activists we have lost sight of the fact that terminations have to be managed by another woman for whom we have given no thought. As Bridget pointed out, it is not just assisting in the death of the baby, by your actions you are actually procuring the death of the baby, a being that is a voiceless participant in the process. This situation is quite different from, for example, giving very high dosages of morphine to cancer patients when you know this may hasten their death. In that case the death may be inevitable due to the disease, usually the individual is aware and participates in the decision to take the medication, and there is not another being who is directly affected by the decision. In the case of the late termination the death is not inevitable except for the rare cases of extreme physical abnormality such as encephaly, and the nurse is actively assisting in the death of the baby, an entity with a clearly human form. To ignore the impact on the nurses is unacceptable. It is uncomfortable, as a feminist, to say that the importance of women's 
experiences should be prioritised, that one woman's experience is more deserving of consideration than the other.

I found listening to the nurses' stories, and hearing them describe their feelings and their struggle to balance their personal philosophies and beliefs with the requirements of a service provision, an experience which directly challenged my feminist beliefs. My initial feelings about the nurses and my concern about my academic positioning are revealed in a journal entry during the data collection:

I am unsure about my feelings now in relation to the nurses. When you are away from practice for a considerable period of time and immersed in theory you tend to critique the nature of nursing practice rather harshly due to increasing distance from reality. However, being back in the area has brought back the pressured nature of nursing practice in this setting. Of course the nurses, at times, function in all those ways we talk about - reductionist, task driven and judgmental, comments like: oh she's a real sweetie, or: she's a bit of a dying swan really, are used but they do have a genuine concern for the women and their lives and they "feel" a lot. I have no idea whether this is "caring" I respect the nurses as being between the patients and the doctors - basically at the beck and call of both, but whereas the patients don't "call" as they think the nurses are busy, the doctors do and expect the nurses will respond which, due to the nature of their roles, they do and feel they would be irresponsible if they did not. Sometimes the nurses are off-hand and perhaps don't give the best care they could, but doesn't that happen to people in all situations, are we still expecting something along the dedication, devotion and selfeffacement lines of old which is perhaps an assumption that underlies some of our criticism of ourselves.

For a number of years I believe I had a view of nursing that placed it within the medical hegemony, a part of the oppressive practices carried out in the hospital. I believe this is an element of using the term nursing and the label 'nurse' and relates to my discussion in the previous chapter of the essentialising nature of the term nurse. As a feminist I had not considered the fact that nurses, as embodied women, experience the working world in a different way from other health professionals, whether men or women. Nurses 
cannot be included with any other group because to do so is to ignore their unique concerns. An example of the problems of this may be that of the Unfortunate Experiment at National Women's Hospital (Coney 1988) which I have discussed in Chapter Two. The invisibility of the nurses in terms of speaking up about the research, and the comment at the Cartwright Inquiry about the silence of nurses, I now believe reflects the position of those women who were nurses, within the system at the time the research was being undertaken. A lot of criticism has been aimed at the nurses from both inside and outside the profession, for colluding with the medical profession, yet as a feminist I now believe that the conditions under which those nurses practised would never have tolerated a challenge to the power of the medical establishment. Although power may be considered as discursively constructed and contestable (Shildrick 1997) in the nurses' interpretation of relationships with medicine at that time they considered themselves powerless. The lack of nurses coming forward does not surprise me, the lives of the nurses reflected the lives of women during that period. A feminist exploration of the experiences of nurses at National Women's would be more useful, informative and appropriate to gain understanding, rather than criticism and approbation.

\section{Coping when women have cancer}

It was the experiences of the nurses working with women having mid-trimester terminations that first made me aware of the possible impact of nurses' work on their own state of being. However, as I explored the idea I became aware of the impact nursing women with cancer also had on the nurses. I had an awareness of the issue because of the implications of nurses remaining connected to the patients by their shared embodiment as I have discussed in the previous chapter. However, the 
psychological safety issues inherent in the process of nursing women like themselves was not initially in my thinking. The nurses felt an obvious connection with women who had a diagnosis of cancer and in many instances took this very much to heart, as Isabelle described in relation to a woman she had been caring for:

Sometimes it's difficult I mean, I think about things, you know, I think about how they must be feeling, they're sick and I'm well and how they must think ... last night I couldn't sleep but I was thinking of Mrs A the lady who went to theatre yesterday. She's about the same age as me and she's got [a number] of children. ... I mean it's awful, but particularly the mothers that have young children and the doctor said yesterday about Mrs A, it wasn't even just the fact that she was dying and hadn't had a good day in surgery, it was the fact that they had social problems too, their children were hungry, and she [Mrs A] turned around and she got wind of that, the social worker had got a food parcel to them yesterday or the day before and she got wind of it and she turned around and she said: are my children hungry? And the doctor, she knows that that would be the absolute pits, being sick in hospital and not being able to do anything and having children that were hungry would just, you know, it was that sort of thing .. and it just really gets to you. Just having all those problems on top of being sick ... It makes you, it makes you more ... it makes you grateful for being healthy and being able to, you know, to live and work and to be ok.

Although some of the more experienced nurses now found they could cope with situations such as the terminations, the difficulty of working with women who had advanced cancer was something they still felt, as Sarah said:

I probably find looking after people that have been told they've got cancer and it's very advanced and there's not much we can do and they've got a young family, whatever ... whatever the reason is, that's probably the hardest [part of practice].

An element of the care of the women with cancer was the frustration the nurses felt at not being able to positively contribute to the woman's outcome, accepting the reality of the woman's condition was hard for the nurses both in terms of their own adjustment and the reality of nursing very sick patients, as Bridget explained: 
We are getting more very ill people who are ... who have advanced ovarian cancer and that is certainly impacting on us, and you don't seem to be able to sort of move a patient along and get them to a point where they're feeling, where they seem to be feeling better and they are more independent which happens with most patients, they get over that initial hurdle of being immediately post-op and needing a lot of care and you know ... but these very ill women ... we seem to ... and I'm not sure that we're adjusting well to that, now I'm not sure that I adjust to that very well ... and the thing is that I don't think ... because we don't actually acknowledge that those women are not going to only have a period of say three or four days acuity, in fact they are going to be in that situation for maybe three weeks. So our ... we haven't really mentally shifted and I don't think we always staff to that [level of acuity]. Because those women almost need one to one nursing all the time ... so there needs to be both a mental and emotional adjustment amongst the staff.

All the nurses expressed their feelings about the diagnosis of cancer, particularly in young women, which again confirms their natural feelings of connectedness to the women. The nurses empathised with the sadness of the patient's situation and their frequent comment on the hardness of the work shows the continued effect on them. All the nurses were capable in terms of managing the actual physical tasks involved in caring for the women. As Bridget explained it was absorbing the reality of the situation for the woman that made the work hard:

The Wertheims [an operation for total removal of uterus, fallopian tubes and ovaries] or the ovarian cancer women, and they [the fulltime staff] will get more involved than I will but I only do one duty here and one duty there over a week, but if I work with a person and get some continuity ... the young Wertheims, you know we had one ... we had two women who actually had conceived and here they were having to have a Wertheim's hysterectomy because they had carcinoma of the cervix and they're pregnant. So they had to have a ... and they wanted to be pregnant, so they had to have the surgery and obviously it was going to be a termination of pregnancy too. That was hard.

What made this aspect of the work more difficult for some nurses was the lack of acknowledgment of this stressful aspect of the work, as Alice stated:

I find it hard coping with young people's terminal diagnoses and dealing with the grief of that and seeing the nurses' work not 
acknowledged by the medical team in that area. Nurses work in this ward a lot with terminal diagnoses and staff get really drained by it.

However, although Alice specifically mentions that the doctors did not recognise this element of the nurses' work, it was clear from my own observation and the nurses anecdotes, that although individually acknowledged by nurses, this aspect of practice was not formally acknowledged by the either the medical or nursing management in the area.

It became obvious during my research, that while the emotional labour inherent in the nurses' practice was something they individually acknowledged, it was not formally managed in any way. The nurses struggled to keep themselves intact and safe when managing stressful situations. They used nurses' traditional methods of coping, that is relying on colleagues, particularly those that you become friendly with due to shared experience, to provide an informal support network. Sarah explains the importance of this informal support, particularly when she first started in the area, "Luckily I had started with A and we both felt the same, we were finding our way at the beginning and so we just talked together which was good." She went on to say:

It's wonderful. I don't think you'd cope [without it]. I don't think you could cope. Well I couldn't anyway. It was nice for me to know that ... that A was having ... that A was thinking: oh my god. And like when I went up to the abortion clinic it wasn't till afterwards and I came back and she said: can you ... what did you think of that place? I said: oh it was pretty awful, and she said: I couldn't believe it. And that I wasn't the only person that thought that. I felt very naive actually when I first started working here.

Isabelle also was clear about the importance of shared experiences and how that helped her cope with her exposure to the reality of working with the grief of the women:

Particularly like the new ones [staff], like there's been a few new ones and we've sort of stuck together to deal with the grief situations, 
whereas the, the older staff, the more senior staff, I suppose ... I don't know if you ever get used to it but they ... I think they become more able to cope I suppose. I started around the same time as A and B and we were like oh my god, and we'd talk after work and you know, isn't this awful and that would really help but we'd feel a bit silly going to the senior staff probably and so ... maybe not.

Informal support also meant using people outside the service and friends who were not nurses. At times this was seen as more effective, as Alice explained:

So I have a couple of staff in the ward that I do it to [let off steam], that I'll phone and have a burst. And I have one good friend who is outside nursing totally, who I do it with because she seems ... although it's like talking to someone who hasn't got a clue and it's nice to talk to someone who doesn't have a clue because if you talk to another nurse they'll say: yes I know and exactly the same thing happened to me today, and you don't really want to hear that ...

This type of support is essential and will naturally occur between nurses in the unique and stressful world of working with people who are unwell. However, it does raise the issue of how we expect nurses to continue to care for others when they are not provided with the structures to care for themselves in this type of setting. The need to talk about their experiences becomes quite obvious when you hear the nurses describe the details of their work. It was clear that the nurses try to deal with the stress that their feelings engendered, by talking to people they felt safe with, but why is it that in nursing we rarely recognise and provide the space for that talk as part of a nurse's work environment? Not that every nurse would need this, or need it all the time, but certainly when struggling with stressful elements of practice for the first time, or coping with situations that have not been managed in a way that the nurse feels comfortable about, it seems that caring for the nurse should be of equal importance to caring for the patient.

All the nurses used other nurses for support. Their Otherness, in terms of being those that care for the sick, has always ensured that talking with nurses who understand your 
world, is vital to continuing what is very demanding work. However, it seems that the nurses themselves recognise that particularly difficult situations require more than that. Bridget was quite clear about the lack of formal support, "I don't think we deal with it appropriately, completely, well enough here. I think there should be a, what's the word? [Annette: Debriefing?] Thank you, a debriefing situation for staff." Isabelle also acknowledged this lack:

There's not, not a great deal of support, I mean we're all very sympathetic and we all ... we talk about it and I suppose that's helping in ... but, you know, if, if a nurse is really, really upset about something obviously, another nurse wouldn't say: come and sit down and let's talk about this, it's not ... there's not always time to do that ... and it's not done, I've never seen that done ... I think that you are expected to deal with it and just get on with it really.

In some health services areas particularly oncology wards, hospice nursing, and mental health nursing, the effects of nursing very ill, disturbed or dying patients are recognised and strategies developed to support the nurses in their practice (personal communication). Clinical supervision is recognised within the discipline as being an important issue that nurses should be pursuing in the interests of maintaining their own safety (Irvine 1998). However, it seems in general or acute areas in the hospital the difficulties imposed on nurses through their practice are not acknowledged. Often the only support a nurse can get is that available informally from her colleagues who are sharing the same experiences. The impact of some of the accepted practices that make up the nurses' daily work is not recognised in any formal way and support from the institution is not offered or asked for. It is important to recognise that we, as nurses, do not appear to have considered ourselves or each other and the possible effects of these practices, other than in the very obvious situations such as cancer services, where support to deal with grief and emotional pain are a central part of services concerns. 
women they nursed. Nurses relate to both the problems women experience with their bodies, and the invasive procedures they are subject to as a result the inscription of medical practices on the body. Nurses confront, work and interact with the female body as a biological fact, and when they do this they are confronting an image of themselves as an object at the intersecting discourses of science, medicine and nursing. They work and identify with the women and evidence shows that this makes life stressful for the nurses.

This chapter was difficult to write. Reducing the nurses' experiences, including their responses and feelings, to text, required careful consideration of meaning, and I also had to take every care with the ethical issues to ensure the safety of the nurses. I have presented the nurses' experiences as they were offered to me and perhaps any sense of discomfort felt by the reader of these stories will, in some measure, allow them to enter into the world of the nurse where she is expected to cope with these aspects of practice. In the interests of the safety of women, that is the nurses and the women they nurse, we have to explore these hidden aspects of practice. As Jocalyn Lawler $(1997,49)$ says:

And because we are fundamentally a practice discipline and have a need to speak within, from and to the practice of nursing, we have a need to give voice to our own business. In that sense, much of nurses, business is like women's business - it is taken for granted, it is storied, it is grounded in experiential knowing, and it has been silenced in a patriarchal world.

An additional concern is that as a feminist nurse by not thinking of the nurses' role I may have contributed to the silencing of their voices. As a feminist and a nurse colleague, I feel I have a responsibility to surface, make explicit and address this aspect of the nurse's work, to be part of a process that will enhance the autonomy of women as nurses and enable us to acknowledge and support our unique practices. 
Actually entering into the reality of the woman's experience in gynaecology, of actively engaging with that experience may be so emotionally difficult and feel so unsafe that the nurses may choose to avoid the situation and distance themselves, as a means of coping. I realised how little we speak of these day-to-day dilemmas, and how little support nurses get when managing such challenging situations. I felt strongly about this because of my commitment to feminist principles, and came to believe that, particularly in relation to the mid-trimester terminations, as a feminist I had disregarded the impact on this group of women, of a right for which I had worked. It felt as though I had been part of a feminist discourse that had almost positioned nurses as non-women. As a feminist I had not been aware of the possible impact on the very group of which I was part, labeling a woman as a 'nurse' meant she just had to cope. By uncritically accepting this essentialising of nurses I was supporting the notion that there is something fixed in terms of being a nurse just as Elizabeth Grosz (1994a) argues in relation to the essentialism inherent in the category women. Maybe the lack of recognition of difference amongst nurses left us able to ignore the potential for causing harm. I felt a sense of obligation in terms of making explicit these dilemmas through a feminist lens, and in being active in making the practices of nursing safe for the nurse.

The emotional connections inherent in nursing practice is a factor of the embodied nature of nurses' work and means that nurses have to actively manage this dimension of their everyday practice in some way. The rather ethereal notion of nursing practice, discussed as something separate from an individual nurse, allows for the abstraction of practices and a lack of recognition of the effects of clinical practice on the nurse as an embodied person. In the area of gynaecology, emotional work as an integral part of the nurses' practice would not be an issue if the nurses did not connect themselves to the 
Along with the complexity of nursing women and the difficulties nurses experienced as a result of some significant aspects of working with the women in their care, they also had to manage the relationship with medicine. The medical discourse structured the nurses' daily work and provided another layer of complexity to their practice. The nurses seemed responsible for managing the requirements of this discourse at the macro level and also at the micro level of daily interactions with individual doctors. The next chapter explores this relationship particularly in terms of how the nurses consciously manage their interactions with medicine. 


\section{Chapter 8}

\section{Power and resistance: nurses working with/in the medical discourse}

rior to entering the nurses' world I had not considered exploring the relationship
between nursing and medicine or the nurse-doctor relationship specifically. It was not that I was unaware or underestimated the importance of this but it is a topic which has been addressed by researchers from within nursing (Sweet and Norman 1995; Watson and Feld 1996), and certainly is an area of interest for researchers in many other disciplines (Carpenter 1993; Svensson 1996). It seemed that realistically we could consider this relationship as at times collegial and at times problematic, something that nurses have to work with in areas such as gynaecology where there is a heavy medical presence. However, as I came to be part of the nurses' reality the importance of this relationship and the way it impacted on individual nurses became unavoidable. It became obvious that this was a central issue in the day-to-day practice of the nurses, an issue that they had to actively work at, in the interests of their patients and their own positioning. The nurses raised it as extremely important in their lives and so although initially I did not feel it was an area that I would necessarily pursue, in the light of my conscious positioning of the nurses' concerns as central to this research I realised it must be explored. This chapter then explores the relationship between the nurses and the medical discourse, foregrounding the nurses' voices and focusing firstly on how this relationship is experienced by the nurses, and secondly on resistance in terms of the strategies the nurses use to manage the relationship. 


\section{The nature of power}

The acute, and surgical, nature of the gynaecological services requires nurses and doctors to work together, to interact, and live their working lives in close proximity in a very unpredictable work environment. Nurses' interactive work with doctors in this area is time consuming but central to their practice. It became clear from my formal and informal discussions with the nurses that these were the most difficult relationships they had to manage. The difficulty arose because the nurses struggled with individual doctors, their personalities and practices, as well as the overarching discourse of medicine, and the power and control it exerted in shaping their lives in this setting. The relational work with doctors reflected power relationships which structured the area and the nurses, although being well aware of the doctors' power, strove to work as freely as possible within the structure. There seems an inevitable tension in this area that may relate to the environment which, although in a way belonging to the doctors, is in fact the home of the nurses on a continuous basis. The nurses had chosen to work in this area, they were clear about their choice to either work with women or work in the area of women's health, whereas many of the doctors at trainee intern, house surgeon and registrar level, were merely undertaking the gynaecology and obstetric rotation as part of their general experience in the hospital setting, something they had to do. These doctors changed in three or six monthly cycles, whereas the nurses were much more stable.

When I was collecting data in the gynaecological area for this research I realised that in fact nurses are not the oppressed and subordinate group that I initially thought, and resistance was a notion that encompassed certain practices the nurses described in early conversations with me, which I recorded in my journal thus: 
After working with Rose on Monday I began to realise that the nurses I have spoken to so far clearly identify points of resistance to the prevailing discourses. All three nurses have identified the discourses that they consider shape practice, that is managerism [the system] and medicine. Yet all three also clearly articulate places where they resist strongly the effects of these discourses both on themselves and in relation to doing what they think is best in the interests of the women they are nursing at the time. The [nurse leader's] whole account was a point of resistance and it is interesting that the other two specifically pointed to her management style as essential to their feeling able to practice in a way that did challenge prevailing ideas re management and medicine, and the effects on the experiences of the women.

There is no doubt that the practice of medicine controls the gynaecological area and that the nurses are, to a certain extent, controlled by those practices. However, at times the nurses actively resisted the power of the controlling discourses, they were not victims but rather could be seen from the feminist postmodern position as constituted as different subjects at different points in time (Shildrick 1997). The nurses seemed to shift within these discourses, using a variety of practices and behaviours depending on their interpretation of events. Judith Parker's (1997) notion of the nurse being hybrid was evident in their shifting subjectivity as they worked within the various discourses shaping their work this area. They were not passive subjects, nor did they see the women they cared for as passive. Rather than being victims in the system, the nurses made conscious decisions based on their own experiences and those of the women they were caring for, in a way that tried to circumvent the oppressive discursive practices of the hospital system. At times this led them into confrontation, particularly with the medical system. Each nurse set her own limits in relation to just how far she was prepared to go in challenging the system, the choice being based on personal beliefs about her power in the setting. 
The more senior nurses felt the imbalance in power strongly, confidence in their own knowledge was matched against the powerful position the doctors held just by virtue of their discipline. The rights conferred by this powerful positioning were clear in terms of giving permission for behaviour, particularly from junior doctors, that led to nurses feeling Other - undervalued, unrespected and powerless. At times it is difficult for nurses to see the possibilities ascribed to this position of otherness and marginality by authors such as Rosemaire Tong (1992). As Alice said:

And the nursing opinion not being respected is very disturbing for the nurses, because people [nurses] have been here for a while and you expect that when they say something, that they've said it based on some knowledge and not just off the top of their head for the hell of it. But the medical staff don't understand that. Now from their perspective they're new to the area, they don't know who knows what's what, and they can't take that risk, but for the nurses here it should be acknowledged that their body of knowledge is probably greater than some of the SHO's [senior house surgeons] without any doubt. The more confident the doctors are, the more likely they are to accept a nursing opinion, or to ask things. It's when they lack confidence in themselves, in their own decisions that they can't trust us. So that sort of stuff causes conflict, and then there's the feeling that some of the doctors feel as though they can speak to you like you have no value and it's part of life that we [the nurses] all seem to feel ... it's something that doesn't happen in any other area of life except when we come to work. Well, you walk out these doors, and there's people out there that respect you! Who wouldn't dream of speaking to you like that! And even if they didn't respect you probably wouldn't speak to you like that! But in here for some reason, it's quite, quite acceptable, and we feel powerless to do anything about it.

The relationships between doctors and nurses, particularly in relation to power, were made explicit and normalised by the practices of the doctors in the area. Because of the nature of the acute gynaecological service and the interdependence of medical and nursing practice, this powerful and at times demeaning medical discourse had to be accommodated by the nurses. Although Alice said that she felt nurses are powerless, I believe the nurses worked at setting boundaries to medical power. At times the actions of the nurses showed a very clear resistance to the prevailing practices of medical 
discourse and they appeared active in the discursive structuring of power as discussed by Foucault (1990).

The nurses gave examples that illustrate the power of the medical discourse and the manner in which the doctors believe they own and control the experience of the patients. Although discourse was not a word that the nurses used, examples such as the following from Rose, where she discusses alternative health practices and orthodox medicine, acknowledge medical power:

I believe that if somebody doesn't want to have treatment that's fine as long as they're quite clear why they don't want to have treatment [but] people choose not to have conventional western medicine and then come back and that can sort of be quite detrimental for them as far as coming back into a system where the system is very aware that they went to alternative medicine. Whereas I don't see that as a problem really, because it's part of them trying to control their health and also I don't personally think that western medicine has all the answers so ... a lot of cancer patients where they are scared of having surgery, they don't want radical surgery ... they'll quite often go away and try something else and may end up coming back into the system because of bleeding really heavily and it hasn't worked or it has only worked for a certain amount of time. I still think they get the same treatment but there is that atmosphere, she had alternative treatment and it's sort of like a black mark against her. You'll always be aware of it, and it's almost taken like a personal criticism against the doctors because of the fact that they think: well they refused the first time and if only they knew I was doing them a favour taking them in next time ... It's alright to try after nothing else has worked, like it's alright to try if you're dying and you've tried chemotherapy, you've tried the radiotherapy, you've had the surgery and you're on your last legs, then it's fine to try alternative therapy, but try it first and ...

The individual controlling practices of doctors also provided an insight into their beliefs about their powerful positioning. Sarah described the actions of a particular doctor and was quite clear about her opinions in relation to medical practice:

And there's a few doctors around with the attitude: well she doesn't need to know that, if I tell her she needs an operation, she gets an operation, and that's what he said. These doctors have no empathy. Like she's moving house and for the first time in ten years is having a 
holiday alone with her husband and he just says: well you're bleeding and you have pain and you're not going anywhere, and if you'd gone to theatre last night you wouldn't be feeling like this now [vomiting and miserable]. But I'm sure the specialist said he wouldn't do her last night anyway. They're awful, like they're just so fast and she had to call the SHO [Senior House Surgeon] back and say: can you please tell me what's happening?

The power of the medical discourse in structuring and controlling the practice of the nurse and her involvement with the women's bodies was clear when the practices of medicine were documented. It is in the implementation of these practices that the doctors' power over patients and nurses resides. Doctors are considered responsible for the admission of women to the area - either acute or planned, diagnosis - undertaking major interventions such as surgery, determining progress and agreeing to discharge. Nurses work within the boundaries of medical decisions in relation to these aspects of patient management. For the nurses some of these practices could be very contentious. An example of the way the nurse's work is structured by her relationship with medicine was given by Bridget, a very experienced nurse, when she described her frustration and mounting concern over the medical decisions which shaped her care of a patient:

I mean on Friday afternoon we've got another elderly patient in this ward. When I took her over on Thursday afternoon, she'd had her catheter out in the morning, she was in pain and I gave her intramuscular pethidine. She couldn't void [pass urine] so I put it [the catheter] back ... so that was her second catheter, that was Thursday afternoon. On Friday morning we were told to take the catheter out again, she was barely drinking because she didn't feel like drinking, added to which she is NIDDM [non-insulin dependent diabetic], so we took the catheter out, I did as I was told, I took the catheter out, took the IV line down and two hours later, oh I should add that when I recatheterised her on the Thursday afternoon she only had $150 \mathrm{mls}$ in her bladder but pre-operatively she had been going to the loo about every hour. So what's her muscle tone and bladder tone like? Anyhow, so on Friday I took the catheter out as I was told, took the IV fluids out, two hours later she's writhing in pain, gave her some more pethidine, encouraged her to go to the loo ... she cannot void. So I rang the house surgeon and he said: Oh. I said: you were going to chart voltarin, and he said: oh I want to review it or something like that. Another hour goes by, I'm handing over to afternoon staff, so I try him 
again. He said: oh well give her the voltarin and if she can't void put the catheter back. In the end I rang him again and said: look, this woman cannot void, we need to put a catheter in ... do you think we need a suprapubic catheter? Oh I'm not putting in a suprapubic, he said. Well, here it is Monday and the woman has had now four indwelling catheters. Now where is the appropriate management of that patient Annette? They're not looking after the patient.

Most nurses found the limitations to their practice imposed by medical protocols, irritating. For example, often the nurse knew that a woman was well enough, and needed to go home for a number of reasons which related to her life outside hospital. However, both the nurse and the patient may have had to wait for a considerable period of time, often for a junior doctor, to carry out a further assessment of the patient. This assessment was often based on measurable data such as laboratory results, plus a brief discussion with the patient, both of which the nurse would have already woven into her assessment. The nurses found this situation frustrating and humiliating, often leading to them feeling embarrassed, and that they had not worked well with either the patient or the doctor. All the nurses described situations where they and the patients had to wait for long periods of time. The patient feels the nurse is part of the reason she is being kept from leaving hospital, and the doctor feels that nurse has no understanding of the urgency of medical work and that it has to be prioritised. As Isabelle described:

I came on in an afternoon shift and went down to scanning to find the scan [of a patient] and it wasn't ready, hadn't been typed up, then about half an hour later it arrived and I rang one of the doctors to come and view it. He said he'd be up and he came to the ward saw somebody else, didn't even look at the scan, then left the ward again. She [the patient] by this stage was just ... just had enough and she just said: I've just had enough, I've got my young baby here, and she was really stressed and just wanted to go. I said: I'll get back in touch with the doctor again. Phoned the doctor and he just said to me that he had more important people to see than her and that she wasn't sick, she was hysterical and he'd get up there and see her when he could. He slammed the phone down on me. 
Although the nurses recognised the implications of this situation for the women in terms of many precious hours spent waiting, challenges were only made by the nurses who felt confident about their knowledge and ability to make autonomous decisions. Henrietta, for example, had confidence not only in her own ability, but in the innate commonsense of the women:

We are not stupid and this: no she can't go home until the pain has gone for 24 hours, and you get women with me actually encouraging, saying: go if you want to, no you don't have to sign yourself out I'll write that you wanted to go and you've gone. We're a 24 hour service, all you have to do is ring and you can come back any time you like, we will not turn you away because you scarpered ... but the doctors haven't got the confidence that the woman will come back.

The responsibility for the maintenance of nurse-doctor relationships seemed to belong to the nurses and, in this way, appeared to reflect social expectations that relational work is women's, and therefore nurses', work, a reflection of attitudes Deborah Lupton (1995, 160) ascribes to "the relative meanings of masculinity and femininity that adhere to the doctor and nurse role". This was acknowledged in the following account from Bridget in relation to a particular doctor:

She had a wonderful bedside manner, we've actually had two woman doctors like that in the last couple of years, who have had really excellent bedside manners. They've been really patient focused. One was a [type of doctor] and she was told by the consultant that she was behaving like a nurse ... because she used to sit on the side of the bed and talk to the patient.

An entry in my journal explains how influential I thought the nature of the work, and the pressure inherent in ward practices, seemed to be on nurse-doctor relationships. How this was handled by the nurses was significant:

I think it is the doctors at house surgeon level that seem to cause the most friction, it may again have a lot to do with the acute nature of the ward. For example, last week, the ward was about half full and on top of that over the am and pm shifts there were 17 women admitted acutely, at least half of them went to theatre. This puts incredible 
pressure on the nurses and the doctors, everyone is fraught but the doctors seem "allowed" to take this out on the nurses, whereas the nurses have to just bite their lips and get on with it.

The nurses absorbed behaviour which reflected the power difference. Although the independence of the nurse was encouraged through the nursing discourse, as I discussed in Chapter Six, by being subject to certain behaviours the nurse was reminded of the imbalance in power and authority between nurses and doctors. Sarah explained the effects of this in relation to specific problems she had experienced:

... we realise he just had a paddy and threw the syringes on the floor and things. I mean, at first I used to feel ... I didn't like it ... I felt really threatened and when he gets mad he gets really close to you and shouts and, you know, really gets in your space. You know, I can't, I can't deal with that. I do find confrontation quite hard. I think there is a time and place for it and sometimes, if I'm feeling quite emotional and that, I have to go away and get a ... take a deep breath and just, just carry on.

It is more difficult if the nurse is relatively new, her positioning and lack of confidence can make it harder to respond to overbearing medical behaviour. This was a situation Rachel felt was compounded by her embodied position as a young women:

I think at the moment we don't really have good communication at all between the medical and nursing staff and that makes it really hard, and it makes it especially hard as a new grad, a young woman coming in here, the others can be really assertive with the consultants that come flying in here dishing out orders.

However, the nurses maintained some sympathy towards the doctors and recognised that they were also under pressure from the 'system', something they both had to struggle with. As Rachel explains, "They [the doctors] start off ok but they change, they just get really burnt out same as we do, I don't know how you overcome that ... everyone gets rundown and tired because they're fighting a big system too." Rose also felt that there were mitigating reasons at times for the way the doctors behaved: 
I think a lot of it probably comes from stress to be honest, because at times it can get very stressful here and while they're [the doctors] examining another woman or trying to work out doing an assessment up here, they might have been paged easily three or four times and that constant pressure that they've sort of got to churn through ... so I think a lot of the time they may just examine them, write what they want done in the notes and they're gone and you think well hang on a minute. They come across as quite rude and the fact that they haven't communicated because they've written something in the notes then they may have had to dash off to delivery suite for some emergency and they haven't finished and you don't know what to do with the woman, you don't know where they're up to. It can make things quite stressed and quite difficult.

Other nurses such as Henrietta were not quite so forgiving stating that "the docs take level three papers in arrogance and control, they like to seem to control everything, you know, they like to control the patients, they like to control the nursing staff as well". However, Rose felt nurses had to take some responsibility for the relationship. There may be difficulties, these could be accommodated within the notion of helping the patients, the smooth running of the area meant working at the relationships between members of the 'team'. As Rose said:

Well it's a two way thing isn't it, respect for your judgment, whether you meet them half way, I suppose I think you need to always meet people half way. I think that it's good that they [doctors], come and tell you so they're communicating with you, but also sometimes it's important for you to go and ask them ... and help them because I think essentially we're here for the woman and you're a team player so the important thing is that we basically get our act together so that we're giving the best care to the women.

Also, the problems of communication with the doctors were seen by Rose to have a positive side in terms of developing the possibilities of nursing practice:

Well I like the work, I like women's health it's interesting, I like the autonomy that you have. Because the fact is, we don't get a lot of communication but we get a lot of autonomy, basically they're [doctors] very heavily reliant on our assessments and our interventions. 
An example of this reliance on the nurse's ability was the admission procedure which resulted in the patients being seen in the first instance by a nurse. She would often carry out an assessment and collect the initial baseline data. In this situation, as Rose says:

I think you're almost the eyes of the doctor so you have to quickly do like a physical assessment and then quickly ask them a few questions and if there's written information you've got a better idea and you really look at what's, what.

One of the significant factors that affected the nurses' level of tolerance towards medical practices and that reinforced the power relationships, was the experience of the doctors, what level of training they were at and their general commitment to the area. It was quite clear that for some nurses the attitude of the younger doctors was part of their enculturation into medicine. An element of the medical discourse seemed to be the natural superior positioning of the doctor vis a vis the nurse, part of the "hierarchical observations" referred to by Foucault $(1995,170)$, which support disciplinary power. The doctors came to believe in their superior positioning and there was little difference whether they were men or women. I asked the nurses about the difference between men and women doctors, as I noted in my journal:

It was interesting that the TI's [trainee interns], HS's [house surgeons], a registrar and the specialist on the ward at the time were all women. At afternoon tea I asked whether anyone thought that it made a difference and the answer was no. The nurses thought that it was just the usual personality issue and that due to them all "going through the same education system" they all came out with pretty much the same sort of attitudes.

Henrietta was more specific when she said, "They [women doctors] don't treat the nursing staff differently, in fact you get a lot more bitchiness from a female doctor than you do from a male." However, diversity of practice and being amongst doctors was acknowledged, just as it was between nurses, as Bridget stated: 
Particular doctors, if they're on, you can just relax, you know, you've got a good house surgeon and a good registrar who will respond to their pagers, who will give you good information, who will be able to make decisions, who will prioritise and you just relax and you just know the duty will go so much better. Other times, you will have the opposite and it's a real burden.

The doctors slotted into a privileged and controlling discourse that gave them a clearly marked position of importance. However, the doctors were coming into the nurses' space and initially there was the feeling that the doctors had to prove themselves, the respect of the nurses had to be earned. An essential element of this respect was the attitude of the doctor towards both nurses and patients. Although skill was a very important factor in the nurses' assessment, the way the individual doctor related to nurses and patients was an important aspect in the nurses' judgement and coloured their overall opinion, as Rose describes:

Oh I suppose at first, like everyone, it's their personality and attitude and the way they come across to you and the patients, and just watching them with the patients, watching them when they do vaginal examinations, maybe how and what they communicate to their registrars as far as the assessment and then what they choose as treatment ... their skill and communication would be the most important things.

Informal training of the new doctors was part of the nurses' work when the change in medical staff occurred. Not only was this training related to acceptable ways of managing aspects of their practice, as Sarah says it's "just little things like: oh you haven't cleaned up, did you realise you have left the speculum on the IV trolley or what have you", but also their enculturation into how the area worked and the expectations the nurses had of the doctors' behaviour towards women patients and the nurses. Sarah's example, which follows, describes her training of a new doctor in acceptable use of language, by being aware herself of his words and reflecting them back in the context of the sensitive nature of the procedure: 
... actually the doctors that we've got at the moment are pretty good but some of them just don't think when they say things sometimes. And some of them are fine, you can say: did you realise what you just said? You just said that we were going to suck that baby ... that woman's dead baby out with something like a vacuum cleaner. That's what he said. And he said: I didn't, did I? I said yes and he said: oh, my god. And he was really nervous and he hadn't been here that long ... obviously he just said the first thing.

Although the doctors were located overall in a more powerful space and, therefore, had inalienable rights in terms of ultimate power and control in the ward, the nurses were aware of the doctors' place in the medical hierarchy, their newness, and general lack of knowledge and experience. Because of this the nurses had no qualms about their role in instruction. Although difficult, and at times causing some nurses a great deal of exasperation, the situation was manageable due to the junior level of the doctors involved. Managing them was considered part of the nurses' work, something the nurses learned to do as Isabelle illustrates in the following example:

Well normally mostly the medical students would just come and check with one of the nurses to make sure it was ok to ask the patient if they could go to theatre with them, just to make sure it's an appropriate person to ask. But on this Friday two medical students went in to see A without even asking me if it was ok. I came in during the second one [medical student], asking her consent to go to theatre and also give her a pelvic examination under anaesthetic. He wasn't even explaining it to her, I just heard him say: can I give you a pelvic examination. She'd agreed to the first one [student] and the second one she said: no, but she said that he could come in and watch the operation. And then he turned round to me ... A is a bit slow, she's just very, very slow and she slurs her speech a bit, and he just made the assumption that she was on sedation, and he said in front of her, which was really embarrassing: oh is she on sedation, or has she been sedated. I just turned round to him and I was really annoyed, and said no. I was just glaring at him, not to say another word, and he walked out. I followed him and I just told him that it was really inappropriate to say that in front of A. I was angry, I had to say something I was so angry because she [A], must have to put up with this all her life. I really wanted to say something for her because ... it's awful people are so insensitive to people's feelings and they just come out with stupid things. And it's just not good enough, like he's got to learn some manners, I know he's got to learn his job but also he's got to learn manners about how he should be speaking to people. He went red, he 
was embarrassed and he apologised and then tried to explain that he didn't want her to consent if she'd had a sedative but it was the way he said it. It's the first time I've ever had to do it [challenge the doctors]. I was a bit nervous when ... I was angry first so it didn't just ... nothing stopped me, while I was saying it I was a bit jittery, I was a bit nervous but next time I think I'd be better about it.

Relationships with senior medical staff were more ambivalent, yet nurses such as Henrietta thought:

... the consultants are easier to deal with, more likely to let go of a patient. I think the woman gets a better deal from the consultants because they know how much they can let go, it has been proven to them over and over again that women are sensible.

The consultants are permanent leaders of the medical teams and their power is rarely challenged. They were not in the area as often as other doctors due to responsibilities such as operating, conducting out-patient clinics and the private practice part of their work. In Rose's view nurses "tend not to have much to do with the consultants, to be honest". However, although not as visible, they were still very influential in shaping the work of the nurses. The particular likes and dislikes of the consultants had to be observed and maintaining these unique observances was part of the nurses' work. Sometimes this could be frustrating as Rachel explains:

At the end of the day each consultant has a way that they like things done and they haven't standardised that so we can't actually ..., if we just went ahead ... we've got one person who will take out a haemovac [drain] if it's drained, less than say $50 \mathrm{mls}$ in a duty, that person will say yes take that out, whereas another consultant it's got to be less than $3 \mathrm{mls}$ for the last 24 hours before that'll come out so ... I mean .. I feel that those are decisions nursing staff are capable of making but they can't, you've got to go strictly by doctors orders, so that is really controlling a lot of our practice. It's the same for removal of catheters and staples and everything else.

The relationship with the consultants was sustained through knowledge of their practices, and by ensuring that other staff, including doctors, were aware of the 
requirements of individual specialists. For some nurses, while recognising the importance and the position of these rather shadowy figures, they did not impinge heavily on their day to day work. Other nurses in management and the senior positions had a closer relationship that had developed over a longer period of time. As Bridget said, "I feel that most of the consultants, well they know my name so they must think I'm okay and I get the impression most of them have a degree of confidence in me." However, the nurse works with difference in doctors, including the senior consultants, they accommodate their idiosyncrasies with little challenge and carry out tasks in the way that the doctor prefers. Part of this seems to relate to an awareness of the more vulnerable place individual nurses have in the system and the lack of guaranteed support from nurse colleagues outside the area, if an issue becomes one of the doctors opposed to the nurses. Problems in relationships with senior doctors were more serious, the discourse of medicine at this level was not to be taken lightly, confrontation would always lead to the nurse being in the inferior and, therefore, vulnerable position.

\section{The culture of resistance}

In terms of the nurses' resistance to subjugation by the dominant discourses within the area, Meaghan Morris' $(1988,62)$ notion of "strategic specification" has been useful. Morris uses this term when discussing Foucault and the usefulness of his work on power-knowledge in relation to exploring the history of women. Strategic specification refers to the possibility of going beyond merely seeing women as historically constituted but rather as "invested and traversed by relations of power-knowledge" (ibid). In relation to my research and the notion of nurses' resistance, the idea of strategic specification allowed for the constant shifting in positioning of the nurses as they balanced their personal beliefs about their practice, their perceptions of their 
vulnerability and the danger of challenging the prevailing, accepted and constantly reinforced power of medical and management ideologies. Strategic specification in this area conveyed the sense of diversity and multiplicity of positioning. The nurses in the research both subconsciously and consciously employed strategic specification in relation to any given situation. At times this specification was very much in keeping with social expectations and traditional ideas about the way nurses should work. At other times the nurse deliberately chose to move outside normal expectations and function from quite a different point, often in opposition to expectations of nurses held by other discourses.

Resistance is deliberate, the nurse challenges accepted practices and may do this either overtly or in some instances covertly. Nurses' bending of the rules was explored in a study by Sally Hutchinson (1990) who labelled this element of nurses' behaviour "responsible subversion" (ibid, 3). This bending of the rules was an element of nurses' resistance practices in the gynaecological setting, as Henrietta illustrates:

We ring them to say: this lady's ready to go home, and: oh I'm busy doing something; well can she go? No she can't I've got to come and see her. So they stand at the end of the bed and say: how's your pain, how's the bleeding, alright you can go. And we're perfectly capable, do it all the time but deviously, you know, it's all covert that we do it, how's your bleeding doing, do you need a script for contraception, we don't want you in here again next time. And you're constantly setting them up so they can scarper safely. They [doctors] see us as being pushy. Good from a woman's point of view, bad from the doctor's point of view.

Like the nurses in Hutchinson's study, the nurses in this research made judgements about whether to resist or not based on their "knowledge, ideology and experience" $(1990,3)$. Each nurse had control over the level of resistance that she felt was appropriate given the set of circumstances that were in position at any point in time. 
However, there is little doubt that the doctor was seen as the powerful figure and medicine the controlling discourse in the area. The nurses on the whole challenged on a one to one basis in micro situations, that left the structuring of the area intact. At times they are considered to have over-stepped the mark and their resistance will bring them into conflict with the doctors and, therefore, the management structures of the area. This leads to a situation that can be dangerous for the nurse. The danger could be very real and result in a response from the management and medical world that ensured the nurse felt the consequences of taking action that was considered in opposition to, and not in the interests of, these powerful and controlling discourses. The response was seen in disciplinary actions, the idea being that the results of such action would be unavoidable and leave the nurse in no doubt about the effects her actions could have on her self. Ensuring the docility of the nurses seemed to be part of a strategy which maintained the authority of medicine.

The senior nursing staff fostered a culture in the area in which the nurses were encouraged to resist, not in a conflictual or aggressive way, but in terms of taking the action they thought appropriate. They were encouraged to think carefully about the implications of their actions. The nurse leader was clear about her resistance to the discourses shaping the area, which she believed were political and reflected certain attitudes between the disciplines. She was outspoken in her opinions and the staff were clear about her feelings in relation to the attitudes of medicine and management and the congruency of her beliefs about nursing and feminism. These beliefs were apparent in her own practice and her publicly stated opinions. Her beliefs allowed the nurses to behave in certain ways and encouraged individual decision making in relation to practices they felt were inappropriate. However, encouraging nurses to speak out about 
situations they were unhappy with may have led to some of the problems experienced between nurses and doctors. An entry in my journal describes my impressions of the nurse leader's positioning due to her beliefs:

I think the problem that the management would see with [the nurse leader] is that she continually focuses on the nurses and the patients and will not be subsumed into either the medical or management discourse.. her whole being in the area is a point of resistance due to her philosophy ... her ideas and philosophy are so antithetical to the dominant and dominating discourses that they are now out to neutralise that resistance by perhaps getting rid of her ... even though there may be some problems with her management she is tireless in her resistance and her commitment to women.

Doctors have at their disposal a range of practices that can be marshalled through their alignment with management, to support their power over the nurses. While I was in the gynaecological area certain disciplinary actions were undertaken that related to practices of the nurses that challenged medicine. It would be inappropriate and unethical to go into the detail of the reviews that took place during the research, as they included people who were outside the scope of my study and who are no longer part of the management structure in the area.However, an entry in my journal, while not naming or individualising staff, illustrates the way in which the nurses were dealt with:

This review was instigated, according to the management, by comments and concerns raised about the ward. No-one will specify who by, but apparently it has quite clearly come from the doctors. The comments were verbal, so not only are they not "owned", they have not been written down for the nurses to see. The review was undertaken while [the nurse leader] was on holiday and the New Zealand Nurses Organisation representative (a staff member) was told of the meetings the morning they occurred when she had just come off night duty. The acting unit manager went to the meetings held for the nurses but was not permitted to attend the doctors' meeting. The review document is quite clearly a review of the nursing staff only ... They [the nurses] are trying to retaliate by putting their concerns in writing but they have received little encouragement from the management. 
This example shows the way in which a so called ward review was instigated by management on the basis of issues raised by, as far as the nurses could ascertain, anonymous people who were not prepared to commit their concerns in writing so they could be properly considered and addressed. It was in fact a review of the nursing staff. The nurses felt that there was no possibility of discussions between nurses and the doctors, the discussions between medical staff and management about the nurses, occurred without the nurses present. When holding the meeting between management and nursing staff, no attempt was made to give the nurses adequate warning or assist them to attend the meeting. In the face of the power apparent in these actions and the signals it sent to the nurses as far as their importance in the review went, there was little resistance from the nurses.

A more personal example occurred during this research when a medical consultant made a complaint to management about a senior member of the nursing staff, based on what was clearly a difference in opinion about nursing practices. However, this led to the nurse being subject to demeaning management practices, leaving little doubt in anyone's mind as to the marginal nature of nursing when it came to a challenge from medical power. The authority of medicine was seen as legitimate, whereas that of the nurse must be proved. Again, although it is not appropriate within the scope of this research to go into the details of this particular disciplinary action, it was clear from my discussions with the nurse leader and my own observations, that her resistance to being subsumed by these other discourses was a significant factor in her being placed in a very difficult and personally stressful situation. In a way her whole being was a point of resistance because of her refusal to quietly accept the rigorous review she was subject to, as I noted in my journal: 
She [the nurse leader] is still having a lot of problems with 'management' and her review. It seems that she is really having the pressure put on to conform to the ideology. Basically, the management is doctor focused and wants her to stop questioning and get on with being part of the discourse rather than constantly questioning it.

Strategic specification (Morris 1988), that is how the nurse positions herself in relation to a situation, is dependent on a number of factors. The confidence of each nurse is a major factor in their decision to challenge the orthodox practices of the area. However, for the nurses in my research this was coupled with their own personal state of being at the time. By this I mean their feelings about the danger inherent in taking a stand, how strong they felt in terms of managing the possible repercussions of their actions, and the importance of the issue over-all. All these factors could fluctuate on a daily basis. Sarah illustrates such fluctuations:

I feel quite confident saying ... if somebody says to me: I don't want to have this operations, I feel quite happy in saying, in standing up for her, if she says: oh I'm not really sure that I want to have an examination, or: I can't have that today - I can't have that evac [evacuation of the products of conception] today, I can't have that D\&C [dilatation and curettage] I have to go home, I've only just found out the baby has died, I can't do it. I'm [Sarah] fine and if the doctors rant and rave that's fine, that doesn't worry me. And I also think too, it depends on how my day's going, if I'm feeling a bit on edge and you know, I don't want to get yelled at ...

The identity of the nurse and the reality of how she felt affected her judgement as to the limits of her choices in moving outside the subservient and docile role that many other health professionals would prefer the nurse to occupy. Sarah goes on to explain:

I think newness [of the nurse to the area] too, you know, when the doctors get really busy and really stressed and you say: oh can you chart Mrs so-and-so's fluids [intravenous], and they shout at you, when you're new it's like - oh my god, I've only just asked you to chart some fluids and that's your job. And it's really upsetting, but I think once you've been here a little while you think: what's your problem? But having said that, if I'm having a bad day and somebody shouts at me I think: oh don't shout at me. You know, I feel just as vulnerable, but more often than not it's fine, it's: oh come on! 
Resistance is different from advocacy which is now an accepted strategy in nursing practice (Potter and Perry 1997). Advocacy encompasses the idea of the nurse working on behalf of the patient to ensure, as far as is possible, that the patient is a fully informed and active participant in the management of their health-related experience. Patricia Potter and Anne Perry state that "to support, uphold, and speak up for the values of others is advocacy" (ibid, 312). Advocacy has elements of supporting the woman's decisions, presenting options and helping the woman feel as though she has some degree of control. However, resistance is where the nurse takes a stand, where her actions can be considered as putting her in a situation where she is at odds with the expectations of a specific discourse, be it medicine or management. Normal practices are challenged through resistance, which requires the nurse to acknowledge that she will not accept a particular practice or action that is taking place. Working in the role of advocate may occasionally require the nurse to work to resist certain practices. She will make the decision, based on her judgement in response to the particular set of circumstances, to circumvent accepted practices in the interests of the patient. Rose explains:

Like the first person on call is a house surgeon and even if you know there's a TI [trainee intern] on call, you're assessing the woman, how quickly do they need to be seen, how quickly do they need to be sorted out and sort of knowing a TI's going to take one or two hours doing an assessment and an examination, well you think some women just can't cope with that because they're physically in so much pain and potentially very unwell or even emotionally very distressed. Like I had a lady who had a miscarriage and she was absolutely distraught, the last thing she wants to do is answer a hundred and one questions when some may be totally irrelevant to making the assessment and getting her sorted out and getting the best medical treatment. I suppose you're making a decision which. I don't know whether the medical doctors would always agree with but I tend to, if I call a house surgeon and they say call a TI I might say: well no, I'm not happy because this woman is really distressed, or something like that. 
Rose also recognised that the response of doctors to resistance was affected by the characteristics of the individual nurse:

It depends on different doctors, what kind of rapport you've got with them, some are really good and say: that's fine. And I think it also probably depends on the nurse as well so ... They know you're thorough and that you've assessed things and you say: well look this is because her blood pressure's this and her pulse is high, she looks pale, and she's tachycardic, she's breathless and I want her seen as soon as you can because she's been called in as an ectopic, then they usually understand or you say they're bleeding really heavily and there's no point having a TI come up.

Strategic specification also acknowledges resistance as being a specific behaviour that occurs at a point in time, not something that is a constant factor in the nurses' practice. There are particular moments during the nurses' work when they will decide to take a certain course of action that is in opposition to the normal practice and that would be seen by the medical profession as a challenge to their power. But because the ideologies of medicine and management controlled the area the nurses were wary as to the lengths they would go to in terms of taking on the system. The ability to resist is affected by a number of circumstances that are very fluid. It depended on the individual nurse and her beliefs about her role in relation to the particular patient. It also depended on what she judged were the right decisions for herself and the person in the circumstances. Rose discussed how she approached the situation of not agreeing with medical decisions:

I think it probably depends on the situation, who the woman is, really, how much pressure the whole environment is under at that time. I mean hopefully, you could talk about it, certainly if I wasn't happy with a decision I would like to think that even if I ... well I'll listen to what they have to say, sometimes I may even go away and think about it and then think: no I'm not happy with this decision, and I'll say no I'm not happy and why, or ask them: oh, why couldn't you do this. And I think as lot of it's to do with, well I think you just have to be honest really. 
The nurse makes a judgement based on a number of complex factors, two of the most important being knowledge and expertise. The senior nurses were more confident, they knew the area, they knew the variety of clinical situations that were likely to arise and they knew the appropriate actions that should be taken in certain situations. Although they allowed some difference in relation to the individuality of the doctors' practice, they had a clear idea of what was acceptable and what was not, the newer nurses were not so confident. However, they all felt that resistance depended on their own state of mind, their strength and their feelings at that particular time. Resistance is something that required the nurse to step outside her usual role, to be seen, to make herself conspicuous. This required a feeling of being strong enough to cope with the possible consequences of that action. Obviously the nurse weighed up how far she would go, what she considered reasonable behaviour was measured against her own beliefs about her nursing practice balanced against the needs of the woman. Whether or not to take action that would set her against the powerful discourses and that was at odds with the beliefs medicine has about its control of patients in the area, was a personal decision.

There is no doubt that the nurses recognised that challenging medical practices was dangerous, an action that could threaten their very survival in the system. Deciding on the limits of their acceptance and tolerance of behaviour they felt inappropriate, was made by the individual nurse in relation to her own internal beliefs. Her resistance or lack of it is strategically specified by professional enculturation, personal perceptions about power and powerlessness and the vulnerability or strength she felt at any given moment. Doctors may be challenged, boundaries to that challenge were often set by considerations such as the professional level of the doctor, rather than the actual nature of the situation. Young and inexperienced trainee interns could be challenged by all the 
nurses, this was part of the socialisation process which the nurses felt was part of their role, as discussed earlier. The interns' practices could be openly and vigorously resisted in the interests of the patients. As Henrietta says, "Oh TI's, they [nurses] take it out on TI's, they give them a rough time." Overall, most nurses felt the medical world would not accommodate a major challenge to their authority, by a nurse. Alice was quite clear about who she felt had the power, and the nurses' positioning, if it became a choice:

There are particular people on the medical teams that aren't going to go anywhere and eventually, I know that the two of us will clash in a major way and I will lose. And now that might sound negative, but I've seen it and I've no reason to think that it would be any different with me because there's a lot of me as a group and not many of them and when you come down to it, who's the hardest to replace?

As the doctors became more senior, more established in the area of gynaecology, the nurses were more careful in their response, often commenting on their practices, yet not feeling they could challenge the situation. Although it is extremely rare for nurses to be dismissed because of problems with senior doctors it is a possibility that nurses feel exists. Isabelle mentioned this when we discussed informed consent:

... usually once somebody's consented to an operation, that's it, it's final sort of thing. We don't really say, start asking them: are you sure you're doing the right thing. I'd be out of a job, I mean all you can do is make sure that they know they're having it. I think: is it always necessary, but it's not my job really to think that.

In a journal entry I voice my concern about the discussions routinely held between specialist and patient prior to the removal of healthy ovaries which necessitates hormone replacement therapy:

The patient was being told about the operation and about whether her ovaries should be removed. The patient's ovaries are perfectly health, she is having the hysterectomy for menorrhagia [heavy bleeding] of two years duration. The taking out of the ovaries was explained in such a way and given the rider that the gynaecologist would recommend it, that the patient agreed. She was told that there was a $2 \%$ chance of developing ovarian cancer in her ovaries and that due to 
her age they were coming to the end of their useful life anyway ... She was told that as the ovaries were coming out she would have to take HRT for the rest of her life but that this was a good thing because it would prevent her getting fractures over the age of eighty which occurred in $25 \%$ of women (in other words didn't occur in $75 \%$ of women and this woman would not be considered in the at risk category due to ethnicity and size). There was absolutely no discussion of the risks or side effects of HRT.

It seemed that this was a situation where nurses could have discussed the issues with the doctors. If fully informed consent was to be given, nurses had a responsibility to ensure that women had the information required. Also, a very important part of the nurses' practice is educating patients about their prescribed drugs. When I raised the issue with two of the most senior nurses who were in a position to discuss such issues with the doctors, they did not feel they could challenge this aspect of medical practice. Even when considered in the light of informed consent, they did not seem to think such action was sensible for a nurse to take.

It seemed to me that the danger of resistance was a perception rather than a reality. It was something that arose from the nurse's feelings about her position and her belief in her value. The power of the medical discourse seemed based on ideological power, rather than on the basis of actual experience. In fact the medical staff have little real control over the nurses when it comes to the safety of their position. Although, as in the case of the nurse leader, medical power can ally itself with management power in an attempt to control nursing practices, actually removing the nurse from her position would be very difficult. In my experience of nursing I have never known of a situation where a doctor has been directly instrumental in the dismissal of a nurse, yet the possibility that this may occur is very much a controlling influence in the nurses' decisions in relation to resistance. While life can be made very difficult for a nurse by 
individual doctors, in the public medical system they are not the employer, the hospital management is the body with whom the nurse has her employment contract. Modern development of nursing has meant that the nurses are directly responsible to either the nursing hierarchy or in more recent years with the restructuring of the medical system, to managers who, in the gynaecological area, have also been nurses. Therefore, the direct threat posed by the doctors to the nurses' professional survival is minimal in reality yet it seems a large consideration for the nurses, a situation that reflects their shared beliefs about the control of the medical discourse.

Nurses resisting the taken for granted power of the doctors will not be comfortable for those doctors who experience it. The nature of competing discourses and the resulting conflict may mean that a degree of discomfort will exist between the two disciplines. If nurses are going to resist what they consider inappropriate behaviours and incorporate this into their role as patient advocate, we will have to explore how best to manage this tension. Cultural practices which ensure dependency on the doctor reinforce the prestige and control of medicine. Such practices ensure the nurse is confronted with her limits and feels the boundaries in relation to medicine, the reality of the patient is at times lost in this reassertion of power. The gynaecological ward is a contested space in terms of the nurses' continued presence in opposition to the frequent changes in more junior doctors. However, the reality is, as I summed up in a brief journal entry, "no matter how efficient, experienced and skilled you, the nurse, are, always remember this is my [that is the doctor's], place".

This chapter completes the interpretation of the three key areas of nursing identified by the nurses in the gynaecological ward as having a major impact on their reality. The 
following chapter brings together the analysis chapters in an integrated discussion. This discussion weaves together these threads with those explored in the earlier chapters related to knowing gynaecology as a specialty, feminist and nursing epistemology and methodology. It is these themes that form this feminist exploration of women working as nurses in the gynaecological ward. 


\section{Chapter 9}

\section{Interweaving the texts}

7 his research is focused on making heard the voices of women as nurses working

in the specialty area of gynaecology. Feminist praxis coupled with notions from postmodernism have been central to this thesis. The process has enabled the surfacing of nurses' voices and the interpretation of their experiences from the position of their embodied reality. This study has contributed to knowledge about nursing in the area of gynaecology from a feminist perspective. However, my aim has not been to arrive at one single representation of this nursing but to add to the continuous stream of women's and nurses' knowledge, through this process of feminist research. As Susan Strickland $(1994,266)$ says in relation to postmodernism:

It opposes the search for coherence and a desire for the 'right answer'. It suggest instead the continuation of 'conversations' conversations having no given goal or end, and not aiming at a single representation of reality.

Through undertaking this research I have come to believe that feminism and nursing have a common goal in terms of their emancipatory project. If we accept that one of the central concerns of nursing research is improvement in the care provided for people, then it can be argued that both feminism and nursing share an emancipatory goal. The nurse is focused on significantly improving the health-related experience for those in her care and the feminist is focused on making a significant contribution to improving women's lives. The commitment to emancipatory action inherent in feminist research takes it beyond many other research approaches. Taking this characteristic into nursing can result in research that explores nursing, nurses and the people they care for, with an 
emancipatory focus as part of the outcome. This seems particularly relevant to applied disciplines where much of the research being undertaken explores specific areas of health-related experience with change in mind. Being explicit about the transformatory possibilities throughout the research, not just in the recommendations but in the whole research process, has the potential to make a major contribution to the development of unique methodologies for exploring the world of nurses and their work.

I have found using feminist research a liberating process which provided, within the accepted requirements of research, the freedom for me to develop and explore my own strategies appropriate to the topic. This has a direct point of engagement with the development of nursing research and opens up significant possibilities. Like nursing research, neither feminist research nor research from a postmodern perspective is bound by adherence to one specific methodology or method. As feminist research is informed by the underlying commitment to a certain set of ideals and principles, so nursing research is committed to developing knowledge that will inform nurses and contribute to positive outcomes for those in their care. For nursing and feminist researchers the issue then becomes one of choosing the strategy which most fits the question being explored. The flexibility that is inherent within feminist research can provide the nurseresearcher with the confidence to develop her own methodology to suit the topic as long as underlying principles and assumptions are clearly stated, explicit and supported, and attention paid to central concepts such as authenticity. 


\section{The reflexive thread}

Inherent in feminist research is the notion of reflexivity. This was an invaluable strategy throughout my study. Consideration of reflexivity required me to evaluate my own practice as a feminist researcher throughout the process of my research and was a powerful factor in ensuring that I remained connected to feminist principles. Because of the freedom to choose from a range of data collection strategies from a variety of disciplinary backgrounds, reflexivity was essential to keeping my feminist focus clear and explicit. Reflexivity encouraged critique by the rigorous questioning of myself, my actions as a researcher, and my interactions with those in the study, particularly in relation to power relationships. This is obviously important from a feminist stance in terms of attempting to avoid, as much as possible, any colonization of the participants in my study purely for the purposes of research. However, it also takes the research process to another level in terms of the critiquing the strategies chosen and exploration of the inadequacies of the methods. Therefore, reflexivity assists in the development of actual methodology as well exploring the relationships within the research. The relationship between the researcher and the methodology is explored via the use of reflexivity in a conscious and sometimes hard to confront way. This could be seen as strengthening the methodology overall by ensuring the fit between methodology, topic and researcher.

Reflexivity prevented my sinking completely into the world of the nurses due to my being a nurse involved in participant-observation with other nurses, and my immersion in my own disciplinary world. Although the positivist notion of objectivity was untenable in my research due to my philosophical positioning and the type of research I 
was undertaking, engaging in a process that required me to explore my actions and reactions enabled me to distance myself in a way that enhanced the research process. It enabled me to find the position that was acceptable to both myself as the nurseresearcher and to the nurses I worked with. Initially, finding this position as a nurseresearcher had to be worked at and was one of the hardest elements of the data collection part of the research. At times I did have trouble with my role and found myself crossing the boundary between researcher, with a focus on interpretation of experience, and clinical nurse, with a focus on appropriate patient management. However, there was a clear difference between myself and the nurses whose whole focus was on their work and their daily life in the ward.

At times when I was working closely with a nurse and she was immersed in her work in a difficult situation I was tempted to focus on the laudification of nurses. The stress and the nature of their work made me feel at times that people should see them as 'saints'. Yet, through the process of reflection that reflexivity requires I could acknowledge these feelings, put them in context and make these aspects of their work explicit. It was not my role to position the nurses as saints but rather to make explicit and explore the kind of work that they are silently required to undertake as part of their day-to-day practice. Before being involved in this research I thought I had a sense of the reality of nursing practice in gynaecology. In fact by doing the research, by working with the nurses, my view changed. This alteration in my thinking occurred because of the challenges raised by my positioning as a feminist nurse-researcher rather than a practicing nurse. As Susan Strickland $(1994,271)$ says:

Understanding across difference involves a reflexive and dialectical interplay of perspectives. Other perspectives inform me not only 
about them and their situation, but of me and mine; my now altered self-understanding allows new understanding of others which modifies my understandings further, and so on, in a continuous process of revision and expansion.

Reflexivity is a notion that also supports the recent development of reflective practice in nursing. ${ }^{1}$ If reflexivity is seen as engaging with the research process and critiquing the nature of that process throughout, then this can be illuminating for reflective practice. I believe that the more powerful concept of reflexivity from a feminist perspective, with its inherent notions of power and control, has the potential to be extremely useful for nurses. Reflection, on the other hand, is a process that may not require the same consideration of power and control and their effects in terms of shaping and influencing relationships within the hospital and all health care settings. If the reflective nurse practitioner engages in this reflexive process it will enhance her thinking about her actions and her exploration of the assumptions or evidence which underpin her clinical decisions.

\section{The written word}

I, like many feminist researchers, believe that the emancipatory project of feminist research requires consideration of the way the written word is presented to the world. Therefore, constructing the text that represents the research is a political act. The act of writing and the exploration of theory are essential elements of feminist activism. Feminist praxis required me as the researcher to bring together theory and practice to explore the experiences of women as nurses. The construction of my thesis and attention

\footnotetext{
${ }^{1}$ Reflective practice as discussed in nursing is based on the work of Donald Schön (1983) The Reflective Practitioner: How Professionals Think in Action. See the work of Christopher Johns (1998) for an example of reflective practice in nursing based on the work of Schön.
} 
to the use of language has been a conscious part of the research process and an element of emancipatory intent. By consciously working at the actual style of writing my awareness of the importance of writing as feminist activism developed. Focusing on the way that the work of other authors is cited is important as a way of foregrounding women's scholarship and making explicit my commitment to the use of nursing literature. Wherever relevant nursing literature was drawn on and critiqued, I endeavored to do this in a way that acknowledged respect for the authors' contribution to the knowledge of a discipline that has only recently begun the formal academic development of its theoretical base. As a feminist nurse-researcher this was important as in nursing we explore theoretical notions from other disciplines, transfer them into a very applied discipline and work to integrate particular philosophical positions in a way that enhances nursing research and practice. Drawing on the work of nurse-scholars was important to show this development and to highlight the innovative and unique work being done by those involved in this difficult project.

Acknowledging the political implications in the act of writing also led to my awareness of whose voice is represented in the gynaecological texts. There appears to be a lack of women's voices as nurses in both the history of gynaecology and in the literature related to gynaecology in the mainstream nursing texts. Medicine is central, foregrounded still in the management of women's illness, rather than the concerns of nurses and the women patients for whom they care. The specialty area has been and still is shaped by the male discourse of medicine and it appears that the nursing discourse represented in the texts supports this perception that it is the medical view that is paramount. Why is it that positioning the woman's experience of the condition as central, and the nursing care 
required as an immediate adjunct, is not the accepted format of mainstream nursing texts? How we position the person and their experience in these texts is a central part of recognizing the political activism inherent in writing. It also reflects our beliefs about the importance of people, that is the patient, nurse and doctor, that are involved in a woman's gynaecological experience. Focusing on medical management supports the continued dominance of the medical discourse in the treatment and importance of patient care. The way that gynaecology is represented in major nursing texts highlights the way that the medical interpretation of this area has been absorbed and is reproduced in nursing. By understanding this we can begin to consider the change that is necessary to reflect the 'differentness' of nurses' work in the area of health and illness. Rather than foregrounding signs, symptoms and medical management in these texts, positioning the voices of women and the work of the nurse as central reflects a commitment, first and foremost, to the needs of the woman and then to how the nurse's work will support her through a specific gynaecological event. This would reflect the concern of nurses and the importance of their work. This is not to say that the knowledge from medicine is not useful or necessary, such information can obviously assist a nurse in her clinical practice. However, the positioning of that knowledge must be considered in terms of the importance that is given to the various knowledges that inform nursing practice. Privileging nursing knowledge is for me an essential factor in the emancipatory agenda of feminist research, particularly in the area of gynaecology. I recognised that as a feminist nurse-researcher, changing the representation of women, not only the nurse but also the patient, is part of the emancipatory project of feminism and requires addressing within nursing. 


\section{Integrating diversity}

Working with the notion of diversity has been a fundamental and challenging part of my research. This diversity has been at the epistemological level as well as at the intimate level of nurses' practice. Epistemological diversity relates to the differences between standpoint feminism and the postmodern position. From a theoretical point of view I had to work with the tension between these two positions if I was to incorporate both into my study.

As I have discussed in Chapter Four I believed that notions from both standpoint and postmodern approaches could inform my research. It quickly became obvious during this research that there were certain shared concerns that were specific to the practice of nurses in this particular gynaecological setting. This is not to say that all the nurses shared the 'experience' of these common concerns. However, these commonalities provided a starting point for exploring the nurses' practice as they were issues raised by all those in the study. These specific areas of concern, as I have discussed in Chapters Six, Seven and Eight, were those of women as nurses working with women, working with women experiencing terminations or terminal cancer and the nurses' relationships with the medical world. Acknowledging the nurses' shared 'view', as distinct from experiences, of issues inherent within their practice in the gynaecology ward, provided a theoretical starting point for exploring their work in the area. This seemed congruent with thinking from the standpoint feminist position.

However, this highlighted the epistemological tension as within these shared concerns the nurses had their own unique subjectivity. This was particularly evident in their 
relationships with the medical discourse and individual doctors. In this situation the nurses' constructed subjectivity was evident when they outlined the way they would decide at any given moment, how to manage the nurse/doctor relationship and whether or not they could cope with the confrontation that might result from their resistance to the requirements of the medical discourse. From the postmodern perspective the notion that subjects are discursively constructed at any given time appeared to be supported by each nurse as she described her own specific point of view.

Thinking through this theoretical diversity I came to believe that trying to integrate standpoint feminism and postmodernism into a single research approach was not necessarily of value, rather accepting the tension and consciously working with that tension could enhance the research. While some researchers may consider these approaches incompatible I found using both led to the notion of diversity also being woven into my practice as a researcher. Philosophically I felt that although I was working with these different perspectives my feminist ontological position was the beginning point. Then, within that frame, I was able to use notions from both the standpoint and postmodern positions. Starting from a shared view of certain aspects of practice is not incompatible with also considering nursing as being responsive to, and active in, the discursive practices in gynaecology.

Using feminist concepts and incorporating notions from postmodernism allowed me to present a range of experiences from the nurses working in gynaecology. The diversity of the nurses and their practice has been foregrounded in relation to major influences they identified as affecting their working lives in this setting. In particular the concept of 
difference from feminist and postmodern theorising allowed me to work with diversity, both my own and the nurses', rather than concentrate on a representation of some universalising form of nursing in the gynaecological area. Feminist and postmodern theorising have much to contribute in terms of avoiding essentialising and normalising diverse practices. It now, therefore, seems more appropriate to consider the notion of nursing(s) just as there are feminism(s), to show the range of possibilities and practices in the act of a nurse, nursing. By consistently talking about nursing as some reified entity we silence the polyvocality of nurses. As nurses we become imbued with a sense that we are all engaged in the same enterprise instead of encouraging diversity and the enhancement of unique practice. Homogeneity does not exist among nurses any more than it does in the experiences of women.

At times the experiences of an individual nurse will be directly at odds with those of her colleagues. However, this does not need to be constructed as negative. If we can start to build on the diversity of practice that comes from each nurse bringing her self to her work, this may allow nurses to develop as individuals and encourage the validation of each nurse and her unique contribution. It may be that many of the difficulties that arise in some areas of practice do so because we do not value diversity. The nurse that practices differently, rather than being supported to do so, is more often expected to conform to accepted practices imposed by the institutional culture and supported by senior staff in the area. If the nurse continues to be seen as different she will often be considered the other, marginalised and outside the group who have conformed. From my research it seems that 'fitting-in' becomes part of the conscious work of nurses new to the area and particularly for those that have newly graduated. This may be 
particularly so in the acute setting. Nurses working outside the institutional structure, for example in the community, often state that they are able to work independently and develop a more individualised approach to practice. However, working within the actual four walls of the institution makes it much more difficult for nurses to exert their difference. Here nurses are positioned by the major discourses in the acute setting, as an essential group of women, part of whose work is to enact the requirements of more powerful groups. Nurses are often seen as colluding in the medical control of areas such as gynaecology and at times the discourse of nursing constructs the nurses as powerless in this situation. While at times this is the case, clearly the nurses in this study struggled with this situation and worked to exert their independence and support the women in their care during their hospital experience.

Consciously working with difference in the nurse and her practice may result in a more harmonious working situation. To be able to say with confidence that "she does this differently from me but we both achieve the same end in terms of patient care ..." may well support nurses, encourage them to think through the reasons for their actions and the possibilities that they as individuals will bring to the care of their patients. However, perhaps essentialising nurses and their practice is more comfortable. Requiring conformity in practice and inter-relationships can mean that the working environment is safe, there is a degree of anonymity in a universalising approach to 'nursing', we are not so conspicuous, and our actions can be subsumed into the actions of the collective group. Being an individual and encouraging individuality means that the person becomes more clearly different, is more obvious and must be prepared to accept the responsibilities of her own actions. Communicating the uniqueness of our 
work and our discipline, may be enhanced by a commitment to considering ourselves individuals, clearly responsible for our own actions while working within the boundaries prescribed by legal and professional requirements.

The debates that occur within feminism about the linking of feminist and postmodern theory became real when considering the way that focusing on difference could enhance nursing practice. There is no doubt that at times the collectivity that is formed by identification as nurses can be extremely useful in terms of recognising the power of the group and working towards change as a united force. I believe there can be problems if the notion of difference is taken to the point where collectivity can never be considered as a position of strength. Taking a postmodern view of difference which focuses on the partial, the multivocal, and avoiding at all costs an essentialist notion of nurses or nursing, may well result in leaving unchallenged the external discourses that continue to shape the reality of nurses. To work towards changing the structures within which nurses practice and to join with consumers to shape the discourse of health and illness, nurses may well need a sense of common purpose where their partiality is subsumed for strategic reasons. It may be extremely useful when working as an advocate for patients or any community, to use the collectivity of nurses as a powerful force in pushing for change. This is a strategy that has worked for a number of women's issues that required the power of a large group, such as gaining women's suffrage and the right to control fertility. Acknowledging the usefulness of the collective voice is, I believe, compatible with recognising that in the major areas of nurses' work such as clinical practice, research or education, the concept of difference can be extremely powerful. This avoids 
homogeneity and any sense of a nurse being one dimensional and representative of all nurses.

It became very apparent during this research that one of the crucial factors in changing the way that nurses work is leadership. The role of the nurse leader in the gynaecological ward was central to the nursing culture in the area. She influenced and shaped the way the nurses viewed their practice. The nurse leader, by her work and her interaction with patients, nurses and other health professionals, was a role model for a number of the nurses and set expectations for independent practice in the area. She embodied an ideology and philosophy which was reflected in her positioning in relation to the management and medical discourses and which was frequently seen as a challenge to their power and control. Taking such a stance often led to this nurse's marginalisation from these powerful discourses, relegated to the other to be managed in a way that would ensure her submissiveness. Resisting this showed courage and commitment to her beliefs and was recognised by the nurses in the area. Because she held a certain set of feminist beliefs and her talk reflected these beliefs, the nurses were quite clear about her position and the centrality of the women as the focus of their work. This is not to say that all the nurses identified with the nurse leader's ideas. However, they acknowledged her positioning and the way this gave them the power to choose the way they worked. Her openness about her opinions and beliefs were seen as valuable for the ward and the nurses realised that they were given a freedom to develop their own practice that may not be available to them in other areas of practice. 
Difference in this particular gynaecological setting was encouraged by the nurse leader. The nurses in this study were encouraged to appear as individuals. The wearing of their own clothes in an acute surgical setting was very different and allowed the nurses to express their individuality. It was interesting that the older nurses, although citing hygiene reasons, rarely wore their own clothes, it was the younger and newer nurses that most often chose to appear different, to accentuate their difference from each other. I wondered if rather paradoxically this related to a sense of professional identity. Although it has been accepted that a nurse's uniform adds to the image of professionalism, wearing your own clothes makes a statement about individuality, that you want to and are comfortable being seen as an individual and, therefore, being clearly identifiable. Perhaps newly graduated nurses have more of a feeling of independence that should be fostered to support the development of feelings of independence in terms of practice.

\section{On being a woman}

In the gynaecological setting there is a uniqueness about the work, due to nurses confronting the reality of being a woman on a daily basis. Added to the stress of working in an acute area is the nature of the conditions that result in a woman being admitted to the gynaecological area. The nurses identified the relatedness between the patient's experience and their own embodiment as women as a major factor in their work, it was an element of their practice that could not be ignored. Working with women who are acutely ill, particularly with terminal disorders such as cancer, affects the nurse and causes distress through the nurse's identification with the woman's experience and the impact of the illness on her life. At times it seems that this 
identification can be positive. Identifying with the psychological trauma that a woman may experience due to the intimate and invasive practices she may be subject to, such as vaginal examinations, can enhance the nurse's practice and allow her to mediate on the basis of some shared understanding of the difficulty inherent in such situations. On the other hand nurses may well find that the requirements of the work may lead to a form of distancing from the procedure. For example, if each nurse thought of the foetus from a mid-trimester termination in terms of her role in preventing its development of a normal life, being involved would surely be intolerable. The work would be so difficult that it may well not be done. Distancing herself from the foetus as a human life may well be the natural and normal process that any person in the situation would use to remain functional and able to do the work. It may be the most realistic strategy for managing such stressful aspects of practice. Specific elements of practice, such as terminations, require a nurse to draw on her own resources with little or no help to manage the process. It seems there are few situations that equal this, where the nurse, although supporting the provision of a service, must be able to manage the psychological impact of being an active participant in an event where the outcome is the prevention of the development of life, for whatever reasons.

Nurses' struggled to manage the difficult areas of their work, such as caring for women with advanced cancer or having mid-trimester terminations. The expectation that nurses will just cope with situations and events that many members of society would find almost impossible to accept, is one that needs acknowledgment and conscious management. The significant amount of nursing literature, particularly in the area of mental health, related to burnout acknowledges the effects that clinical work can have 
on a nurse, yet little of this literature addresses stress experienced in the acute setting. It seems an area that is ignored for some reason. Acute nursing in areas such as gynaecology seems to be considered functional without the potential to impact on the nurse in the same way that say nursing the dying or the mentally ill will have. Yet this research clearly shows that this is not so.

\section{Working with power}

The issues of power and control in the gynaecological service are factors which the nurses feel shape their work and their feelings about themselves. My exploration of the influence of medical hegemony on the clinical reality of the nurses working in gynaecology leads to a sense that some tension between the two professional groups may be inevitable in this acute setting. The tension felt by the nurses in relation to doctors reflected the pervasiveness of the practices of medicine and the way it shaped their practice and made them feel as women at work. It was interesting that whether the doctors were men or women made little difference, it was the practices of each doctor that affected the nurses. The tension in this environment relates in some part to the way that services are provided with junior medical staff being under pressure due to the needs of a service which integrates obstetric and gynaecological care. This often results in the doctor being unavailable to the nurses and the patients. This tension is heightened by the doctor being ultimately responsible for the care of the patient yet the nurse is the person who is constantly involved with the patient, she understands within a wider context, the needs of the patient experiencing a particular illness. Nurses are aware that there is a tension within which they have to work yet they strive to manage this in the interests of the patients. However, in this situation the nurse is positioned in a very 
difficult space. She knows the limits of her responsibility, yet also knows the patient and what is reasonable action to take, but she is then enmeshed in the power attributed to medicine by society and feels restricted in her ability to circumvent or question medical decisions. In acute areas such as gynaecology the nature of the work will also add to the tension particularly when both junior doctors and new nurses struggle to develop their confidence and to manage the daily stress inherent in acute clinical work.

In this setting the differences of individual doctors are absorbed by nurses. The doctors are 'allowed' by the culture to express their idiosyncrasies, it is expected, and when the doctors change due to their rotation through the various areas the nurses quickly assess and react to their individual personalities. Even the most junior doctors are soon known by name and temperament, a situation that does not seem to happen in reverse, that is adapting to the ways of individual nurses is not considered an elemental part of a doctors' work. Negotiating the relationship in the gynaecological area, although it could be considered to be the responsibility of both the doctor and the nurse, in fact seems much more a factor in the nurses' work. There is no doubt that they feel the relationship often in a very personal way, that it affects them more than it would appear to affect the doctors. In my own work experience I have rarely heard doctors discussing their relationships with the nurses yet it is a frequent topic of discussion for nurses in areas where they work closely. The power inherent in medicine is reflected in this situation where the nurses have a need to know the doctors yet the doctors do not feel the need to know the nurses. Attempts at cross disciplinary communication have not been particularly successful and may well relate to the low priority the medical world gives to the concerns of what it perceives as the less powerful group of nurses. 


\section{Knowing gynaecology}

Having some knowledge of the development of gynaecology has highlighted the manner in which people, often women, in the role of nurses, have long been active in the specialty area of the prevention and treatment of women's illnesses It seems particularly apposite at the close of the millennium to look back, understanding that knowledge about the past can inform our future. Undertaking this study from a feminist philosophical stance has been invaluable in terms of locating modern gynaecology as women's business controlled by men. A feminist reading of the history of gynaecological services from last century makes it evident that the views and voices of women have not been encouraged or valued. Understanding the development of the discourse of gynaecology and some of the events that have contributed to its development can illuminate the way in which discourses that shape the area have contributed to the shaping of nursing practice. At times it appears that nurses have unknowingly supported practices that did not always benefit women. The work of nurses being so intertwined with the practice of medicine has led to situations where we have been seen as passive in the face of oppressive practices towards women, such as the experiments at National Women's Hospital. Also, based on the understanding that since the development of modern nursing we have been party to changes in medical practice, nurses must have supported practices that ensured medical control of women and the continued assumption that women should not be in control of their own decisions.

Knowing, being aware of the historical shifts that have shaped practice in specific areas such as gynaecology, enables us to see that the structure and delivery of such services 
are not immutable. This can then encourage questioning on both the macro level in terms of taken for granted approaches to the management of women's illnesses, and the micro level in terms of challenging the practices of medicine and management in this area. This is particularly so in situations where the nurse knows these practices may impact negatively on the woman experiencing the service or that the woman is agreeing to strategies in circumstances where she has not received as much information as possible and is not aware that she may have choices in the way her illness is managed.

Critiquing the development of a specialist area of gynaecology does not mean denying the positive effects it can have on women's lives. While collecting the data for this research, I was told many times in informal conversations with women patients how they were looking forward to being relieved, even if only temporarily, of many of the uncomfortable and debilitating symptoms they were experiencing. What the critique does for us as nurses is give us the ability to understand the reasons that care is provided in a certain way, to explore who controls the service in reality and to reflect on what that means for us and our practice. Important questions such as how the structure affects the women whom it is meant to serve and how we can ensure that the best possible service is provided, are not only opened up for discussion by nurses but the questioning is seen as an important part of our practice.

\section{And the future}

Arising from the findings of this research are a number of areas that need addressing to support and enhance the practice of nurses in the gynaecological area. Also, there are 
many commonalities shared by feminist and nursing praxis, not least their emancipatory agenda, that can contribute to the development of theory and practice in both.

There are significant stresses inherent in nursing in the gynaecological setting, compounded it seems by the danger of working intimately with the embodied experience of the other, that is woman to woman. Research into the effects of clinical work in the gynaecological setting will help develop an understanding of the strategies nurses use to manage difficult work that is required as part of clinical practice. This would also make explicit elements of clinical work that society requires of nurses which have the potential to be psychologically unsafe for the nurse. Through the use of methodologies such as feminist action research, strategies could be developed with the nurses to ensure they are useful, focused on their concerns and evaluated for their utility.

Research exploring the choices nurses make in relation to conformity and/or individuality in the context of practice, will contribute to our understanding of the way they perceive themselves in the context of their work. From this research strategies may be developed that will enhance individuality and support difference within the close working relationships required in this acute setting. Also, in recognition of diversity, research with nurses to explore the impact of ethnicity and sexuality on practice in the gynaecological area would contribute to knowledge about the act of nursing in this unique setting with the focus on women and gynaecological illness. This type of research would contribute to the development of nurses' practice in a wide range of clinical settings and be useful in nursing education where, although technical skills will 
be presented as uniform practices, we need to encourage students to develop their own unique selves as nurses.

Exploration from a nursing perspective into how to manage the nurse-doctor relationships in the acute setting may contribute to improving these difficult but essential inter-disciplinary relationships. It may be important to accept that some degree of tension is inherent in a setting such as gynaecology, but that it can be managed by the nurses due to their knowledge and expertise in the area. Recognising that nurses can actively manage the relationship may well make them feel empowered to become more vocal and insist that communication strategies be introduced, particularly when new doctors enter the area.

To address the emancipatory potential of this research I have particularly focused on what could be done for nurses who work with women experiencing a termination of pregnancy. As a feminist I have been challenged during this research by the realisation that women as nurses were rarely, if ever, considered in the struggle for women's right to choice of termination of her pregnancy. Because of this I felt the need to focus on this part of the nurses' work with some urgency. What follows are strategies that I have developed for managing the mid-trimester terminations which the nurses have identified as particularly difficult. These strategies have been discussed with the nurse leader in the area with the intention of implementing and evaluating them to enable the nurse to integrate this difficult aspect of practice into her work in a way which ensures her own safety. The suggestions for practice are based on the principle that both women, the 
patient and the nurse, are experiencing the termination although obviously in very different ways.

* The complexity of nursing women experiencing a mid-trimester termination and the possible effects on the nurse need to be recognised through a process of formal discussion with all concerned. The consultants who hand over the administration of the drugs to the nurses need to have an understanding of how this places the nurse as active in procuring the abortion.

* There needs to be formal and confidential discussions with the nurses, either individually or in a group, to clarify their values in relation to mid-trimester termination so that feelings about the process, such as fear and anxiety, can be explored in a supportive and safe atmosphere.

* When a nurse first works with a woman having a mid-trimester termination she needs to work with an experienced nurse as often as necessary until the new nurse considers herself able to manage on her own.

* Wherever possible, ensuring continuity of care for the woman and the nurse was considered important by the nurses. In fact, some nurses have said they would prefer to see the whole termination through as much as is realistically possible. The fragmentation of the experience for the nurse can make it more difficult, particularly if they are taking over when the woman has established a relationship with another nurse. 
* The changeover of duties time, when care is passed on to another nurse, can be used as a debriefing time for the nurse. In a sense not only is care of the woman being handed over but the care of the nurse is handed over.

* After the termination and the woman has been discharged, debriefing is absolutely essential and appears to be the most crucial aspect affecting the nurse's experience. Nurses felt that debriefing should not be just a chat in the tearoom but a managed process that may require several discussions as issues may emerge for the nurse over a number of days. This process is offered to every nurse and is taken up by her as she feels the need. Experienced nurses should always be offered this support even if confident in their ability to manage terminations as each experience can be very different and impact on the nurse to a greater or lesser degree.

These strategies are not expensive and if managed appropriately will not impact negatively on the working of the ward or unit. What incorporating such practices does is support the nurse in her position alongside the woman having the termination. Valuing the nurse and recognising the difficult aspects of her work and the possible trauma that may be caused can alleviate a considerable amount of stress for clinical nurses.

To gain further understanding and enhance practice in this setting, research with the women patients experiencing specific gynaecological conditions and the way women interpret these experiences is essential. Undertaking research focused solely on the women patients seems essential to understanding the nature of the gynaecological 
services. This can also support, through publication, the centering of the woman in the gynaecological illness experience and begin to make the woman patient's voice heard. Based on this research the women's voices could be foregrounded in gynaecological texts, their experience positioned first. In terms of nursing being focused on the needs of the patient this research can provide the knowledge for this to occur.

Feminist research from specific epistemological positions will continue the movement of feminist research in nursing in line with the developments of theory in feminist scholarship, and allow us to contribute to the scholarly and philosophical debates which inform and develop feminist praxis. The basic feminist principles espoused in much of the nursing literature reflects the ontological position of many feminist nurseresearchers. Nurse-researchers who are now moving into the realm of epistemological positioning can contribute to the debate in terms of how these ideas can be worked with in an applied discipline. The diversity and flexibility of feminist research methodologies has much to offer nurse-researchers in terms of exploring the relevance and utility of the wide variety of methodologies that an applied discipline has to draw on to develop knowledge.

Considering writing as action has not traditionally been an accepted part of nursing practice. However, viewing writing as activism may encourage nurses to consider the need for them to take an active role in presenting ideas through the written media. Expressing their views about aspects of health and illness and bringing them to the attention of those in power can be taught as an important responsibility of nurses. Critique of texts across a range of nursing practice areas, but particularly in the area of 
basic or fundamental knowledge and practice, needs attention from a feminist perspective in relation to the centrality of women's experience. The focus on these texts is pressing due to their place in the education of most nurses and because many nurses in practise refer to them extensively .

\section{A personal reflection}

Undertaking this research has been one of the most all-encompassing and powerful experiences of my life. The requirements of feminist theory have been demanding in terms of attention to the interrelational aspects of the research, yet this has also been one of the most rewarding and enjoyable aspect of the process. There is no doubt that this project has shaped my view of nursing and has had a significant impact on my work as a nurse-educator. However, being involved in this very personal journey has also shaped my life outside nursing and affected the way I view my world. The experience, while demanding in terms of commitment, energy and focus has had a great impact on myself, and will, I hope, make a significant contribution to nursing knowledge. Contributing to knowledge development in nursing is the responsibility of us all, it is a requirement of the evolutionary process in nursing. We can all contribute in our own ways, not looking for any finite endpoint but by adding our voices and by doing so, writing ourselves into the construction of knowledge, knowledge that nurses can draw on now and in the future. 


\section{Appendix I}

Registered Nurses' Information Sheet

My name is Annette Huntington, I am a senior lecturer in the School of Nursing, Health and Environmental Sciences at Wellington Polytechnic, a registered general and obstetric nurse and I am also a student undertaking post-graduate study at Victoria University. My study requires me to undertake a major research project to explore nursing practice. For this project I want to explore with nurses the experience of nursing women who are living through uniquely female health-related events which have resulted in women becoming patients in a gynaecology ward. I believe this is an extremely complex and demanding area of practice for nurses which has not been explored in depth. I expect to be working in the ward, on my research for approximately one year.

I would appreciate it if you would consider taking part in the study.

If you agree to participate in the research I would like to work with you during your normal duty hours to understand what nursing practice involves in this area. I would also like to have some discussions about the issues for you working in this setting. The discussions will take place at a time and place convenient to you. I would like to tape record our discussions, rather than take notes, as this will help me concentrate on our conversation. The tapes will be transcribed without using your real name and wiped at the end of the study. To make sure I am accurately presenting your views I will return the transcripts to you so you can read or comment on them. At this stage you may add to, or change the transcripts. Your confidentiality will be assured as your name will be known only to myself. When I write up the research report I will use a pseudonym to protect your identity and the identity of other women in the study. No identifying information such as the name of your workplace, your age or address will be included in 
the report. However, I may quote some of your words verbatim to illustrate particular points, if that is acceptable.

You are free to withdraw from the research at any time and any information you have given me will be destroyed.

The research report has to be submitted to the University to fulfill the requirements of a Doctor of Philosophy degree. However, I would like to explore the possibility of publishing the results of the study in academic journals and at relevant conferences and venues related to women's health.

Although there may be no direct benefit for you I hope, by exploring this area, we can collectively contribute to the development of nursing knowledge in the area of women's health with the aim of positively influencing the experiences of nurses and women patients.

If you have any questions about the study please contact me at work on 385-0559 $\mathrm{x} 8315$, or at home on 386-3386. Or you may contact my principal supervisor Dr Patricia Laing at the Department of Social Work, Victoria University of Wellington.

I hope you will enjoy taking part in this research project.

Annette Huntington 


\section{Appendix II}

\section{Registered Nurses Consent Form}

I have read the research study information sheet provided by Annette Huntington and have had the opportunity to discuss the project with her.

I understand the nature and purpose of Annette's study which is to explore the topic of nurses nursing women who are living through health-related events that have resulted in them becoming a patient in a gynaecology ward and that the project is being undertaken as part of Annette's course of study.

I have been assured that my confidentiality is protected and that no identifiable information about me or my patients will be revealed in any written or verbal reports about the study.

I agree to participate in the research on the understanding that I may with draw at any time.

Signed

Researcher.

Witness.

Date. 


\section{References}

Achterberg, Jeannie. 1991. Woman as Healer: A Comprehensive Survey from Prehistoric Times to the Present Day. London: Rider.

Adams, W.E., and D.W. Taylor, eds. 1974. Gowland and Cairney's Anatomy and Physiology for Nurses. 8th ed. Christchurch: N.M.Peryer.

Alderman, Charlotte. 1985. A tale of two gloves. Nursing Times 81(44):62.

Alice, Lynne, and friends, 1998. Bodies, Sexualities and Identities. In Feminist Thought in aotearoa new zealand: connections and differences, edited by Rosemary Du Plessis and Lynne Alice. Auckland: Oxford University Press.

Allen, David G., Karen K. Allman, and Penny Powers. 1991. Feminist nursing research without gender. Advances in Nursing Science 13(3):49-58.

Allen, Karen M., and Janice M. Phillips, eds. 1997. Women's Health Across the Lifespan: A Comprehensive Perspective. Philadelphia: Lippincott-Raven Publishers.

Anderson, Kenneth, Lois Anderson, and Walter D. Glanze, eds. 1994. Mosby's Medical, Nursing and Allied Health Dictionary. 4th ed. St Louis: Mosby-Year Book.

Anderson, Joan M. 1991. Reflexivity in Fieldwork: Toward a Feminist Epistemology. IMAGE: Journal of Nursing Scholarship 23(2):115-118.

Angus, John. 1984. A History of the Otago Hospital Board and its Predecessors. Dunedin: Otago Hospital Board.

Annells, Merilyn. 1997. Grounded theory method, part I: within the five moments of qualitative research. Nursing Inquiry 4(2):120-129.

Appendices of the Journal of the House of Representatives. 1891. Report of the Dunedin Hospital Enquiry Commission. Volume H-I. 20.

Armstrong, Nicola and Rosemary Du Plessis. 1998. Shifting Certainties, complex Practices: Reflections on Feminist Research. In Feminist Thought in aotearoa new zealand, edited by Rosemary Du Plessis and Lynne Alice. Auckland: Oxford University Press.

Atkinson, Paul, and Martin Hammersley. 1994. Ethnography and Participant Observation. In Handbook of Qualitative Research, edited by Norman K. Denzin and Yvonna S. Lincoln. Thousand Oaks: Sage.

Barbee, Evelyn L. 1994. A Black Feminist Approach to Nursing Research. Western Journal of Nursing Research 16(5):495-506. 
Barker-Benfield, Ben. 1975. Sexual Surgery in Late Nineteenth Century America. International Journal of Health Services 5(2):279-298.

Bent, Katherine N. 1993. Perspectives on Critical and Feminist Theory in Developing Nursing Praxis. Journal of Professional Nursing 9(5):296-303.

Bernard, H. Russell. 1995. Research Methods in Anthropology: qualitative and quantitative approaches. 2nd ed. California: AltaMira Press

Booher, Bridget. 1996. Beyond the Birthing Room: Monica Green. Duke University. http://www.admin.edu/alumni/dm3/green.txt.html

Borbasi, Sally. 1994. To be or not to be? Nurse? Researcher? Or both? Nursing Inquiry 1(1):57.

. 1995. To be or not to be? Nurse? Researcher? Or both? Nursing Inquiry 2(2):117.

Bordo, Susan R. 1989. The Body and the Reproduction of Femininity: A Feminist Appropriation of Foucault. In Gender/Body/Knowledge/ Feminist

Reconstructions of Being and Knowing, edited by Alison M. Jagger and Susan R. Bordo. New Jersey: Rutgers University Press.

Braidotti, Rosi. 1990. The problematic of 'the feminine' in contemporary French philosophy: Foucault and Irigaray. In Feminine Masculine and Representations, edited by Terry Threadgold and Anne Cranny-Francis. Sydney: Allen and Unwin.

Bunkle, Phillida. 1991. Women and Power: how can we change the system? Health Care for Women International 12:379-391.

1992. Becoming Knowers: Feminism, Science, and Medicine. In Feminist Voices:

Womens Studies Texts for Aotearoa/New Zealand, edited by Rosemary Du Plessis. Auckland: Oxford Unity Press.

Bunkle, Phillida, and Sandra Coney. 1987. An Unfortunate Experiment at National Women's Hospital. Metro, June, 46-65.

Burns, Nancy, and Susan Grove. 1993. The Practice of Nursing Research: Conduct, Critique and Utilization. 2nd ed. Philadelphia: W.B. Saunders.

Campbell, Jacquelyn C., and Sheila Bunting. 1991. Voices and Paradigms: Perspectives on critical and feminist theory in nursing. Advances in Nursing Science 13(3):1-15.

Carpenter, M. 1993. The subordination of nurses in health care: towards a social divisions approach. In Gender, Work and Medicine: Women and the Medical division of Labour, edited by E. Riska and K. Wegar. London: Sage Publications 
Carryer, Jenny. 1995. Feminist Research: strengths and challenges. Contemporary Nurse 4(4):180-186.

. 1997. A feminist appraisal of the experience of embodied largeness; a challenge for nursing. $\mathrm{PhD}$ thesis, Massey University.

Carter, H. 1994. Confronting patriarchal attitudes in the fight for professional recognition. Journal of Advanced Nursing 19(2):367-372.

Cheek, Julianne, and Trudy Rudge. 1995. Only connect ... feminism and nursing. In Scholarship in the discipline of nursing, edited by Genevieve Gray and Rosalie Pratt. Melbourne: Churchill Livingstone.

Chinn, Peggy L. 1995. Peace and Power: Building Communities for the Future. 4th ed. New York: National League for Nursing Press.

Chinn, Peggy L., and Charlene E. Wheeler. 1985. Feminism and Nursing. Nursing Outlook 33(2):74-77.

Christensen, Judith.C. 1990. Nursing Partnership: A Model for Nursing Practice. Wellington: Daphne Brasell Associates Press.

Cixous, Hélène. 1981. The Laugh of the Medusa. In New French Feminisms: An Anthology, edited by Elaine Marks and Isabelle de Courtivron. New York: Shocken Books.

Clare, Judith. 1991. Teaching and Learning in Nursing Education: a critical approach. $\mathrm{PhD}$ Thesis, Massey University.

Coffey, Amanda, Beverley Holbrook, and Paul Atkinson. 1996. Qualitative Data Analysis: Technologies and Representations. Sociological Research Online 1(1). <http://www.socresonline.org.uk/socresonline/1/1/4.html >

Committee of Inquiry into Allegations Concerning the Treatment of Cervical Cancer at National Women's Hospital and Other Related Matters. 1988. The Report of the Cervical Cancer Inquiry. Auckland: Government Print.

Coney, Sandra. 1988. The Unfortunate Experiment. Auckland: Penguin Books. 1993. Unfinished Business. Auckland: Women's Health Action.

Contraception, Sterilization, and Abortion Act. 1977. Reprinted 1992. Government Print.

Cook, Judith A, and Mary Margaret Fonow. 1990. Knowledge and Women's Interests: Issues of Epistemology and Methodology in Feminist Sociological Research. In Feminist Research Methods, edited by Joyce McCarl Neilsen. Colorado: Westview Press. 
Court, Marian, and Helena. 1998. Positioning, Subjectivity, and Stories: Feminist poststructuralist research narratives. In Feminist Thought in aotearoa new zealand, edited by Rosemary Du Plessis and Lynne Alice. Auckland: Oxford University Press.

Daly, Mary. 1991. Gyn/Ecology: The Metaethics of Radical Feminism. London: The Women's Press.

Dallery, Arleen B. 1989. The Politics of Writing (the) Body: Écriture Féminine. In Gender/Body/Knowledge/ Feminist Reconstructions of Being and Knowing, edited by Alison M. Jagger and Susan R. Bordo. New Jersey: Rutgers University Press.

Dally, Ann. 1991. Women under the knife: a history of surgery. Chester: Clara Hartley Books.

Darbyshire, Philip. 1995. Reclaiming 'Big Nurse': a feminist critique of Ken Kesey's portrayal of Nurse Ratched in One Flew Over the Cuckoo's Nest. Nursing Inquiry 2(4):198-202.

De Beauvoir, Simone. 1989. The Second Sex. Translated by H.M. Parshley. New York: Random House.

DeMarco, Rosanna, Jacquelyn Campbell, and Judith Wuest. 1993. Feminist Critique: Searching for meaning in research. Advances in Nursing Science 16(2):26-38.

de Ras, Marion, and Victoria Grace, eds. 1997. Bodily Boundaries, Sexualised Genders \& Medical Discourses. Palmerston North: The Dunmore Press.

de Vore, Colleen. 1993. Evaluation and nursing education: where to now? Nursing Praxis in New Zealand 8(1):16-24.

Denzin, Norman K., and Yvonna S. Lincoln, eds. 1994. A Handbook of Qualitative Research. Thousand Oaks: Sage.

Di Stefano, Christine. 1990. Dilemmas if Difference: Feminism, Modernity and Postmodernity. In Feminism/Postmodernism, edited by Linda J. Nicholson. New York: Routledge.

Diamond, Irene, and Lee Quimby, eds. 1988. Feminism and Foucault: Reflections on Resistance. Boston: Northeastern University Press.

Diprose, Rosalyn. 1994. The Bodies of Women: Ethics, embodiment and sexual difference. London: Routledge.

Dixon, Jean. 1990. ..... And the Nurses were Deafening in their Silence. Nursing Praxis in New Zealand 5(3):4-11.

Dixon, Laurenda S. 1994. Beware of wandering womb - painterly reflections of early gynecological theory. Cancer Investigation 12(1):66-73. 
Donahue, Patricia M. 1985. Nursing the Finest Art: An Illustrated History. St Louis: C.V. Mosby.

Dow, Derek. 1994. Annotated Bibliography for the History of Health and Medicine in New Zealand. Otago: University of Otago.

1991. Springs of charity? The Development of the new Zealand Hospital System, 1876-1910. In A Healthy Country: Essays on the Social History of Medicine in New Zealand, edited by Linda Bryder. Wellington: Bridget Williams Books.

Duffy, Mary E. 1985. A Critique of Research: A Feminist Perspective. Health Care for Women International 6:341-352.

Duncan, Susan. 1997. Autopsy as Gaze: The construction of the Hermaphrodite Corpse as a Text of Sexual Difference. In Bodily Boundaries, Sexualised Genders \& Medical Discourses, edited by Marion de Ras and Victoria Grace. Palmerston North: The Dunmore Press.

Du Plessis, Rosemary and Lynne Alice, eds. 1998. Feminist thought in aoteoroa/new zealand. Auckland: Oxford University Press.

Ehrenreich, Barbara, and Deidre English. 1973a. Complaints and Disorders: The Sexual Politics of Sickness. Glass Mountain Pamphlet no.2. New York: The Feminist Press.

. 1973b. Witches, Midwives, and Nurses A History of Women Healers. New York: The Feminist Press.

. 1979. For Her Own Good: 150 Years of the Experts' Advice to Women. London: Pluto Press.

Elder, Ruth Gale., Winifred Humphreys, and Cheryl Laskowski. 1988. Sexism in Gynecology Textbooks: Gender Sterotypes and Paternalism, 1978 through 1983. Health Care for Women International 9(1):1-17.

Emden, Carolyn. 1995. A magnificent chaos: feminist (nursing) comments on Western philosophy. Nursing Inquiry 2(1):29-35.

Fahy, Kathleen. 1997. Postmodern feminist emancipatory research: is it an oxymoron? Nursing Inquiry 4(1):27-33.

Farrar, Patricia. 1996. Unruly Bodies and Disruptive Voices - Foucault, Fine, Kristeva and Haug: Discourses of Power and Resistance. Paper presented at conference, Feminisms in Transit 3.

Fine, Michelle. 1994. Working the Hyphens: Reinventing Self and Other in Qualitative Research. In Handbook of Qualitative Research, edited by Norman K.Denzin and Yvonna S. Lincoln. California: SAGE Publications. 
Flax, Jane. 1990. Postmodernism and Gender Relations in Feminist Theory. In Feminism/Postmodernism, edited by Linda J. Nicholson. New York: Routledge.

Fogel, Catherine I., and Nancy Fugate Woods, eds. 1995. Women's Health Care: A Comprehensive Handbook. Thousand Oaks: SAGE Publications.

Fonow, Mary M., and Judith A. Cook, eds. 1991. Beyond Methodology: Feminist Scholarship as Lived Research. Bloomington: Indiana University Press.

Foucault, Michel. 1975. The Birth of the Clinic: An Archeology of Medical Perception. Translated by A.M. Sheridan Smith. New York: Vintage Books.

. 1977. What is an Author. In Language, Counter-memory, Practice, edited by D. Bouchard. New York: Cornell University Press.

. 1983. Structuralism and Post-structuralism: an interview with Michel Foucault by Gérard Raulet. Telos 55:195-211.

. 1990. The History of Sexuality: an introduction. Vol. 1. Translated by Robert Hurley. New York: Vintage Books.

. 1995. Discipline and Punish: The Birth of the Prison. Translated by Allan Sheridan. 2nd ed. New York: Vintage Books.

Fraser, Nancy. 1991. The Uses and Abuses of French Discourse Theories for Feminist Politics. In Critical Theory Now, edited by Philip Wexler. London: The Falmer Press.

Froggatt, Katherine. 1998. The place of metaphor and language in exploring nurses' emotional work. Journal of Advanced Nursing. 28(2):332-338.

Fulton, Robert V. 1922. Medical Practice in Otago and Southland in the Early Days. NP: Dunedin.

Garland, Gordon, Joan Quixley, and Michael Cameron. 1971. Obstetrics and Gynaecology for nurses. 3rd ed. London: Hodder and Stoughton Educational.

Giddings, Lynne. S. 1997. In/visibility in Nursing: Stories from the Margins. PhD thesis. University of Colorado.

Glaser, Barney G., and Anselm L. Strauss. 1967. The Discovery of Grounded Theory. Chicago: Aldine.

Glass, Nel, and Kierrynn Davis. 1998. An Emancipatory Impulse: A Feminist Postmodern Integrated Turning Point in Nursing Research. Advances in Nursing Science. 21(1):43-52.

Gluckman, Laurie K. 1976. Tangiwai: a medical history of 19th century new zealand. Auckland: Dr L.K. Gluckman. 
Gray, Genevieve, and Rosalie Pratt. 1991. Towards a Discipline of Nursing.

Melbourne: Churchill Livingstone.

. 1995. Scholarship in the discipline of nursing. Melbourne: Churchill Livingstone.

Grbich, Carol. 1999. Qualitative Research in Health: an introduction. St Leonards: Allen \& Unwin Pty Ltd.

Griffiths, Vivienne. 1991. Doing Feminist Ethnography on Friendship. In Rethinking:

Feminist Research Processes Reconsidered, edited by Judith Aldridge, Vivienne Griffiths, and Anne Williams. Feminist Praxis Monograph series, no 33. Manchester: Manchester University.

Gross, Elizabeth. 1986. What is Feminist theory? In Feminist Challenges: Social and Political Theory, edited by C. Pateman \& E. Gross. Sydney: Allen \& Unwin.

. 1988. The in(ter)vention of feminist knowledges. In Crossing boundaries: Feminism and the Crtique of Knowledge, edited by B. Caine, E.A. Grosz, and M. Lepervanche. North Sydney: Allen and Unwin.

Grosz, Elizabeth. 1989. Sexual Subversions: three French feminists. St. Leonards: Allen \& Unwin.

. 1994a. Sexual Difference and the Problem of Essentialism. In The essential difference, edited by Naomi Schor and Elizabeth Weed. Bloomington: Indiana University Press.

. 1994b. Volatile Bodies: Towards a corporeal feminism. St Leonards: Allen \& Unwin

1995. Space, time, and perversion: essays on the politics of bodies. New York: Routledge.

Hagell, Elizabeth I. 1989. Nursing knowledge: women's knowledge. A sociological perspective. Journal of Advanced Nursing 14(3):226-233.

Hall, Jane. 1996. Challenges to Caring: Nurses as Wounded Healers. The Australian Journal of Holistic Nursing 3(2):12-18.

1997. Nurses as Wounded Healers: The journey to healing the person and the profession. The Australian Journal of Holisitc Nursing 3(2):12-18.

Hall, Joanne M, and Patricia E. Stevens. 1991. Rigor in feminist research. Advances in Nursing Science 13(3):16-29.

Haraway, Donna. 1990. A Manifesto for Cyborgs. In Feminism/Postmodernism, edited by Linda J. Nicholson. New York: Routledge, Chapman and Hall. 
Harding, Sandra. 1991. Whose Science? Whose Knowledge? Thinking from Women's Lives. New York: Cornell University Press.

1992. How the Women's Movement Benefits Science: Two Views. In Inventing Women: Science, Technology and Gender, edited by Gill Kirkup and Laurie Smith Keller. Cambridge: The Open University.

. 1993. Reinventing Ourselves as Other: More New Agents of History and Knowledge. In American Feminist Thought at Century's End: A Reader, edited by Linda S. Kauffman. Massachusetts: Blackwell.

Hartsock, Nancy. 1990. Foucault of Power: A Theory for Women? In

Feminism/Postmodernism, edited by Linda J. Nicholson. New York: Routledge, Chapman \& Hall.

Heide, Wilma Scott. 1982. Feminist activism in nursing and health care. In Socialization, sexism, and sterotyping: women's issues in nursing, edited by Janet Muff. St Louis: C.V. Mosby.

Hochschild, Arlie Russell. 1983. The Managed Heart: Commercialisation of Human Feelings. Berkeley: University of California Press.

Holloway, Immy, and Stephanie Wheeler. 1996. Qualitative Research for Nurses. Oxford: Blackwell Science.

Hubbard, Ruth. 1990. The Politics of Women's Biology. New Jersey: Rutgers University Press.

Huntington, Annette D. 1995. Nurses Nursing Women: Integration of Nursing and Feminist Knowledge in the Gynaecological Service Setting. Paper presented at Conference, Research for Practice: Making a Difference.

. 1996. Nursing research reframed by the inescapable reality of practice: a personal encounter. Nursing Inquiry 3(3):167-171.

Huntington; Annette D., Jean Gilmour, and Anne O'Connell. 1996. Reforming the practice of nurses: decolonization or getting out from under. Journal of Advanced Nursing 24(2):364-367.

Hutchinson, Sally A. 1990. Responsible Subversion: A Study of Rule-Bending Among Nurses. Scholarly Inquiry for Nursing Practice 4(1):3-17.

Hutchinson, Sally A., Margaret E. Wilson, and Holly S. Wilson. 1994. Benefits of Participating in Research Interviews. IMAGE: Journal of Nursing Scholarship 26(2):161-164.

Irigaray, Luce. 1980. When Our Lips Speak Together. Translated by Carolyn Burke. SIGNS: Journal of Women in Culture and Society 6(1):69-79.

1985a. Is the Subject of Science Sexed? Cultural Critique 1:73-89. 
. 1985b. This Sex which is not One. Translated by Catherine Porter with Carolyn Burke. New York: Cornell University Press.

. 1987. Je, tu, nous: Toward a Culture of Difference. Translated by Alison Martin. New York: Routledge.

Irvine, Hazel. 1998. Professional Supervision for Nurses and Midwives. Wellington: Winston Churchill Memorial Turst Board.

Jackson, Debra. 1997. Feminism: a path to clinical knowledge development.

Contemporary

Nurse 6(2):85-91.

Jayaratne, Toby E, and Abigail J. Stewart. 1991. In Beyond Methodology: Feminist Scholarship as Lived Research, edited by Mary Fonow and Judith Cook. Bloomington: Indiana University Press.

Jeffreys, Elaine. 1991. What is 'Difference' in Feminist theory and Practice? Australian Feminist Studies 14:1-13.

Johns, Christopher. 1998. Caring through a reflective lens: giving meaning to being a reflective practitioner. Nursing Inquiry 5(1):18-24.

Johnstone, Patricia M.G. 1998. Maori Women and the Politics of Theorising Difference. In Feminist thought in aotearoa new zealand: connections and differences, edited by Rosemary Du Plessis and Lynne Alice. Auckland: Oxford University Press.

Jordanova, Ludmilla. 1989. Sexual Visions: Images of Gender in Science and Medicine between the Eighteenth and Twentieth Centuries. Madison: The University of Wisconsin.

Keddy, Barbara. 1992. The coming of age of feminist research in Canadian Nursing. The Canadian Journal of Nursing Research 24(2):5-10.

Keddy, Barbara, Sharon L. Sims, and Phyllis N Stern. 1996. Grounded Theory as feminist research methodology. Journal of Advanced Nursing 23(3):448-453.

King, Sir Frederic Truby. Lecture notes on midwifery and gynaecology. 1885. MS1120. Alexander Turnbull Library: NLNZ.

King, Kathryn E. 1994. Method and methodology in feminist research: what is the difference? Journal of Advanced Nursing 20(1):19-22.

Knafl, Kathleen A., and Agatha Gallo, 1995. Triangulaiton in Nursing. In Principles and Practice of Nursing Research, edited by Laura A. Talbot. St. Louis: Mosby.

Koutroulis, Glenda. 1990. The Orifice Revisited: Women in Gynaecological Texts. Community Health Studies XIV(1):73-83. 
Kristeva, Julia. 1986. Stabat Mater. In The Female Body in Western Culture, edited by S.R. Suleiman. Massachusetts: Harvard University Press.

Laing, Patricia. Forthcoming. The Unshackling of Maori and White women: Proliferating differences and Hybrid Desires in Health.

Lather, Patti. 1986. Research as Praxis. Harvard Educational Review 56(3):257-277. . 1991. Getting Smart. Feminist Research and Pedagogy with/in the Postmodern. London: Routledge.

Lawler, Jocalyn. 1991a. Behind the Screens: Nursing, Somology and the Problem of the Body. United Kingdom: Churchill Livingstone

. 1991b. In Search of an Australian Identity. In Towards a Discipline of Nursing, edited by Genevieve and Rosalie Pratt. South Melbourne: Churchill Livingstone.

1995. Response: To be or not to be? Nurse? Researcher? Or both? Nursing Inquiry 2(1):57.

. 1997. The Body in nursing. South Melbourne: Churchill Livingstone.

Lennon, Kathleen, and Margaret Whitford. 1994. Knowing the Difference: Feminist Perspectives in Epistemology. London: Routledge

Leonard, Diana, and Lisa Adkins. 1996. Sex in Question: French materialist feminism. London: Taylor \& Francis.

Lewis, Sharon M., Idolia Cox Collier, and Margaret M. Heitkemper, eds. 1996. Medical-Surgical Nursing: Assessment and Management of Clinical Problems. 4th ed. St Louis: Mósby.

Lichtman, Ronnie., and Susan Papera, eds. 1990. Gynecology: well-woman care. Connecticut: Appleton \& Lange.

Lorde, Audre. 1992. Age, race, class and sex: women redefining difference. In Knowing Women, edited by Helen Crowley and Susan Himmelweit. Cambridge: Polity Press.

Lowenberg, June S. 1993. Interpretive research methodology: broadening the dialogue. Advances in Nursing Science 16(2):57-69.

Lumby, Judy. 1997. The feminised body in illness. In The Body in Nursing, edited by Jocalyn Lawler. South Melbourne: Churchill Livingstone.

Lupton, Deborah. 1994. Medicine as Culture. London: Sage Publications.

1995. Perspectives on power, communication and the medical encounter: implications for nursing theory and practice. Nursing Inquiry 2(3):157-163. 
MacPherson, Kathleen I. 1983. Feminist methods: a new paradigm for nursing research. Advances in Nursing Science 5:17-25.

Maggs, Christopher J. 1983. The Origins of General Nursing. London: Croom Helm.

Marks, Elaine, and Isabelle de Courtivron, eds. 1981. New French Feminisms: An Anthology. New York: Schocken Books.

Mason, Diana J., Barbara A. Backer, and Alicia Georges. 1991. Toward a Feminist Model for the Political Empowerment of Nurses. IMAGE: Journal of Nursing Scholarship 23(2):72-76.

Mason-Hohl, Elizabeth. 1940. Preface to The Diseases of Women by Trotula of Salerno, translated by Elizabeth Mason-Hohl. N.p.: The Ward Ritchie Press.

May, Carl. 1992. Nursing work, nurses' knowledge, and the subjectification of the patient. Sociology of Health and Illness 14(4):472-487.

McClintock, A.H. 1966. The Encyclopaedia of New Zealand. Vol. 2. Wellington: Government Print.

McHoul, Alec, and Wendy Grace. 1995. A Foucault Primer: Discourse, Power and the subject. Victoria: Melbourne University Press.

McQueen, Anne. 1997. The emotional work of caring, with a focus on gynaecological nursing. Journal of Clinical Nursing 6(3):233-240.

Meleis, Afaf Ibrahim. 1997. Theoretical Nursing: Development and Progress. 3rd ed. Philadelphia: Lippincott.

Millen, D. 1997. Some Methodological and Epistemological Issues raised by Doing Feminist Research on Non-Feminist Women. Sociological Research Online, 2(3). <http://www.socresonline.org.uk/socresonline/2/3/3.html >

Moore, Anne A., and Melinda Durham Noonan. 1996. A Nurse's Guide to Hormone Replacement therapy. Journal of Obstetric, Gynecologic, and Neonatal Nursing 25(1):24-31.

Moroney James. 1966. Surgery for Nurses. Edinburgh: E \& S Livingstone.

Morris, Meaghan. 1988. The Pirate's Fiancée. London: Verso

Morse, Janice M., ed. 1991. Qualitative Nursing Research: A Contemporary Dialogue. Newbury Park: Sage.

Moscucci, Ornella. 1993. The Science of Women: Gynaecology and Gender in England 1800-1929. Cambridge: Cambridge University Press.

Mount, Ellis, and Barbara A. List. 1994. Milestones in Science and Technology. 2nd ed. Arizona: Oryx Press. 
Mulligan, Joan E. 1992. Nursing and Feminism: Caring and Curing. In The Knowledge Explosion: Generations of Feminist Scholarship, edited by Cheris Kramarae and Dale Spender. New York: Teachers College Press.

Nicholson, Linda J., ed. 1990. Feminism/Postmodernism. New York: Routledge.

Nicolson, Malcolm. 1988. Medicine and racial politics: changing images of the New Zealand Maori in the nineteenth century. In Imperial Medicine and Indigenous Societies, edited by David Arnold. Manchester: Manchester University Press.

Nielsen, Joyce M., ed. 1990. Feminist Research Methods: Exemplary Readings in the Social Sciences. San Francisco: Westview Press.

Oakley, Ann. 1981. Interviewing women: a contradiction in terms. In Doing Feminist Research, edited by Helen Roberts. London: Routledge and Kegan Paul.

O'Dowd, Michael J. and Elliot E. Philipp. 1994. The History of Obstetrics and Gynaecology. Carnforth: The Parthenon Publishing Group.

Ojanuga, Durrenda. 1993. The medical ethics of the "Father of Gynaecology", Dr J Marion Sims. Journal of medical ethics 19:28-31.

Opie, Anne. 1992. Qualitative Research, Appropriation of the 'Other' and Empowerment. Feminist Review 40:52-69.

Parker, Barbara, and Judith McFarlane. 1991. Feminist theory and nursing: An empowerment model for research. Advances in Nursing Science 13(3):59-67.

Parker, Judith. 1997. The body as text and the body as living flesh: metaphors of the body and nursing in postmodernity. In The Body in Nursing, edited by Jocalyn Lawler. South Melbourne: Churchill Livingstone.

Patai, Daphne. 1991. U.S. Academics and Third World Women: Is Ethical Research Possible? In Women's Words: the feminist practice of oral history, edited by Sherna Berger Gluck and Daphne Patai. New York: Routledge.

Perry, Patsy A. 1994. Feminist Empricism as a Method of Inquiry in Nursing. Western Journal of Nursing Research 16(5):480-494.

Phoenix, Ann. 1995. Practising Feminist Research: The Intersection of Gender and 'Race' in the Research Process. In Researching Women's Lives from a Feminist Perspective, edited by Mary Manyard and Jane Purvis. London: Taylor \& Francis Ltd.

Pohl, Joanne M., and Carol J. Boyd. 1993. Ageism Within Feminism. IMAGE: Journal of Nursing Scholarship 25(3):199-203.

Polit, Denise F., and Bernadette P. Hungler. 1995. Nursing Research: Principles and Methods. 5th ed. Philadelphia: J.B. Lippincott. 
Porter, Roy. 1996a. Hospitals and Surgery. In The Cambridge Illustrated History of Medicine, edited by Roy Porter. Cambridge: Cambridge University Press.

. 1996b. What is Disease? In The Cambridge Illustrated History of Medicine, edited by Roy Porter. Cambridge: Cambridge University Press.

Porter, Sam. 1996. Men Researching Women Working. Nursing Outlook 44(1):22-26.

Potter, Patricia A., and Anne G. Perry. 1997. Fundamentals of Nursing: concepts, process and practice. 4th ed. St Louis: Mosby-Year Book.

Ramazanoglu, Caroline. 1992. On Feminist methodology: Male Reason versus Female Empowerment. Sociology 26(2):206-212.

Reinharz, Shulamit. 1992. Feminist Methods in Social Research. New York: Oxford University Press.

Rosaldo, Renato. 1994. Subjectivity in social analysis. In The Postmodern Turn: New Perspectives on Social Theory, edited by Steven Seidman. Cambridge: Cambridge University Press.

Rowland, Beryl. 1981. Medieval Woman's Guide to Health: The First English Gynaecological Handbook. Ohio: Kent State University Press.

Rudge, Trudy. 1995. Response: Insider ethnography: researching nursing from within. Nursing Inquiry 2(1):58.

1996. Nursing wounds: exploring the presence of abjection in nursing practice. Nursing Inquiry 3(4):250-251.

Sampselle, Carolyn M. 1990. The Influence of Feminist Philosophy on Nursing Practice. Image: Journal of Nursing Scholarship 22(4):243-247.

Sandelowski, Margarete. 1981. Women, Health and Choice. Englewood Cliffs: PrenticeHall.

. 1995. Sample Size in Qualitative Research. Research in Nursing \& Health 18:179183.

Schön, Donald A. 1983. The Reflective Practitioner: How Professionals Think in Action. USA: Basic Books.

Schor, Naomi. 1994. This Essentialism Which Is Not One: Coming to Grips with Irigaray. In the essential difference, edited by Naomi Schor and Elizabeth Weed. Bloomington: Indiana University Press.

Seibold, Carmel, Lyn Richards, and Dawn Simon. 1994. Feminist method and qualitative research about midlife. Journal of Advanced Nursing 19(2):394-402. 
Shildrick, Margrit. 1997. Leaky Bodies and Boundaries: Feminism, Postmodernism and (Bio)ethics. London: Routledge.

Sigerist, Henry. 1951. A History of Medicine: Primitve and Archaic Medicine. New York: Oxford University Press.

Sigsworth, Janice. 1995. Feminist Research: its relevance to nursing. Journal of Advanced Nursing 22(5):896-899.

Smeltzer, Suzanne C., and Brenda G. Bare., eds. 1996. Brunner and Suddarth's Textbook of Medical-Surgical Nursing. 8th ed. Philadelphia: Lippincott.

Smith, Pam. 1992. The Emotional Labour of Nursing: How nurses care. Hampshire: Macmillan.

Speedy, Sandra. 1991. The Contribution of Feminist Research. In Towards a Discipline of Nursing, edited by Genevieve Gray and Rosalie Pratt. Melbourne: Churchill Livingstone.

. 1997. Nursing and Feminism: a glance backwards, a gaze forwards. Nursing Inquiry 4(4):217-218.

Speert, Harold. 1996. Obstetric and Gynecologic Milestones Illustrated. New York: Parthenon.

Stanley, Liz, ed. 1991. Feminist Praxis: Research, Theory and Epistomology in Feminist Sociology. London: Routledge.

Stanley, Liz, and Sue Wise. 1993. Breaking Out Again: Feminist Ontology and Epistemology. 2nd ed. London: Routledge.

Stevens, Patricia E. 1993. Marginalized women's access to health care: A feminist narrative analysis. Advances in Nursing Science 16(2):39-56.

Stevenson, Annette. 1994. In Search of New Zealand Nursing History; a literature review. Occasional Paper 1. Wellington: Wellington Polytechnic.

Stewart, Felicia, Felicia Guest, Gary Stewart, and Robert Hatcher. 1981. My Body, My Health: The Concerned Woman's Book of Gynaecology. New York:Bantam Books.

Street, Annette F. 1992. Inside Nursing: A Critical Ethnography of Clinical Nursing Practice. Albany: State University of New York Press.

. 1995. Guest Editorial. Contemporary Nurse 4(2):50-52.

Streubert, Helen J., and Dona Rinaldi Carpenter. 1995. Qualitative Research in Nursing: Advancing the Humanistic Imperative. Philadelphia: J B Lippincott. 
Strickland, Susan. 1994. Feminism, Postmodernism and Difference. In Knowing the Difference: Feminist Perspectives in Epistomology, edited by Kathleen, Lennon and Margaret Whitford. London: Routledge.

Svensson, Roland. 1996. The interplay between doctors and nurses - a negotiated order perspective. Sociology of Health \& Illness 18(3):379-398.

Sweet, Sarah J., and Ian J Norman. 1995. The nurse-doctor relationship: a selective review. Journal of Advanced Nursing 22(1):165-170.

Talbot, Laura. 1995. Principles and Practice of Nursing Research. Missouri: MosbyYear Book.

Theriot, Nancy. 1993. Women's Voices in Nineteenth Century Medical Discourse: A Step toward Deconstructing Science. SIGNS: Journal of Women in Culture and Society 19(1):1-31.

Thornhill, Gill. 1997. Trotula of Salerno. In Museum of Women in Science and Technology [Online]. http://www.mala.bc.calnmoneil/trotula.htm

Timpson, Joanne. 1996. Abortion: the antithesis of womanhood? Journal of Advanced Nursing 23(4):776-785.

Tong, Rosemarie. 1992. Feminist Thought: A Comprehensive Introduction. London: Routledge.

Trotula of Salerno. 1940. The Diseases of Women. Translated by Elizabeth MasonHohl. N.p.: The Ward Ritchie Press.

Versluysen, M.C. 1980. Old Wives' Tales? Women Healers in English History. In Rewriting Nursing History, edited by C. Davies. London: Croom Helm.

Walker, Kim. 1995. Nursing, narrativity and research: towards a poetics and politics of orality. Contemporary Nurse 4(4):56-163.

Walker, Lorraine O., and Mindy B. Tinkle. 1996. Toward An Integrative Science of Women's Health. Journal of Obstetric, Gynecologic and Neo-Natal Nursing 25(5):379-382.

Watson, Jean. 1990. The Moral Failure of the Patriarchy. Nursing Outlook 38(2):6266.

Watson, Paul, and Anne Feld. 1996. Factors in Stress and Burnout among Paediatric Nurses in a General Hospital. Nursing Praxis in New Zealand 11(3):38-46.

Webb, Christine. 1984. Feminist Methodology in Nursing Research. Journal of Advanced Nursing 9(3):249-256. 1986. Women as Gynaecology Patients and Nurses. In Feminist Practice in Women's Health Care, edited by Christine Webb. Chichester: John Wiley and Sons. 
. 1992a. The use of the first person in academic writing: objectivity, language and gatekeeping. Journal of Advanced Nursing 17(6):747-752.

. 1992b. What is Nursing? British Journal of Nursing 1(11):567-568.

. 1993. Feminist research: definitions, methodology, methods and evaluation. Journal of Advanced Nursing 18(3):416-423.

, ed. 1986. Feminist Practice in Women's Health Care. Chichester: John Wiley and Sons.

Wheeler, Charlene Eldridge, and Peggy L Chinn. 1991. Peace and Power: a handbook of feminist process. 3rd ed. New York: National League of Nursing Press.

Williams, Anne. 1991. Practical Ethics: Interpretive Processes in an Ethnography of Nursing. In Rethinking: Feminist Research Processes Reconsidered, edited by Judith Aldridge, Vivienne Griffiths, and Anne Williams. Feminist Praxis monograph series, no 33. Manchester: Manchester University.

Wilson, Helen. 1998. Examining Holistic Health Care. Kai Tiaki Nursing New Zealand 4(10):18-20.

Wood, Pamela and Lynne Giddings. 1991. The Symbolic Experience of Hysterectomy. Nursing Praxis in New Zealand. 6(3):3-7. 